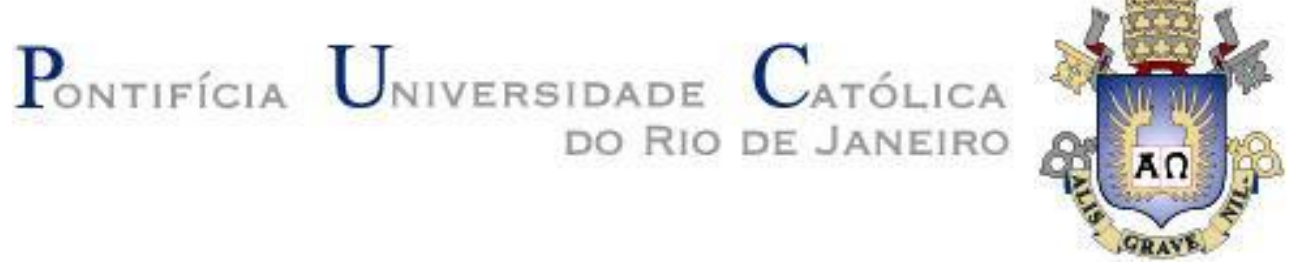

Marcos Vinícius de Oliveira Martins

\title{
Análise dos parâmetros de soldagem por fricção (FSW) através das medidas de torque e forças envolvidas
}

no processo.

Dissertação de Mestrado

Dissertação apresentada como requisito parcial para obtenção do grau de Mestre pelo Programa de Pósgraduação em Engenharia de Materiais e de Processos Químicos e Metalúrgicos do Departamento de Engenharia Química e de Materiais da PUC-Rio.

Orientador: Prof. José Roberto Moraes d'Almeida Coorientador: Prof. José Luís Lopes da Silveira 


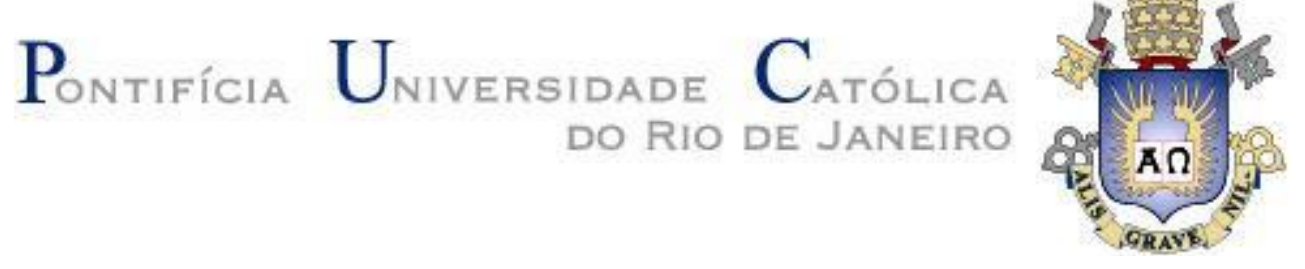

Marcos Vinícius de Oliveira Martins

\begin{abstract}
Análise dos parâmetros de soldagem por fricção (FSW) através das medidas de torque e forças envolvidas
\end{abstract}

no processo.

Dissertação apresentada como requisito parcial para obtenção do grau de Mestre pelo Programa de Pósgraduação em Engenharia de Materiais e de Processos Químicos e Metalúrgicos da PUC-Rio. Aprovada pela Comissão Examinadora abaixo.

Prof. José Roberto Moraes d'Almeida Orientador Departamento de Engenharia Química e de Materiais - PUC- Rio

Prof. José Luís Lopes da Silveira Coorientador Departamento de Engenharia Mecânica - POLI/UFRJ

Prof. Marília Garcia Diniz Departamento de Engenharia Mecânica - UERJ

Prof. Valter Rocha dos Santos Consultor Técnico - PUC-Rio

Rio de Janeiro, 12 de setembro de 2019. 
Todos os direitos reversados. É proibida a reprodução total ou parcial do trabalho sem autorização da universidade, do autor e do orientador.

Marcos Vinícius de Oliveira Martins

Graduado em Engenharia Mecânica pela Universidade do Estado do Rio de Janeiro (UERJ) em 2014.

Ficha Catalográfica

Martins, Marcos Vinícius de Oliveira

Análise dos parâmetros de soldagem por fricção (FSW) através das medidas de torque e forças envolvidas no processo / Marcos Vinícius de Oliveira Martins ; orientador: José Roberto Moraes d'Almeida ; co-orientador: José Luís Lopes da Silveira. - 2019.

143 f. : il. color. ; $30 \mathrm{~cm}$

Dissertação (mestrado)-Pontifícia Universidade Católica do Rio de Janeiro, Departamento de Engenharia Química e de Materiais, 2019.

Inclui bibliografia

1. Engenharia Química e de Materiais - Teses. 2. Soldagem por friç̧ão. 3. Torque. 4. Força axial. 5. Ferramenta com rosca. 6. Microdureza. I. D’Almeida, José Roberto Moraes. II. Silveira, José Luís Lopes da. III. Pontifícia Universidade Católica do Rio de Janeiro. Departamento de Engenharia Química e de Materiais. IV. Título. 


\section{Agradecimentos}

Sendo esta página de livre escrita do autor, tenho a dizer que agradecer a todos que viram minha trajetória para conclusão desta dissertação não é uma tarefa trivial, pois é preciso se ter muita atenção e tentar garantir ao máximo que não se esqueceu de ninguém. Assim:

Agradeço primeiramente a minha família e a todos meus amigos que acompanharam toda a minha trajetória do curso de mestrado.

Agradeço aos meus amigos de pré-vestibular e meus amigos de faculdade que viram minha trajetória como estudante.

Agradeço ao meu orientador José Roberto Morais D'Almeida e ao meu coorientador José Luís da Lopes da Silveira por todos os ensinamentos e por nunca terem desistido de mim.

Agradeço a Laboratório de Instrumentação Mecânica (LITMEC) do Centro Brasileiro de Pesquisas Físicas (CBPF), local onde trabalho, por ter fabricado a ferramenta e me apoiado para a conclusão desta dissertação.

Agradeço meus colegas de trabalho, principalmente ao amigo Fernando Pinto de Pino (in memoriam), que acompanharam este período.

Agradeço a Saulo Brinco por ter me cedido à ferramenta de soldagem.

Agradeço a Karen Johanna Quintana por ter me ajudado nos testes de soldagem.

Agradeço a Juliana Modesto pelo corte a água feita em minhas amostras.

Agradeço a Professora Marília Diniz pelo embutimento, lixamento e polimento das amostras.

Agradeço a Marianna Giffoni e a Paula Roberta por terem me auxiliado com a preparação das amostras.

Agradeço ao Geovanio Lima e a professora Marysilvia da UFRJ pelos testes de Microindentação Instrumentada.

Agradeço aos meus amigos que moraram na República Biricutico por terem acompanhado meu esforço.

Agradeço ao tempo, sim ele mesmo, por ter me concedido este aprendizado.

Assim, agradeço a todos!

O presente trabalho foi realizado com apoio da Coordenação de Aperfeiçoamento de Pessoal de Ensino Superior - Brasil (CAPES) - Código de Financiamento 001. 


\section{Resumo}

Martins, Marcos Vinícius de Oliveira; d'Almeida, José Roberto Morais (Orientador); da Silveira, José Luis Lopes (Co-orientador). Análise dos parâmetros de soldagem por fricção (FSW) através das medidas de torque e forças envolvidas no processo. Rio de Janeiro, 2019. 143 p. Dissertação de Mestrado - Departamento de Engenharia Química e de Materiais, Pontifícia Universidade Católica do Rio de Janeiro.

A união de materiais por soldagem é um dos processos mais utilizados na fabricação de estruturas. A soldagem traz maior confiabilidade, segurança ao projeto e resistência mecânica das uniões. Atualmente, diversas indústrias, tais como aeronáutica e automotiva, têm procurando utilizar materiais de baixa densidade e alta resistência mecânica, como as ligas de magnésio e de alumínio. Porém, estas ligas dificultam o processo de união através da soldagem convencional, que tem no seu principal fundamento a fusão do material, por possuírem baixa soldabilidade. Nas ligas de $\mathrm{Mg}$ e de $\mathrm{Al}$ há a formação uma camada de óxido que precisa ser removida durante o processo de soldagem, além de apresentarem grande susceptibilidade a geração de defeitos, tais como trincas e poros durante o processo de resfriamento da solda. A soldagem por fricção ou por mistura mecânica (FSW) foi desenvolvida como uma alternativa às técnicas de soldagem e uso mais comum existente na indústria, pois esta técnica elimina a fusão do material reduzindo, assim, os defeitos que surgiriam com a soldagem convencional. Por ser uma solda de estado sólido, tem a possibilidade de unir materiais dissimilares, polímeros, compósitos, ligas ferrosas e não ferrosas. O presente trabalho buscou avaliar parâmetros de soldagem variando a velocidade de soldagem $(v)$ e velocidade de rotação da ferramenta $(\omega)$ utilizando uma ferramenta com rosca. Foram analisados o torque e as forças presentes no processo. Os resultados foram comparados com os resultados obtidos com uma ferramenta de soldagem sem rosca. A qualidade da solda foi correlacionada com os parâmetros de soldagem utilizados por meio de ensaios de dureza e tomografia. Foi concluído que a ferramenta com rosca gera defeito de túnel e demanda maior energia do processo em relação ao torque e à força axial. O comportamento das forças envolvidas no processo foi o mesmo para ambas as geometrias de 
ferramenta. A microdureza ao longo do eixo neutro mostrou a mudança entre a zona de mistura, zona termicamente afetada e o metal de base.

\section{Palavras - chave}

Soldagem por fricção; torque; força axial; ferramenta com rosca; microdureza; defeito de túnel. 


\section{Abstract}

Martins, Marcos Vinícius de Oliveira; d'Almeida, José Roberto Morais (Advisor); da Silveira, José Luis Lopes (Co-advisor). Analysis of the parameters of friction welding (FSW) through the measures of torque and forces involved in the process. Rio de Janeiro, 2019. $143 \mathrm{p}$. Dissertação de Mestrado - Departamento de Engenharia Química e de Materiais, Pontifícia Universidade Católica do Rio de Janeiro.

The joining of materials by welding is the process most used in the fabrication of structures. Welding brings greater reliability, safety to the design and mechanical strength of the joints. Today, many industries, such as aeronautics and automotive, are looking to use low density and high mechanical strength materials such as magnesium and aluminum alloys. However, these alloys hinder the bonding process through conventional welding, which has in its main foundation the melting of the material, because they have low weldability. In $\mathrm{Mg}$ and $\mathrm{Al}$ alloys there is a layer of oxide that needs to be removed during the welding process, besides being very susceptible to the generation of defects, such as cracks and pores during the process of cooling the weld. Friction stir welding (FSW) was developed as an alternative to most commonly used in industry welding techniques, as this technique eliminates melting of the material thus reducing defects that would arise with conventional welding. To being a solid state weld, it has the possibility of joining dissimilar materials, polymers, composites, ferrous and non-ferrous alloys. The present work seeked to evaluate welding parameters by varying the welding speed $(v)$ and tool rotation $(\omega)$ using a threaded tool. The torque and forces were analyzed and the results will be compared with the results obtained with a threadless welding tool. The quality of the weld will be correlated with the welding parameters used by means of hardness test and tomography. It was concluded that the threaded tool generates tunnel defect and demands higher process energy. The behavior of the forces involved in the process was the same for both tool geometries. The microhardness along the neutral axis showed the clear the change between the mixing zone, thermally affected zone and the base metal. 


\section{Keywords}

Friction stir welding, torque, axial force, threaded tool, microhardness, wormhole. 


\section{Sumário}

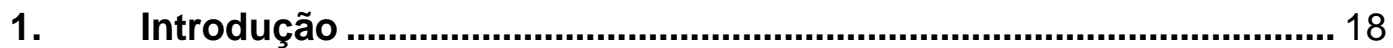



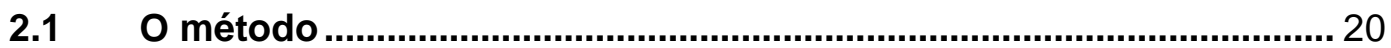

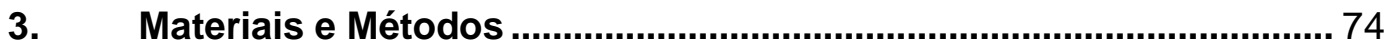

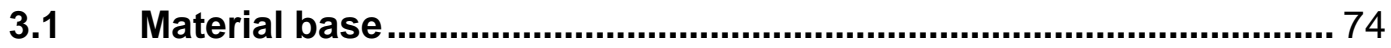





3.4 Análise metalográfica ..................................................................... 82

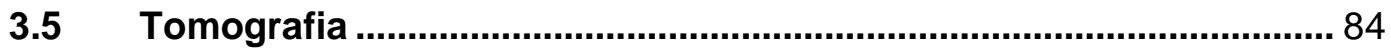



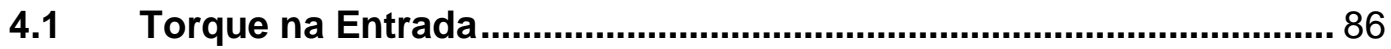

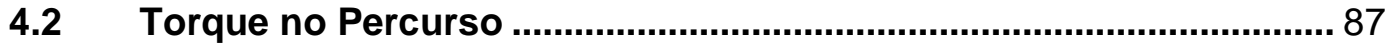

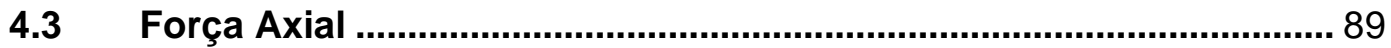

4.3.1 Força Axial Máxima ......................................................................... 90

4.3.2 Força Axial no Percurso .................................................................. 92

4.4 Força de Soldagem na Entrada ......................................................... 94

4.5 Forças de Soldagem no Percurso ...................................................... 95

4.6 Força Transversal na entrada............................................................. 97

4.7 Força Transversal no Percurso .......................................................... 98

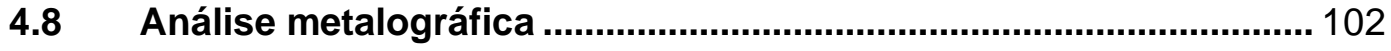

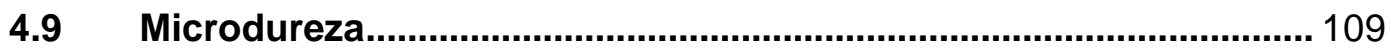

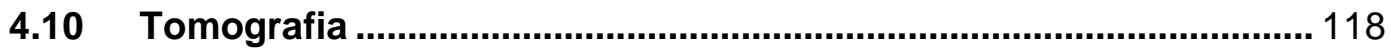

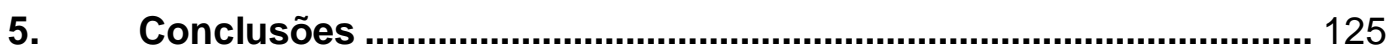

6. Sugestões para trabalhos futuros.................................................. 127

7. Referências Bibliográficas .......................................................... 128

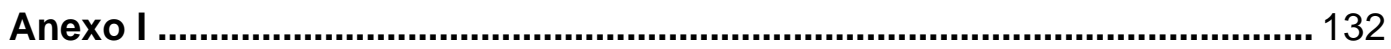



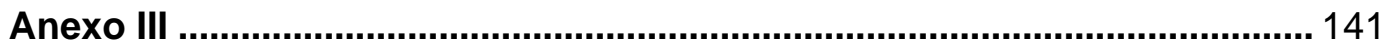




\section{Lista de Figuras}

Figura 1 - Chapas soldadas por FSW: a) Alumínio com 1" de espessura $(25,4 \mathrm{~mm})$; b) Titânio com 1" de espessura (25,4mm); c) Alumínio com $2 \mathrm{~mm}$ de espessura; d) Polímero de $1 / 8$ de polegada $(3,127 \mathrm{~mm})$. Fotos tirada no Laboratório de Estruturas Leves em São José dos Campos, pelo autor.

Figura 2 - Técnica de FSW: a) Início da rotação e aproximação da ferramenta à chapa; b) Fase de entrada da ferramenta na chapa, que se inicia com a penetração do pino; c) contato do ombro com as peças, atingindo a profundidade de penetração desejada; d) avanço da ferramenta com uma velocidade de soldagem e rotação constantes para formar o cordão da solda.

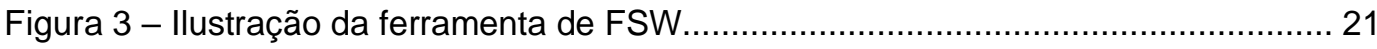

Figura 4 - Representação das forças envolvidas no processo. ................................... 22

Figura 5 - Gráfico de torque na entrada da ferramenta na amostra [26] ...................... 26

Figura 6 - Mostra os pontos da curva que são analisados. Ponto 1: início do processo; Ponto 2: Máxima força atingida; Ponto 3: estabilização das forças; Ponto 4: Saída da ferramenta do corpo de prova [27] .................................................... 27

Figura 7 - Forças de soldagem para 900RPM e $300 \mathrm{~mm} / \mathrm{min}[27]$.............................. 28

Figura 8 - Forças transversais para 900RPM e 300 mm/min [27]. ............................. 28

Figura 9 - Variação da força axial em função da velocidade de rotação para todas

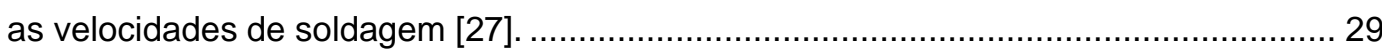

Figura 10 - Comparação das forças durante a fase de soldagem [27] ......................... 29

Figura 11 - Força axial em função da rotação para as fases de penetração e soldagem [28].

Figura 12 - Forças transversais em função da velocidade de rotação para todas as velocidades de soldagem propostas [28]

Figura 13 - Forças axiais durante a fase de penetração (pluging phase) [28]............... 35

Figura 14 - Forças axiais durante a fase de soldagem (welding phase) [28].................. 35

Figura 15 - Torque e máxima temperatura vs. velocidade de rotação [29] ..................... 37

Figura 16 - Descrição da temperatura em função para a velocidade de soldagem de $3,4 \mathrm{~mm} / \mathrm{s}$ para as três condições analisadas [29] ................................................ 38

Figura 17 - Descrição da temperatura em função para a velocidade de soldagem de $6,8 \mathrm{~mm} / \mathrm{s}$ para as três condições analisadas [29].

Figura 18 - Distribuição de Microdureza para as três condições do experimento 800 RPM; $6,8 \mathrm{~mm} / \mathrm{s}$ [29].

Figura 19 - Microdureza vs. Velocidade de soldagem [29].

Figura 20 - O tamanho de grão é representado em função da temperatura máxima atingida em função da velocidade de soldagem [29]

Figura 21 - Distribuição de dureza para 200RPM e 2,54mm/s [29]. 
Figura 22 - Tensão de ruptura por velocidade de rotação [29] …................................ 42

Figura 23 - Dimensões do corpo de prova para testes de tração [31] ....................... 44

Figura 24 - Potência (a) e energia específica (b) em função da velocidade de

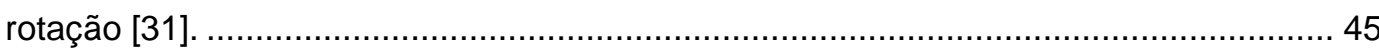

Figura 25 - Micrografias que mostram o crescimento de grão para o aumento da

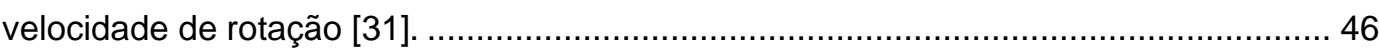

Figura 26 - Variação do torque (T0) em função da velocidade de rotação [31]............. 46

Figura 27 - Dureza do cordão de solda e da ZTA em relação à velocidade de



Figura 28 - Dureza do Cordão de solda e sua ZTA em relação ao torque [31]. ............ 47

Figura 29 - Valores das propriedades mecânicas obtidos nos testes de tração [31]...... 48

Figura 30 - Medidas de Torque e Potência em função da velocidade de soldagem [31].

Figura 31 - Força vs. Deformação. Maior valor encontrado em (C10), a mais baixa

(C8) e de um intermediário (C4), (C10: 14,73 KN; C8: 10,97 KN; C4: 12,56 KN) [32] ... 50

Figura 32 - Efeito individual da velocidade de rotação (a), tempo de soldagem (b) e a penetração (c) sobre a resistência ao cisalhamento das juntas soldadas [32]. 51

Figura 33 - Micrografias ópticas do ponto de solda realizada sob condição $C 4$, que mostra: (a) a microestrutura das diferentes regiões $\mathrm{FSpW}$, (b) A região de transição entre SZ e TMAZ e (c) TMAZ [32].

Figura 34 - Perfis de microdureza para condições de soldagem C4 (resistência intermediária), C8 (menor resistência) e C10 (maior força) [32].

Figura 35 - Correlação entre Torque, Força de soldagem e tamanho de grão em função da rotação. (a) resultados para a liga 2219; (b) resultados para a liga 5083;

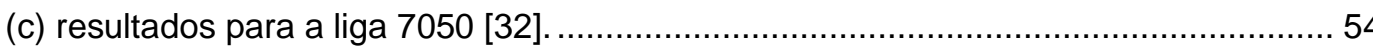

Figura 36 - Gráfico de relação Flow Stress vs. RPM [32]... 56

Figura 37 - (a): Características do corpo de prova; (b): Características da ferramenta FSW [22].

Figura 38 - Curvas Tensão vs. Deformação para ligas de alumínio soldadas por MAG e soldadas por FSW - 5083-H112 + 5083-H112 [22].

Figura 39 - Curvas Tensão vs. Deformação para ligas de alumínio soldadas por MAG e soldadas por FSW - 5383-H116 + 5383-H116 [22]. 58

Figura 40 - Curvas Tensão vs. Deformação para ligas de alumínio soldadas por FSW - 5083-H112 + 5383-H116 [22].

Figura 41 - Perfil de comportamento do Torque [25].

Figura 42 - Perfil de comportamento da Força Axial (Fz) e Força de soldagem (Fh) durante o experimento [25]

Figura 43 - Torque (M) em função da rotação $(\omega)$ e as curvas ajustadas [25] . ............... 61

Figura $44-M 0, M f$ e $n$ em função da velocidade de soldagem (v) [25] ...................... 62

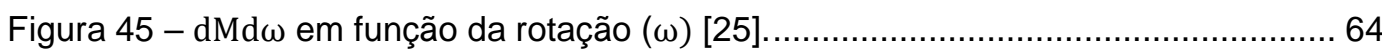

Figura 46 - Potencia (W) vs Rotação (RPM) calculadas com a equação 27 [25] ........... 65 


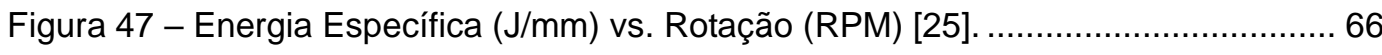

Figura 48 - Caminhos realizados pela solda nos dois experimentos realizados [38]...... 67

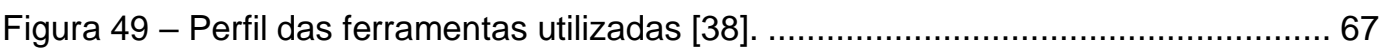

Figura 50 - Imagens de raios-X das soldas produzidas, mostram a formação do tunel (wormhole) [38]....

Figura 51 - Macrografia da secção reta das amostras para cada ferramenta utilizada [38].

Figura 52 - Variação de dureza das zonas de soldagem estudadas [39] ...................... 71

Figura 53 - Regiões as quais os corpos de prova foram retirados [39] ....................... 71

Figura 54 - Esboço do corpo de prova para teste de micro-tração [39] .......................... 71

Figura 55 - Curva característica do teste de indentação instrumentada para os

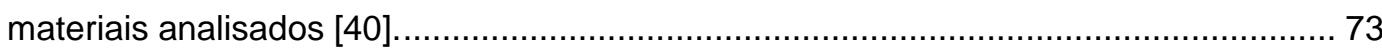



Figura 57 - (a) Dinamômetro Kistler 9272; (b) Amplificador de sinal Kistler 5070. ......... 76

Figura 58 - Método de adaptação do CNC para realização dos ensaios. ...................... 76

Figura 59 - Representação 2D da ferramenta de soldagem.................................... 77

Figura 60 - Representação esquemática dos dois momentos da indentação [43][44] . . 77

Figura 61 - Curva característica do ensaio de indentação instrumentada [43][44] ......... 78



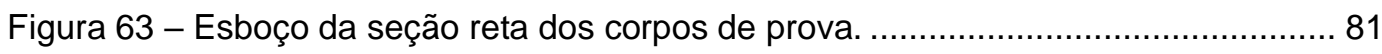

Figura 64 - (a) Corpo de prova cortado à água. (b) Amostras embutidas. ..................... 83

Figura 65 - Corpos de prova cortados à água para a análise de tomografia.................. 84

Figura 66 - Gráfico de torque na entrada separado por velocidade de soldagem. ......... 86

Figura 67 - Gráfico de torque na entrada com os valores médios para cada

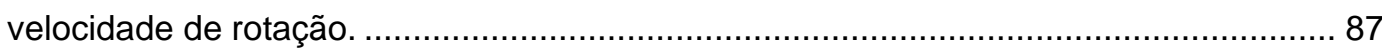

Figura 68 - Valores de torque no percurso, separados por velocidade de soldagem..... 88

Figura 69 - Gráfico de Força axial corpo de prova 5 - 600RPM e $300 \mathrm{~mm} / \mathrm{min}$............. 90

Figura 70 - Força Axial Máxima durante a fase de descida da ferramenta. ................... 91

Figura 71 - Força Axial Máxima Unificada: valores médios e desvio padrão. ................ 92

Figura 72 - Força Axial no Percurso em função da rotação separada pelas

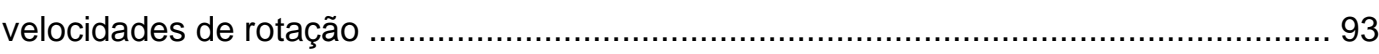

Figura 73 - Gráfico Força de Soldagem CP-5 600RPM e 300 mm/min...................... 94

Figura 74 - Regressão linear para os valores de Força de Soldagem na Entrada. ........ 95

Figura 75 - Gráfico de Forças de Soldagem no Percurso. ........................................... 96

Figura 76 - Forças de Soldagem no Percurso em função da velocidade de

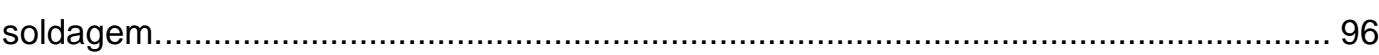

Figura 77 - Gráfico de Força de Soldagem no Percurso com valores unificados

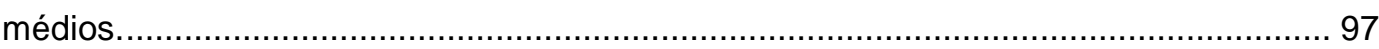

Figura 78 - Gráfico de Fora transversal. CP - 5600 RPM; 300 mm/min. ..................... 98

Figura 79 - Regressão linear para os valores de Força Transversal na Entrada............ 98 
Figura 80 - Forças Transversais no Percurso em função da velocidade de soldagem.

Figura 81 - Gráfico de Forças Transversais no Percurso por velocidade de soldagem com valores unificados. 100

Figura 82 - Imagem do Corpo de prova CP 5 - 600 RPM; $300 \mathrm{~mm} / \mathrm{min}$ atacado quimicamente e o metal de base não atacado . .102

Figura 83 - Imagem de todas as amostras e seus respectivos defeitos. ......................104

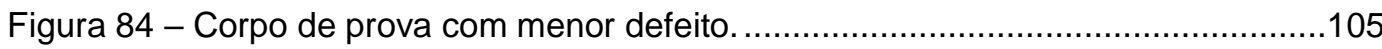

Figura 85 - Exemplo de como foram medidos os defeitos gerados pela soldagem.......105

Figura 86 - Defeito gerado pela soldagem com 1500RPM e $300 \mathrm{~mm} / \mathrm{min}$. .108

Figura 87 - Curva de Deslocamento característica do ensaio de Micro indentação instrumentada para os ensaios realizados no metal de base.

Figura 88 - Curva de Carga para os ensaios de microindentação instrumentada utilizada neste estudo.

Figura 89 - Perfil completo de distribuição de dureza CP-21: 1500 RPM; 300 $\mathrm{mm} / \mathrm{min}$. . .112

Figura 90 - Gráfico de distribuição de dureza CP-05: 600 RPM; 300 mm/min. 112

Figura 91 - Gráfico de distribuição de dureza CP-08: 900 RPM; 300 mm/min. .112

Figura 92 - Gráfico de distribuição de dureza CP-18: 1200 RPM; 300 mm/min. 113

Figura 93 - Gráfico de distribuição de dureza CP-21: 1500 RPM; 300 mm/min. 113

Figura 94 - Gráfico de distribuição de dureza CP-24: 600 RPM; 100 mm/min. .114

Figura 95 - Gráfico de distribuição de dureza CP-33: 900 RPM; 100 mm/min. 114

Figura 96 - Gráfico de distribuição de dureza CP-36: 1200 RPM; 100 mm/min .115

Figura 97 - Gráfico de distribuição de dureza CP-39: 1500 RPM; 100 mm/min. 115

Figura 98 - Tomografia do Corpo de prova réplica para 600RPM e 100 mm/min. ........120

Figura 99 - Tomografia do Corpo de prova réplica para 900RPM e 100 mm/min. ........121

Figura 100 - Tomografia do Corpo de prova réplica para 1200RPM e 300 mm/min. ....122

Figura 101 - Tomografia do Corpo de prova réplica para 1500RPM e 300 mm/min. ....123

Figura 102 - Tomografia do Corpo de prova inteiro réplica para 600RPM e 100 $\mathrm{mm} / \mathrm{min}$. 


\section{Lista de Tabelas}

Tabela 1 - Valores de Torque obtidos nos experimentos. ............................................. 24

Tabela 2 - Parâmetros e Forças dos experimentos. .....................................................36

Tabela 3 - Parâmetros utilizados nos experimentos. .................................................4 44

Tabela 4 - Parâmetros a serem variados para soldagem de carda corpo de prova e

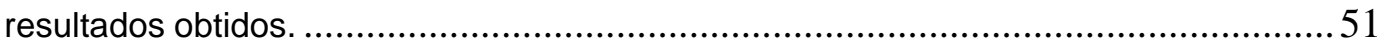

Tabela 5 - Composição química do alumínio 6061 -T6 .............................................. 70

Tabela 6 - Tabela comparativa de resultado entre a Microdureza e de Micro-Tração.... 72

Tabela 7 - Composição química do material de estudo Alumínio Almigo HARD............ 73

Tabela 8 - Composição química material de base [41] ................................................. 74

Tabela 9 - Propriedades mecânicas do material de base [41] .................................... 74

Tabela 10 - Especificações técnicas do CNC utilizado nos testes. ............................... 75

Tabela 11 - Parâmetros utilizados nos testes de microdureza. .................................... 81

Tabela 12 - Amostras selecionadas para os testes de Microdureza Instrumentada....... 82

Tabela 13 - Composição do Reagente Keller para ataque químico. ............................. 82

Tabela 14 - Numeração para rastreabilidade das amostras......................................... 83

Tabela 15 - Parâmetros e critério de seleção dos corpos de prova que foram



Tabela 16 - Especificações Microtomógrado de raios-X Xradia Versa 510 Zeiss. ......... 85

Tabela 17 - Parâmetros do ensaio de Microtomografia.............................................. 85

Tabela 18 - Tabela com a comparação entre os valores das forças com velocidade

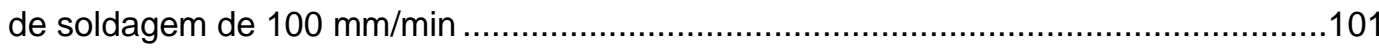

Tabela 19 - Tabela com a comparação entre os valores das forças com velocidade de soldagem de $200 \mathrm{~mm} / \mathrm{min}$

Tabela 20 - Tabela com a comparação entre os valores das forças com velocidade

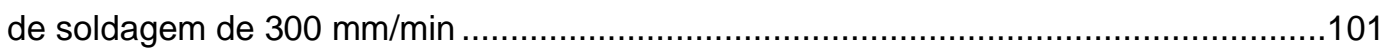

Tabela 21 - Potência de soldagem para os experimentos realizados. ..........................102

Tabela 22 - Dimensões dos defeitos dos corpos de prova analisados..........................106

Tabela 23 - Distribuição de corpos de prova segundo as características dos

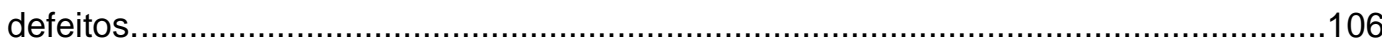

Tabela 24 - Torque no Percurso em ordem crescente para cada corpo de prova.........107

Tabela 25 - Valores de Dureza (HV) e Módulo de Elasticidade Instrumentado para o

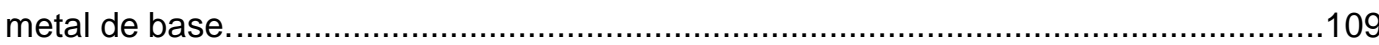

Tabela 26 - Média e Desvio Padrão para a Dureza e o Módulo de Elasticidade

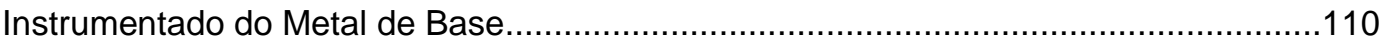

Tabela 27 - Tensão de escoamento calculada para cada conjunto de parâmetros.......117

Tabela 28 - Potência de Soldagem caldulada para o conjunto de parâmetros. 
Tabela 29 - Paramentros organizados em ordem crescente de potência de

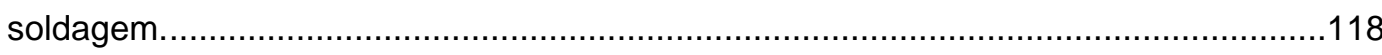

Tabela 30 - Medidas dos defeitos dos corpos de prova ensaiados por tomografia.......118 


\section{Lista de Abreviações}

CNC - Comando Numérico Computadorizado.

EBS - Elétrons Retro Espalhados.

EDX - Espectroscopia de Energia Dispersiva de Raio-X.

FSW - Friction Stir Welding, Soldagem por Fricção ou Mistura Mecânica.

$F_{x}$ - Força Transversal de Soldagem.

$F_{y}$ - Força de Soldagem.

$F_{z}-$ Força Axial de Soldagem.

HRC - Dureza Medida na Escala Rockwell C.

MAG - Método de Soldagem com Gás Ativo (Metal Active Gas).

MEV - Microscopia eletrônica de Varredura.

MIG - Método de Soldagem com Gás Inerte (Metal Inerte Gas).

RPM - Rotação por Minuto

SZ - Zona de Mistura Mecânica (stir zone).

$T$ - Torque.

TIG - Método de Soldagem com Tungstêncio e Gás inerte (Tungsten Inert Gas).

TMAZ - Zona Termo-mecanicamente Afetada (Thermo-mechanically affected zone).

ZTA - Zona Termicamente Afetada.

$v$ - Velocidade de avanço da ferramenta ou velocidade de soldagem.

$\sigma_{0}-$ Tensão de escoamento (Flow Stress).

$\tau$ - Tensão de cisalhamento (Shear stress).

$\omega$ - Rotação. 
Milton Nascimento, Lô Borges e Márcio Borges, Clube da Esquina nº2. 


\section{Introdução}

A soldagem por fricção (FSW) foi desenvolvida como uma alternativa às técnicas de soldagem convencional por fusão de vasto uso como: MIG, MAG, TIG, eletrodo revestido, arco submerso e outras [1]. Estes processos mais usuais da indústria se utilizam da fusão do material e apresentam uma maior tendência de formação de defeitos durante a solidificação do cordão de solda modificando as propriedades mecânicas da região soldada [2][3]. Além disso, por terem geralmente um grande aporte térmico, geram maiores distorções na peça final, necessitam de um operador capacitado e muitos processos requerem gases protetores, materiais de adição e altos níveis de energia, aumentando o custo do processo [4][5].

A FSW apresenta vantagens como: evita a fusão do material, reduzindo a probabilidade de formação de defeitos como porosidades e trincas, mudança de microestrutura, tensões residuais, empenamentos e Zona Termicamente Afetada (ZTA) extensa. Assim, resulta em melhores propriedades mecânicas, pois seu baixo aporte de calor diminui as distorções na peça e na região soldada; não requer metal de adição; as tensões residuais geradas são baixas e há possibilidade de unir materiais dissimilares, tais como polímeros, compósitos, ligas ferrosas e não ferrosas, materiais com baixa soldabilidade e chapas de espessura fina [2][3][6]. A Figura 1 mostra diversos exemplos de soldagem empregando a técnica de FSW de diferentes materiais e diferentes espessuras. Porém, para a realização do processo é preciso uma ferramenta especial com alta resistência mecânica e um equipamento com potência necessária para realizar a soldagem [7].

Nos últimos anos a FSW vem sendo estudada buscando-se a caracterização da solda, seleção de parâmetros ótimos de processo, desenvolvimento e aplicação de modelos para descrever o comportamento da temperatura e o fluxo de material. Uma forma de se avaliar a qualidade da solda é analisar o comportamento do torque e das forças durante o processo de soldagem em função dos parâmetros do processo [8][9].

Assim neste trabalho foram realizadas medições de torque e das forças axiais de avanço e transversal durante os experimentos de FSW com velocidade de penetração e geometria da ferramenta constantes e combinações de rotação e velocidades de soldagem/avanço. Com isso buscou-se avaliar a influência desses 
fatores no comportamento do torque e das forças envolvidas no processo de soldagem.

(a)
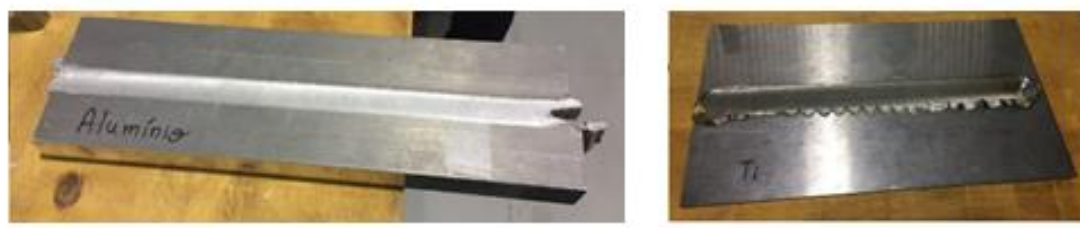

(b)

(c)
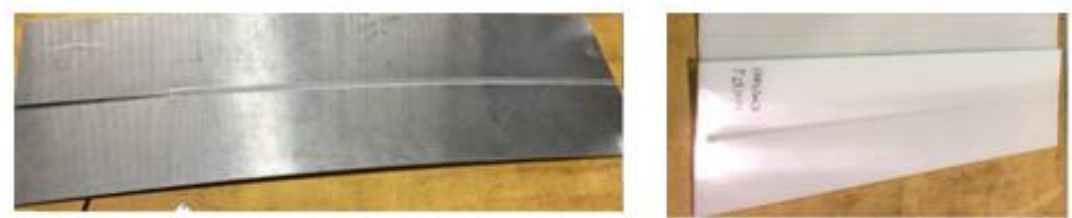

(d)

Figura 1 - Chapas soldadas por FSW: a) Alumínio com 1" de espessura $(25,4 \mathrm{~mm})$; b) Titânio com 1" de espessura (25,4mm); c) Alumínio com $2 \mathrm{~mm}$ de espessura; d) Polímero de $1 / 8$ de polegada $(3,127 \mathrm{~mm})$. Fotos tirada no Laboratório de Estruturas Leves em São José dos Campos, pelo autor. 


\section{Revisão bibliográfica}

\subsection{0 método}

O processo consiste em uma ferramenta giratória que penetra no material, mantendo a rotação, enquanto avança para produzir o cordão de solda, conforme ilustrado na Figura 2, adaptada de [7].

O calor gerado pelo atrito entre a ferramenta e o material a ser soldado, gera um aumento da temperatura localmente, sem atingir a temperatura de fusão do material. Assim, a ferramenta deforma plasticamente o material em estado sólido gerando a união entre as chapas [7].

A ferramenta tem duas funções principais no processo: elevar localmente a temperatura na peça e agitar o material para permitir a união [4]. Portanto, a ferramenta influi no aporte de calor no processo, no fluxo do material, na potência requerida para a realização da solda e na uniformidade da solda. A ferramenta para a FSW geralmente é composta por um ombro e um pino, como é mostrado na Figura 3 [7]. O ombro é o principal responsável pela geração de calor e por evitar a extrusão do material sendo soldado e a formação de rebarbas. O pino tem como função principal agitar e deformar o material próximo à ferramenta. Tanto a geometria do ombro quanto a do pino afetam o fluxo do material. Existem diferentes projetos de ferramentas com variações cilíndricas, cônicas e com canais para o ombro e o pino, os quais são projetados para melhorar a qualidade das soldas [7].

A força axial é máxima na penetração da ferramenta, enquanto que a força de avanço é máxima no deslocamento da ferramenta. A força transversal não é tão significativa, no entanto pode ser um indicador da assimetria da solda. $\mathrm{O}$ torque apresenta um comportamento crescente na penetração da ferramenta e mantém-se praticamente constante durante o deslocamento desta para a formação do cordão de soldagem. A Figura 4, adaptada, mostra o torque e as forças que atuam no processo: força axial, transversal e de avanço [7]. 


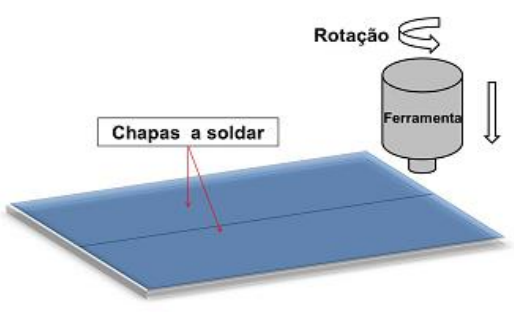

a)



c)

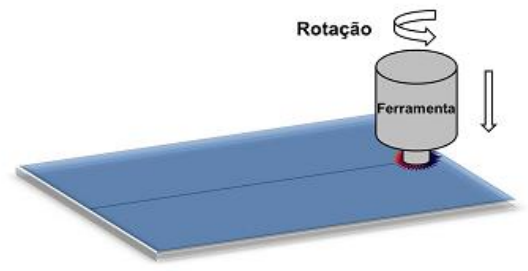

b)



d)

Figura 2 - Técnica de FSW: a) Início da rotação e aproximação da ferramenta à chapa; b) Fase de entrada da ferramenta na chapa, que se inicia com a penetração do pino; c) contato do ombro com as peças, atingindo a profundidade de penetração desejada; d) avanço da ferramenta com uma velocidade de soldagem e rotação constantes para formar o cordão da solda.

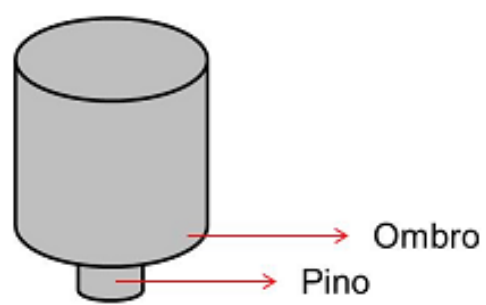

Figura 3 - llustração da ferramenta de FSW.

O torque está relacionado com a resistência do material, com o fluxo do material no processo e com a temperatura no núcleo da solda [10][11][12][13][14], logo, é um parâmetro muito importante para garantir a qualidade da solda e para se entender os fenômenos metalúrgicos gerados no material durante o processo de soldagem. Observou-se experimentalmente que o máximo da temperatura no processo tem uma relação inversa com a medida do torque [8][10]. Além disso, foi observada uma forte relação entre o torque e a temperatura na solda através da tensão de escoamento local no material. Para baixas temperaturas no processo de FSW a tensão de escoamento local no material é alta e, portanto, o valor do torque também apresenta valores altos [7]. 


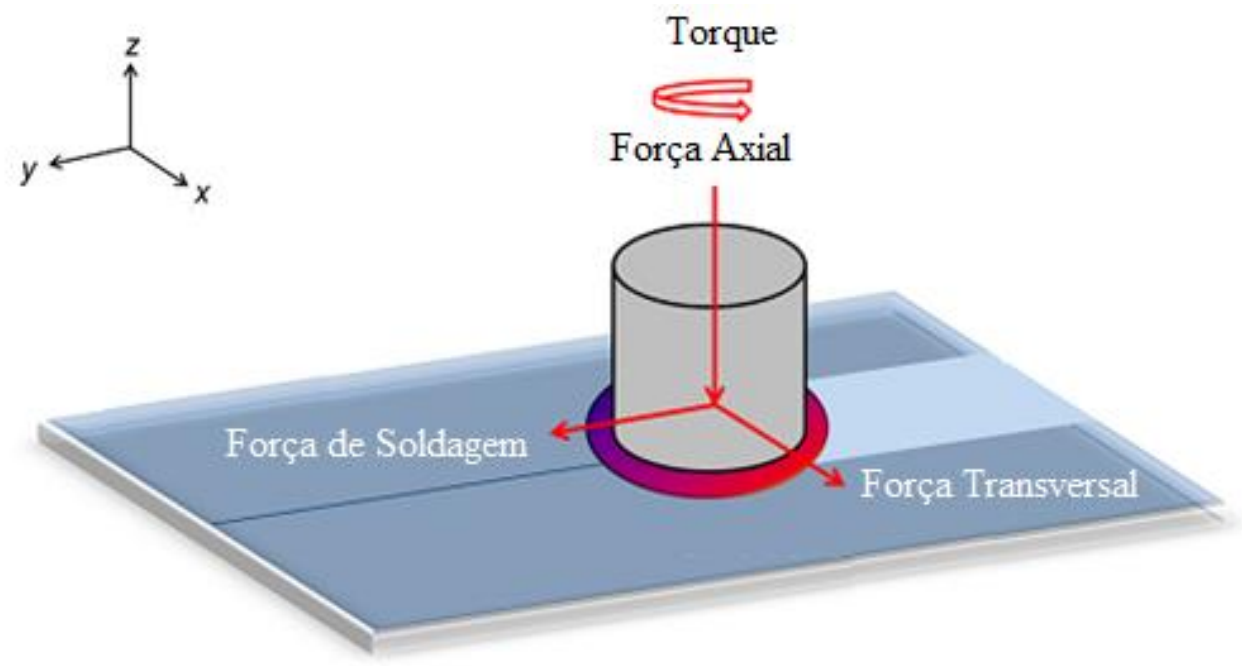

Figura 4 - Representação das forças envolvidas no processo.

Estudos experimentais revelam que o valor do torque tem uma relação linear com o tamanho médio do grão, com a microdureza e com a tensão no núcleo da solda $[8][10][11]$. Conforme o torque aumenta há tendência de aumentar o tamanho médio do grão, a microdureza e a tensão no núcleo da solda diminuem. A influência do torque nas propriedades mecânicas da solda pode ser atribuída à relação entre o torque e a temperatura, por meio da tensão de escoamento local no material [7].

O torque também é importante na seleção do equipamento para a realização das soldas e no projeto da ferramenta usada na FSW [15][16].

A potência de soldagem está diretamente relacionada com o torque e com a velocidade de rotação da ferramenta no processo de acordo com a eq. (1) $[7][12][17][18][19][20][21][22][23]:$

$$
P=M \omega+F_{x} v
$$

Onde:

- $\quad P$ : a potência em Watts;

- $M$ : o torque em N.m;

- $\omega$ : a velocidade de rotação da ferramenta em $\mathrm{rad} / \mathrm{s}$;

- $F_{x}$ : a força de avanço em $\mathrm{N}$;

- $\quad v$ : a velocidade de soldagem $\mathrm{em} \mathrm{m} / \mathrm{s}$. 
A energia específica representa o calor gerado no processo por unidade de comprimento e pode ser calculada a partir do torque e das velocidades de rotação e de soldagem segundo a eq. (2) [7][10][17][18][20][21][23]:

Eq. (2)

$$
E s=\frac{P}{v}=M \frac{\omega}{v}
$$

Onde:

- Es: energia específica em $\mathrm{J} / \mathrm{mm}$;

- $\quad P$ : potência dada em Watts;

- $\omega$ : velocidade de rotação da ferramenta em $\mathrm{rad} / \mathrm{s}$;

- $\quad v$ : velocidade de soldagem $\mathrm{em} \mathrm{mm} / \mathrm{s}$.

$\mathrm{O}$ artigo Analysis of Torque in Friction Stir Welding of Aluminum Alloy 5052 by Inverse Problem Method [24] trata da obtenção dos parâmetros através do método do problema inverso. O critério de seleção envolve os principais parâmetros do processo como: velocidade de rotação $(\omega)$ e velocidade de avanço $(v)$.

Porém, a geometria da ferramenta e as propriedades do material não foram consideradas. O modelo proposto por Cui, utilizado no artigo, é descrito pela eq. (3) $[25]$ :

Eq. (3)

$$
M=A+B v+(C+D v) e^{-(a b+v) \omega}
$$

Onde:

- $\quad v$ : velocidade de avanço;

- $\omega$ : velocidade de rotação;

- $\quad A, B, C, a, b$ : são parâmetros obtidos de forma experimental.

O modelo apresenta um comportamento exponencial de decaimento em que o torque é função da velocidade de avanço $(v)$ e da rotação $(\omega)$. Este artigo analisou as velocidades de avanço (v) de: 100, 200 e $300 \mathrm{~mm} / \mathrm{min}$ [24].

A Tabela 1 [24] mostra os dados experimentais para o torque em função da velocidade de rotação para algumas das velocidades de soldagem analisadas. 
Tabela 1 - Valores de Torque obtidos nos experimentos.

\begin{tabular}{|c|c|c|c|c|c|c|}
\hline \multirow{2}{*}{} & \multicolumn{9}{|c|}{ Velocidade de Soldagem } \\
\cline { 2 - 7 } & \multicolumn{2}{|c|}{$\mathbf{1 0 0} \mathbf{~ m m} / \mathbf{m i n}$} & \multicolumn{2}{c|}{$\mathbf{2 0 0} \mathbf{~ m m} / \mathbf{m i n}$} & \multicolumn{2}{c|}{$\mathbf{3 0 0} \mathbf{~ m m} / \mathbf{m i n}$} \\
\hline $\begin{array}{c}\text { Rotação } \\
(\mathbf{R P M})\end{array}$ & $\begin{array}{c}\text { Torque } \\
\text { (Nm) }\end{array}$ & $\begin{array}{c}\text { Desvio } \\
\text { Padrão }\end{array}$ & $\begin{array}{c}\text { Torque } \\
\text { (Nm) }\end{array}$ & $\begin{array}{c}\text { Desvio } \\
\text { Padrão }\end{array}$ & $\begin{array}{c}\text { Torque } \\
\text { (Nm) }\end{array}$ & $\begin{array}{c}\text { Desvio } \\
\text { Padrão }\end{array}$ \\
\hline $\mathbf{6 0 0}$ & 13,395 & 0,832 & 14,650 & 0,231 & 12,431 & 1,122 \\
\hline $\mathbf{9 0 0}$ & 10,300 & 0,280 & 9,624 & 0,483 & 11,068 & 0,128 \\
\hline $\mathbf{1 2 0 0}$ & 7,756 & 0,240 & 7,557 & 0,410 & 8,301 & 0,040 \\
\hline $\mathbf{1 5 0 0}$ & 6,264 & 0,095 & 6,191 & 0,140 & 6,547 & 0,113 \\
\hline
\end{tabular}

Os resultados mostraram que, para todas as velocidades de soldagem, o aumento na rotação diminui o valor do torque. Este fenômeno está relacionado com as rotações mais altas que produzem um aumento de temperatura no material [24].

No artigo Mechanistic models and experimental analysis for the torque in FSW considering tool geometry and process velocities [26] foi estudada a influência da velocidade de soldagem, rotação e penetração da ferramenta.

Os experimentos foram divididos em três partes: somente o pino, somente ombro e ferramenta completa (pino + ombro) [26].

Os parâmetros usados no modelo foram estimados pelo método conhecido como "problema inverso" usando o torque experimental dos testes em laboratório. Se os parâmetros forem constantes, o modelo estará calibrado com os resultados dos testes. Caso contrário, os parâmetros serão descritos por uma função.

O torque de penetração da ferramenta $\left(M_{p p}\right)$, em N.m, é dado eq. (4) [26]:

\section{Equação 4}

$$
M_{p p}=\tau_{1} G+C v_{p}
$$

Onde:

- $\tau_{1}$ : Módulo de Cisalhamento;

- G: Fator de Geometria da Ferramenta,

- C: Parâmetro estimado pelo método do problema inverso.

- $\quad v_{p}$ : Velocidade de penetração;

Sendo o fator de geometria da ferramenta dado pela eq. (5) [26]: 
Eq. (5)

$$
G=\int r d A_{s}+\int r d A_{L}+\int r d A_{l}
$$

Onde:

- $A_{S}$ : área do ombro da ferramenta;

- $A_{L}$ : área lateral do pino;

- $A_{l}$ : área inferior ou de contato direto do pino.

Pôde ser observado através dos experimentos que o principal fator para o aumento da temperatura das amostras foi a velocidade de rotação $(\omega)$ e a velocidade de avanço (v). Com maiores rotações, havia um aumento na temperatura da amostra. Assim, pode-se concluir que o limite de escoamento do material sofre uma variação local afetando os valores de torque desenvolvidos no processo [26].

O torque $\left(M_{w p}\right)$ durante a soldagem é função do torque inicial de entrada da ferramenta $\left(M_{p p}\right)$ e a velocidade de soldagem $\left(v_{s}\right)$ através da eq. (6) [26]:

Eq. (6)

$$
M_{w p}=M_{p p}+D v_{w}
$$

Onde:

- $\quad M_{w p}$ : Torque, em N.m, durante a fase de soldagem;

- $\quad M_{p p}$ : Torque, em N.m, durante a fase de penetração;

- $v_{\mathrm{w}}:$ Velocidade de soldagem em $\mathrm{mm} / \mathrm{min}$.

O parâmetro D, apresentado pela eq. (7) [9], inclui os efeitos da velocidade de rotação nas forças de torque. Durante a penetração o material aumenta sua temperatura localmente, assim há diminuição da tensão de escoamento e, logo, as forças de torque correspondentes serão de menor valor.

$$
D=D 1 e^{-D 2 w}
$$

Onde:

- D1 parâmetro em N.m/mm/min;

- $\mathrm{D} 2$ em $\mathrm{RPM}^{-1}$

- $\quad w$ : Velocidade de Rotação em RPM 
A Figura 5 [26] mostra a entrada da ferramenta na amostra. No ponto 4 há o efeito no torque, quando o material extrudado toca o ombro da ferramenta. $\mathrm{O}$ máximo torque está representado pelo ponto 5 que mostra o torque quando ocorre a penetração total do pino.

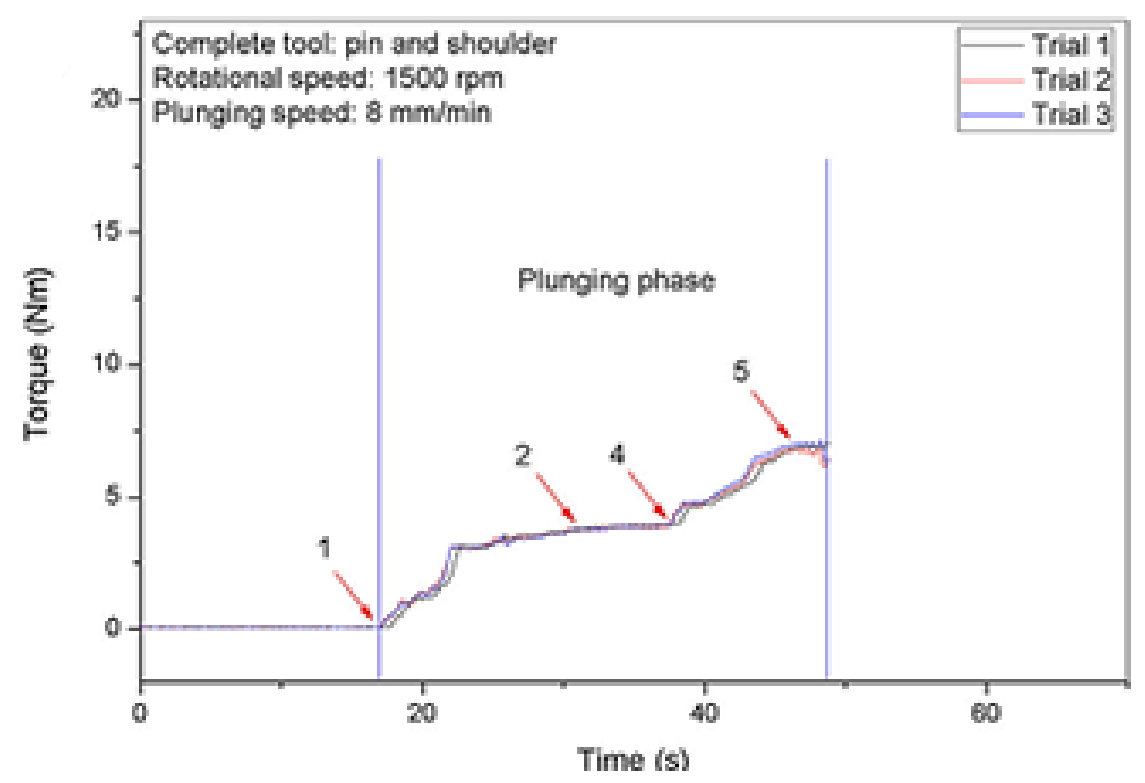

Figura 5 - Gráfico de torque na entrada da ferramenta na amostra [26].

Os resultados experimentais mostraram que os valores máximos do torque e da força axial são apresentados durante a fase da entrada da ferramenta na peça e que são influenciados pelas velocidades de rotação e de penetração, bem como pela geometria da ferramenta. Enquanto as forças de avanço e transversal apresentaram os valores máximos durante a fase do percurso e mostraram influência das velocidades de rotação e de soldagem. O método de problema inverso foi implementado com sucesso para ajustar os modelos propostos em função dos parâmetros do processo de $F S W$, os quais mostraram concordância adequada com as medições experimentais.

$\mathrm{O}$ artigo Analysis for the forces in FSW for aluminum alloy considering toll geometry and process velocities [27] analisou experimentalmente as forças na fase de soldagem (welding phase) e fase de entrada da ferramenta (plunging phase) para soldas com quatro velocidades de rotação $(\omega)$ : 600, 900, 1200 e 1500 RPM e três velocidades de soldagem $\left(v_{w}\right): 100,200$ e $300 \mathrm{~mm} / \mathrm{min}$. Todos os experimentos foram feitos com velocidade de penetração de $8 \mathrm{~mm} / \mathrm{min}$ e com uma 
profundidade de 4,1mm. A Figura 6 [27] ilustra o sinal de análise para uma velocidade de soldagem de $100 \mathrm{~mm} / \mathrm{min}$.

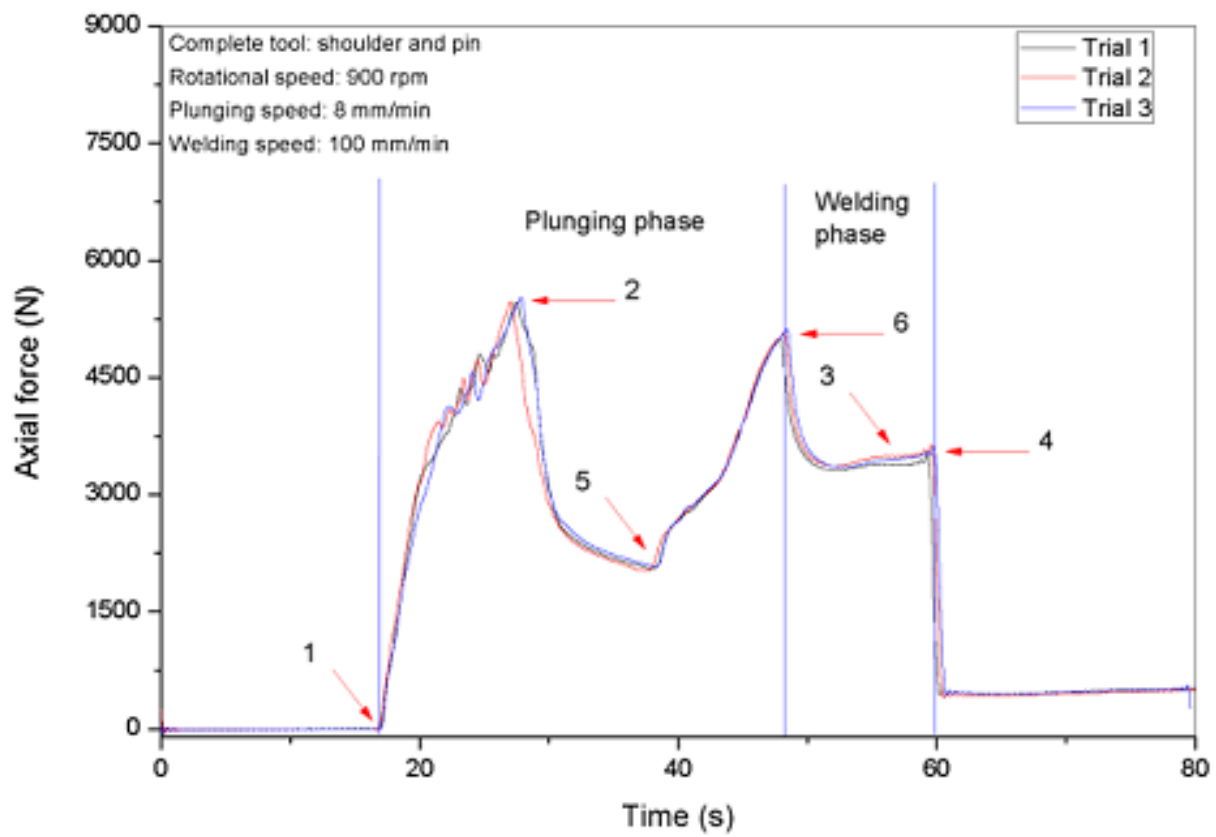

Figura 6 - Mostra os pontos da curva que são analisados. Ponto 1: início do processo; Ponto 2: Máxima força atingida; Ponto 3: estabilização das forças; Ponto 4: Saída da ferramenta do corpo de prova [27].

Durante a fase de entrada (plunging phase), após o pico devido à entrada do pino, há um aumento da força, representado pelo ponto 5 , devido ao ombro da ferramenta entrar em contato com o material extrudado durante esta fase.

O ponto 6 representa a mudança da fase de entrada da ferramenta para a fase de soldagem, onde a ferramenta começa a soldar efetivamente o material e o pino já entrou por completo. Durante esta fase, a ferramenta permanece em altura constante em relação a peça. Logo a área de contato entre a peça e a ferramenta permanece constante. Assim, após uma pequena região de transiente, as forças permanecem constantes até o final do processo.

As forças de soldagem e as forças transversais não apresentam valor significativo durante o processo de entrada da ferramenta (pluging phase), Figuras 7 e 8 [27], entre os pontos 1 e 2, pois nesta fase a ferramenta atua na direção axial. Durante a fase de soldagem (welding phase) existem valores máximos nos pontos 3 e 4, mas há estabilização entre esses pontos. 


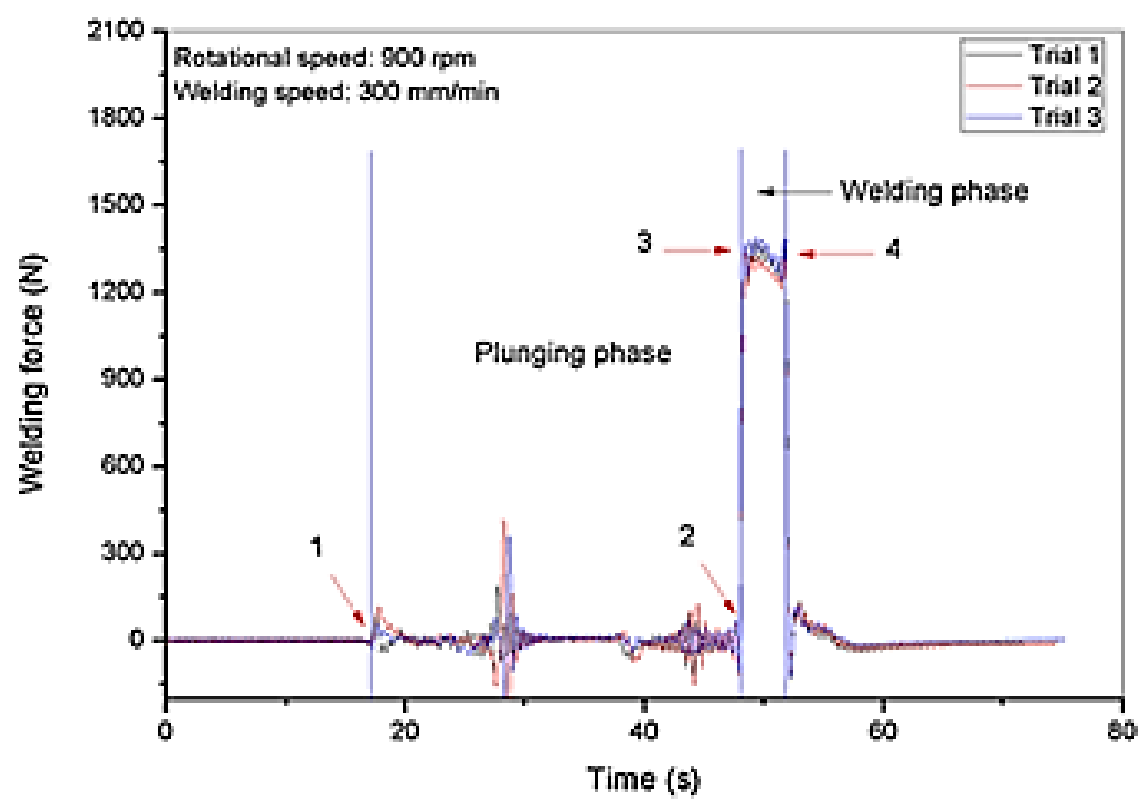

Figura 7 - Forças de soldagem para 900RPM e $300 \mathrm{~mm} / \mathrm{min}$ [27].

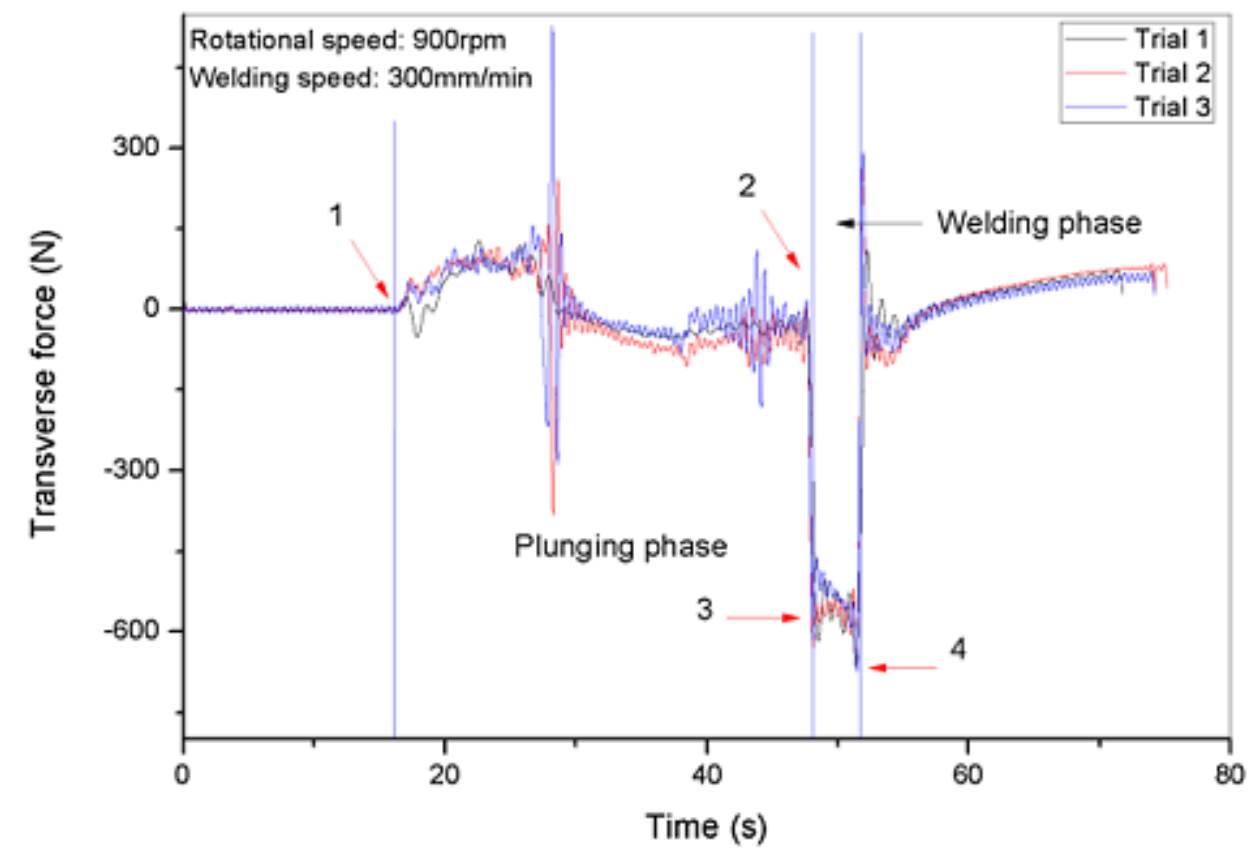

Figura 8 - Forças transversais para 900RPM e $300 \mathrm{~mm} / \mathrm{min}$ [27].

Durante a fase de entrada e a fase de soldagem, a força axial apresenta um decaimento exponencial com o aumento da velocidade de rotação, como mostrado na Figura 9 [27]. 




Figura 9 - Variação da força axial em função da velocidade de rotação para todas as velocidades de soldagem [27].

No entanto, durante a fase de soldagem, a força axial aumenta com o aumento da velocidade de soldagem, como mostrado na Figura 10 [27]. Assim, com maiores velocidades de soldagem há uma redução no aporte de calor para a peça, pois haverá um menor tempo de exposição. Logo, com menor aporte de calor haverá uma menor variação local do limite de escoamento do material e, assim, haverá maiores valores para as forças transversais.

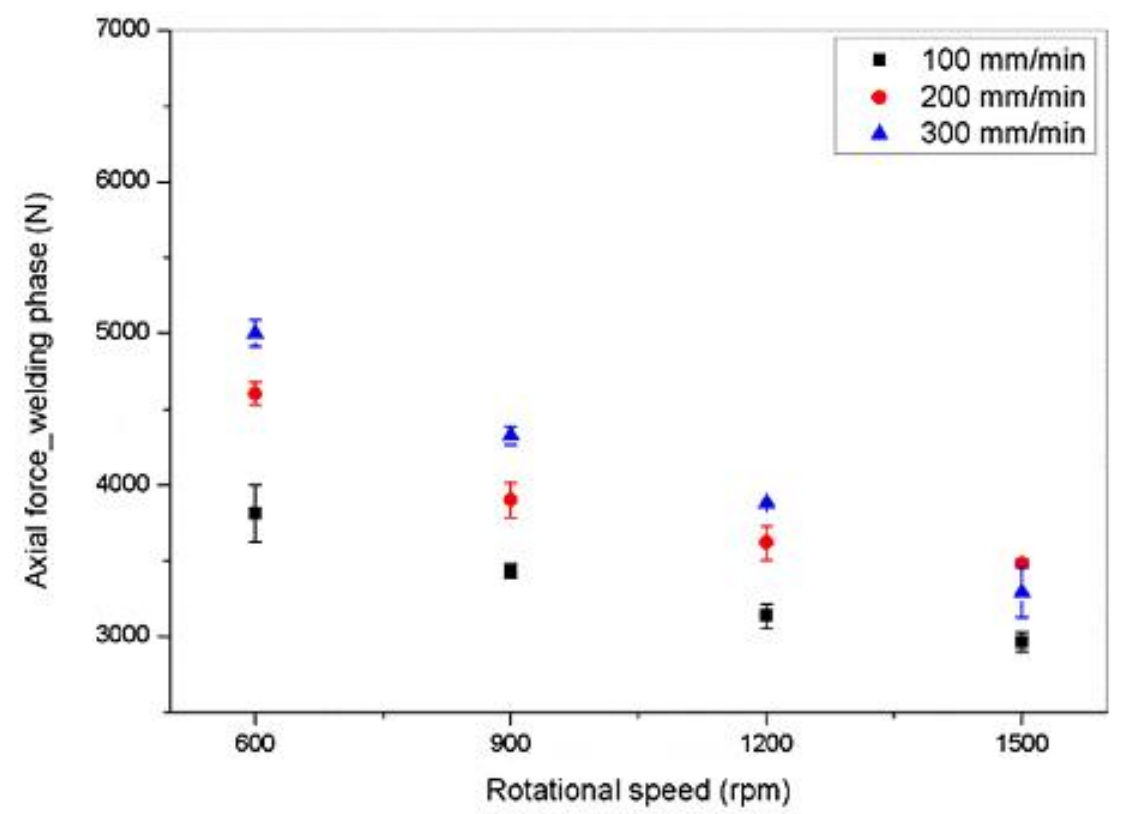

Figura 10 - Comparação das forças durante a fase de soldagem [27]. 
No artigo Mechanistic models for the forces in FSW of aluminum alloy 5052-H34 [28] é desenvolvido um modelo para descrever as forças axiais em função da geometria da ferramenta e da rotação, velocidade de penetração e velocidades de soldagem. A força axial é modelada individualmente para as fases de penetração e soldagem. Além disso, um modelo é desenvolvido para descrever a força de soldagem em função das velocidades de rotação $(\omega)$ e velocidade de soldagem $\left(v_{w}\right)$ para a ferramenta completa (pino + ombro).

As forças axiais e as forças de soldagem são as principais forças do processo e são críticas nas fases de penetração e soldagem, respectivamente, enquanto a força transversal, que tem uma menor magnitude, poderia ser um indicador da assimetria ou defeitos do processo.

Baseado na descrição física do processo $F S W$ e nos dados experimentais para as forças, modelos mecânicos são propostos para a força axial durante a penetração e a fase de soldagem e a força de soldagem durante a soldagem efetivamente. O método do problema inverso é usado para estimar os parâmetros dos modelos usando as medidas de força como dados de entrada. Quando os parâmetros estimados apresentam valores discrepantes para cada combinação de fatores (velocidades e geometria da ferramenta), eles são descritos como uma função desses fatores. Finalmente, os modelos são calibrados com os resultados da força experimental e, dependendo da diferença relativa, os modelos são ajustados se necessário.

As forças axiais $\left(F_{a}\right)$ durante a soldagem por $F S W$ podem ser descritas pela eq. (8) que leva em consideração a área lateral e transversal da ferramenta e a velocidade de soldagem $(v)[28]$ :

Eq. (8)

$$
F_{a}=\sigma l A_{T}+\tau l A_{L}+C v
$$

Onde:

- $A_{T}=$ área transversal da ferramenta $\left(\mathrm{m}^{2}\right)$;

- $A_{L}=$ área lateral da ferramenta $\left(\mathrm{m}^{2}\right)$;

- $\quad v=$ velocidade linear que corresponde a $v_{p}$ para a velocidade de penetração e $v_{w}$ para velocidade de soldagem $(\mathrm{mm} / \mathrm{min})$; 
- $\sigma l=$ Tensão de escoamento do material $(\mathrm{Pa})$;

- $\quad \tau l=$ Tensão de cisalhamento do material $(\mathrm{Pa})$;

- $C=$ Parametro estimado pelo método do problema inverso (N.min/mm).

A equação 8 é reescrita utilizando-se o critério de Von Mises, gerando a eq. (9) [28]:

Eq. (9)

$$
F_{a}=\sigma l\left(A_{T}+\frac{A_{L}}{\sqrt{3}} A\right)+C v
$$

A influência do aporte de calor no limite de escoamento $(\sigma l)$ está diretamente relacionada pela velocidade de rotação $(\omega)$, ou seja, quanto maior a velocidade de rotação maior será o calor aportado na peça [28].

As forças de soldagem $\left(F_{w}\right)$ são obtidas com a eq. (10) [28] que utilizou o critério de Von Mises:

Eq. (10)

$$
F_{W}=\sigma l\left(\frac{A_{L}}{2}+\frac{A_{T}}{\sqrt{3}}\right)
$$

Onde:

- $\mathrm{A}_{\mathrm{T}}=$ área transversal da ferramenta $\left(\mathrm{m}^{2}\right)$;

- $\mathrm{A}_{\mathrm{L}}=$ área lateral da ferramenta $\left(\mathrm{m}^{2}\right)$;

- $\sigma \mathrm{l}=$ Tensão de escoamento do material $(\mathrm{Pa})$;

Para o cálculo das áreas laterais e transversais são utilizadas as eq. (11) e eq. (12), respectivamente [28]:

$$
A_{T}=\int_{0}^{r p} \int_{0}^{2 \pi} r d \theta d r+\int_{r p}^{r 0} \int_{0}^{2 \pi} r d \theta d r
$$


Eq. (12)

$$
A_{L}=\int_{0}^{h p} \int_{0}^{2 \pi} r d \theta d l
$$

Onde:

- $\quad r p$ : raio do pino;

- $r 0$ : raio do ombro;

- $h p$ : comprimento do pino.

Os experimentos foram realizados com a velocidade de penetração constante de $8 \mathrm{~mm} / \mathrm{min}$, penetração efetiva de $4,1 \mathrm{~mm}$, velocidade de rotação $(\omega)$ : 600, 900, 1200 e 1500 RPM e velocidade de soldagem $\left(v_{w}\right): 100,200$ e 300 $\mathrm{mm} / \mathrm{min}$.

Concluiu-se que as forças axiais durante a fase de soldagem e de penetração diminuem exponencialmente com o aumento da velocidade de rotação. A Figura 11 [28] mostra o gráfico de forças axiais para a fase de soldagem e para a fase de penetração em função das velocidades de rotação.



Figura 11 - Força axial em função da rotação para as fases de penetração e soldagem [28].

Na fase de penetração é obtido o maior valor de força axial, não é afetada pela velocidade de soldagem. Durante a fase de soldagem, a força axial aumenta 
com o aumento da velocidade de soldagem. Para maiores velocidades de soldagem, o tempo disponível para a entrada de calor no processo é reduzido e, assim, o material é menos amolecido, a tensão de escoamento local é menos reduzida e a força axial é maior. A influência da velocidade de soldagem nas forças axiais depende da velocidade de rotação; para baixas rotações, que fornecem menor entrada de calor, a força axial é mais afetada pela velocidade de soldagem.

As forças de soldagem e forças transversais são afetadas pela velocidade de soldagem. Para uma velocidade constante de soldagem, as forças de soldagem apresentam valores maiores que as forças transversais e ambas as forças aumentam com o aumento da velocidade de soldagem, devido ao reduzido tempo disponível para a entrada de calor no processo. A influência da velocidade de rotação na força de soldagem é mais significativa para maiores velocidades de soldagem.

Além disso, a influência da velocidade de rotação nas forças transversais depende da velocidade de soldagem. Para uma velocidade de soldagem de 100 $\mathrm{mm} / \mathrm{min}$, a força transversal não é influenciada pela velocidade de rotação. No entanto, para uma velocidade de soldagem de $200 \mathrm{~mm} / \mathrm{min}$, a força transversal é influenciada pela velocidade de rotação e para uma velocidade de soldagem de $300 \mathrm{~mm} / \mathrm{min}$, a força transversal apresenta um decaimento exponencial com o aumento da velocidade de rotação. Processos com velocidades de soldagem mais altas e baixas velocidades de rotação reduzem a entrada de calor e, consequentemente, a força transversal aumenta, o que pode ser interpretado como um aumento da assimetria da solda [28].

A Figura 12 [28] traz o gráfico mostrando a variação das forças transversais em função da velocidade de rotação e das velocidades de soldagem. 


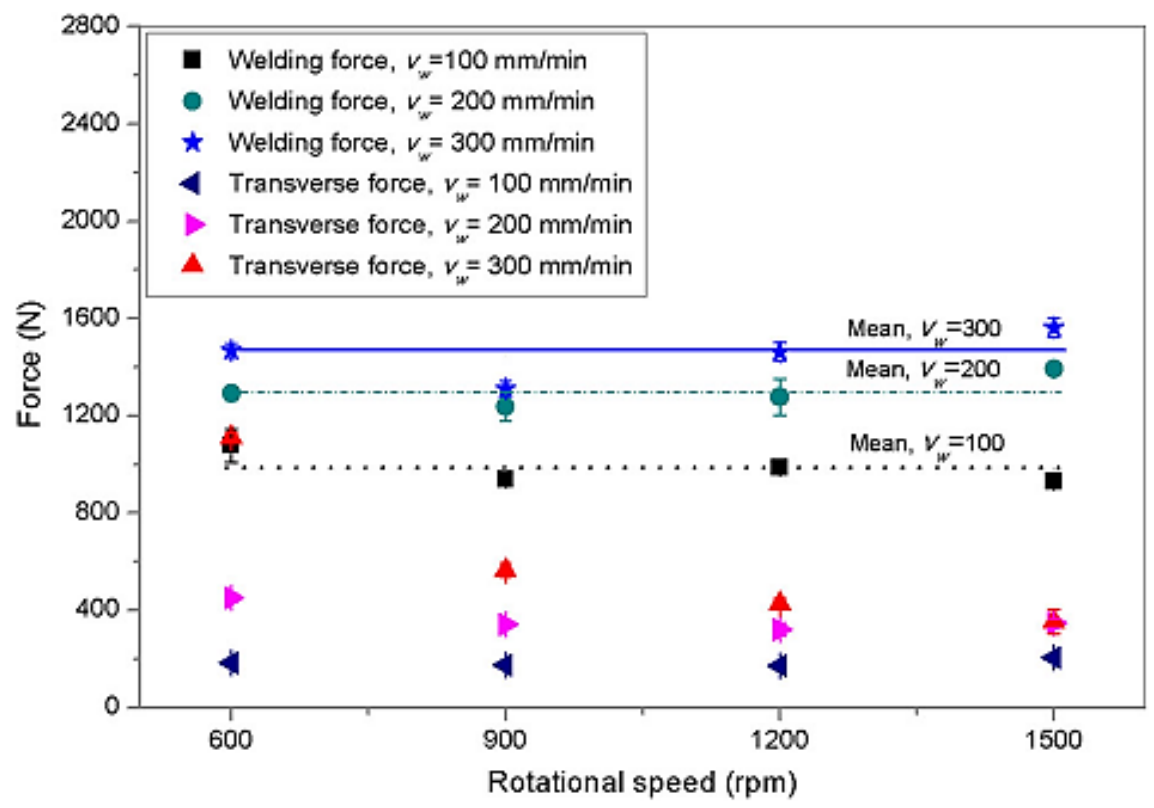

Figura 12 - Forças transversais em função da velocidade de rotação para todas as velocidades de soldagem propostas [28].

De acordo com estes resultados experimentais, a velocidade de rotação tem menor influência nas forças de soldagem. Portanto, o limite de escoamento é descrito pela Equação 12 e se torna uma função linear descrita pela eq. (13) [28]:

$$
\sigma_{l}=A v_{w}+B
$$

Onde:

- $v_{w}=$ para velocidade de soldagem $(\mathrm{mm} / \mathrm{min})$;

- $\sigma l=$ Tensão de escoamento do material $(\mathrm{Pa})$;

- $\quad A, B$ : Parâmetros estimados de maneira experimental. Os valores obtidos para esses parâametros foram $\mathrm{A}=3,2 \cdot 10^{4} \mathrm{e} \mathrm{B}=1,07710.10^{7}$.

Uma comparação entre os dados obtidos de forma experimental e pelo modelo matemátio está apresentada nas Figuras 13 e 14 Os resultados apresentados mostram uma boa correlação entre o modelo e os dados obtidos de forma experimental. 


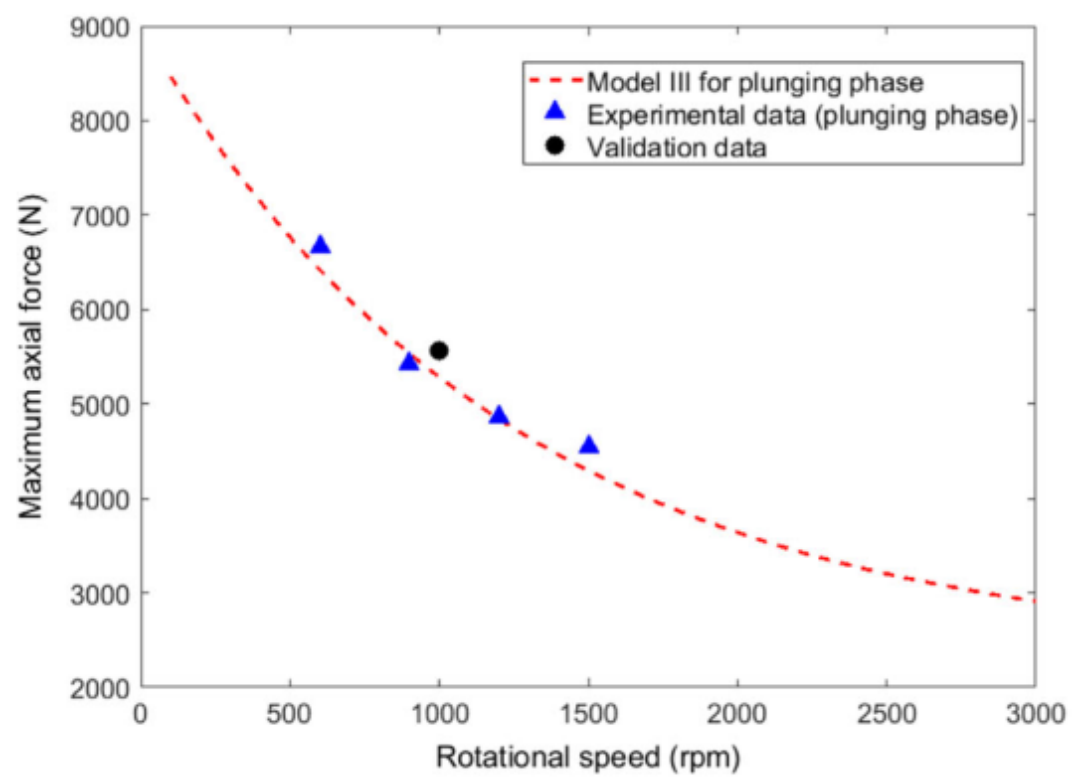

Figura 13 - Forças axiais durante a fase de penetração (pluging phase) [28].

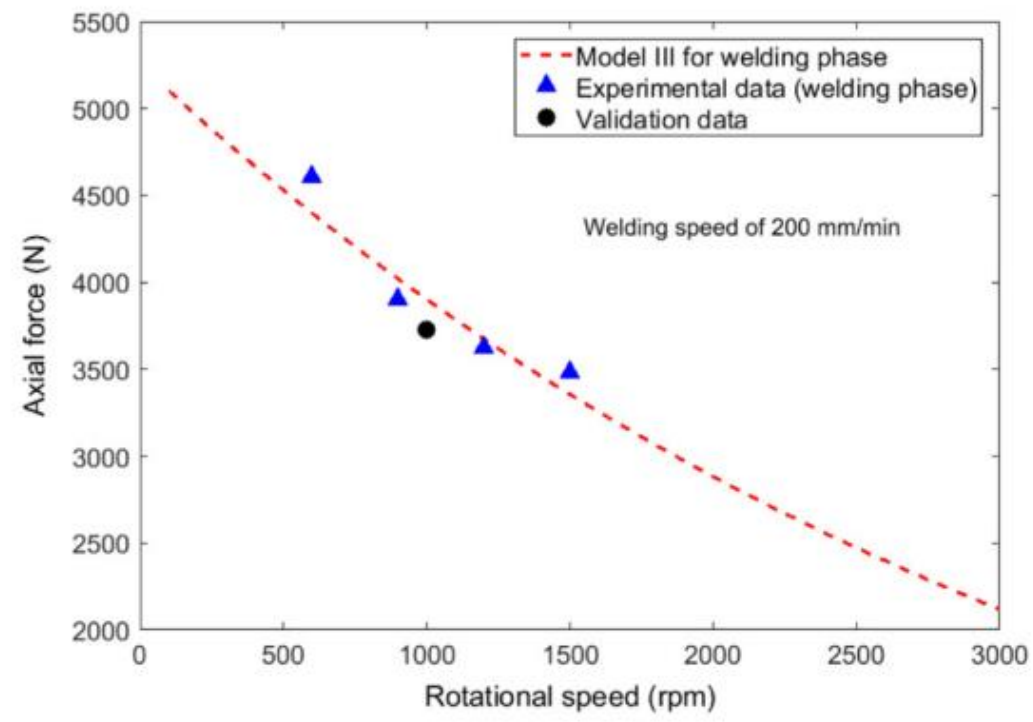

Figura 14 - Forças axiais durante a fase de soldagem (welding phase) [28].

Ao final concluiu que:

1. A força axial está diretamente relacionada com a geometria da ferramenta, com a velocidade de rotação e com a velocidade de entrada. Enquanto que durante a fase de soldagem, a força axial estabilizada é influenciada pela interação entre a geometria da ferramenta e as velocidades de rotação e soldagem.

2. Durante as duas fases, a força axial é fortemente afetada pela velocidade de rotação. Em geral, a força axial decai exponencialmente com o aumento da rotação. 
3. A força de soldagem e a força transversal_atuam somente durante a fase de soldagem e são afetadas principalmente pela velocidade de soldagem. Para uma velocidade de soldagem constante, a força de soldagem é consideravelmente maior que a força transversal. Uma análise prévia destas forças pode evitar a quebra da ferramenta durante a fase de soldagem e permitir uma seleção adequada dos parâmetros para o processo de FSW.

4. O modelo proposto para descrever a força axial e a força de soldagem considerando a geometria da ferramenta, o limite de escoamento, a deformação do material e as velocidades do processo estão em concordância com os resultados experimentais.

No artigo Effects of thermal boundary conditions in friction stir welded AA7050-T7 sheets [29] os autores buscam avaliar os efeitos metalúrgicos que a soldagem por $F S W$ pode causar. Foram utilizadas chapas de alumínio com $6,25 \mathrm{~mm}$ de espessura e foram avaliadas três condições de troca térmica: Ao ar (In air ou IA), com uma lâmina de líquido refrigerante de aproximadamente $25 \mathrm{~mm}$ (Under Water ou UW) e com uma mistura de 50\% de etileno glicol $+50 \%$ água e $30 \mathrm{lb}$ (aproximadamente $15 \mathrm{~kg}$ ) de gelo seco (sub-ambient ou SA), sendo que nesta última condição foram atingidas temperaturas de $-25 c^{\circ}$ na superfície da placa. A Tabela 2 [29] mostra os parâmetros de soldagem e as forças resultantes no eixo Z, forças longitudinais ao cordão de solda, medidas nos experimentos.

Tabela 2 - Parâmetros e Forças dos experimentos.

\begin{tabular}{|c|c|c|c|c|c|c|c|c|c|c|c|}
\hline $\begin{array}{c}\text { Velocidade de } \\
\text { Rotação (RPM) }\end{array}$ & $\mathbf{1 5 0}$ & $\mathbf{2 0 0}$ & $\mathbf{2 5 0}$ & \multicolumn{2}{|c|}{$\mathbf{3 0 0}$} & \multicolumn{2}{|c|}{$\mathbf{4 0 0}$} & $\mathbf{5 4 0}$ & $\mathbf{6 5 0}$ & $\mathbf{8 0 0}$ & $\mathbf{1 0 0 0}$ \\
\hline $\begin{array}{c}\text { Velocidade de } \\
\text { Soldagem } \\
\text { (mm/s) }\end{array}$ & 1,7 & 2,54 & 3,40 & 3,40 & 6,80 & 3,40 & 5,10 & 6,80 & 6,80 & 6,80 & 10,20 \\
\hline $\begin{array}{c}\text { Forças In Air } \\
\text { (N) }\end{array}$ & 25,80 & 25,80 & 26,69 & 24,69 & 33,81 & 22,24 & 25,80 & 28,02 & 30,69 & 33,36 & 37,81 \\
\hline $\begin{array}{c}\text { Forças Under- } \\
\text { Water (N) }\end{array}$ & 35,59 & 35,59 & 34,70 & 31,14 & 39,15 & 29,369 & 34,25 & 39,15 & 39,15 & 40,48 & 45,59 \\
\hline $\begin{array}{c}\text { Forças Sub- } \\
\text { ambient (N) }\end{array}$ & - & - & - & 35,59 & - & - & 40,48 & 41,37 & - & - & - \\
\hline
\end{tabular}


Os resultados foram subdivididos em 5 itens:

I. Torque $v s$. temperatura

Quanto maior a velocidade de rotação, maior será a temperatura local. Isso faz com que o limite de escoamento local do material diminua e, assim, haverá um fluxo maior de material deformado e um menor esforço de torque. A Figura 15 [29] mostra a comparação da velocidade de rotação com o torque para os experimentos IA - In-Air e $U W$ - Under Water e também mostra no mesmo gráfico a máxima de temperatura alcançada para cada rotação.

Os valores de torque para soldas UW - Under Water são maiores que para as soldas IA - In-Air, pois a temperatura máxima é menor pelo fato da transferência de calor da solda para o meio (água) ser relativamente mais alta. $\mathrm{O}$ maior torque observado para soldagem UW - Under Water é, sem dúvida, relacionado à baixa temperatura do material em contato com a ferramenta. As temperaturas mais baixas correspondem a maiores tensões para que ocorra a deformação (flow stress), assim, levaria a um esforço maior (toque) para se realizar o processo de soldagem.

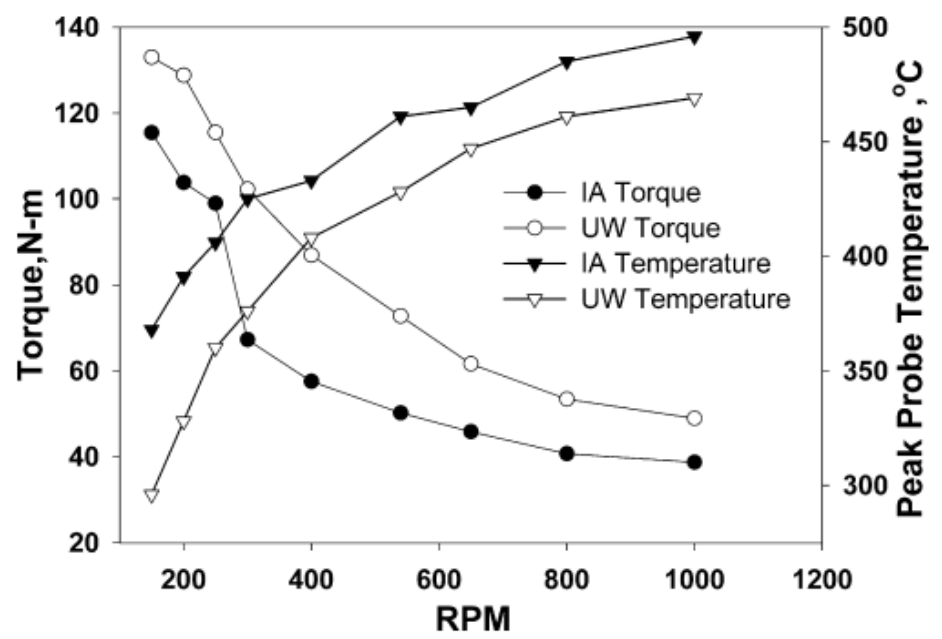

Figura 15 - Torque e máxima temperatura vs. velocidade de rotação [29].

\section{Ciclos Térmicos}

Foi observado que a maior temperatura atingida foi de $350 \mathrm{C}^{\circ}$. Para as condições de in-air e under water as taxas de aquecimento foram similares, mas para under water o resfriamento foi mais rápido. A condição sub-ambiente é claramente diferente das outras. Ela possui um menor valor inicial e final de 
temperatura e o tempo de resfriamento é muito menor. As Figuras 16 e 17 [29] mostram os resultados da análise de temperatura.

Foi utilizado um modelo aproximado para a distribuição da temperatura através da superfície de uma placa fina. A eq. (14) [30] mostra este modelo aproximado:

Eq. (14)

$$
T=T_{0}+\frac{Q}{2 \pi k} \cdot \frac{1}{r} \cdot \exp \left(\frac{-V(r-x)}{2 \alpha}\right)
$$

Onde:

- $T_{0}$ : a temperatura inicial da chapa;

- $Q$ : energia total gerada pela fonte;

- $r$ : distância radia ao ponto de geração de energia, ou seja, a fonte;

- $\quad V$ : velocidade de soldagem;

- $\quad \alpha$ : fator de difusividade térmica;

- $\quad x$ : coordenada na direção de soldagem.

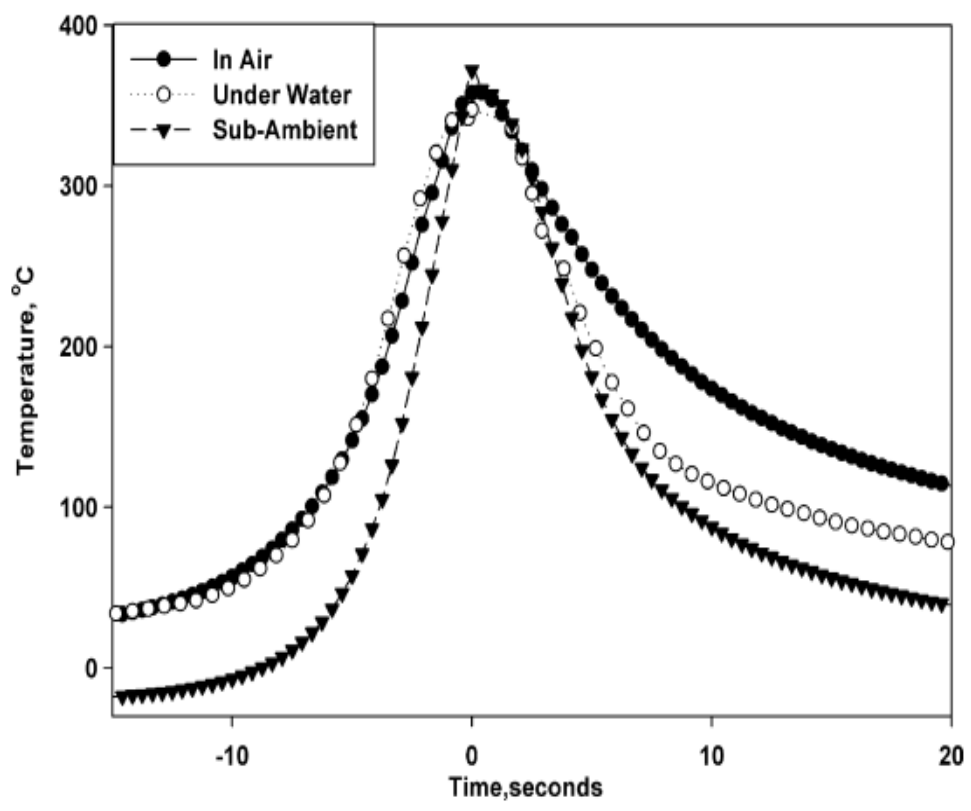

Figura 16 - Descrição da temperatura em função para a velocidade de soldagem de 3,4 $\mathrm{mm} / \mathrm{s}$ para as três condições analisadas [29]. 


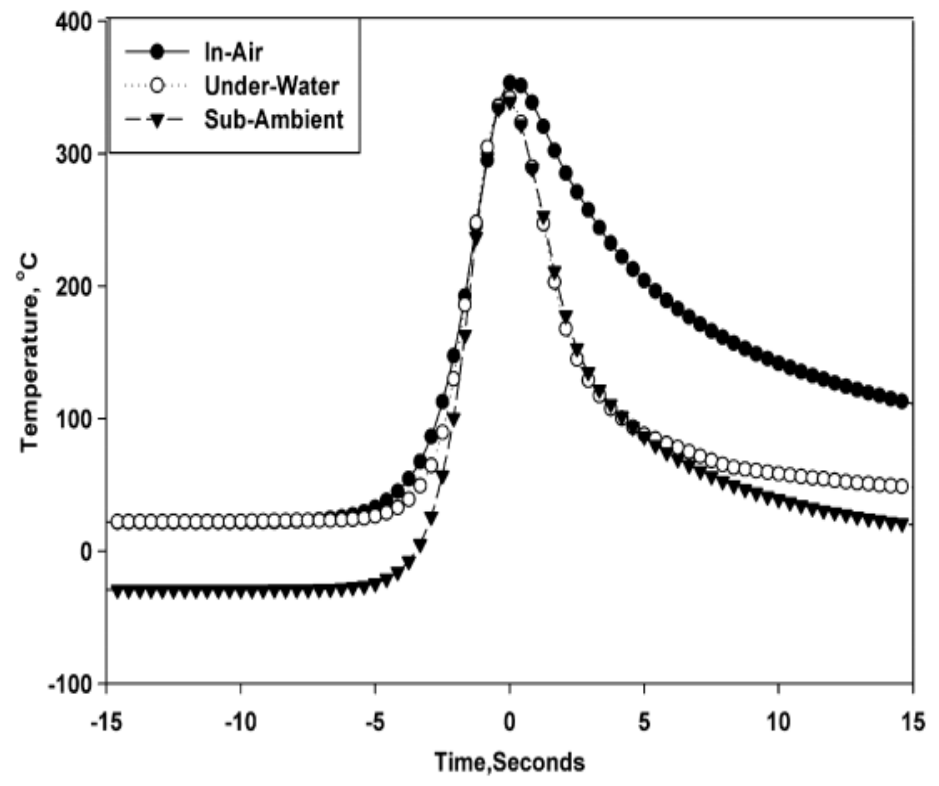

Figura 17 - Descrição da temperatura em função para a velocidade de soldagem de 6,8 $\mathrm{mm} / \mathrm{s}$ para as três condições analisadas [29].

\section{Distribuição da dureza}

Foram feitos testes de dureza Vickers com carga de 1000g e tempo de aplicação da carga de $10 \mathrm{~s}$ para determinar as durezas do material em função da distância do ponto de medida ao plano médio da solda.

Foi observado que a distribuição de dureza teria a forma típica de "W", como esperada pelos autores. Assim, concluiu-se que não houve uma diferença discrepante entre as durezas de cada experimento. A Figura 18 [29] mostra a distribuição de dureza em relação ao centro do cordão de solda.

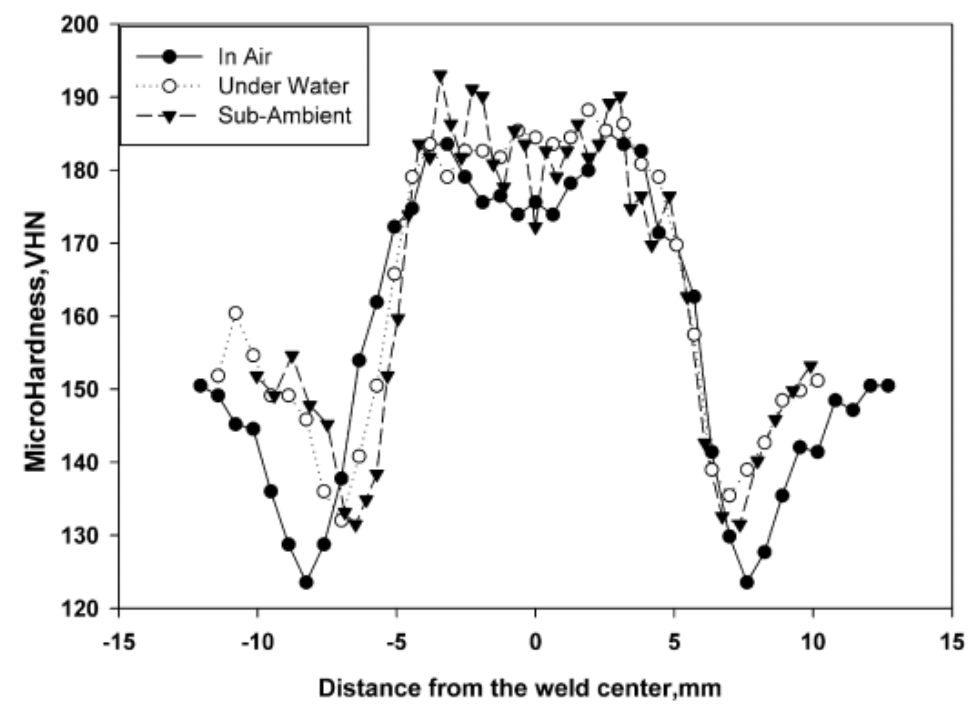

Figura 18 - Distribuição de Microdureza para as três condições do experimento 800 RPM; $6,8 \mathrm{~mm} / \mathrm{s}$ [29]. 
A zona termicamente afetada apresenta os valores de dureza mínimos nas três condições, ao contrário do que se observa na região de cordão de solda onde estão os maiores valores de dureza das amostras.

O aumento da dureza com o aumento a velocidade de soldagem não é uma função linear. $\mathrm{O}$ aumento é rápido em baixas velocidades de soldagem e, em seguida, diminui bruscamente com o aumento da velocidade de soldagem. $\mathrm{Ou}$ seja, é um parâmetro muito sensível a variação da velocidade de soldagem. A Figura 19 [29] traz a distribuição de dureza em função da velocidade de soldagem.

\section{Crescimento de grão}

$\mathrm{Na}$ velocidade de soldagem de $6,8 \mathrm{~mm} / \mathrm{s}$ foram realizadas três soldagens com rotações diferentes. Na Figura 20 [29], as setas indicam os tamanhos de grãos correspondentes para soldas no IA - In-Air e UW - Under Water feitas com os mesmos parâmetros. A Figura 20 [29] mostra também o tamanho de grão em relação a temperatura máxima desenvolvida durante a soldagem. Note que os símbolos em branco foram resfriados ao ar (IA - In-Air) e os símbolos preenchidos foram resfriados submergidos (UW - UnderWater).

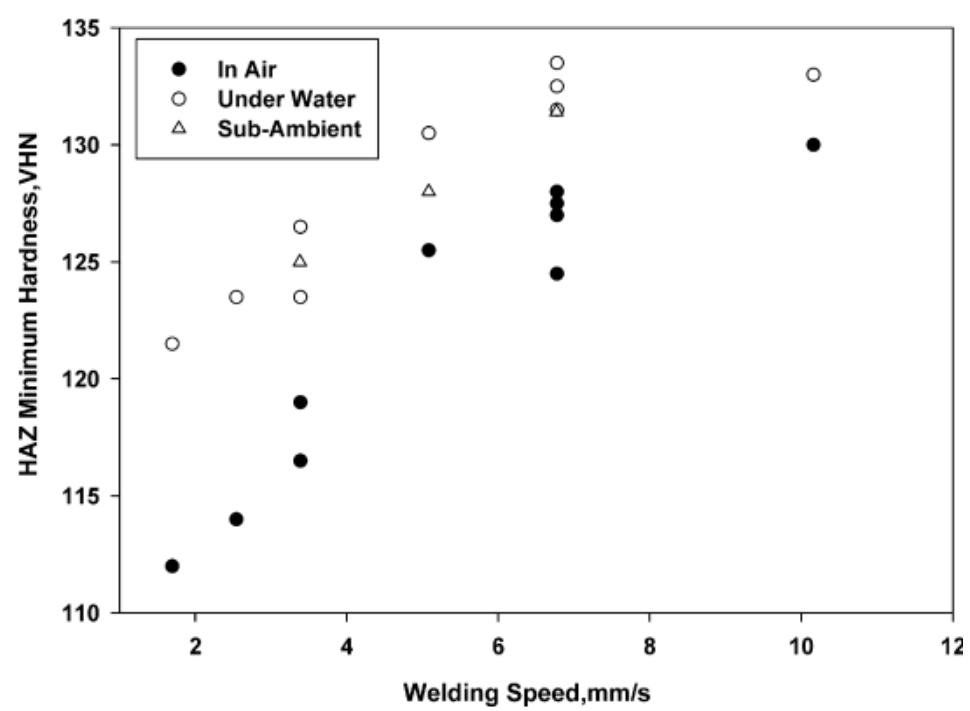

Figura 19 - Microdureza vs. Velocidade de soldagem [29]. 


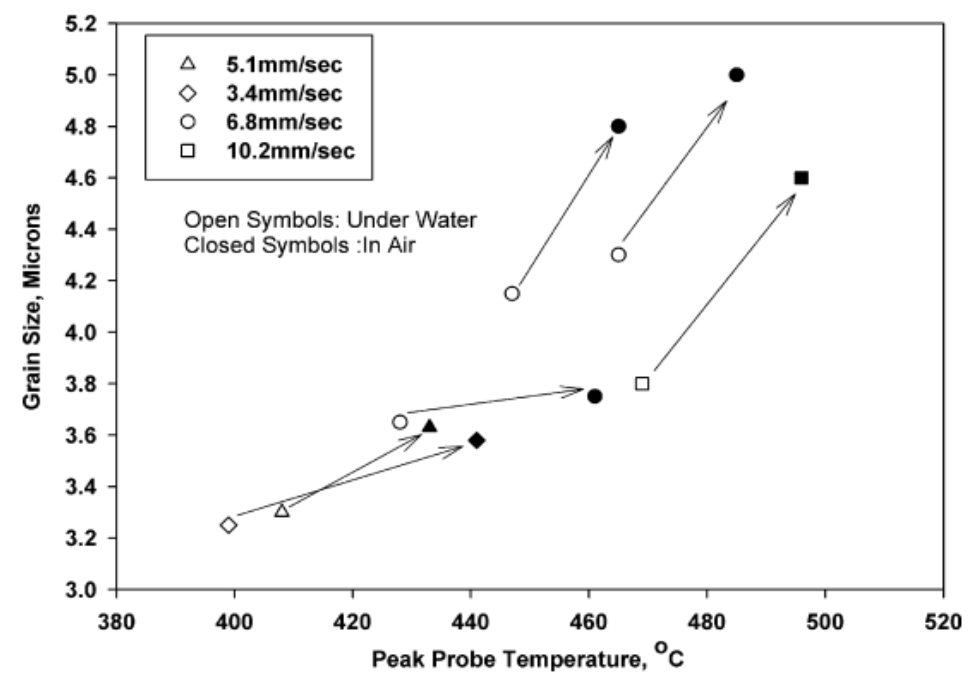

Figura 20 - O tamanho de grão é representado em função da temperatura máxima atingida em função da velocidade de soldagem [29].

O tamanho de grão UW é consistentemente menor que o IA. Isso pode ser atribuído a menor temperatura desenvolvida durante a soldagem sob as condições UW. Esse comportamento pode ser associado ao fato de que há uma recristalização e crescimento de grão pós-soldagem.

\section{Tensão-deformação VS Dureza.}

As soldas em UW tendem a ser mais resistentes mecanicamente do que as soldas em IA. O único caso em que isto não aconteceu foi para a soldagem em 200 RPM (velocidade de soldagem de 2,54 mm/s), no qual a solda UW foi menos resistente que a solda IA correspondente.

Os corpos de prova em questão romperam no cordão de solda. A partir de todos os dados de tração foi possível concluir que a rotação não é o único parâmetro para predizer a qualidade da solda. A Figura 21 [29] mostra a distribuição de dureza para 200 RPM com velocidade de soldagem 2,54 mm/s. A Figura 22 [29] mostra a tensão de ruptura dos corpos de prova em relação a rotação em que foram soldados.

Este estudo trouxe conclusões e correlações importantes como:

1. Todos os parâmetros sendo iguais (rotação e velocidade de soldagem) a soldagem sob a água em comparação com a soldagem ao ar resulta em:

- Temperatura da soldagem reduzida.

- Maior torque e consumo de energia. 
- Diminuição do tamanho de grão do cordão de solda.

- Taxas de resfriamento aumentadas na ZTA.

2. Nas condições estudadas, o pré-resfriamento a $-25 \circ \mathrm{C}$ não fornece um benefício significativo em comparação com a soldagem sob a água à temperatura ambiente.

3. A resistência à tração transversal exibe uma forte correlação com a dureza mínima da ZTA.

4. Taxas de resfriamento aumentadas resultam em dureza aumentada.

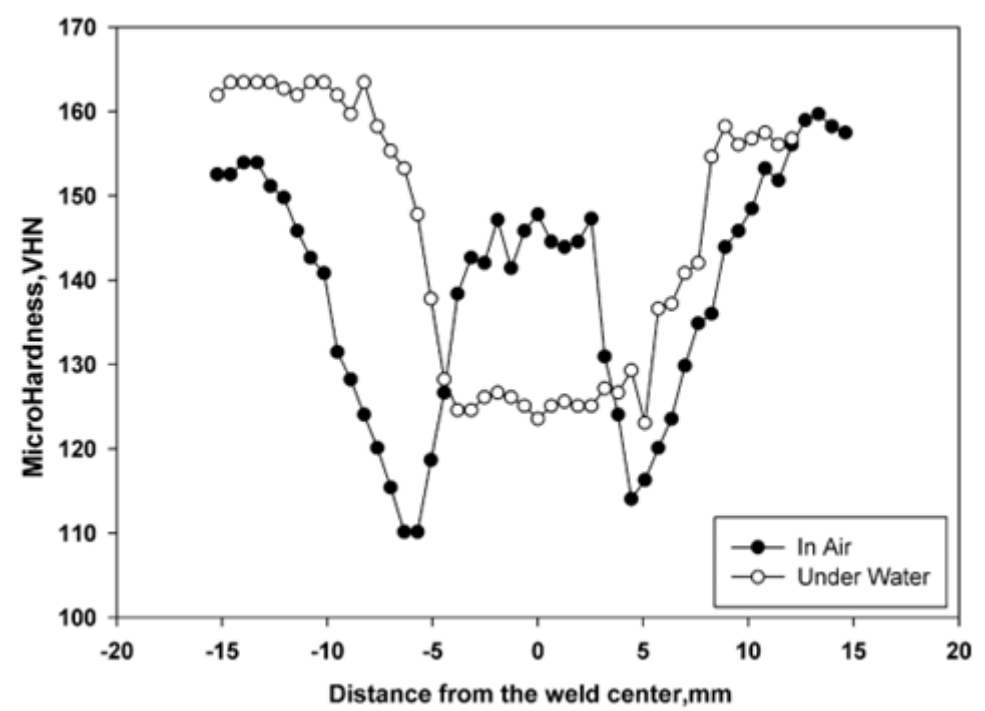

Figura 21 - Distribuição de dureza para 200RPM e 2,54mm/s [29].

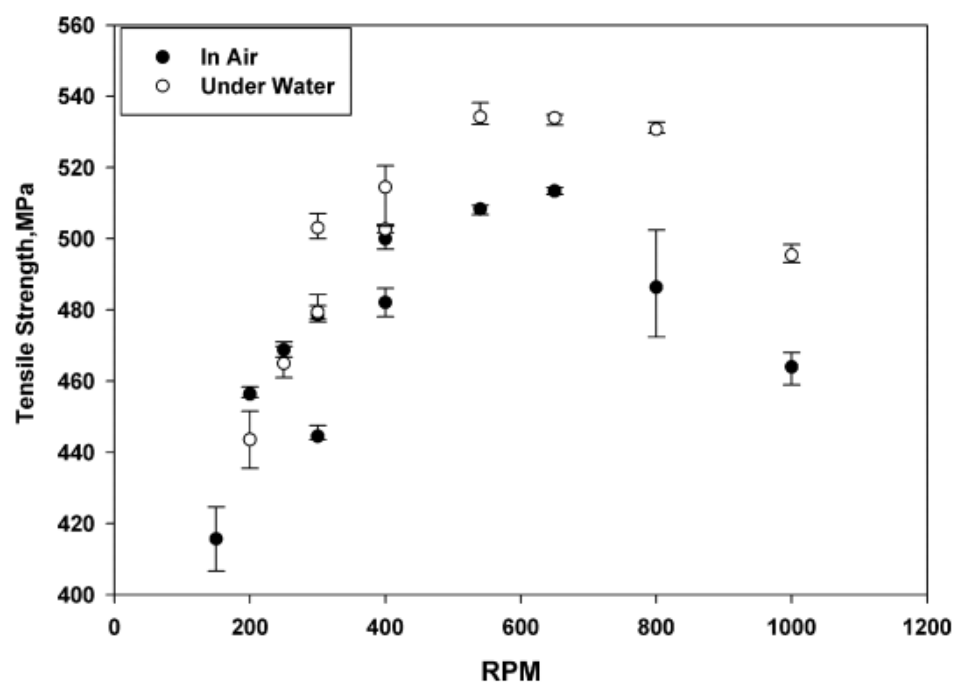

Figura 22 - Tensão de ruptura por velocidade de rotação [29]. 
No artigo Process-structure property relationships for nugget and heat affected zone regions of AA2524-T351 friction stir welds [31] os pesquisadores avaliaram os efeitos da velocidade de rotação $(\omega)$, velocidade de soldagem $(v)$ forças axiais $\left(F_{z}\right)$ por:

- Testes de microdureza Knoop. Com 100 gramas de carga e 25 segundos de tempo de aplicação da carga;

- Propriedades mecânicas, com testes de tração e corpo de prova definido conforme a Figura 23 [31]. Foram realizados testes usando toda e espessura da solda ou somente com a raiz da solda;

- Análise da microestrutura e da zona termicamente afetada (ZTA), por Microscopia eletrônica de Varredura (MEV) utilizando Elétrons Retro Espalhados (EBS) e Espectroscopia de Energia Dispersiva de Raio-X (EDX) para definir a composição química.

Utilizou como material base chapas de alumínio A2524-T351 com 6,4 mm de espessura e ferramenta com ombro de $20,3 \mathrm{~mm}$ e pino de $7,1 \mathrm{~mm}$, com $6,2 \mathrm{~mm}$ de comprimento e com rosca de passo de 0,794 $\mathrm{mm}$ e com ângulo de hélice de rosca de entrada da ferramenta de $2,5^{\circ}$ de ângulo. Assim, foram realizadas soldas de $560 \mathrm{~mm}$ de comprimento com apenas três parâmetros. As soldagens foram divididas em três grupos distintos: efeitos da velocidade de rotação, efeitos da velocidade de soldagem, efeito da força axial. A Tabela 3 [31] traz os parâmetros utilizados no estudo. 


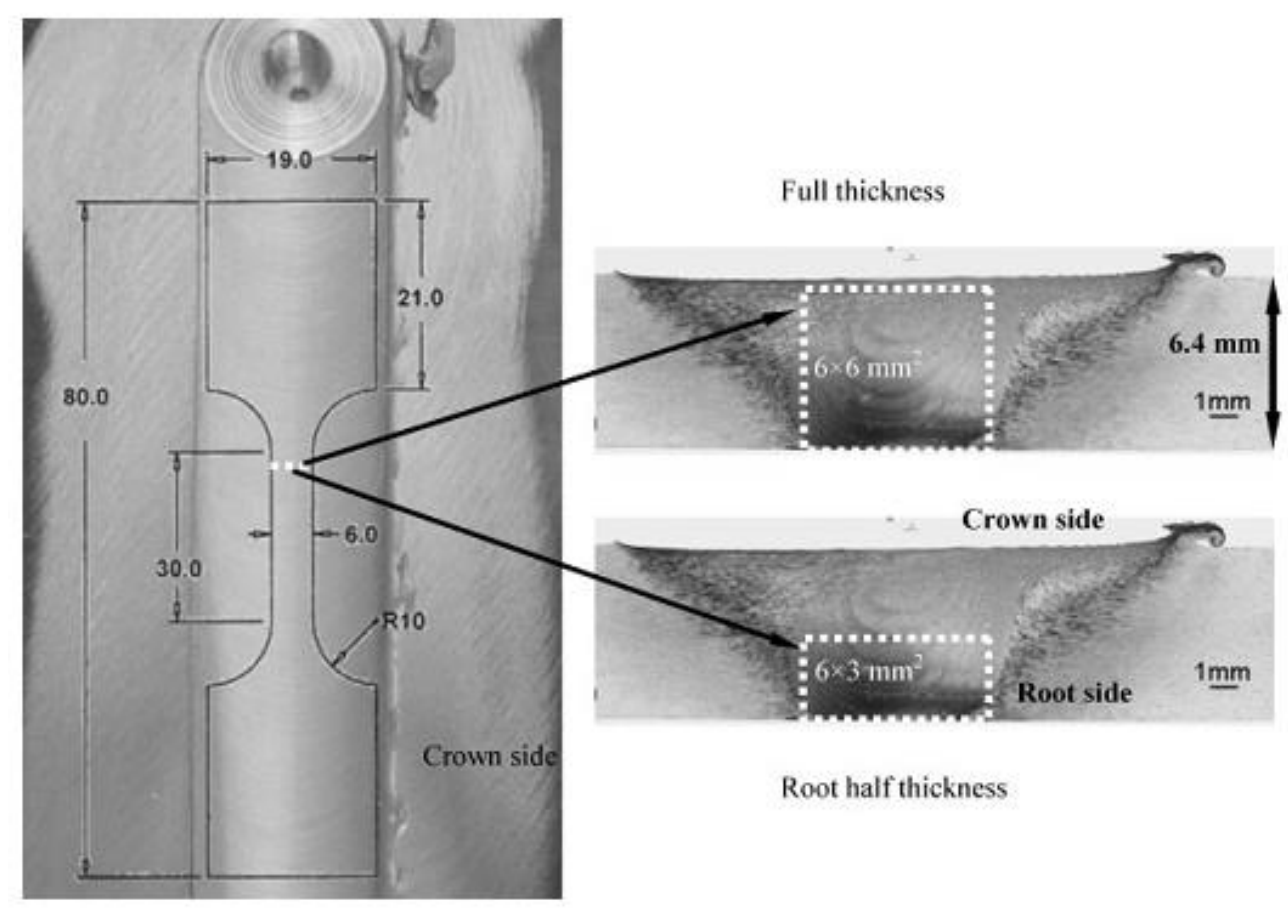

Figura 23 - Dimensões do corpo de prova para testes de tração [31].

Tabela 3 - Parâmetros utilizados nos experimentos.

\begin{tabular}{|c|c|c|c|}
\hline Espécime & $\begin{array}{l}\text { Velocidade de Rotação } \\
\text { (RPM) }\end{array}$ & $\begin{array}{c}\text { Velocidade de soldagem } \\
(\mathrm{mm} / \mathrm{s})\end{array}$ & $\begin{array}{l}\text { Força Axial } \\
\quad(\mathbf{K N})\end{array}$ \\
\hline \multicolumn{4}{|c|}{ Efeitos da Velocidade de Rotação. } \\
\hline 929 & 150 & 2,11 & 42,3 \\
\hline 926 & 200 & 2,11 & 42,3 \\
\hline 917 & 300 & 2,11 & 42,3 \\
\hline 927 & 480 & 2,11 & 42,3 \\
\hline 928 & 600 & 2,11 & 42,3 \\
\hline 934 & 800 & 2,11 & 42,3 \\
\hline \multicolumn{4}{|c|}{ Efeitos da Velocidade de Soldagem } \\
\hline 919 & 300 & 1,27 & 42,3 \\
\hline 917 & 300 & 2,11 & 42,3 \\
\hline 918 & 300 & 3,36 & 42,3 \\
\hline 931 & 300 & 4,23 & 42,3 \\
\hline \multicolumn{4}{|c|}{ Efeitos da Força Axial } \\
\hline 930 & 300 & 2,11 & 29,9 \\
\hline 935 & 300 & 2,11 & 42,3 \\
\hline 932 & 300 & 2,11 & 46,7 \\
\hline
\end{tabular}

Variando somente a velocidade de rotação $(\omega)$, tendo a velocidade de soldagem $(v)$ e força axial $\left(F_{Z}\right)$ constante, foi calculada a energia especifica $(\mathrm{J} / \mathrm{mm})$ e a potência $(W)$ através dos valores de torque $\left(T_{0}\right)$ medidos. Estes dois fatores possuem pouca variação abaixo de 600 RPM. Além disso, possuem o mesmo comportamento, pois ambos são relacionados à velocidade de soldagem. 
Ou seja, a energia específica é apenas a potência dividida pela velocidade de soldagem, que nesse caso era constante. A Figura 24 [31] ilustra os valores medidos para a energia específica e a potência.

Os resultados mostraram que quanto maior a rotação da ferramenta, maior o tamanho dos grãos. A Figura 25 [31] mostra claramente a evolução da microestrutura em função da velocidade de rotação.

Acredita-se que o torque $\left(T_{0}\right)$ está relacionado com a temperatura alcançada durante a soldagem. A Figura 26 [31] mostra que $T_{0}$ declina rapidamente entre 150 e 480 RPM. Para valores de $T_{0}$ entre 480 e 800 RPM, a redução é mais lenta, talvez indicando que tenha sido alcançado um patamar contínuo de fluxo de material.
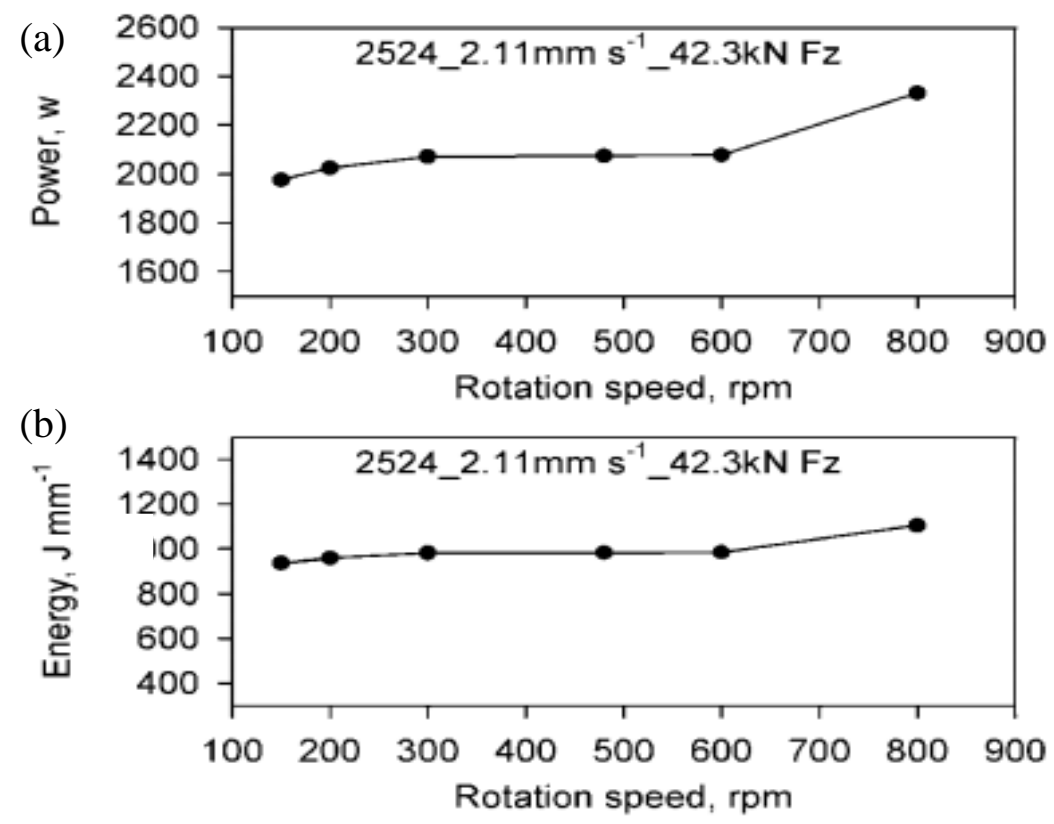

Figura 24 - Potência (a) e energia específica (b) em função da velocidade de rotação [31]. 


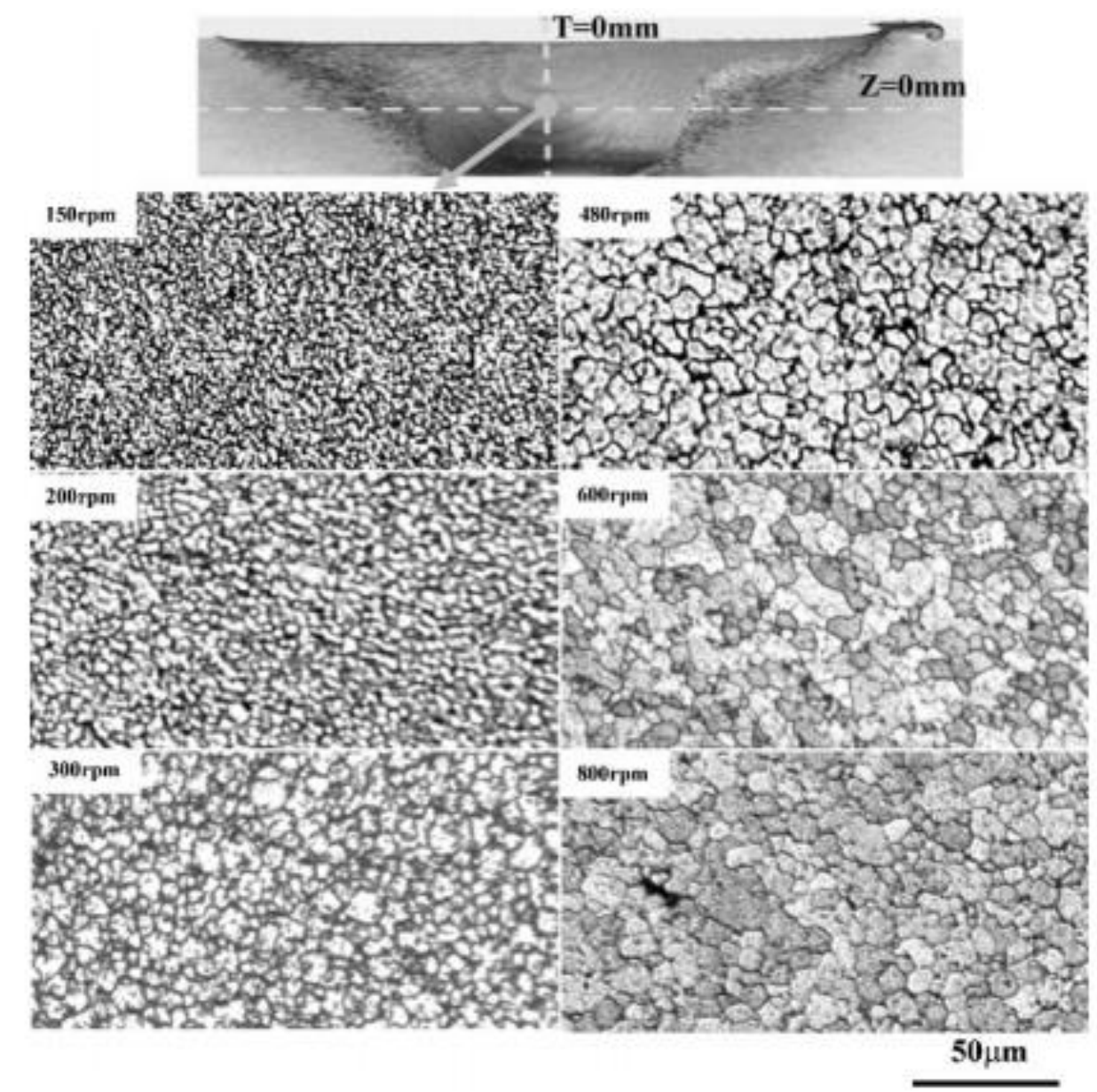

Figura 25 - Micrografias que mostram o crescimento de grão para o aumento da velocidade de rotação [31].

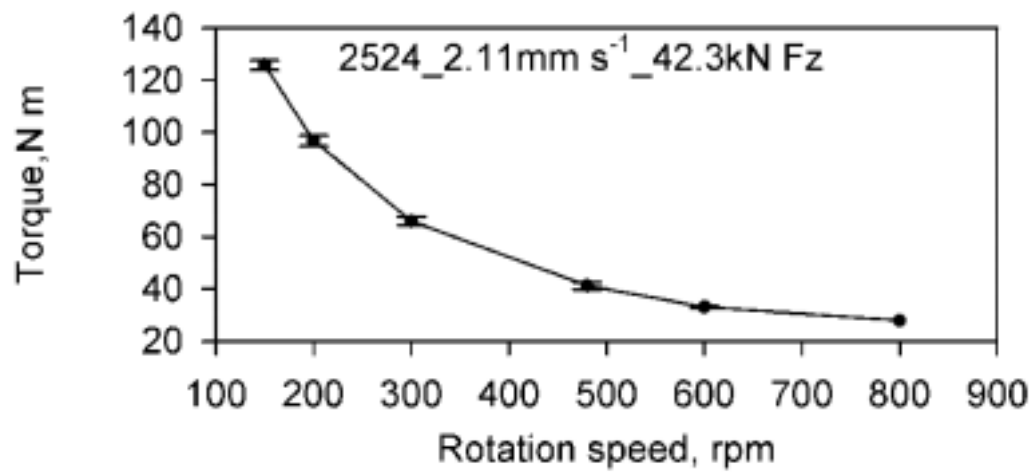

Figura 26 - Variação do torque $\left(\boldsymbol{T}_{\mathbf{0}}\right)$ em função da velocidade de rotação [31].

A Figura 27 [30] mostra os valores de dureza para o cordão de solda e para a zona afetada termicamente (ZTA) em função da velocidade de rotação. Vale observar que o cordão de solda apresenta valores de dureza muito próximos aos da ZTA para rotações de 150 RPM. 


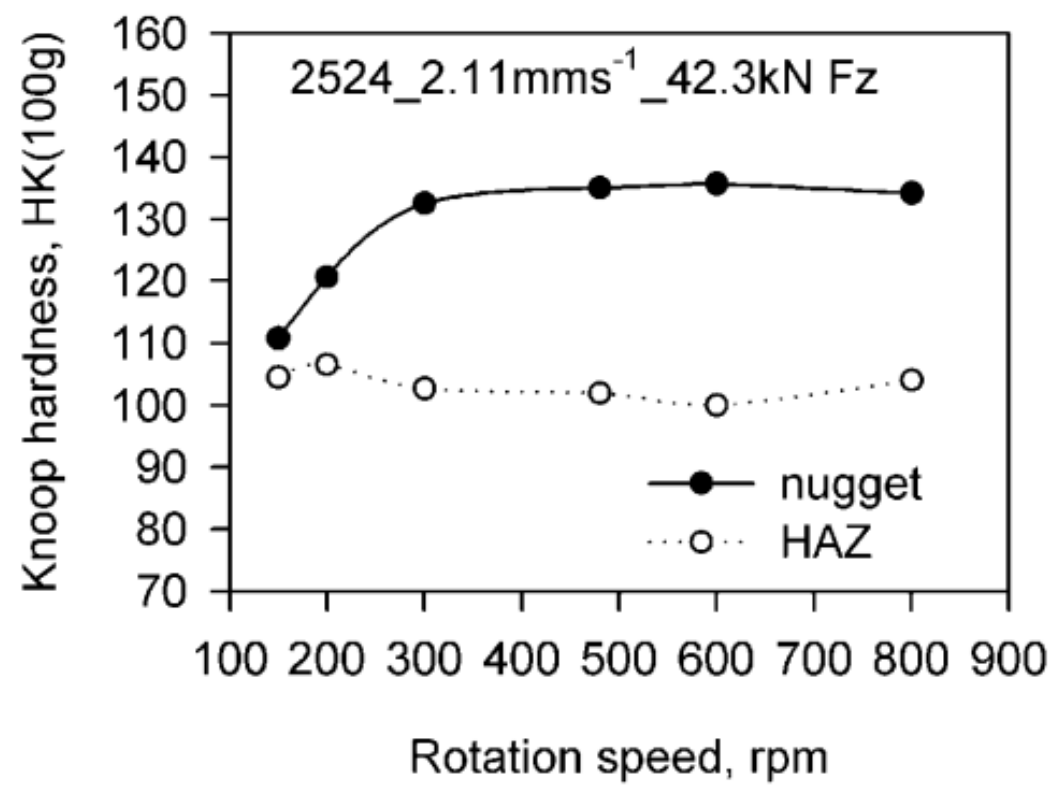

Figura 27 - Dureza do cordão de solda e da ZTA em relação à velocidade de rotação [31].

A Figura 28 [31] traz a correlação entre as durezas medidas e $T_{0} . \mathrm{O}$ cordão de solda apresenta uma relação linear do tamanho de grão com $T_{0}$, o que corresponderia a uma redução do tamanho de grão com aumento de $T_{0}$. Os valores de dureza para o cordão apresentam uma relação inversamente proporcional.

A Figura 29 [31] resume os efeitos da mudança da velocidade de rotação em relação às propriedades mecânicas do material.



Figura 28 - Dureza do Cordão de solda e sua ZTA em relação ao torque [31]. 

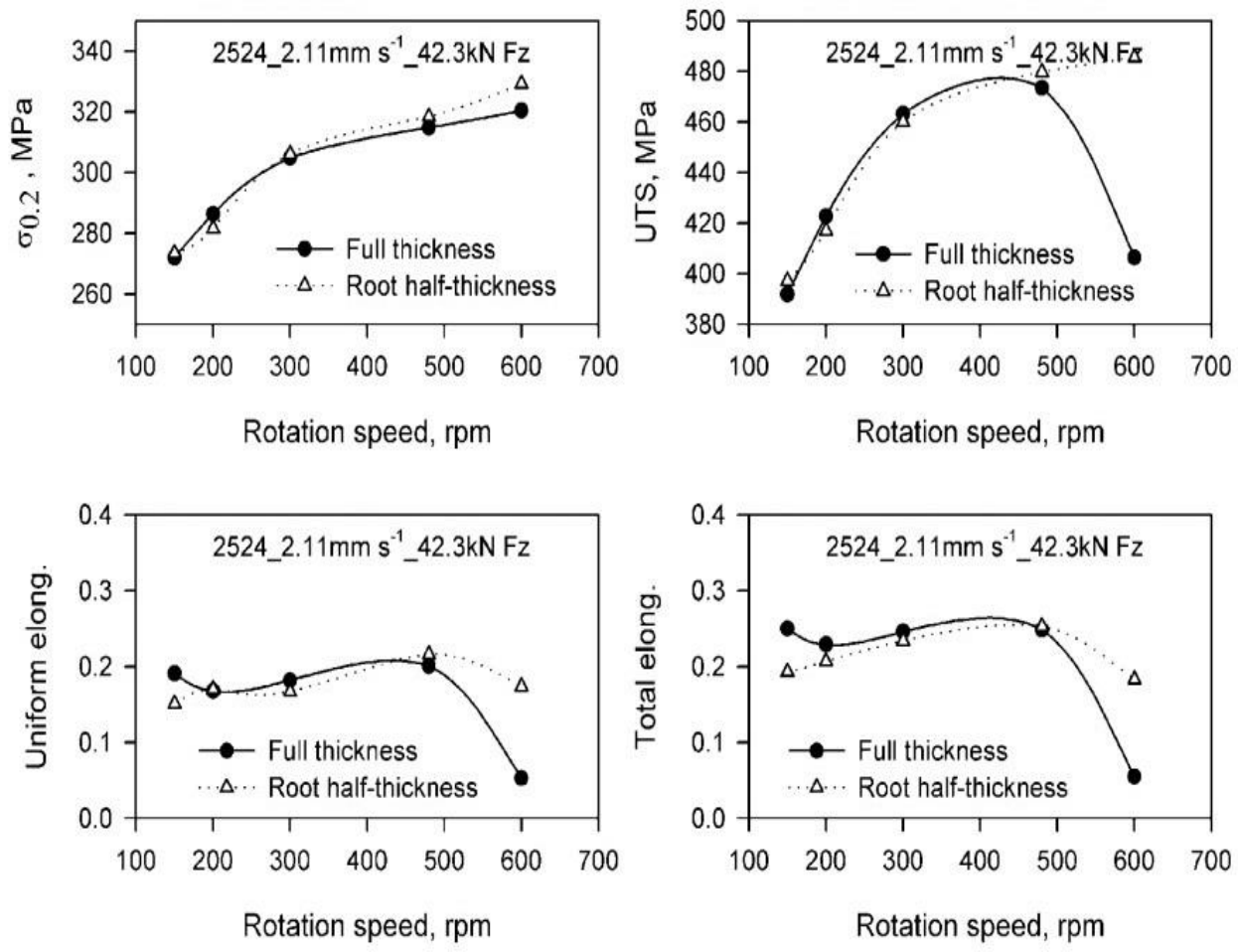

Figura 29 - Valores das propriedades mecânicas obtidos nos testes de tração [31].

Variando somente a velocidade de soldagem $(v)$ e mantendo constantes a velocidade de rotação $(\omega)$ e a força axial $\left(F_{z}\right)$ foi concluído que os valores de torque e a potência de soldagem são diretamente proporcionais à velocidade de soldagem (v), todavia este aumento não é muito significativo. A Figura 30 [31] mostra os gráficos contendo os valores de torque e potência em função da velocidade de soldagem. 

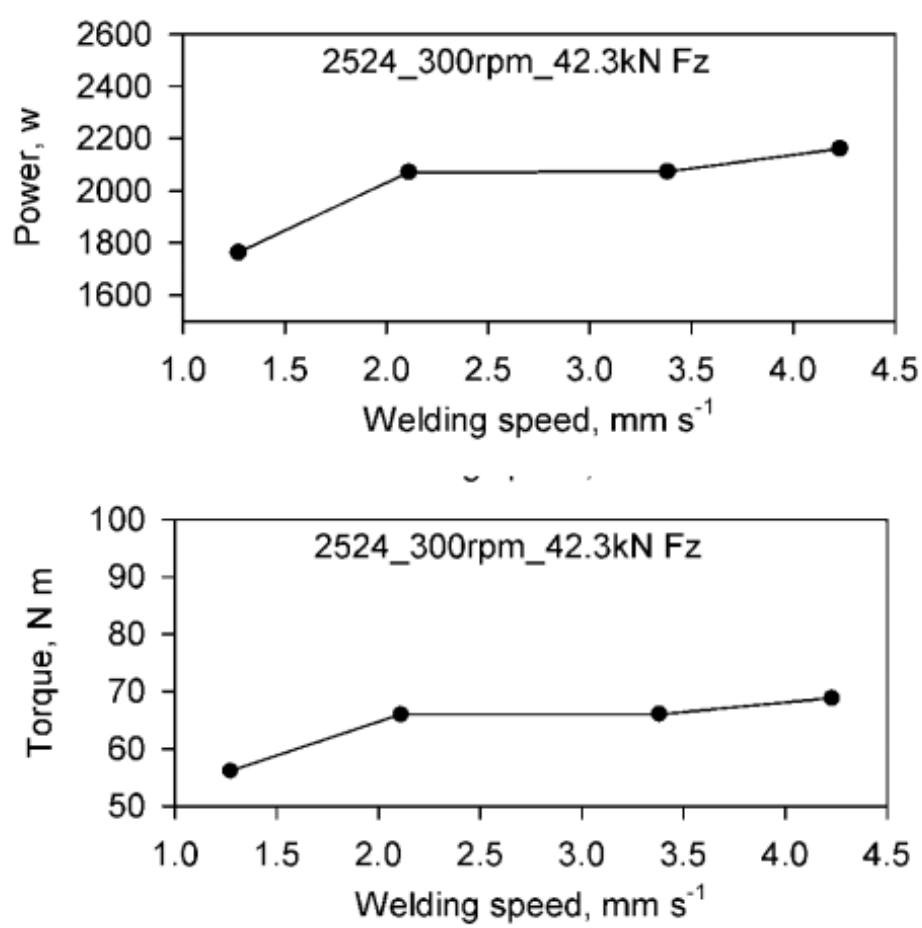

Figura 30 - Medidas de Torque e Potência em função da velocidade de soldagem [31].

Para as condições analisadas, os resultados indicam que os efeitos nas propriedades mecânicas e na microestrutura podem ser obtidos aumentando-se a temperatura do processo. O estudo também mostrou que a temperatura máxima de solda é inversamente relacionada ao torque medido $T_{0}$. Assim, esse é um parâmetro útil para a caracterização e modificação de solda.

O artigo Optimization of Friction Spot Welding Process Parameters for AA2198-T8 Sheets [32] avaliou parâmetros para soldagem por Friction Stir Spot Welding (FSpW) de uma liga de alumínio (AA2198-T8) que foi utilizada por ser uma liga de baixa densidade $2.400 \mathrm{~kg} / \mathrm{m}^{3}$ ), alto módulo específico, valores de módulo de elasticidade acima de $82 \mathrm{GPa}$, resistente à fadiga e à corrosão. Realizou-se quinze experimentos em corpos de provas distintos (C1-C15), com planejamento de experimentos pelo método Taguchi, onde analisou-se três fatores (velocidade de rotação, tempo de soldagem e profundidade de penetração do pino) sobre as forças de resistência ao cisalhamento das juntas soldadas. A Tabela 4 [32] mostra os parâmetros utilizados em cada corpo de prova e o resultado das forças de resistência ao cisalhamento de cada junta soldada. A Figura 31 [32] traz o resultado do ensaio de cisalhamento para três amostras sob condições de soldagem distintas. 


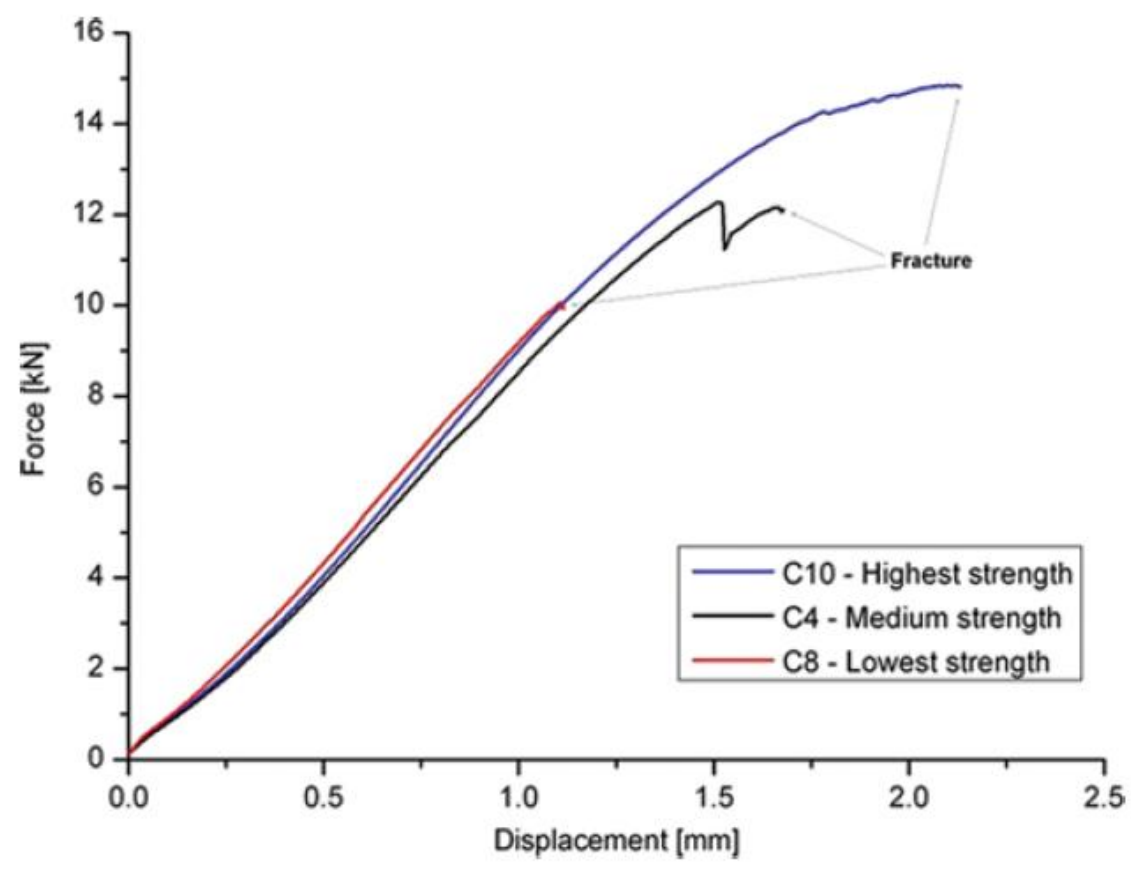

Figura 31 - Força vs. Deformação. Maior valor encontrado em (C10), a mais baixa (C8) e de um intermediário (C4), (C10: 14,73 KN; C8: 10,97 KN; C4: 12,56 KN) [32].

A Figura 32(a) [32] mostra que valores entre 1500 e 2000 RPM estão entre os valores ideais. A Figura 30(b) [32] mostra que um curto tempo de soldagem (4 s) leva a menor resistência, ao passo que o aumento do tempo para $7 \mathrm{~s}$ leva a resultados muito superiores. Tempos de soldagem longos não afetam significativamente a resistência das juntas, por isso não são vantajosos e possuem um efeito negativo sobre a produtividade. A Figura 30(c) [32] mostra que a profundidade do pino em 4,7 mm apresenta maior valor de força. Entretanto, não se pode concluir diretamente dos resultados se quanto maior a profundidade de penetração, maiores serão as forças, pois para 5,2 $\mathrm{mm}$ de profundidade obteve-se o mesmo valor de força que para $4,2 \mathrm{~mm}$. 
Tabela 4 - Parâmetros a serem variados para soldagem de carda corpo de prova e resultados obtidos.

\begin{tabular}{|c|c|c|c|c|}
\hline $\begin{array}{c}\text { Corpos de } \\
\text { Prova }\end{array}$ & $\begin{array}{c}\text { Rotação } \\
\text { (RPM) }\end{array}$ & $\begin{array}{c}\text { Tempo de } \\
\text { soldagem (s) }\end{array}$ & $\begin{array}{c}\text { Penetração } \\
\text { (mm) }\end{array}$ & $\begin{array}{c}\text { Resistência ao } \\
\text { Cisalhamento (KN) }\end{array}$ \\
\hline C1 & 1500 & 4 & 3,7 & $10,98 \pm 1,70$ \\
\hline C2 & 1500 & 7 & 4,2 & $13.71 \pm 0,40$ \\
\hline C3 & 1500 & 10 & 4,7 & $14,71 \pm 0,30$ \\
\hline $\mathbf{C 4}$ & 2000 & 4 & 4,2 & $12,56 \pm 0,74$ \\
\hline $\mathbf{C 5}$ & 2000 & 7 & 4,7 & $14,46 \pm 0,40$ \\
\hline $\mathbf{C 6}$ & 2000 & 10 & 3,7 & $13,61 \pm 0,33$ \\
\hline $\mathbf{C 7}$ & 2500 & 4 & 4,7 & $12,73 \pm 0,68$ \\
\hline $\mathbf{C 8}$ & 2500 & 7 & 3,7 & $10,74 \pm 1,82$ \\
\hline $\mathbf{C 9}$ & 2500 & 10 & 4,2 & $13,55 \pm 0,71$ \\
\hline $\mathbf{C 1 0}$ & 2000 & 10 & 4,7 & $14,73 \pm 0,71$ \\
\hline $\mathbf{C 1 1}$ & 2500 & 10 & 4,7 & $13,75 \pm 0,24$ \\
\hline $\mathbf{C 1 2}$ & 2000 & 4 & 4,7 & $11,59 \pm 0,13$ \\
\hline $\mathbf{C 1 3}$ & 2000 & 13 & 4,7 & $14,70 \pm 0,56$ \\
\hline $\mathbf{C 1 4}$ & 2000 & 10 & 4,2 & $14,20 \pm 0,10$ \\
\hline $\mathbf{C 1 5}$ & 2000 & 10 & 5,2 & $14,20 \pm 0,36$ \\
\hline
\end{tabular}

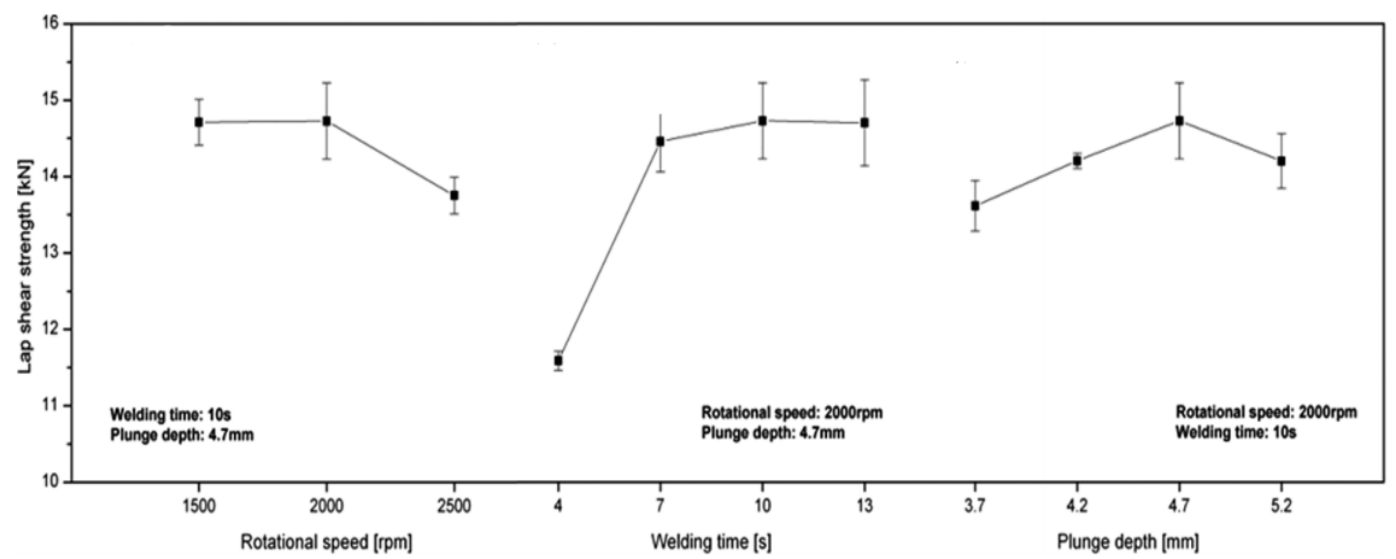

Figura 32 - Efeito individual da velocidade de rotação (a), tempo de soldagem (b) e a penetração (c) sobre a resistência ao cisalhamento das juntas soldadas [32].

A Figura 33 [32] mostra uma micrografia óptica da seção transversal ao longo do plano de simetria de uma das soldas realizadas no corpo de prova $\mathrm{C} 4$. As três zonas diferentes formadas na região de solda são identificadas como a zona de agitação (SZ), a zona afetada termo-mecanicamente (TMAZ) e a zona afetada pelo calor (HAZ).

A Figura 33 [32] também apresenta a microestrutura das diferentes regiões da solda. A SZ é composta por grãos equiaxiais finos e recristalizados, resultantes 
do calor do atrito e da agitação mecânica do material. As diferentes dimensões do grão dentro da SZ são devidas ao fluxo de material e gradientes de temperatura dentro desta região. O material adjacente, que está em contato com a superfície externa da ferramenta, forma uma região de transição entre SZ e TMAZ (Figura 33 (b)). A TMAZ é caracterizada por uma recristalização da estrutura com os grãos (Figura 33 (c)); esta região tem como característica uma estrutura altamente deformada. A HAZ é adjacente a TMAZ. Esta região é afetada apenas pelo gradiente de temperatura, não há qualquer deformação plástica. A microestrutura da HAZ consiste principalmente de grãos alongados.

Medidas de microdureza foram realizadas para as condições de solda C4, C8 e C10 e os resultados são mostrados na Figura 34[32], que também mostra a extensão do diâmetro da ferramenta.

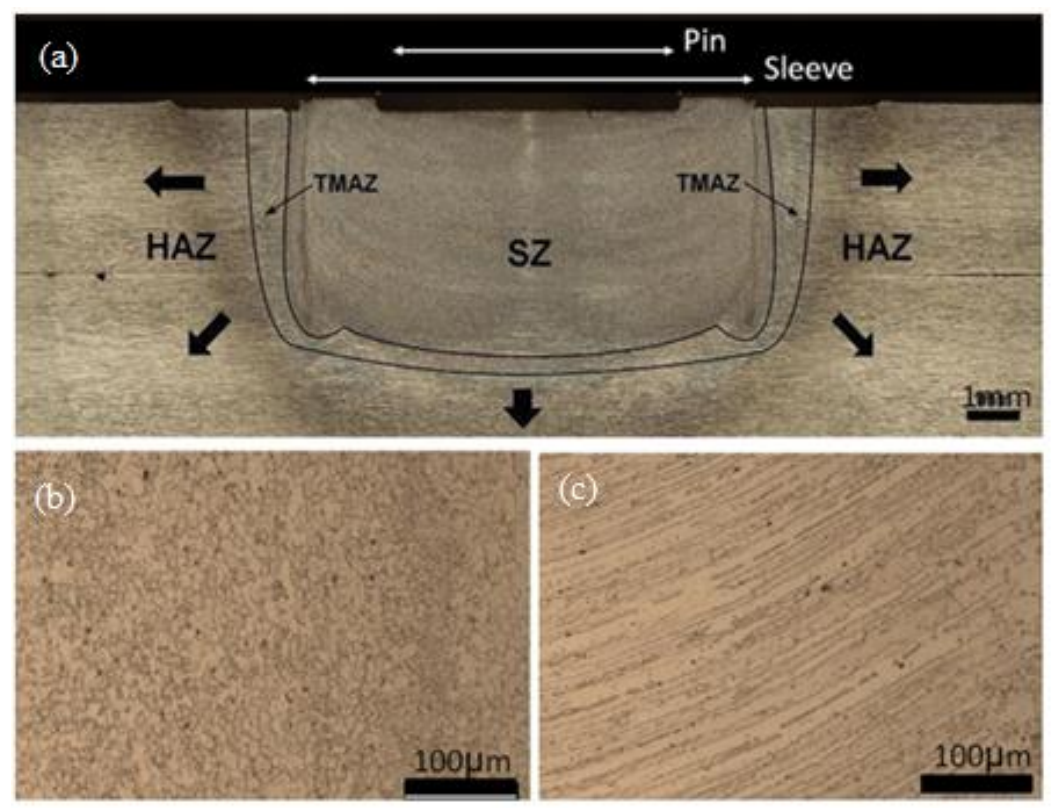

Figura 33 - Micrografias ópticas do ponto de solda realizada sob condição $\mathrm{C} 4$, que mostra: (a) a microestrutura das diferentes regiões FSpW, (b) A região de transição entre $S Z$ e TMAZ e (c) TMAZ [32]. 




Figura 34 - Perfis de microdureza para condições de soldagem C4 (resistência intermediária), C8 (menor resistência) e C10 (maior força) [32].

Assim, concluiu-se que a melhor combinação de parâmetros seria: a velocidade de 2000 RPM, profundidade de penetração do pino de 4,7 mm e tempo de soldagem de $10 \mathrm{~s}$. Isto se deve ao fato de que menos calor é gerado em função da fricção.

Solda com perfis de microdureza com grande variação de dureza ao longo da seção transversal são soldas que rompem com uma força muito baixa, ou seja, ter uma grande variação da dureza resulta em uma solda com baixa resistência ao cisalhamento.

A análise da fratura mostrou que os defeitos se iniciam na fronteira entre as regiões TMAZ e HAZ.

No Artigo Process Response Parameter Relationships in Aluminium Alloy Friction Stir Welds [33] realizaram-se ensaios com velocidade de soldagem constante $(1,27 \mathrm{~mm} / \mathrm{s})$ variando apenas a velocidade de rotação em três ligas de alumínio 5083-O; 2219-T87; 7050-T751.

Buscou-se, assim, correlacionar o torque e a força de soldagem (x-force) de cada experimento com o tamanho de grão e a tensão necessária para ocorrer a deformação, ou seja, a tensão de escoamento (flow stress). A Figura 35 [33] mostra a correlação entre o torque e a rotação e a variação do tamanho de grão com a força de soldagem em função da rotação para cada liga de alumínio utilizada neste estudo. 

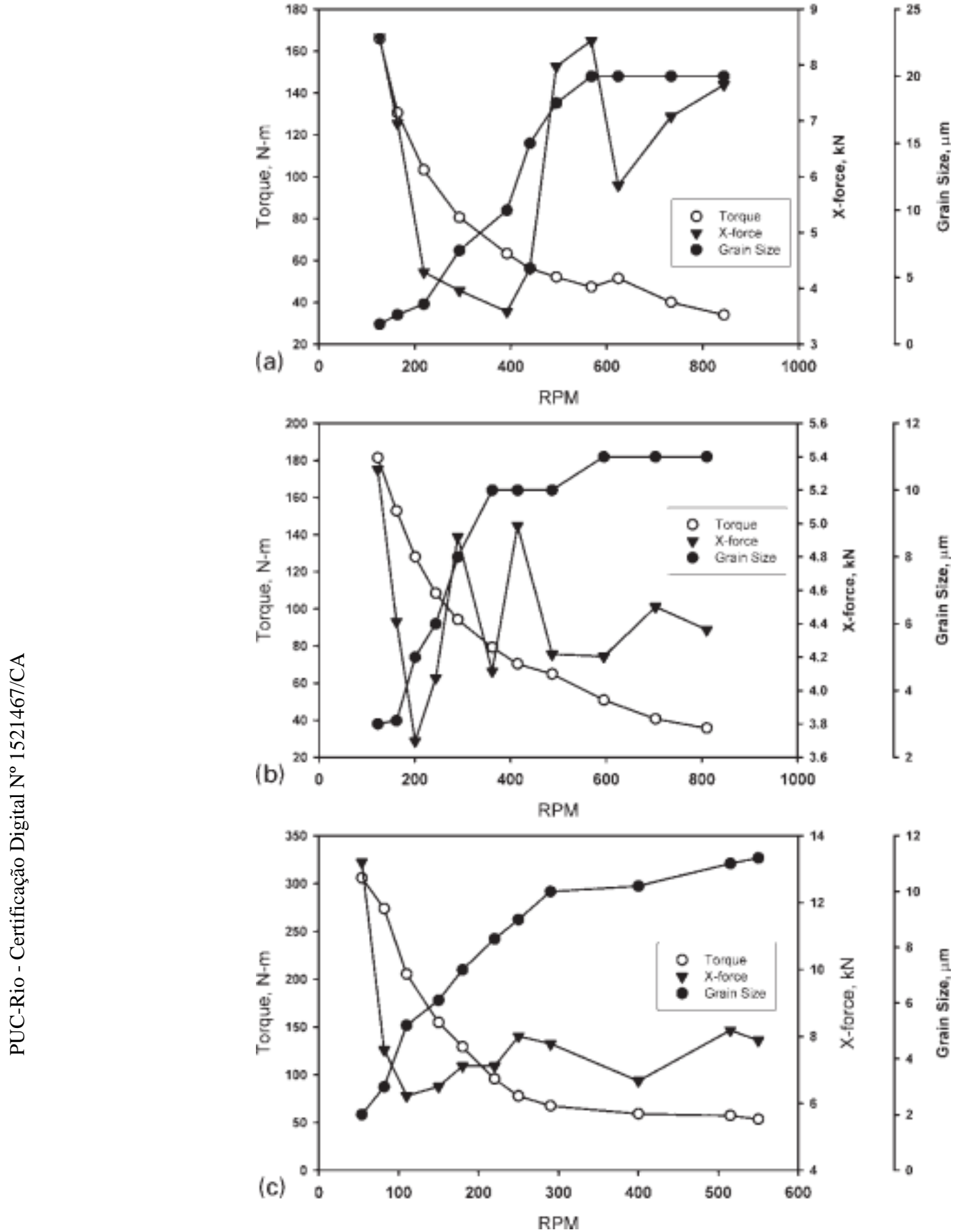

Figura 35 - Correlação entre Torque, Força de soldagem e tamanho de grão em função da rotação. (a) resultados para a liga 2219; (b) resultados para a liga 5083; (c) resultados para a liga 7050 [33].

O que se vê é que a curva de tamanho de grão tem o comportamento inverso a curva de torque. O tamanho do grão cresce de maneira brusca em baixas rotações e a curva de torque decresce de maneira brusca em baixas rotações. 
Observa-se também que tamanho de grão e o torque ficam estáveis, com pouca variação, a partir de determinado valor de rotação.

Os experimentos mostraram que torque, rotação e tamanho de grão possuem uma relação, por duas razões [33]:

i. O torque está diretamente ligado à tensão necessária para causar fluxo plástico.

ii. O tamanho do grão está diretamente relacionado (não linearmente) com a temperatura que o material alcança durante a soldagem.

A tensão de cisalhamento na interface ferramenta/peça está ligada a resistência ao cisalhamento do material e não ao coeficiente de atrito. Assim é concluído que a queda nos valores de torque está associada a queda na tensão necessária para causar fluxo plástico com o aumento da rotação. Esta queda está associada ao aumento da temperatura da peça a ser soldada. O aumento do tamanho de grão está associado diretamente ao aumento da temperatura da peça. Este argumento é embasado por Sato et. al [34], que mostrou uma relação exponencial, baseada na lei de crescimento de grão, entre a temperatura de soldagem e o tamanho do grão.

Foi assumido que o flow stress é constante em toda a soldagem e os valores de torque (T) podem ser usados para calcular a tensão média de tensão de cisalhamento (shear strength $-\tau$ ) do material em contato com a ferramenta pela eq. (15) [35]:

$$
\tau=\frac{T}{2 \pi\left(\frac{r_{s}{ }^{3}}{3}+z r_{p}{ }^{2}\right)}
$$

Onde:

- Tensão de cisalhamento (shear stress)

- $T$ : Torque.

- $z$ : Comprimento do pino da ferramenta.

- $r_{s}$ : Raio do ombro.

- $r_{p}$ : Raio do pino. 
A tensão de tensão de escoamento (flow stress - $\sigma_{0}$ ) pode ser calculada multiplicando-se os valores de tensão de cisalhamento por $\sqrt{3}$ [32]. Assim obtémse a eq. (16) :

Eq. (16)

$$
\sigma_{0}=\tau \sqrt{3}
$$

Assim, foi gerado um gráfico da tensão necessária para causar o fluxo plástico versus velocidade de rotação (RPM). A Figura 36 [32] mostra os valores de flow stress por RPM.

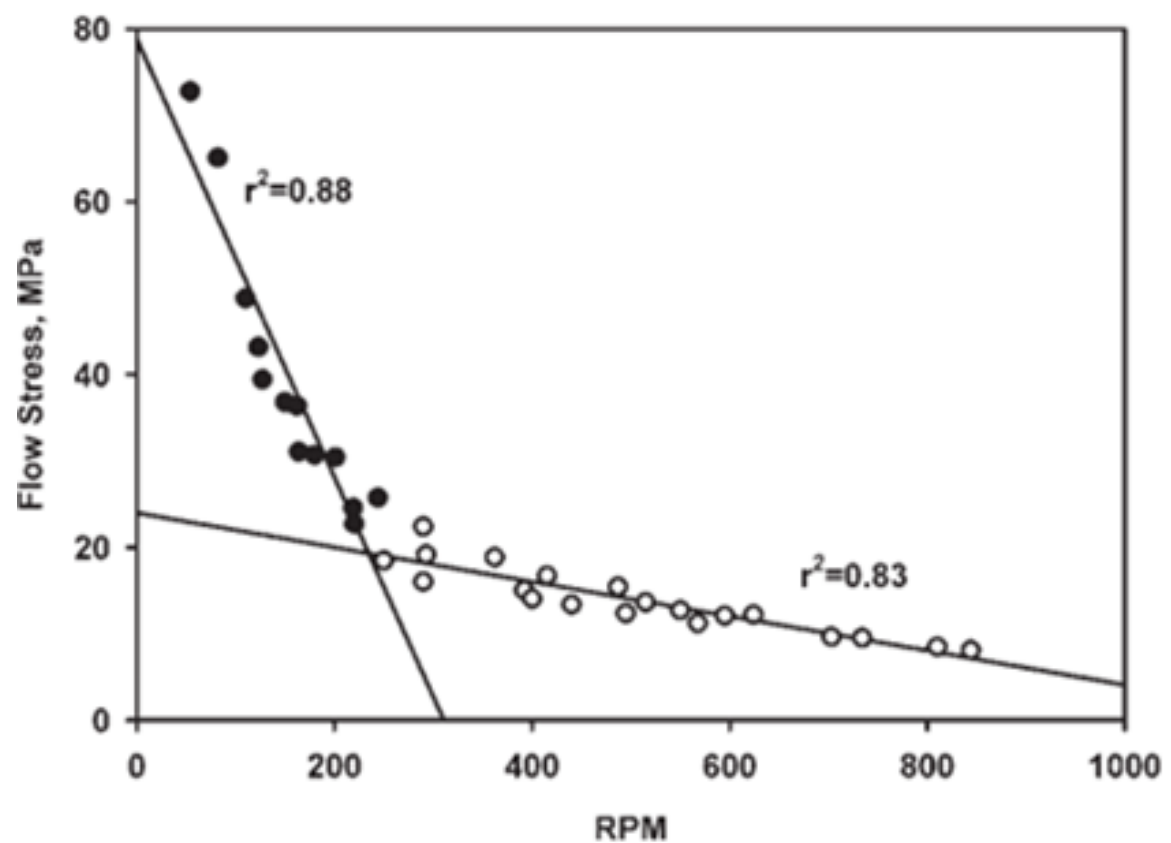

Figura 36 - Gráfico de relação Flow Stress vs. RPM [32].

As linhas de regressão foram ajustadas como coeficiente de correlação de 0,88 e 0,83 , respectivamente. A interseção entre essas retas gera um bom parâmetro para separar as condições de alta rotação e de baixa rotação. Este ponto traz valores de $235 \mathrm{RPM}$ e $19 \mathrm{MPa}$.

A conclusão final foi de que pode ser possível construir gráficos Torque vs RPM para permitir otimização do processo, orientando a escolha apropriada de parâmetros de processamento para uma dada liga.

$\mathrm{O}$ artigo Mechanical properties of friction stir welded aluminum alloys 5083 and 5383 estuda o comportamento da curva tensão vs deformação para corpos de 
prova de alumínio 5083-H112 e 5383-H116 soldados por MAG e soldados por FSW [22]. As condições usadas foram as seguintes:

1 Dois corpos de prova para cada condição (N1 e N2)

2 Soldagem de duas chapas com a seguinte configuração:

a. $5083-\mathrm{H} 112+5083-\mathrm{H} 112$;

b. 5083-H112+5383-H116;

c. $5383-\mathrm{H} 116+5383-\mathrm{H} 116$.

3 Ensaios de tração com corpo de prova retirado das chapas como apresentado na Figura 37(a) [10].

4 Condições de soldagem MAG:

a. Metal de Adição: 5183;

b. Diâmetro do fio de adição: $1,2 \mathrm{~mm}$;

c. Gás: $100 \%$ inerte;

d. Velocidade de soldagem: $450 \mathrm{~mm} / \mathrm{min}$;

e. Fonte: 18 Amperes e 21 Volts;

f. Ângulo da tocha: $50^{\circ}$.

5 Condições de soldagem FSW:

a. Rotação: 1500RPM;

b. Velocidade de Soldagem: $4 \mathrm{~mm} / \mathrm{s}$;

c. Temperatura da solda: Aproximadamente $370^{\circ} \mathrm{C}$.

d. Ferramenta: $\mathrm{d} 1=4 \mathrm{~mm}, \mathrm{~d} 2=5 \mathrm{~mm}, \mathrm{~d} 3=15 \mathrm{~mm}, \mathrm{~h}=5,4 \mathrm{~mm}$, como descrito na Figura 36(b) [22].


Figura 37 - (a): Características do corpo de prova; (b): Características da ferramenta FSW [22]. 
O processo de soldagem prejudicou as propriedades mecânicas dos materiais. Assim, foi concluído que os corpos de prova soldados por fricção têm propriedades superiores, ou no mínimo iguais, aos soldados por soldagem por fusão. As Figuras 38, 39 e 40 trazem os resultados do estudo em gráficos tensão vs deformação [22].

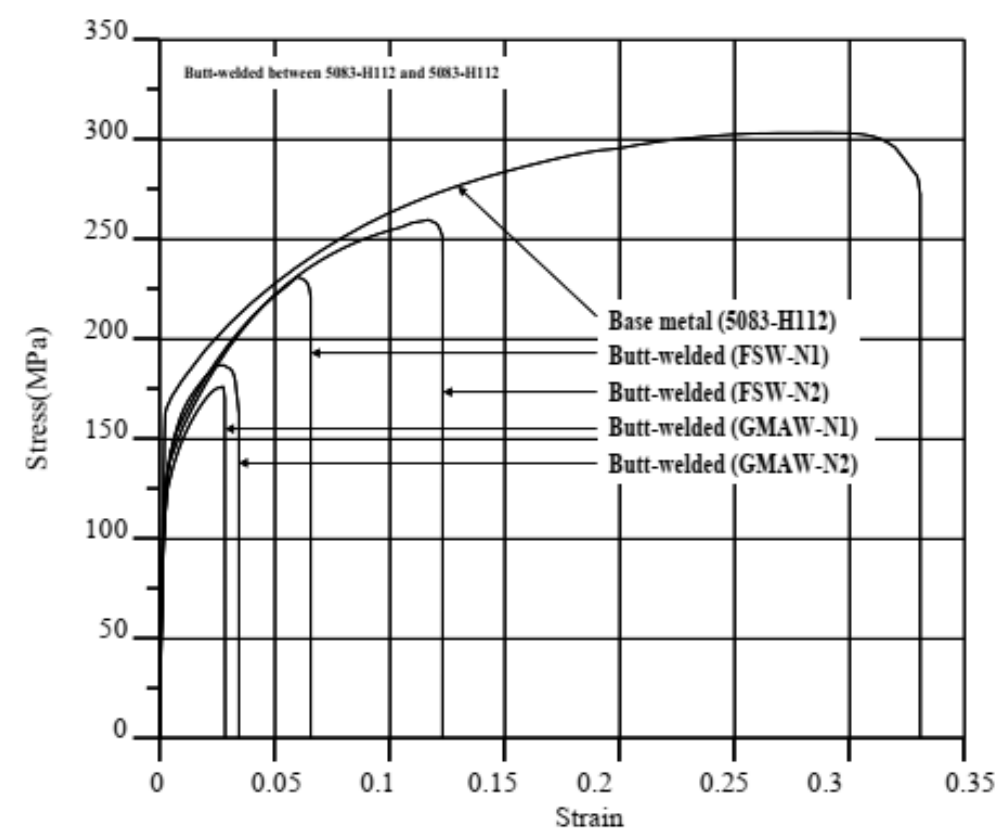

Figura 38 - Curvas Tensão vs. Deformação para ligas de alumínio soldadas por MAG e soldadas por FSW - 5083-H112 + 5083-H112 [22].

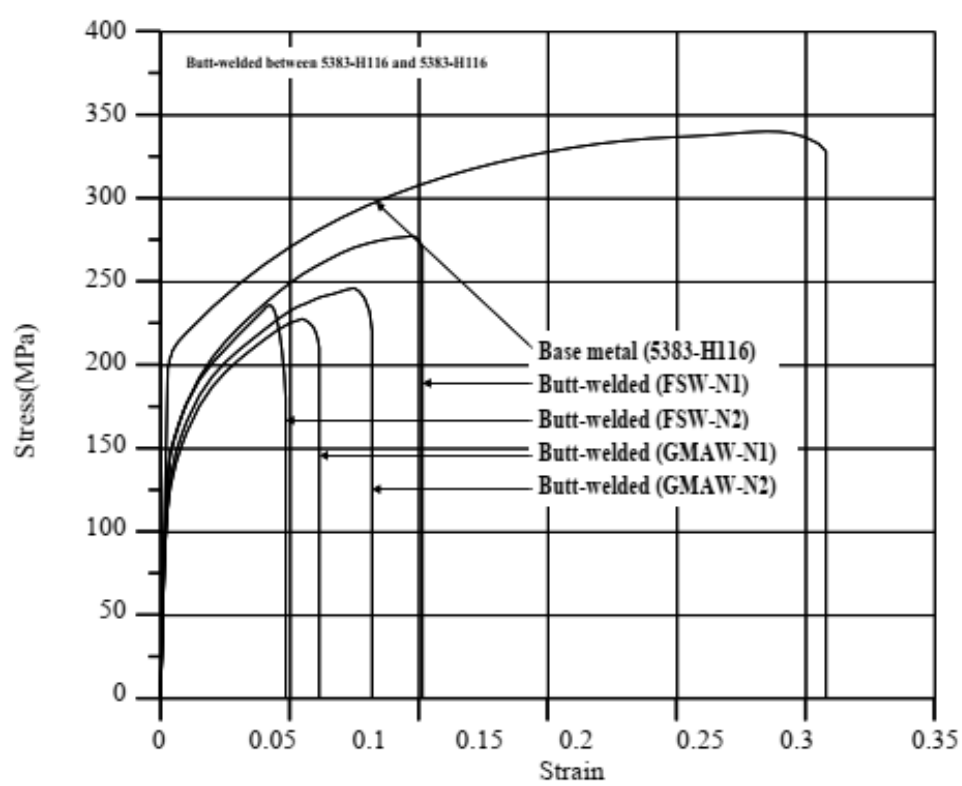

Figura 39 - Curvas Tensão vs. Deformação para ligas de alumínio soldadas por MAG e soldadas por FSW - 5383-H116 + 5383-H116 [22]. 


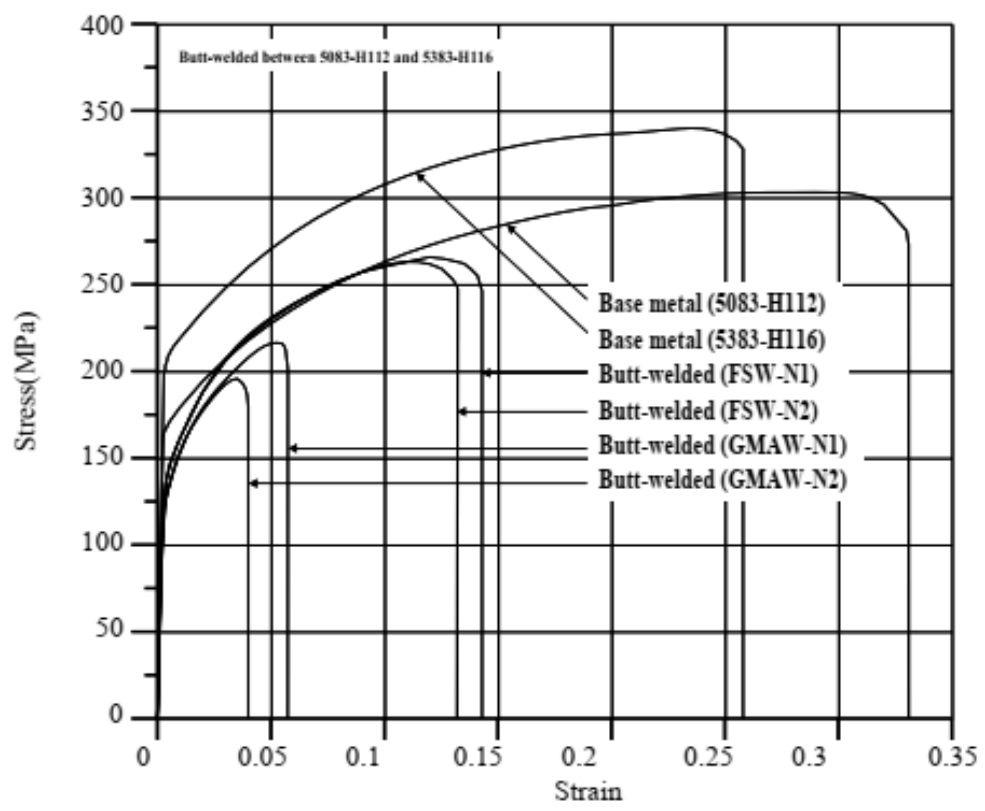

Figura 40 - Curvas Tensão vs. Deformação para ligas de alumínio soldadas por FSW $5083-\mathrm{H} 112+5383-\mathrm{H} 116$ [22]

O processo de FSW possuiu como principal vantagem/atrativo permitir a união de materiais em estado sólido em baixa temperatura, abaixo do ponto de fusão do material [22].

Os autores citaram, entretanto, as suas limitações, que são [36][37]:

- As propriedades mecânicas da região soldada são afetadas pelos parâmetros de soldagem tais como: largura e profundidade do cordão de solda, velocidade de rotação e avanço e resfriamento da região soldada.

- O pino da ferramenta de FSW é consumível e suas dimensões afetam as propriedades da junta soldada.

- A posição da soldagem é limitada devido à orientação da máquina FSW.

- A velocidade do FSW é geralmente mais lenta que a da soldagem por fusão. Assim limita a produção em série.

$\mathrm{O}$ artigo A model relating tool torque and its associated power and specific energy to rotation and forward speeds during friction stir welding/processing [25] estuda um modelo para o Torque $(\mathrm{M})$ em função da velocidade de rotação e da velocidade de soldagem: $M=f(w, v)$. Além disso, estudou modelos para a 
Potência da Ferramenta $\left(\mathbf{P}_{\text {Tool }}\right)$ e Energia Específica $\left(E_{S}\right)$, sendo ambos derivados do modelo do torque (M) [25].

Assim, o torque está diretamente associado à temperatura da zona de mistura (stir zone) e é um fator importante para compreender os efeitos metalúrgicos subsequentes ao processo de FSW [25].

A taxa de geração de calor $\left(\boldsymbol{Q}_{\boldsymbol{F}}\right)$ durante o FSW é igual a potência mecânica desenvolvida pelo movimento da ferramental $\left(\boldsymbol{P}_{\text {Tool }}\right)$ e é definida pela eq. (17) [25]:

Eq. (17)

$$
Q_{F S}=P_{\text {Tool }}=M \omega+F_{x} v
$$

Vale observar que a força de soldagem é, na maioria dos casos, menor que $1 \%$ do valor do torque. Assim pode-se aproximar a eq. (18) para somente [25]:

Eq. (18)

$$
Q_{F S}=P_{\text {Tool }} \cong M \omega
$$

Obtendo-se valores de Calor Gerado $\left(Q_{F S}\right)$ pode-se mensurar a energia específica $\left(E_{S}\right)$ pela eq. (19) [25]:

Eq. (19)

$$
E_{S}=\frac{Q_{F S}}{v} \cong M \frac{\omega}{v}
$$

Os experimentos foram realizados com velocidade de soldagem entre 43 a $250 \mathrm{~mm} / \mathrm{min}$ e rotações de 63 a 1400RPM. As Figuras 41 e 42 [25] mostram perfil de comportamento do Torque (M), Força Axial (Fz) e Força de Soldagem (Fh) em função do tempo de experimento.

Uma curva exponencial decrescente é a que melhor descreveu os pontos experimentais do torque $(\mathrm{M})$ em função da rotação $(\omega)$. A Figura 43 [25] mostra os resultados e as curvas aproximadas para o torque. 


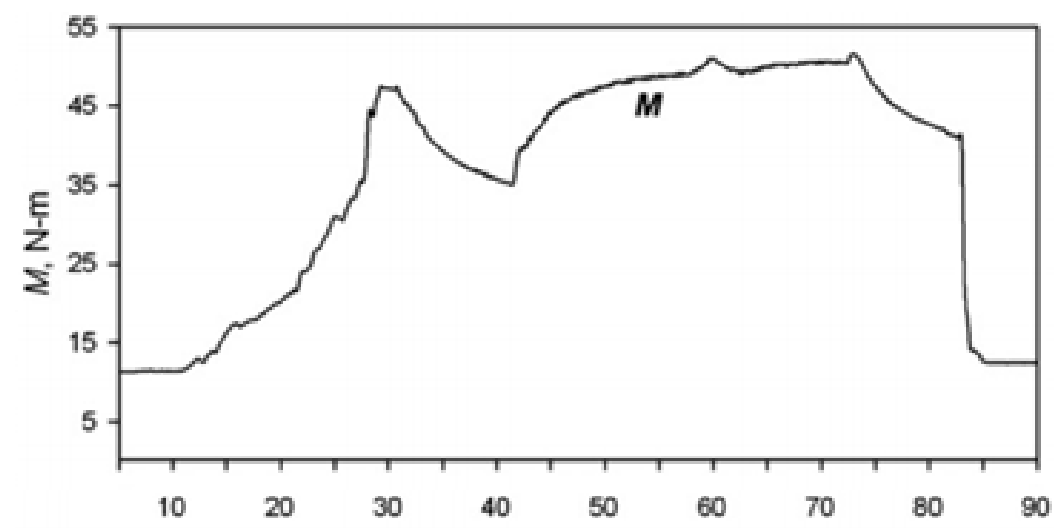

Time. $\mathrm{S}$

Figura 41 - Perfil de comportamento do Torque [25].

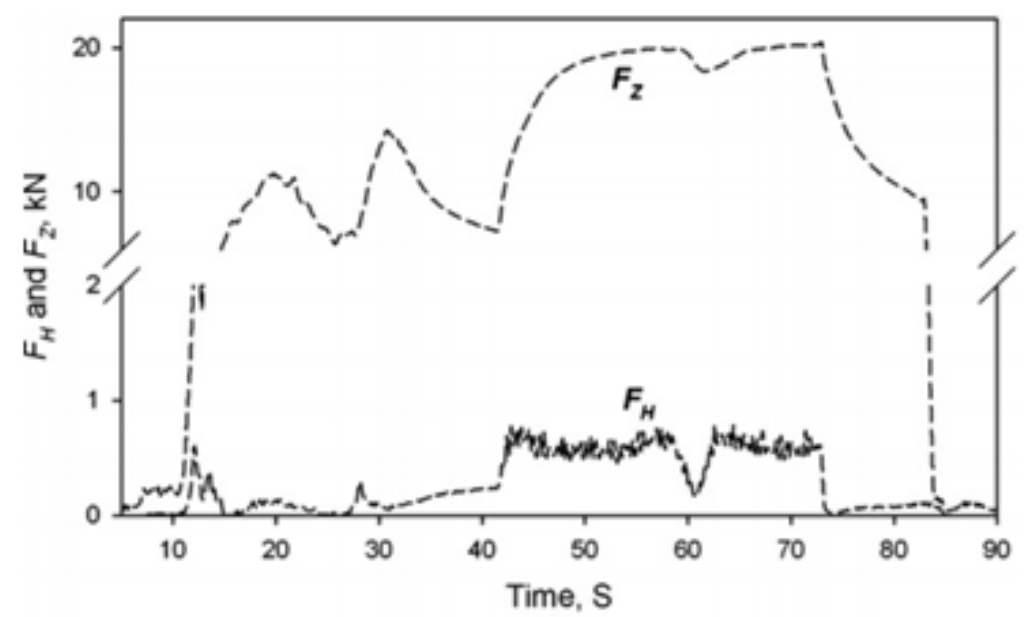

Figura 42 - Perfil de comportamento da Força Axial (Fz) e Força de soldagem (Fh) durante o experimento [25].

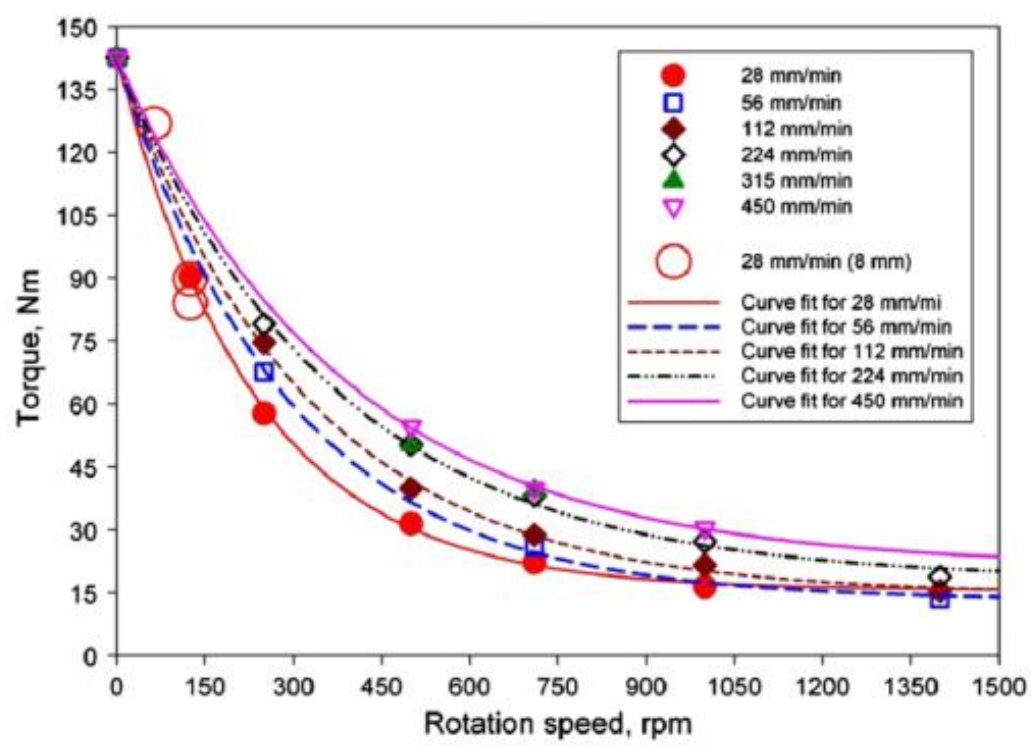

Figura 43 - Torque (M) em função da rotação ( $\boldsymbol{\omega})$ e as curvas ajustadas [25].

A exponencial negativa é matematicamente definida pela eq. (20) [25]. 


$$
M=M_{0}+M_{f} e^{-n \omega}
$$

Onde:

- $M_{0}$ : valor mínimo de torque.

- $M_{f}$ : Fator pré-exponencial.

- $n$ : Fator de decaimento.

O próximo passo do modelo que foi avaliar a correlação de dados de torque (M) com a velocidade de soldagem e a dependência entre eles. A Figura 44 [25] mostra que ao se gerar gráficos de $M_{0}, M_{f}$ e $n$ em função de $v$, obtém-se equações de primeiro grau, ou seja, retas.

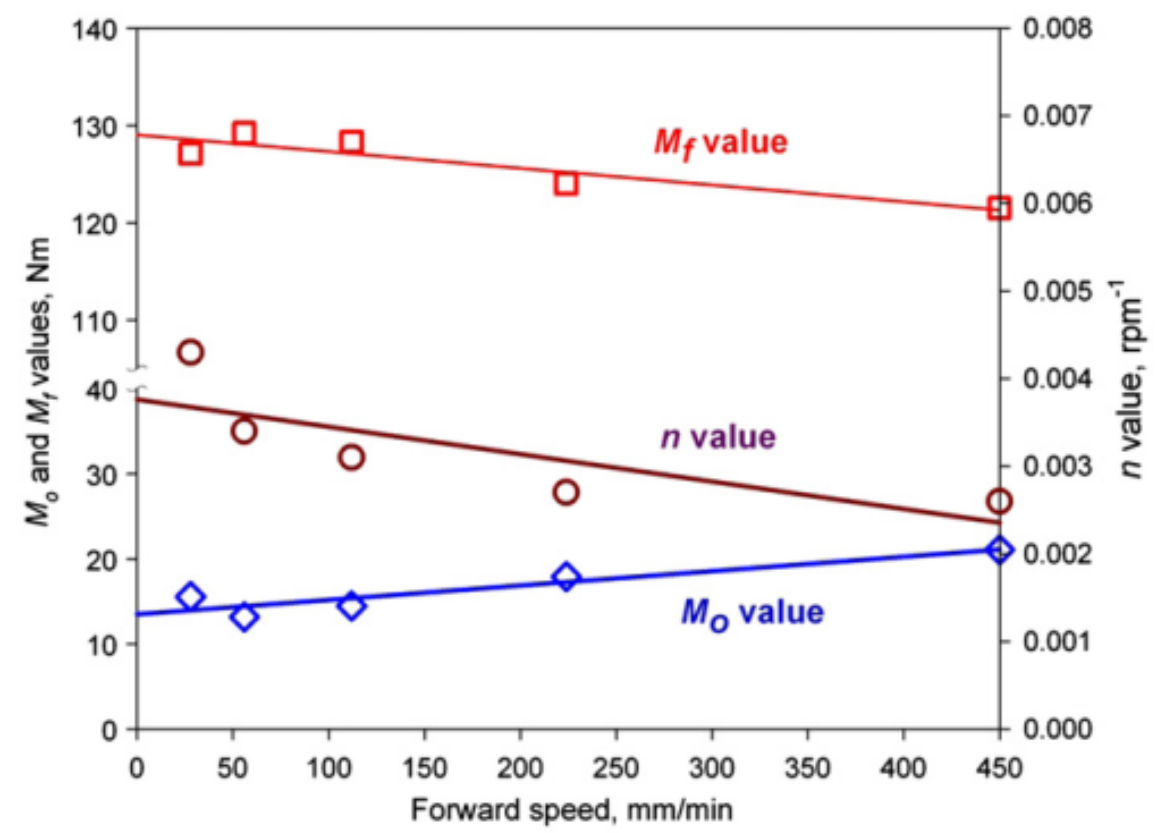

Figura $44-\boldsymbol{M}_{\mathbf{0}}, \boldsymbol{M}_{\boldsymbol{f}}$ e $\boldsymbol{n}$ em função da velocidade de soldagem (v) [25].

Assim, escrevendo as eq. (21), eq. (22), eq. (23) das retas para $M_{0}, M_{f}$ e $n$ respectivamente e substituindo na eq. (19) [25] tem-se a eq. (24):

$$
M_{0}=A+B v=13,5+0,017 v
$$

Eq. (22)

$$
M_{f}=C+D v=129,0-0,017 v
$$


Eq. (23)

$$
n=a+b v=0,00377-3,13 \times 10^{-6} v
$$

$$
M=(A+B v)+(C+D v) e^{-(a+b v) \omega}
$$

Para se encontrar a relação da sensibilidade entre o Torque e a variação da velocidade de soldagem, usou-se a eq. (25) [25]:

Eq. (25)

$$
\frac{d M}{d v}=B\left[D-b \omega(C+D v) e^{-(a+b v) \omega}\right]
$$

Pode-se avaliar também o quão: sensível o torque $(\mathrm{M})$ é em relação à variação da rotação pela eq. (26) [25].

Eq. (26)

$$
\frac{d M}{d \omega}=-(a+b v)(C D V) e^{-(a+b v) \omega}
$$

Para rotações muito baixas há um aumento no torque com acréscimo na velocidade de rotação. Para rotações muito altas estes valores sofrem pouca variação.

A Figura 45 [25] mostra os valores de $\frac{d M}{d \omega}$ em função da rotação. As curvas ajustadas estão em função da velocidade de soldagem.

Substituindo a equação 23 em 17, tem-se a eq. (27) [25]:

Eq. (27)

$$
P_{\text {Tool }}=A \omega+B v \omega+(C \omega+D v \omega) e^{-(a-b v) \omega}
$$

Cuja derivada em relação à rotação resulta na eq. (28) [25]: 
Eq. (28)

$$
\frac{d P_{T o o l}}{d \omega}=M_{0}+M_{f} e^{-n \omega}(1-n \omega)
$$

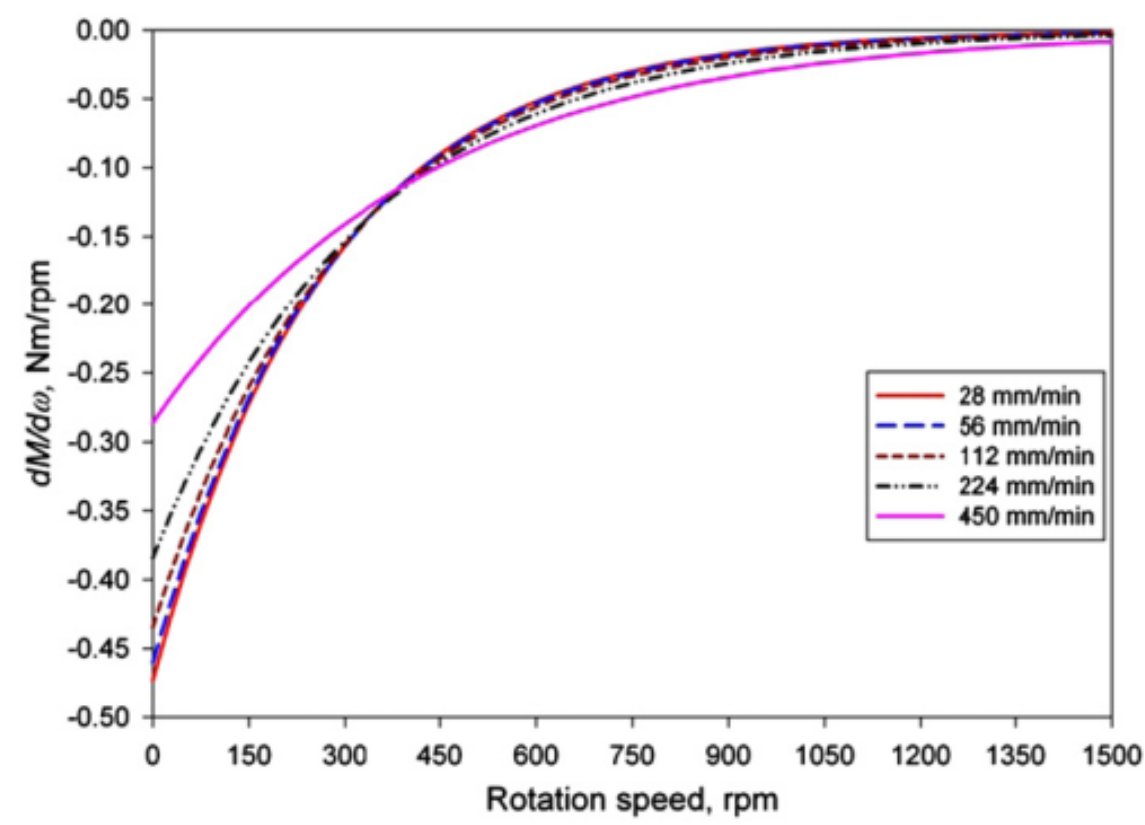

Figura $45-\frac{\mathrm{dM}}{\mathrm{d} \omega}$ em função da rotação $(\boldsymbol{\omega})$ [25].

Substituindo a equação 23 em 17, tem-se a eq. (29) [25]:

Eq. (29)

$$
P_{\text {Tool }}=A \omega+B v \omega+(C \omega+D v \omega) e^{-(a-b v) \omega}
$$

Cuja derivada em relação à rotação resulta na eq. (30) [25]:

Eq. (30)

$$
\frac{d P_{T o o l}}{d \omega}=M_{0}+M_{f} e^{-n \omega}(1-n \omega)
$$

A potência desenvolvida pela ferramenta $\left(P_{\text {Tool }}\right)$ em relação à velocidade de soldagem calculada com a eq. (27) está representada na Figura 46 [25]. 


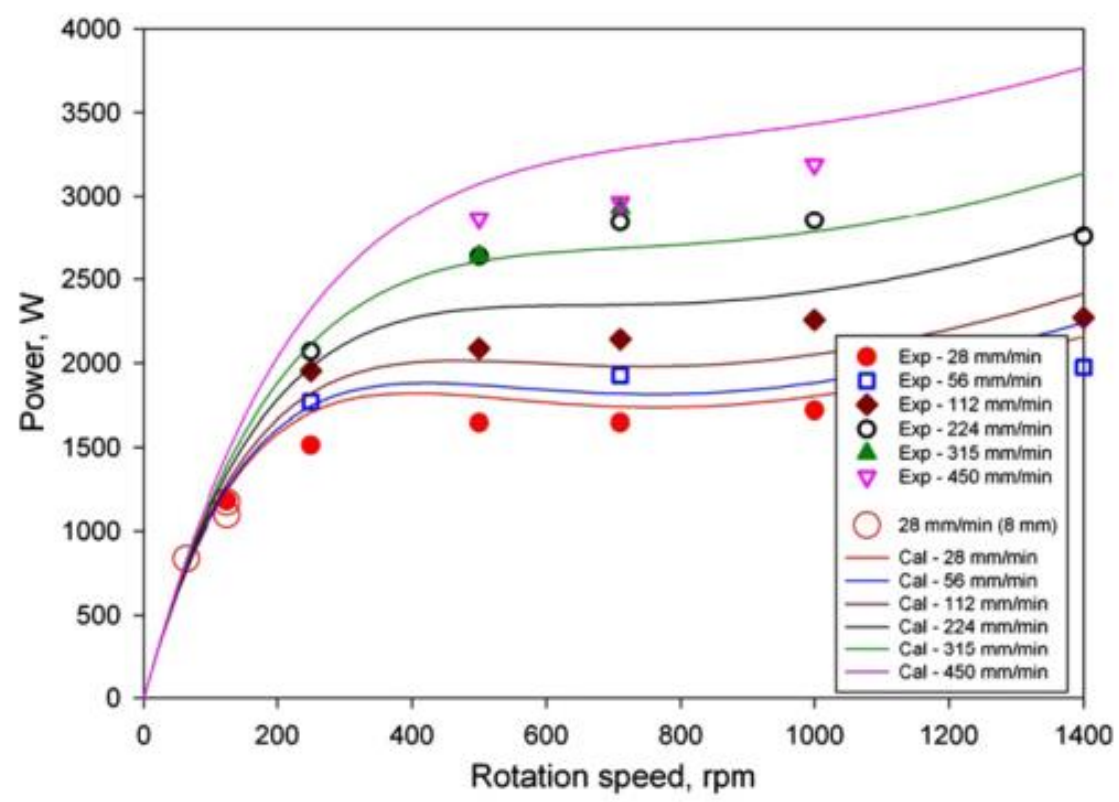

Figura 46 - Potencia (W) vs Rotação (RPM) calculadas com a equação 27 [25].

Substituindo a eq. (23) em eq. (18), tem-se [25]:

$$
E_{s}=\left[M_{0}+M_{f} e^{-n \omega}\right] \frac{\omega}{v}=\left[A+B v+(C+D v) e^{-(a b+v) \omega}\right] \frac{\omega}{v}
$$

$$
\frac{d E}{d \omega}=-(a b \omega+\omega)+\left[A+B v+(C+D v) e^{-(a b+v) \omega}\right] \frac{1}{v}
$$

A curva que representa o comportamento da energia específica $\left(E_{S}\right)$ descrita pela eq. (31) [25] está representada pela Figura 47.

Assim, baseado nos experimentos realizados pode-se concluir que houve uma ótima correlação dos dados adquiridos com as curvas de ajuste.

Concluiu-se que o modelo descreve o torque $(\mathrm{M})$ em função da rotação $(\omega)$ e a velocidade de soldagem $(v)$ com a forma de uma exponencial negativa. 


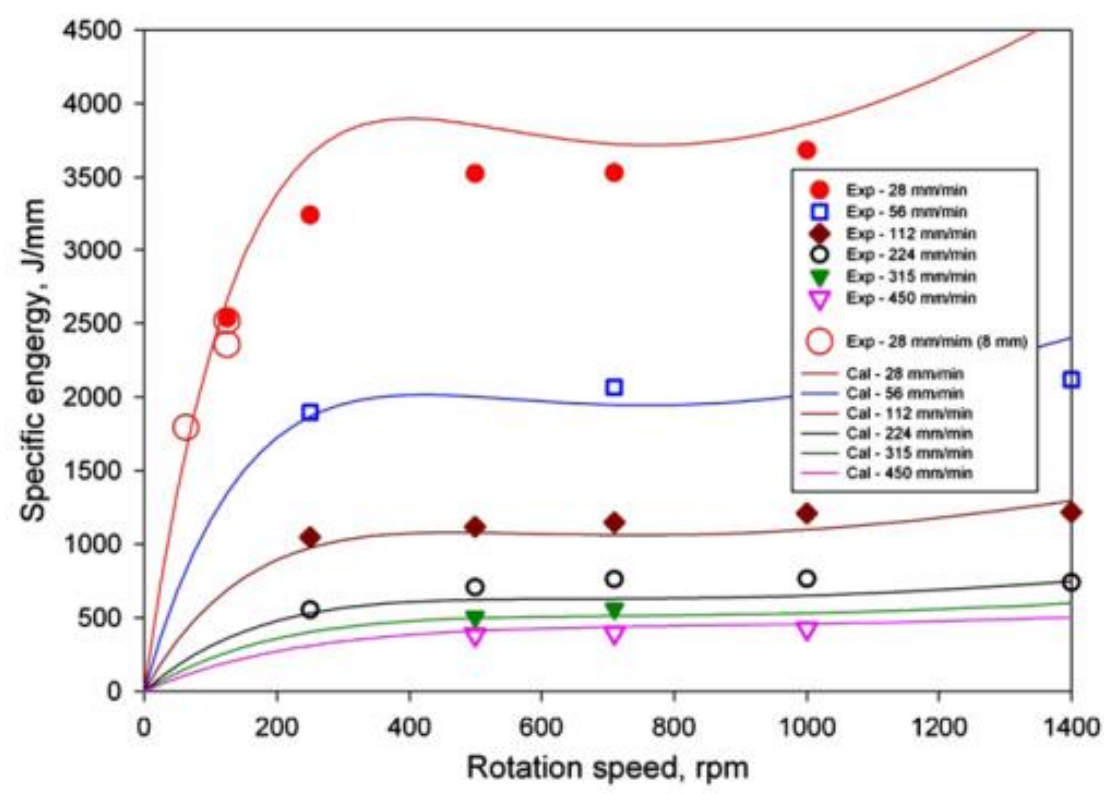

Figura 47 - Energia Específica (J/mm) vs. Rotação (RPM) [25].

Foi confirmado neste experimento que o torque é mais susceptível à variação pela velocidade de rotação do que pela velocidade de avanço. Isto foi explicado pela resistência oferecida pelo material durante a soldagem, ou seja, a deformação e a mistura do material durante a soldagem.

Os modelos derivados do torque para a Potência $\left(P_{\text {Tool }}\right)$ e para a Energia Específica $\left(E_{S}\right)$ demostraram que a potência aumenta pouco com o aumento da velocidade de rotação e a energia específica não é afetada significativamente pela mesma [25].

No artigo A study on internal defects in Friction Stir Welding of Aluminium Alloys [38] foram estudados os defeitos relacionados à soldagem FSW em ligas de alumínio por ensaios destrutivos e não destrutivos. A soldagem foi realizada em duas ligas distintas, Al 5052 e Al 2024, com ferramenta de pino com perfil cônico

Os objetivos principais do estudo foram:

a) Avaliar a influência dos parâmetros de soldagem na qualidade da solda;

b) Avaliar a influência do "caminho" de soldagem, ou seja, o percurso da ferramenta;

c) Determinar a influência do pino da ferramenta na qualidade da solda;

A geometria de ferramenta para soldagem da liga Al 5052 foi de $12,5 \mathrm{~mm}$ de ombro, pino de 4,5mm de comprimento, rosca cônica de $30^{\circ}$ e passo $0,9 \mathrm{~mm}$. Foram realizadas soldagens com dois parâmetros, sendo eles: 1000RPM e 75 
$\mathrm{mm} / \mathrm{min}$ (OP1) e 1500RPM e $150 \mathrm{~mm} / \mathrm{min}$ (OP2). O caminho da solda está apresentado na Figura 48 [38] onde foram utilizados dois caminhos diferentes. Um percurso foi chamado de linear (Simple linear), onde a solda é realizada apenas em um passe e o outro percurso foi denominado de linear reverso (Linear Reverse) onde a solda é realizada em dois passes, de ida e volta sobre o mesmo caminho.

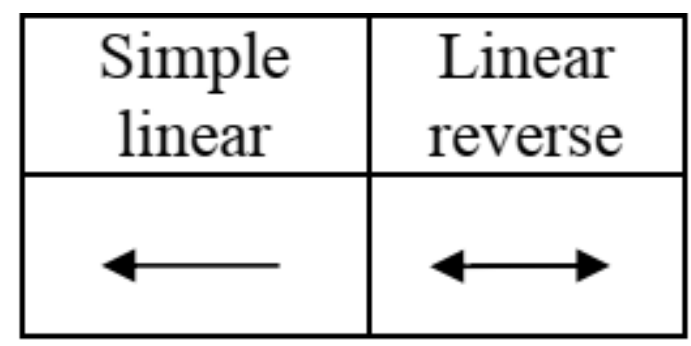

Figura 48 - Caminhos realizados pela solda nos dois experimentos realizados [38].

Os parâmetros utilizados foram 450RPM e $180 \mathrm{~mm} / \mathrm{min}$. Foram utilizadas três ferramentas distintas para a soldagem, como mostrado na Figura 49.

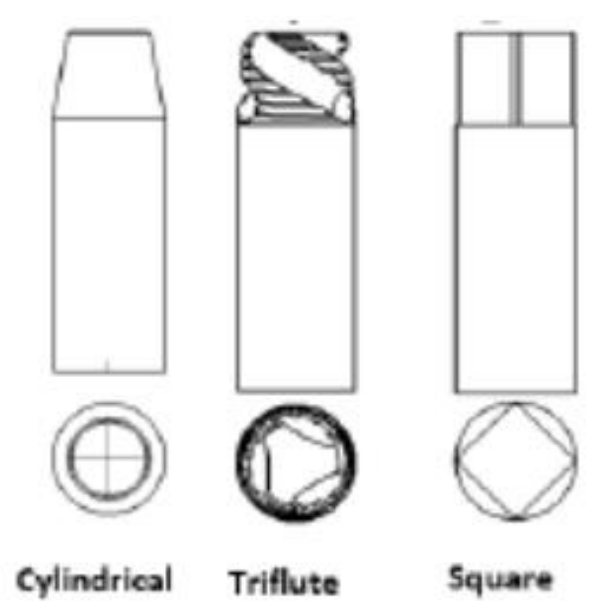

Figura 49 - Perfil das ferramentas utilizadas [38].

Todas as três ferramentas possuiam $4,6 \mathrm{~mm}$ de comprimento de pino. A ferramenta nomeada de Tapered cylindrical possuía $7 \mathrm{~mm}$ de diâmetro maior (próximo ao ombro) e 2,69 mm de diâmetro menor. A ferramenta square possuia $7 \mathrm{~mm}$ de diagonal.

Para os experimentos na liga $\mathrm{Al} 5052$ com os parâmetros OP1, o defeito de túnel foi reduzido quando comparado com parâmetros OP2, tanto para a forma 
simple linear quanto para linear reverse. Este fato ocorreu por que o calor gerado em baixas rotações foi maior que o calor gerado em altas rotações. Isso levaria a uma melhor mistura do material para velocidades de rotação baixa A Figura 50 [38] mostra um defeito interno que corre ao longo do comprimento da solda para cada caminho de solda. A legenda R significa o caminho de retorno da ferramenta e A o caminho de avanço indicado pelas setas.

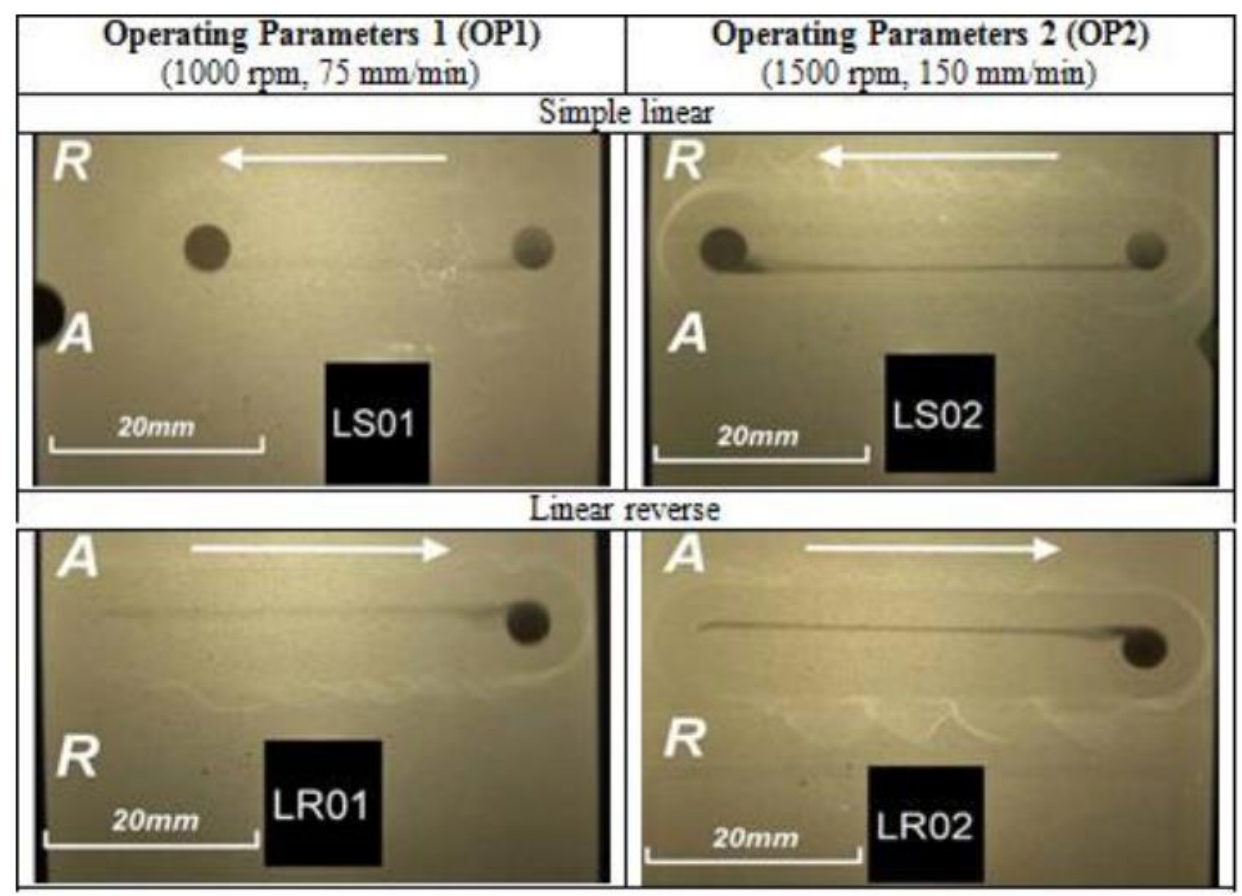

Figura 50 - Imagens de raios- $X$ das soldas produzidas, mostram a formação do tunel (wormhole) [38].

Para a soldagem da liga Al 2024 as amostras soldadas pelas ferramentas com geometria square e triflute não apresentaram defeitos. Porém, as soldas realizadas com tapered cylindrical apresentam um defeito localizado na máxima profundidade do pino. A Figura 51 [38] traz imagens da seeção reta dos corpos de prova para cada ferramenta utilizada. É possível observar claramente que há um defeito de túnel (wormhole).

O defeito de túnel é característico por atravessar toda a amostra. Esse defeito também foi observado na pesquisa conduzida na liga Al 5052, como mostrado na Figura 51 [38]. Defeitos de túnel são atribuídos à mistura inadequada de material durante a soldagem.

Assim, ao final concluiu-se que: 
1) Os defeitos do túnel foram encontrados nas soldas realizadas por um pino tapered cylindrical para as duas ligas.

2) Independentemente do caminho, a solda apresenta um defeito de túnel para o pino tapered cylindrical.

3) Variando os parâmetros operacionais, o tamanho do defeito foi reduzido, mas não eliminado.

4) Soldas livres de defeitos foram produzidas alterando o perfil do pino.

\begin{tabular}{|c|c|c|}
\hline Pin Profile & \multicolumn{2}{|c|}{ Macrostructure } \\
\hline Tapered Cylinder & & $\begin{array}{l}\text { Turnel } \\
\text { Defect }\end{array}$ \\
\hline Triflute & & \\
\hline & & \\
\hline & & \\
\hline
\end{tabular}

Figura 51 - Macrografia da secção reta das amostras para cada ferramenta utilizada [38].

No artigo "Local mechanical properties of the 6061-T6 aluminium weld using micro-traction and instrumented indentation" [39] foram analisadas as propriedades mecânicas da zona de soldagem, sendo esta dividia em metal de base, metal de solda e zona termicamente afetada. $\mathrm{O}$ teste de dureza foi realizado pela técnica de micro indentação instrumentada com a metodologia de OliverPharr, sendo feito um mapa de dureza para poder monitorar a variação de dureza com máxima precisão e determinar algumas propriedades mecânicas como, por exemplo, o Limite de Escoamento e o módulo de Young [39].

Foram utilizadas chapas com as seguintes dimensões: $150 \mathrm{~mm}$ de comprimento, $70 \mathrm{~mm}$ de largura e $9,5 \mathrm{~mm}$ de espessura. $\mathrm{O}$ material possuia como propriedades mecânicas: tensão de ruptura de $310 \mathrm{MPa}$ e limite de escoamento de 270MPa. A composição química do material utilizado está descrita na Tabela 5 [39]: 
Tabela 5 - Composição química do alumínio 6061-T6.

\begin{tabular}{|c|c|c|c|c|c|c|c|c|}
\hline & Al & $\mathbf{M g}$ & $\mathbf{S i}$ & $\mathbf{C u}$ & $\mathbf{F e}$ & $\mathbf{M n}$ & $\mathbf{Z n}$ & $\mathbf{T i}$ \\
\hline \% em peso & 97,630 & 0,986 & 0,561 & 0,310 & 0,289 & 0,052 & 0,024 & 0,018 \\
\hline
\end{tabular}

A técnica de soldagem foi MIEA (Modified Indirect Eletric Arc) e utilizou eletrodo ER4043 em fio com 5,6\% Si e 1,2mm de diâmetro, velocidade de alimentação de $180 \mathrm{~mm} / \mathrm{s}$, fluxo de argônio de 26,6L/min. A velocidade de soldagem foi de $3,6 \mathrm{~mm} / \mathrm{s}$ em modo de spray com um aporte térmico de $1533 \mathrm{~J} / \mathrm{mm}$ [39].

Para os testes de micro indentação intrumentada foi utilizada o equipamento CSM 2-17 com Indentador Vickers. A carga máxima utilizada foi entre 0,1 e $10 \mathrm{~N}$.

Assim, concluiu que houve uma significativa mudança de valores de dureza entre o metal de base, o metal de solda e a zona termicamente afetada. Foi importante observar também um ponto chamado de soft zone onde a dureza cai bruscamente separando a zona termicamente afetada do metal de base [39]. A Figura 52 [39] mostra o resultado obtido no artigo.

Para o teste de módulo de elasticidade e limite de escoamento foram utilizados corpos de prova retirados das zonas de metal de base, termicamente afetada e zona soldada. A Figura 53 ilustra as regiões de onde os corpos de prova foram retirados. A Figura 54 mostra o esboço de fabricação do corpo de prova [39]. 




Figura 52 - Variação de dureza das zonas de soldagem estudadas [39].

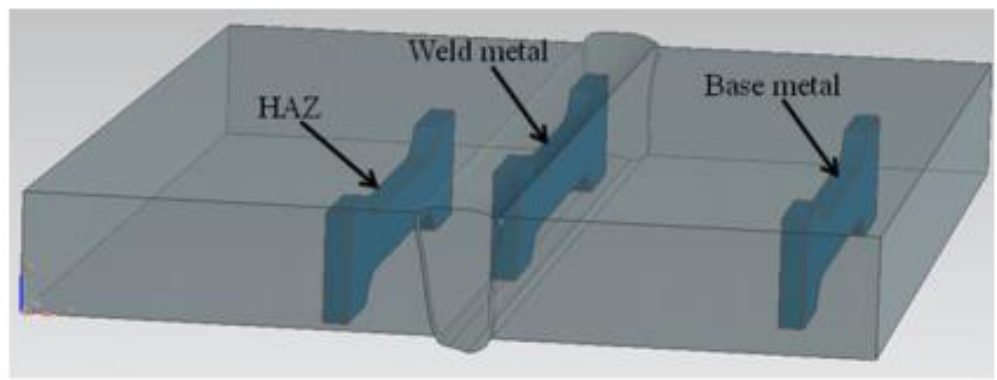

Figura 53 - Regiões as quais os corpos de prova foram retirados [39].

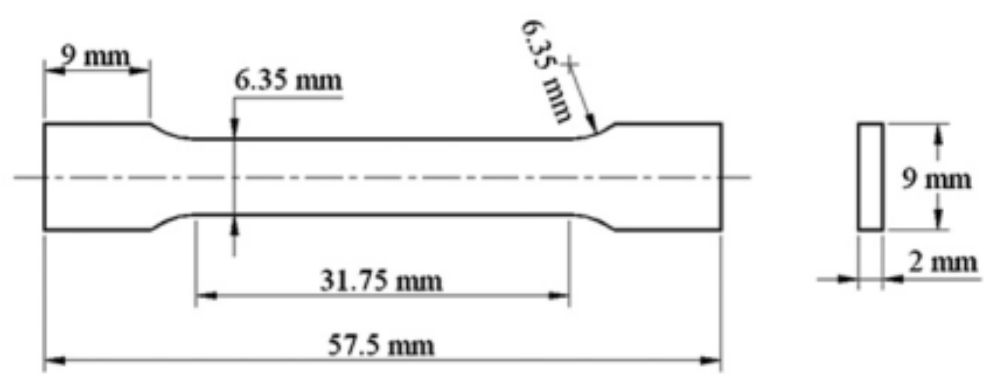

Figura 54 - Esboço do corpo de prova para teste de micro-tração [39].

A Tabela 6 traz as propriedades mecânicas encontradas nos ensaios de microdureza $\left(E_{I T T}:\right.$ Módulo de Elasticidade em microdureza, $\sigma_{y I T T}$ : limite de escoamento em microdureza) e nos testes de micro-tração ( $E_{M T}$ : Módulo de Elasticidade em microdureza, $\sigma_{y M T}$ : limite de escoamento em microdureza). 
Tabela 6 - Tabela comparativa de resultado entre a Microdureza e de Micro-Tração.

\begin{tabular}{|c|c|c|c|c|}
\hline \multirow{2}{*}{} & \multicolumn{2}{|c|}{ Testes de Microdureza } & \multicolumn{2}{c|}{ Testes de Micro-tração } \\
\cline { 2 - 5 } & $E_{I T T}(\mathrm{GPa})$ & $\sigma_{\text {IITT }}(\mathrm{MPa})$ & $E_{M T}(\mathrm{GPa})$ & $\sigma_{\text {yMT }}(\mathrm{MPa})$ \\
\hline Metal de Base & 98,6 & 266 & 68,3 & 263 \\
\hline Material Soldado & 78,0 & 133 & 62,2 & 135 \\
\hline ZTA & 87,4 & 106 & 68,2 & 121 \\
\hline
\end{tabular}

Os resultados dos testes mostram que para o limite de escoamento nos dois testes apresentaram valores muito próximos, exceto para a zona termicamente afetada que apresentou valores com variação de $12 \%$ [39].

Assim, para o metal de base e o metal soldado ambos os testes poderiam ser utilizados para se obter os valores de tensão de escoamento; ao contrário da zona termicamente afetada para a qual, por ser uma região não homogenea, o teste de microdureza não seria o mais indicado pois este tem como característica fazer medidas locais. Já o teste de micro-tração obtém medidas de maneira global ao corpo de prova [39].

A comparação direta entre os testes de microdureza (bulk modulus) e micro-tração (Young modulus) não seria possível também pelo fato de que a microdureza traz o resultado de módulo de Young por compressão uniforme e o material está no regime elasto-plástico, enquanto o teste de micro-tração gera uma deformação uniforme de maneira uniaxial [39].

$\mathrm{O}$ artigo Mechanical Properties of Aluminum Alloys by Instrumented Indentation: Case Study on Almigo Hard [40], estudou as propriedades mecânicas e elastoplásticas do alumínio Almigo Hard, com tratamento térmico T651, por testes indentação instrumentada. A Tabela 7 traz a composição química do material utilizado em estudo.

Foram realizados testes de indentação instrumentada em dois materiais de referência: a liga de Alumínio D16CT1(AlCu4Mg1) e o aço 15Ch2MFa. Utilizouse o nanoindentador NHT CSM Instruments, realizando indentações com carga simples máxima e cargas cíclicas. Para os testes com carga simples máxima foram realizadas seis indentações para cada carga de 1, 2, 5, 10, 50, 100, 200 e 500 mN [40]. 
Tabela 7 - Composição química do material de estudo Alumínio Almigo HARD.

\begin{tabular}{|c|c|c|c|c|}
\hline \multicolumn{6}{|c|}{ Composição Química Al Almigo HARD } \\
\hline Elemento & $\mathbf{C u}$ & $\mathbf{M g}$ & $\mathbf{Z n}$ & $\mathbf{Z r}$ \\
\hline \% em peso & 1,9 & 2,2 & 8,4 & 0,1 \\
\hline
\end{tabular}

Para os testes com cargas cíclicas foram realizados 20 ciclos com incremento de carga de $2 \mathrm{mN}$ até o máximo de $500 \mathrm{mN}$, sendo o início do descarregamento do indentador com $20 \%$ da carga máxima que se deseja atingir [40].

Os resultados foram ratificados pela norma ISO 14577. A Figura 55 traz a comparação entre a aplicação de carga simples máxima de $500 \mathrm{mN}$ com a aplicação cíclica de carga de 500 mN [40].
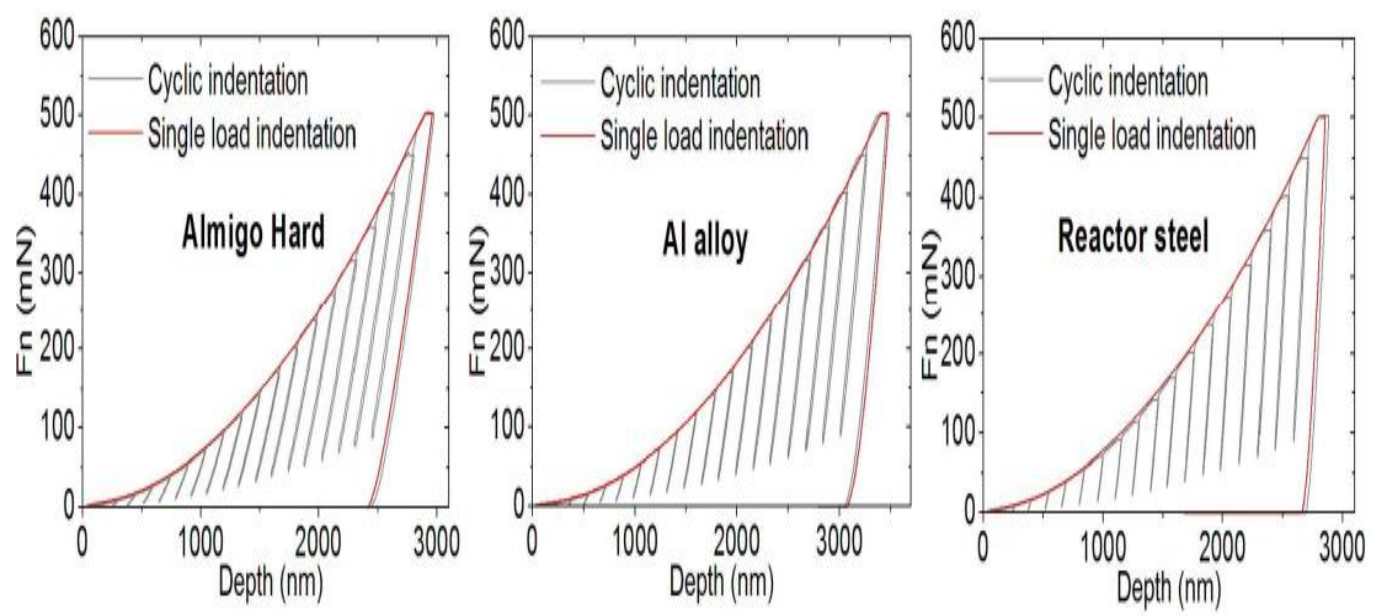

Figura 55 - Curva característica do teste de indentação instrumentada para os materiais analisados [40].

A partir dos resultados obtidos concluiu-se que as durezas obtidas para testes cíclicos e para carga simples máxima não apresentam diferença significativa em 


\section{Materiais e Métodos}

\subsection{Material base}

Foram utilizadas chapas de 5,0 $\mathrm{mm}$ de espessura, de alumínio da série 5000, Al 5052-H34, o qual possui como principal elemento de liga o magnésio. Essa liga é caracterizada por apresentar boa resistência mecânica, boa ductilidade e alta resistência à corrosão em relação a diversas ligas não-ferrosas. As principais aplicações desta liga são na indústria naval e automotiva, principalmente em aplicações estruturais [7]. A composição química e as propriedades mecânicas, dadas pelo fabricante, são apresentadas nas Tabelas 8 e 9 [41].

Tabela 8 - Composição química material de base [41].

\begin{tabular}{|c|c|c|c|c|c|c|c|c|c|}
\hline & \multicolumn{7}{|c|}{ Composição Química Al 5052-H34 } \\
\hline Elemento & $\mathbf{S i}$ & $\mathbf{F e}$ & $\mathbf{C u}$ & $\mathbf{M n}$ & $\mathbf{M g}$ & $\mathbf{C r}$ & $\mathbf{Z n}$ & Outros & $\mathbf{A l}$ \\
\hline \% em peso & 0,25 & 0,40 & 0,10 & 0,10 & $2,2-2,8$ & $0,15-0,35$ & 0,10 & $0,00-0,15$ & restante \\
\hline
\end{tabular}

Tabela 9 - Propriedades mecânicas do material de base [41].

\begin{tabular}{|c|c|c|c|}
\hline \multicolumn{3}{|c|}{ Propriedades mecânicas Al 5052-H34 } \\
\hline $\begin{array}{c}\text { Limite de resistência à } \\
\text { tração (MPa) }\end{array}$ & $\begin{array}{c}\text { Tensão de } \\
\text { escoamento (MPa) }\end{array}$ & $\begin{array}{c}\text { Módulo de } \\
\text { elasticidade (GPa) }\end{array}$ & $\begin{array}{c}\text { Deformação na } \\
\text { fratura (\%) }\end{array}$ \\
\hline $235-285$ & 180 & 70 & de 6 a 12 \\
\hline
\end{tabular}

\subsection{Equipamento}

As soldas foram realizadas em um centro de usinagem CNC Polaris V400 do fabricante ROMI, localizado no Centro de Estudos em Fabricação e Comando Numérico, do Departamento de Engenharia Mecânica da UFRJ, apresentado na Figura 56. As especificações da máquina CNC são apresentadas na Tabela 10. 
Tabela 10 - Especificações técnicas do CNC utilizado nos testes.

\begin{tabular}{|c|c|c|c|c|c|}
\hline \multicolumn{5}{|c|}{ Especificações técnicas do CNC } \\
\hline $\begin{array}{c}\text { Rotação } \\
{[\text { RPM }]}\end{array}$ & $\begin{array}{c}\text { Velocidade de } \\
\text { Avanço }[\mathbf{m m} / \mathbf{m i n}]\end{array}$ & $\begin{array}{c}\text { Torque } \\
{[\mathbf{N m}]}\end{array}$ & $\begin{array}{c}\text { Força } \\
\text { Axial } \\
{[\mathbf{k N}]}\end{array}$ & $\begin{array}{c}\text { Força } \\
\text { Longitudinal } \\
{[\mathbf{k N}]}\end{array}$ & $\begin{array}{c}\text { Força } \\
\text { Transversal } \\
{[\mathbf{k N}]}\end{array}$ \\
\hline $60-6000$ & até 2000 & até 95 & até 9,4 & até 5 & até 5 \\
\hline
\end{tabular}

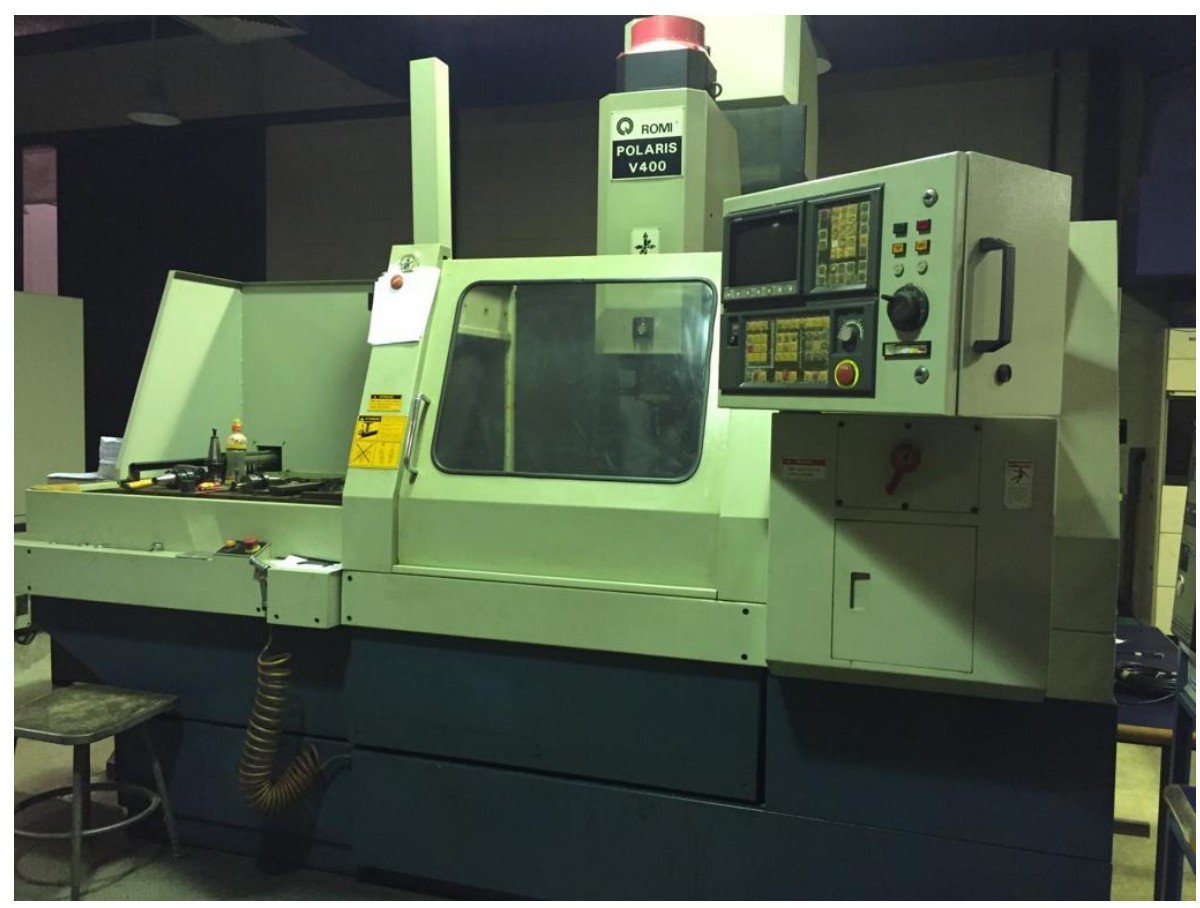

Figura 56 - CNC Vertical V400 ROMI.

Para medir as forças e o torque no processo de $F S W$ foi utilizado um dinamômetro Kistler 9272 com uma capacidade de medição de até $5 \mathrm{kN}$ para as forças longitudinal e transversal, $20 \mathrm{kN}$ para a força axial e $200 \mathrm{Nm}$ para o torque. Para a aquisição dos dados foi utilizado um amplificador de sinal multicanal Kistler 5070. A Figura 57(a) mostra o dinamômetro e Figura 55(b) o amplificador de sinal utilizado [42].

Para a adaptação do centro de usinagem CNC para o processo $F S W$, além do uso do dinamômetro para medir as forças e o torque, foi utilizado um dispositivo de fixação em aço inoxidável, já disponível no laboratório, com dimensões ajustadas ao dinamômetro e às peças a soldar, para garantir a correta disposição durante o processo de soldagem. 

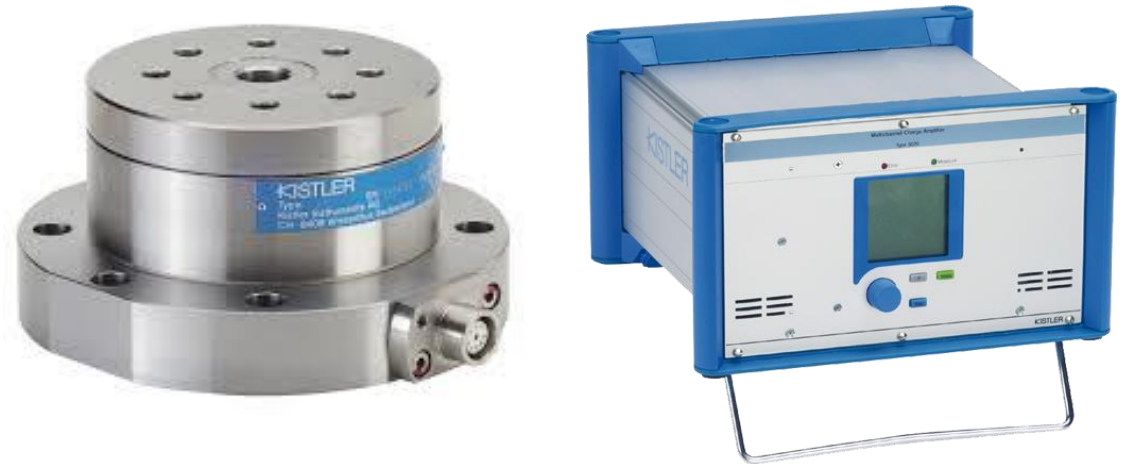

Figura 57 - (a) Dinamômetro Kistler 9272; (b) Amplificador de sinal Kistler 5070.

O dispositivo de fixação é composto por uma placa base, dois elementos de fixação e dois limitadores para impedir a movimentação da peça durante a solda. Os desenhos das peças que compõem o dispositivo de fixação são apresentados no Anexo I. A Figura 58 mostra a montagem do dinamômetro, do dispositivo de fixação e da peça objeto de estudo no centro de usinagem CNC para a realização das soldas pela técnica FSW.

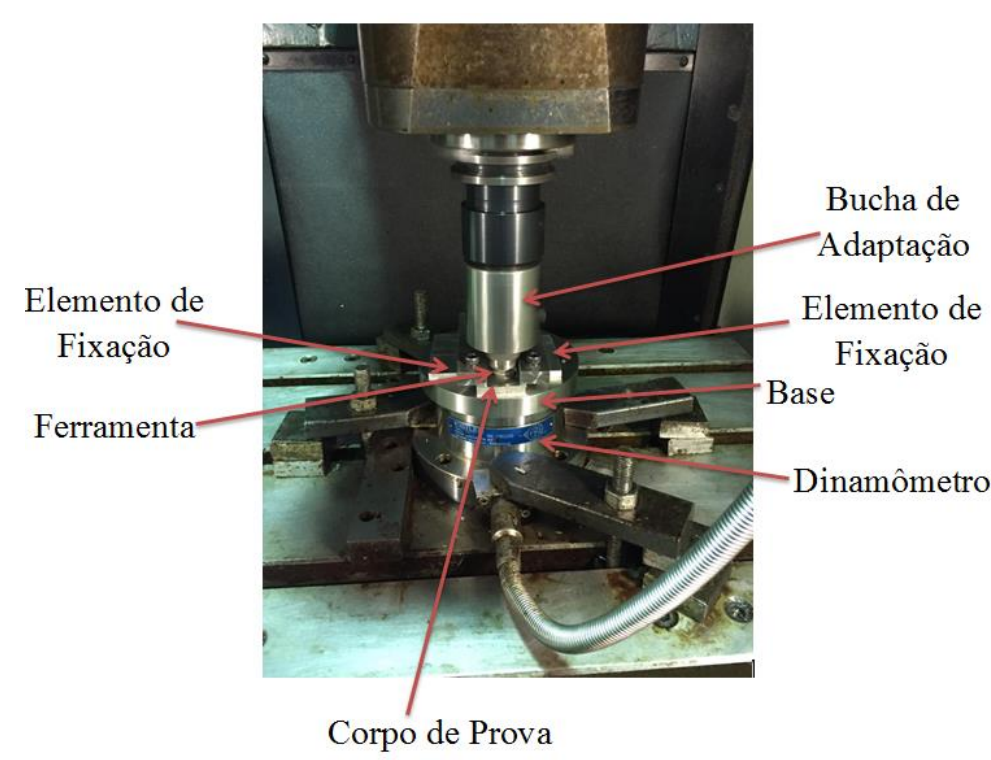

Figura 58 - Método de adaptação do CNC para realização dos ensaios.

A ferramenta utilizada para soldagem é de aço ferramenta H13 com 50HRC de dureza. O pino possui uma rosca cônica de passo métrico de $0,7 \mathrm{~mm}$. Um desenho da ferramenta está no anexo I deste documento. A Figura 59 mostra uma representação em 2D da ferramenta utilizada. 


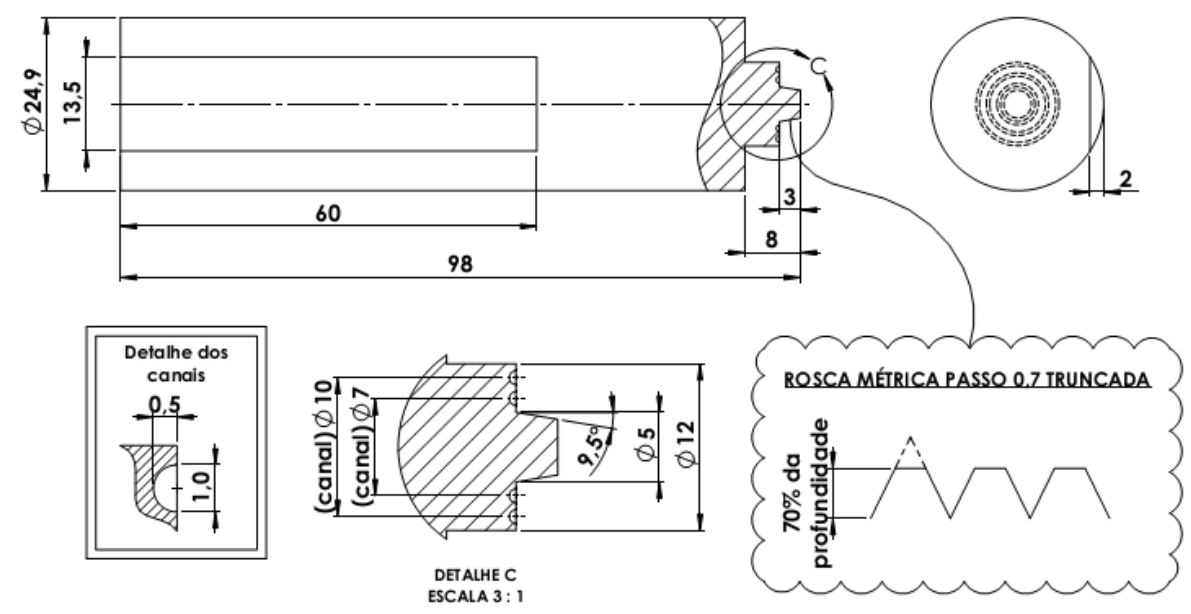

Figura 59 - Representação 2D da ferramenta de soldagem.

Os parâmetros utilizados foram retirados da Tese de Doutorado intitulada Modelo de torque e forças para soldagem de atrito mistura [7]. Os parâmetros utilizados foram:

- Velocidade de penetração da ferramenta: $8 \mathrm{~mm} / \mathrm{min}$.

- Velocidade de rotação ( $\omega):$ 600, 900, 1200, 1500 RPM.

- Velocidade de soldagem (v): 100, 200 e $300 \mathrm{~mm} / \mathrm{min}$.

\subsection{Indentação Instrumentada}

A metodologia de Oliver e Pharr foi utilizada para a obtenção dos valores de microdureza. Esta metodologia se baseia na curva carga vs. penetração para se obter valores de dureza [43][44][45]. A Figura 60, adptada, traz o corte da secção transversal com a representação esquemática dos parâmetros para análise da dureza e a Figura 61,adptada, mostra uma curva característica do ensaio.

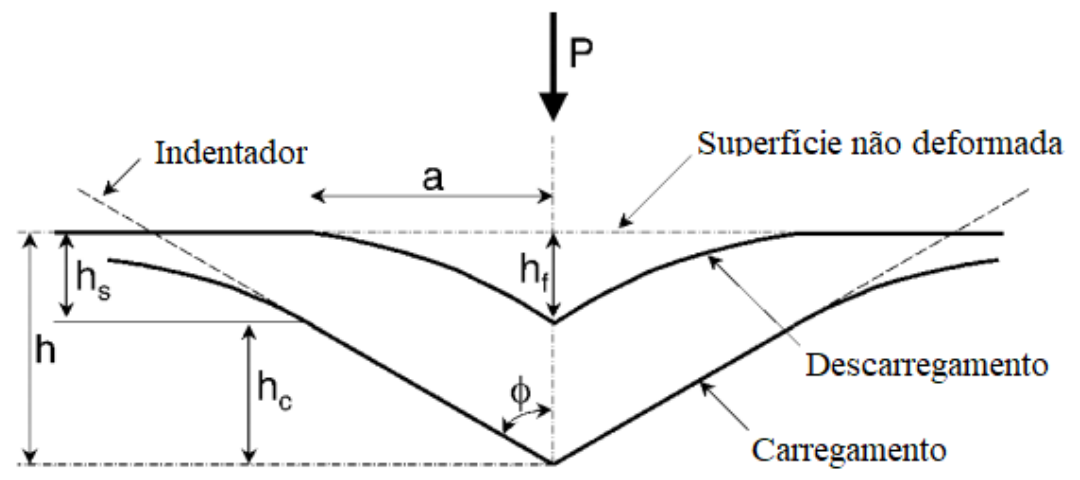

Figura 60 - Representação esquemática dos dois momentos da indentação [43][44]. 
Na Figura 60, $h$ é a penetração máxima alcançada na indentação, $h_{c}$ é a profundidade de contato e $h_{f}$ é a profundidade da marca deixada após o ensaio. Assim, se tem a eq. (33) [43][44][45]:

Eq. (33)

$$
h=h_{s}+h_{c}
$$

Os termos que constam na Figura 61 são:

- $\quad P_{\max }$ : carga máxima aplicada;

- $h_{\max }$ : máxima penetração do indentador com a carga máxima aplicada;

- $h_{f}$ : profundidade final da impressão após a retirada da carga;

- $S=\frac{d P}{d H}:$ Rigidez ao contato.

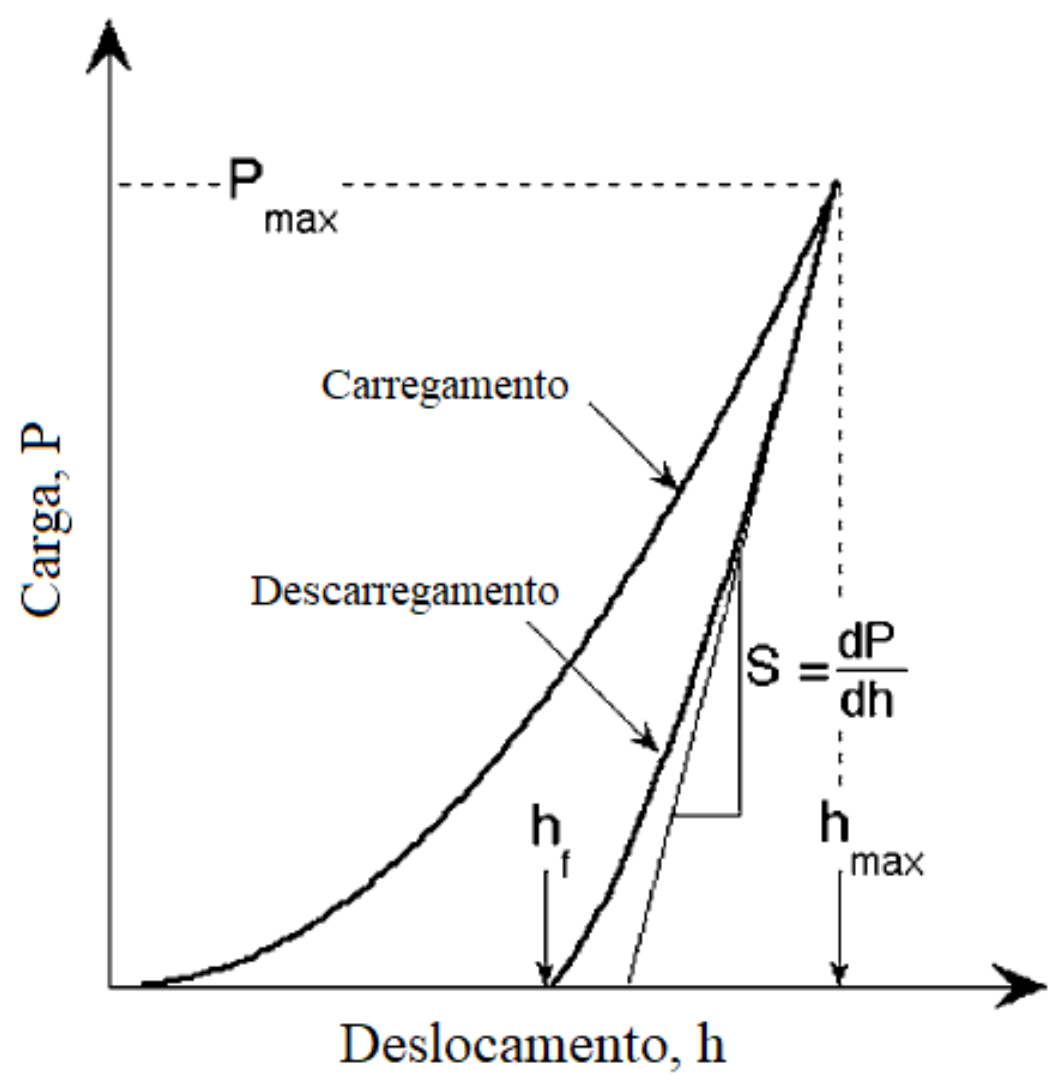

Figura 61 - Curva característica do ensaio de indentação instrumentada [43][44]. 
Os parâmetros mais importantes para a construção da curva $\mathrm{P}$ x h são: a carga máxima $\left(P_{\max }\right)$, o valor da maior penetração $\left(h_{\max }\right)$, a rigidez de contato $(S)$ e a profundidade de deformação permanente após o ensaio $\left(h_{f}\right)$ [43][44][45].

Observa-se que a curva de descarregamento pode ser definida pela eq. (34) [43][44][45]:

Eq. (34)

$$
P=\beta\left(h-h_{f}\right)^{m}
$$

Onde:

- $\quad P$ : carga aplicada;

- $\quad \beta, m$ : parâmetros de ajuste;

- $h$ : profundidade do carregamento

- $h_{f}$ : deformação residual causada pela indentação.

A rigidez ao contato (S) é calculada pela derivada da curva de descarregamento pela eq. (35) [43][44][45]:

$$
S=\frac{d P}{d h}=\beta m\left(h-h_{f}\right)^{m-1}
$$

A medida de dureza pode ser formulada pela eq. (36) [43][44][45]:

Eq. (36)

$$
H=\frac{P_{\max }}{A}
$$

Onde:

- $\quad P_{\max }:$ máxima carga aplicada;

- $A$ : área de contato

A medida de dureza segundo esta metodologia é baseada na área de contato sob carregamento, o que traria um melhor resultado perante a medida convencional de dureza que se baseia na área da impressão deixada pelo indentador após a indentação.

O módulo de Young e a área de contato são parâmetros para determinação da rigidez ao contato que pode ser calculada pela eq. (37) [43][44][45]: 


$$
S=E_{\text {eff }} \frac{2}{\sqrt{\pi}} \sqrt{A}
$$

Onde:

- $A$ : área de contato.

- $E_{\text {eff }}$ : Módulo de Young Efetivo.

O módulo de Young efetivo leva em consideração as deformações elásticas que ocorrem tanto na amostra quanto no indentador. A eq. (38) traz o cálculo do módulo de elasticidade efetivo [43][44][45]:

Eq. (38)

$$
\frac{1}{E_{e f f}}=\frac{\left(1-v^{2}\right)}{E}+\frac{\left(1-v_{i}^{2}\right)}{E_{i}}
$$

Onde:

- E, $v$ : Módulo de Young e Razão de Poisson do material;

- $E_{i}, v_{i}$ : Módulo de Young e Razão de Poisson do indentador.

As medidas de dureza foram realizadas em um equipamento CSM modelo MHT-Z-AE-000, localizado no Laboratório de Processamento e Caracterização de Materiais, LPCM, do Programa de Engenharia de Materiais e Metalurgia da COPPE-UFRJ, mostrado na Figura 62.

Foram realizadas entre dezessete e vinte medidas de dureza sobre a linha de eixo neutro das amostras, conforme mostrado na Figura 63. A Tabela 11 traz os parâmetros utilizados nos testes.

Foram selecionadas para os testes de microdureza instrumentada as amostras apresentadas na Tabela 12. O critério de seleção foi baseado nos esforços de torque no percurso e força axial no percurso onde as amostras que foram soldadas com velocidade de soldagem de $100 \mathrm{~mm} / \mathrm{min}$ possuem os menores valores desses esforços e as soldadas com velocidade de soldagem de 300 $\mathrm{mm} / \mathrm{min}$ possuem os maiores valores desses esforços. 


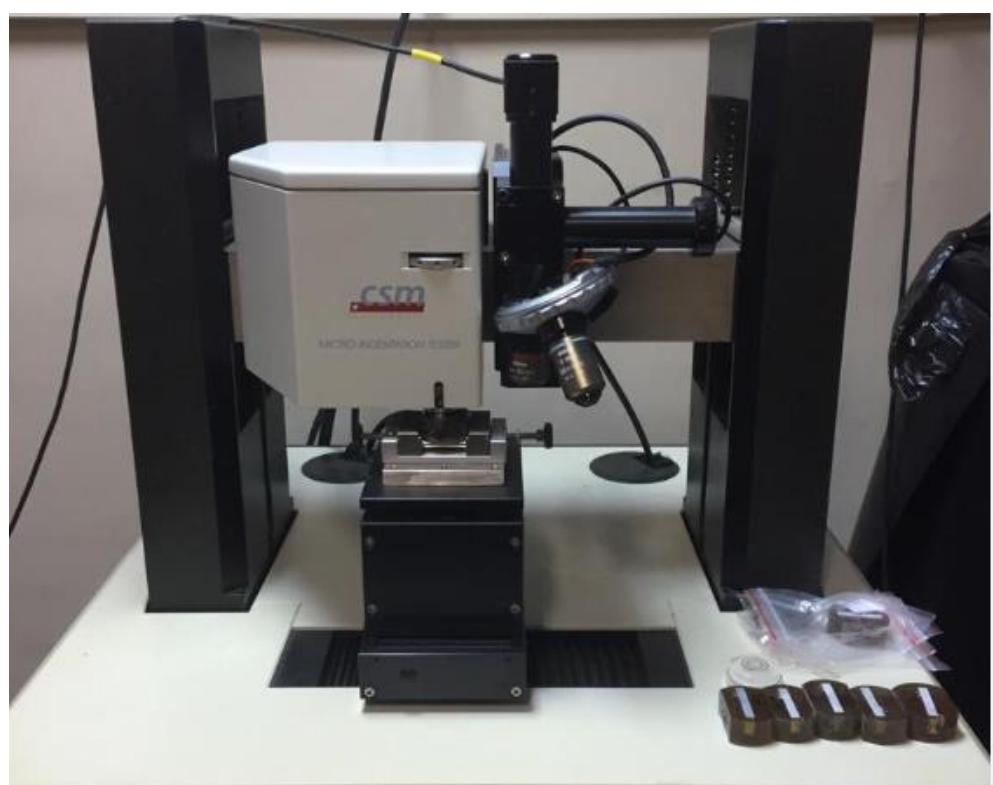

Figura 62 - Indentador utilizado nos testes.



Figura 63 - Esboço da seção reta dos corpos de prova.

Tabela 11 - Parâmetros utilizados nos testes de microdureza.

\begin{tabular}{|c|c|}
\hline Carga máxima aplicada (Pmax) & $300 \mathrm{mN}$ \\
\hline Taxa de aplicação da carga (Load Rate) & $600 \mathrm{mN} / \mathrm{min}$ \\
\hline Taxa de retirada da carga (Unload Rate) & $600 \mathrm{mN} / \mathrm{min}$ \\
\hline Razão de Poisson & 0,347 \\
\hline Tempo total de ensaio & 60 segundos \\
\hline Tempo de espera $($ Hold time $)$ & 5 segundos \\
\hline Espaçamento entre indentações & $400 \mu \mathrm{m}$ \\
\hline
\end{tabular}


Tabela 12 - Amostras selecionadas para os testes de Microdureza Instrumentada.

\begin{tabular}{|c|c|c|}
\hline Corpo de Prova & Rotação $($ RPM) & Velocidade de Soldagem $(\mathbf{m m} / \mathbf{m i n})$ \\
\hline 5 & 600 & 300 \\
\hline 8 & 900 & 300 \\
\hline 18 & 1200 & 300 \\
\hline 21 & 1500 & 300 \\
\hline 24 & 600 & 100 \\
\hline 33 & 900 & 100 \\
\hline 36 & 1200 & 100 \\
\hline 39 & 1500 & 100 \\
\hline
\end{tabular}

\subsection{Análise metalográfica}

As seções transversais das soldas foram analisadas por microscopia óptica.

Inicialmente, foi realizado corte a água das amostras, que a seguir foram embutidas em resina e, então, lixadas até 1200 mesh e polidas com pasta de diamante de $3 \mu \mathrm{m}, 1 \mu \mathrm{m}$ e $1 / 4 \mu \mathrm{m}$. Por fim foi realizado ataque químico utilizandose reagente Keller com as proporções descritas pela Tabela 13 [46]. A Figura 64(a) mostra um corpo de prova cortado e a Figura 64(b) mostra os corpos de prova embutidos para serem submetidos à preparação metalográfica.

Tabela 13 - Composição do Reagente Keller para ataque químico.

\begin{tabular}{|c|}
\hline $\begin{array}{c}\text { 4M Reagente Keller - Tempo de ataque de } 1 \text { a } 3 \\
\text { minutos }\end{array}$ \\
\hline $50 \mathrm{ml}$ de Água destilada. \\
\hline $25 \mathrm{ml}$ de HNO3 (70\%). \\
\hline $15 \mathrm{ml}$ de HCL (38\%). \\
\hline $10 \mathrm{ml} \mathrm{HF} \mathrm{(40 \% ).}$ \\
\hline
\end{tabular}

A Tabela 14 traz a numeração que foi utilizada neste estudo para manter a rastreabilidade das amostras. 

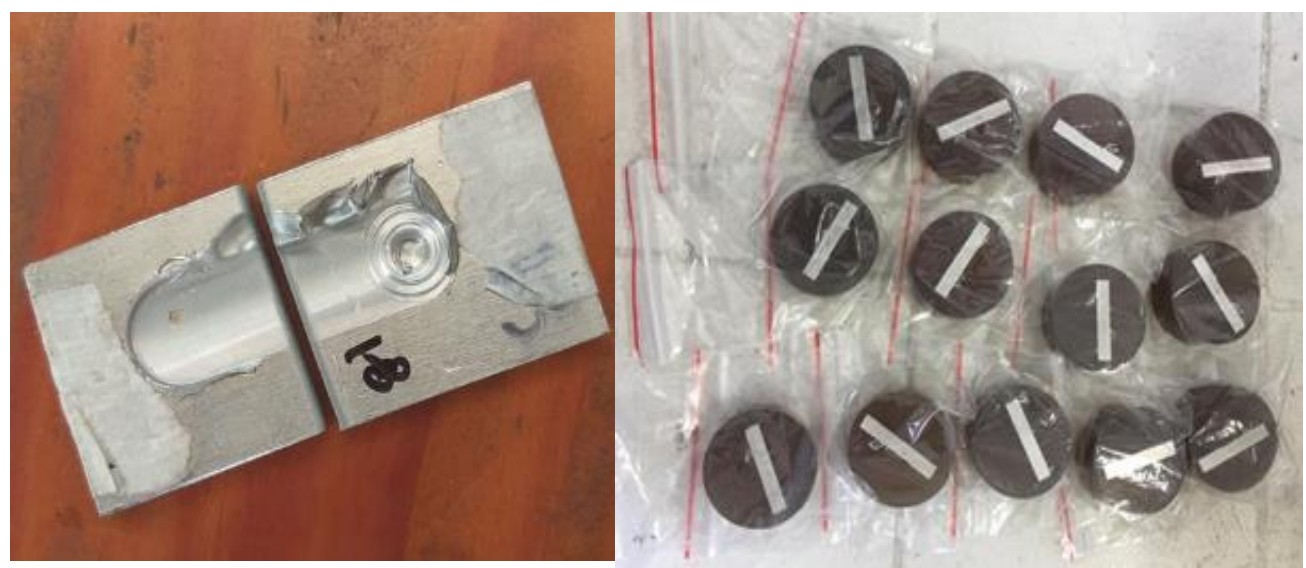

Figura 64 - (a) Corpo de prova cortado à água. (b) Amostras embutidas.

O corte a água foi relizado na Indútria de Material Bélico do Brasil (IMBEL) na Oficina da Seção de Produção Mecânica (FMCE). A etapa de lixamento, embutimento e polimento foi realizado no Laboratório de Caracterização de Materiais da Faculdade de Engenharia da UERJ (LaCaM).

As análises foram realizadas com aumentos de 1x e 2,5x na lupa de aumento Zeiss SteREO Discovery V8, no Laboratório de Metalografia e Tratamentos Térmicos, do Departamento de Engenharia Química e de Materiais da PUC-Rio, como mostrado na [48].

Tabela 14 - Numeração para rastreabilidade das amostras.

\begin{tabular}{|c|c|c|}
\hline Corpo de Prova & Rotação (RPM) & Velocidade de Soldagem $(\mathbf{m m} / \mathbf{m i n})$ \\
\hline 5 & 600 & 300 \\
\hline 8 & 900 & 300 \\
\hline 11 & 600 & 200 \\
\hline 15 & 900 & 200 \\
\hline 18 & 1200 & 300 \\
\hline 21 & 1500 & 300 \\
\hline 24 & 600 & 100 \\
\hline 27 & 1200 & 200 \\
\hline 33 & 900 & 100 \\
\hline 36 & 1200 & 100 \\
\hline 39 & 1500 & 100 \\
\hline 42 & 1500 & 200 \\
\hline
\end{tabular}




\section{$3.5 \quad$ Tomografia}

Os corpos de prova foram cortados à água longitudinalmente para deixar somente a área soldada para o ensaio de tomografia. Esse procedimento visou obter imagens com melhor resolução do que seria obtido empregando o corpo de prova inteiro. A Figura 65 mostra o corpo de prova cortado para o ensaio de tomografia.

Foram analisadas quatro amostras cujos parâmetros de soldagem e critérios de seleção são apresentados na Tabela 15.

Tabela 15 - Parâmetros e critério de seleção dos corpos de prova que foram tomografados.

\begin{tabular}{|c|c|c|}
\hline $\begin{array}{c}\text { Rotação } \\
{[\text { RPM }]}\end{array}$ & $\begin{array}{l}\text { Velocidade } \\
\text { de Avanço } \\
\text { [mm/min] }\end{array}$ & Critério \\
\hline 600 & 100 & $\begin{array}{l}\text { Solda com ótimo aspecto visual e condição que demandou menor } \\
\text { esforço do equipamento. }\end{array}$ \\
\hline 900 & 100 & Condição intermediária. \\
\hline 1200 & 300 & Surgimento de defeito após o lixamento e polimento das amostras. \\
\hline 1500 & 300 & Condição mais extrema que demandou maior esforço para soldagem \\
\hline
\end{tabular}

As análises foram realizadas no microtomógrafo de raios-X XRadia 510 VERSA da Zeiss, localizado no Laboratório de Microtomografia Departamento de Engenharia Química e de Materiais (DEQM) . As especificações do equipamento são apresentados na Tabela 16.

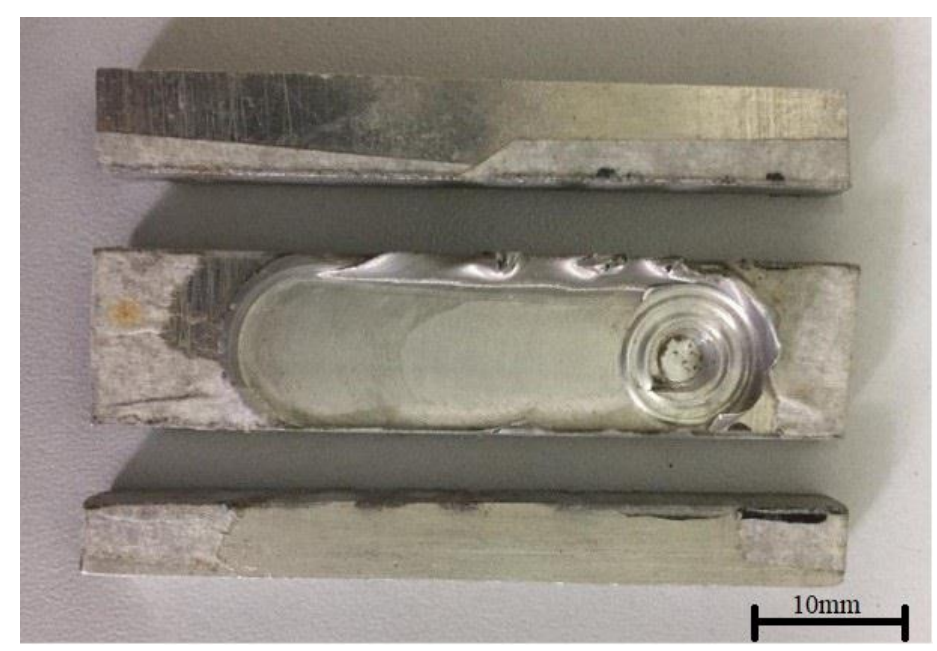

Figura 65 - Corpos de prova cortados à água para a análise de tomografia. 
Tabela 16 - Especificações Microtomógrado de raios-X Xradia Versa 510 Zeiss.

\begin{tabular}{|c|c|}
\hline Resolução Espacial & $0,7 \mu \mathrm{m}$ \\
\hline Voltagem & $30-160 \mathrm{KV}$ \\
\hline Máxima Potência & $10 \mathrm{~W}$ \\
\hline Lentes Objetivas & $0,4 \mathrm{X} ; 4 \mathrm{X} ; 20 \mathrm{X} \mathrm{e} 40 \mathrm{X}$ \\
\hline Máximo tamanho de amostra & $300 \mathrm{~mm}$ \\
\hline Capacidade & $15 \mathrm{Kg}$ \\
\hline
\end{tabular}

Os parâmetros utilizados nas análises deste estudo estão apresentados na Tabela 17.

Tabela 17 - Parâmetros do ensaio de Microtomografia.

\begin{tabular}{|c|c|}
\hline Pixel size & $11 \mu \mathrm{m}$ \\
\hline Magnificação ótica & $0,4 \mathrm{X}$ \\
\hline Tempo de exposição & 0,8 a $1 \mathrm{~s}$ \\
\hline Condições da Fonte & $80 \mathrm{KV}, 87 \mu \mathrm{A}, 7 \mathrm{~W}$ \\
\hline Tempo total de varredura por amostra & $1: 30$ a $1: 45$ \\
\hline
\end{tabular}




\section{Resultados Experimentais}

\subsection{Torque no Início da Soldagem}

Os valores do torque na entrada não sofreram influência da velocidade de soldagem, ou seja, ainda não estava ocorrendo o processo de soldagem. A Figura 66 traz o gráfico de valores para o torque na entrada dos experimentos, separados por velocidade de soldagem.



Figura 66 - Gráfico de torque na entrada separado por velocidade de soldagem.

Pode-se, então, considerar que todos os dados, independente da velocidade de soldagem, são função apenas da velocidade de rotação e os resultados dos diferentes experimentos mostram a dispersão estatística para cada ponto. A Figura 67 traz o gráfico com os valores para o torque na entrada de maneira unificada pela rotação. 


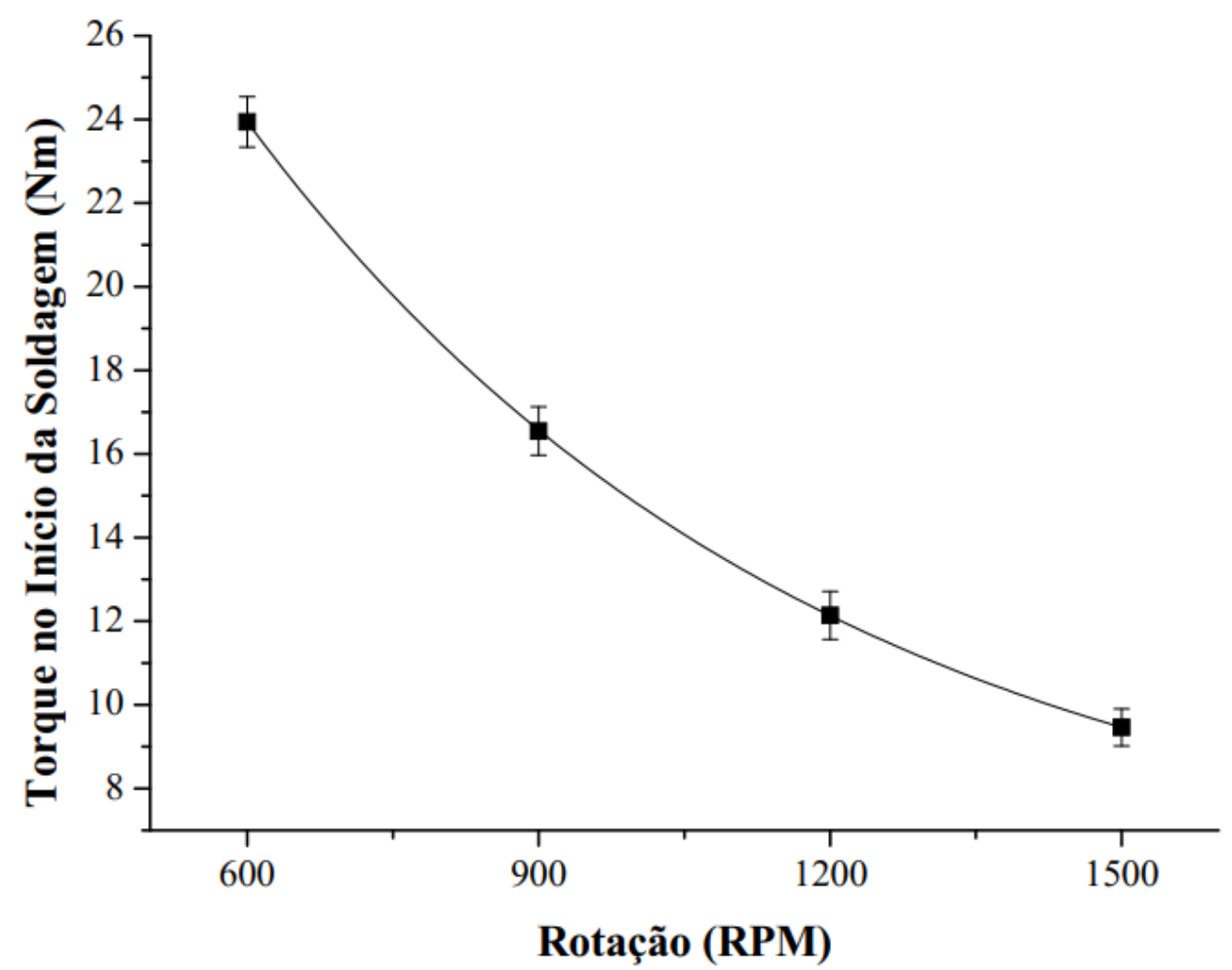

Figura 67 - Gráfico de torque na entrada com os valores médios para cada velocidade de rotação.

Os pontos foram ajustados por uma função de decaimento exponencial que resultou na eq. (39):

$$
y=5,423+18,516 * \exp ^{\left(\frac{x-600}{591,029}\right)} ; R^{2}=1
$$

Os valores obtidos nos diversos experimentos estão apresentados nas tabelas no anexo II.

\subsection{Torque no Percurso}

Diferentemente do torque na entrada, o torque no percurso sofre influência da velocidade de soldagem. O material está aquecido devido ao atrito entre a ferramenta e a amostra a ser soldada. Assim, para maiores rotações, o torque no percurso é menor que para rotações baixas e os valores de torque aumentam conforme se aumenta a velocidade de soldagem. Foi observado que os grupos de 
velocidade de soldagem estão bem definidos, ou seja, para cada velocidade de avanço existem curvas bem definidas, que não se sobrepõem.

A Figura 68 traz os valores de torque no percurso observados nos experimentos.

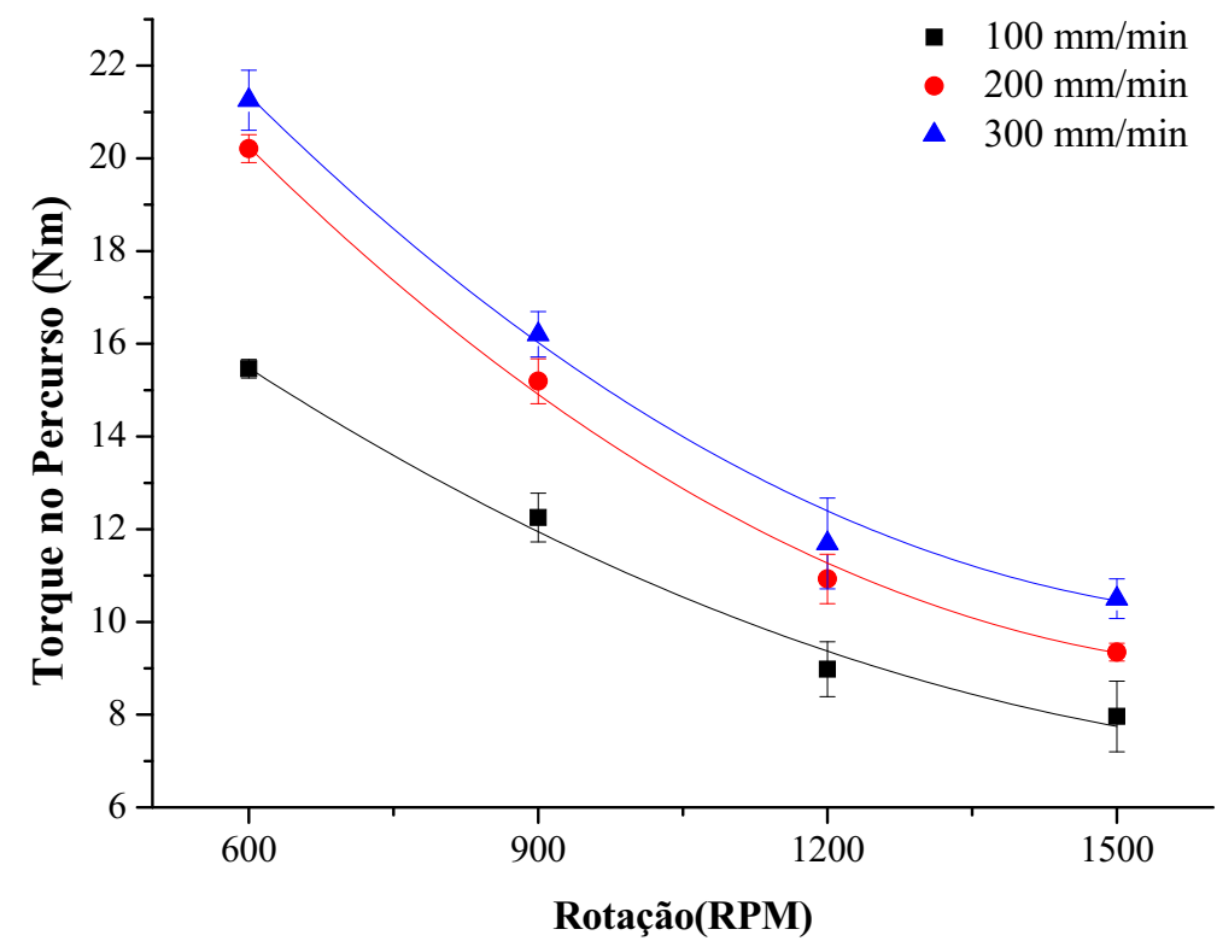

Figura 68 - Valores de torque no percurso, separados por velocidade de soldagem.

A função quadrática foi escolhida para o ajuste dos pontos experimentais pois, apresenta melhor índice de correlação em relação às outras funções de aproximação que foram testadas, a saber: exponencial e linear.

As eq. (40), eq. (41) e eq. (42) trazem a função quadrática de regressão para cada velocidade de soldagem.

Eq. (40)

$$
y(100)=25,398-0,019 x+\left(5,299 \times 10^{-6}\right) x^{2} ; R^{2}=0,996
$$

Eq. (41)

$$
y(200)=36,023-0,032 x+\left(9,4456 x 10^{-6}\right) x^{2} ; R^{2}=0,998
$$

Eq. (42)

$$
y(300)=37,103-0,032 x+\left(9,420 x 10^{-6}\right) x^{2} ; R^{2}=0,997
$$


A função quadrática descreveu o torque neste estudo, o que contraria o comportamento reportado em outros trabalhos, que obtiveram uma função de decaimento exponencial [24][26][27][28][29][48]. A escolha pela função quadrática deveu-se ao fato de que esta mostrou melhor correlação dos dados apresentados comparada a função exponencial de decaimento. Este fato pode ter ocorrido devido ao número de amostras estudadas para o torque no percurso ter sido de apenas três. Caso fosse possível avaliar um número maior de amostras e refinar os resultados a função exponencial, que é a função utilizada na literatura, poderia ter um índice de correlação aceitável.

Os esforços de torque desenvolvidos neste estudo foram superiores aos apresentados por Quintana [7] que utilizou ferramenta sem rosca e com dimensões semelhantes. Isto ocorre devido ao fato de a rosca contida na ferramenta fazer com que houvesse uma maior área de contato para atrito, assim desenvolvendo maiores esforços $[14][16][26][27[47][48]$.

H. Su et.al [14] utilizou ferramenta com rosca semelhante a utilizada neste estudo e mostrou que quanto maior a velocidade de rotação menor será o torque desenvolvido. Os autores observaram que a velocidade de soldagem influência nos valores de torque do processo e que os grupos de velocidade de soldagem são bem definidos. Apesar de ter utilizado ferramenta com pino e ombro de maiores dimensões encontrou valores de torque próximos aos encontrados neste trabalho.

J. W. Pewet al. [16] realizou experimentos com ferramenta de soldagem com rosca, ombro e pino de maiores dimensões em relação a deste estudo. Foi usada uma rotação e velocidades de soldagem parecidas com as deste trabalho e realizou o processo em três ligas de alumínio distintas (Al 7075-T7351, Al 5083H32 e Al 2024-T3) encontrando valores de torque superiores aos encontrados nos experimentos realizados neste trabalho.

\subsection{Força Axial}

A força axial é responsável por manter a ferramenta fixada na altura que se deseja soldar. Nos experimentos foram avaliados dois grupos de força axial: força axial máxima e força axial no percurso. A Figura 69 traz um gráfico descrevendo o comportamento da força axial durante o processo de soldagem. 


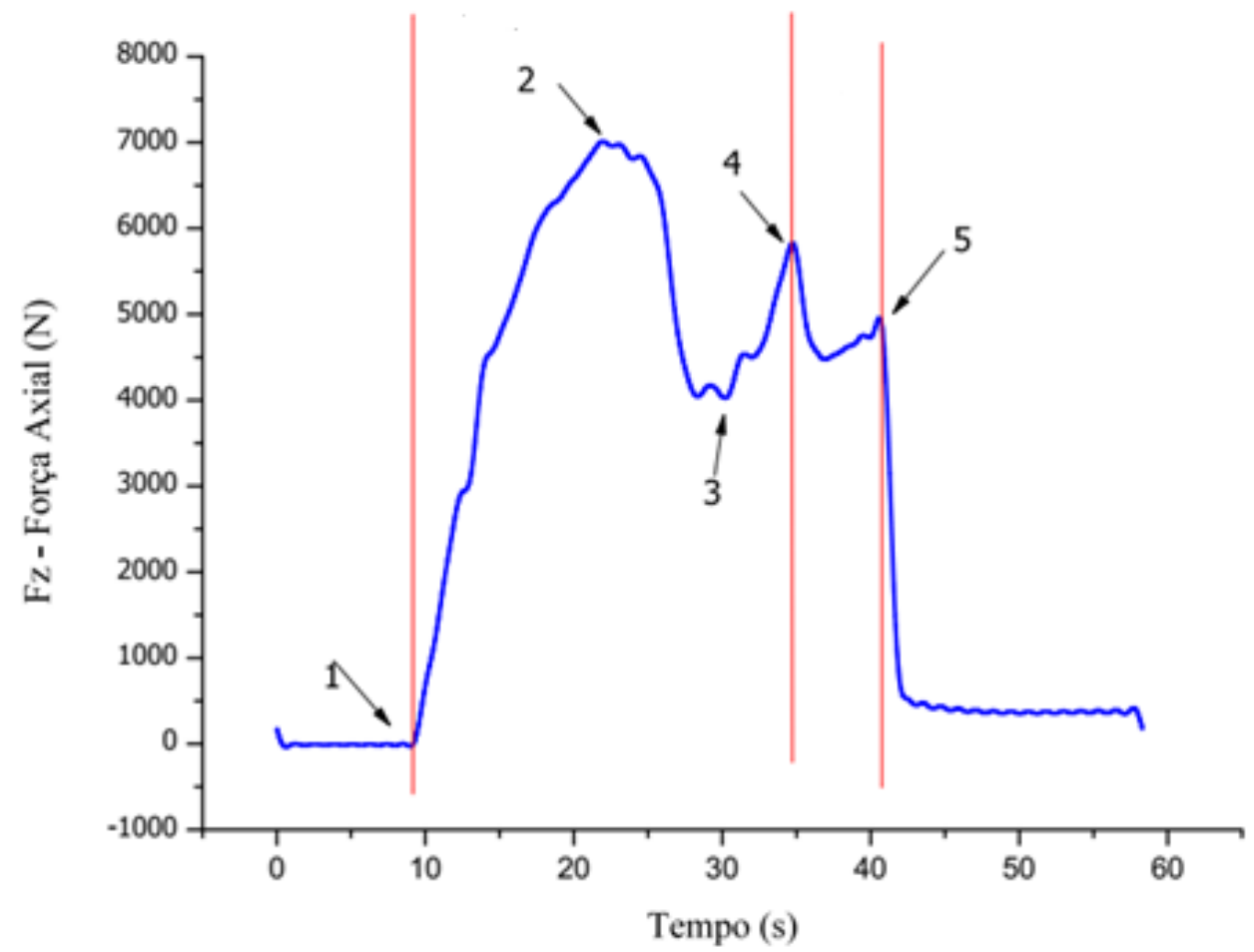

Figura 69 - Gráfico de Força axial corpo de prova 5 - 600RPM e 300 mm/min.

A Figura 69 mostra um comportamento semelhante ao reportado na literatura [27], onde é possível identificar a fase de descida da ferramenta e a fase de soldagem.

$\mathrm{Na}$ fase de descida da ferramenta, compreendida entre os pontos 1 e 4 , se busca o maior valor da força neste intervalo. $\mathrm{Na}$ fase de soldagem, compreendida entre os pontos 4 e 5, a força axial no percurso é a força representada pelo ponto 5.

\subsubsection{Força Axial Máxima}

A força axial máxima está presente durante a fase de descida da ferramenta. Neste período não há influência da velocidade de soldagem. Por isso a força axial máxima tem a mesma característica do torque de entrada, ou seja, não sofre influência da velocidade de soldagem. A Figura 70 traz os valores de força axial máxima separada por grupos de velocidade de soldagem.

Ao se unificar os pontos, estes foram ajustados por uma função linear que resultou na eq. (43). A Figura 71 traz a força axial máxima de maneira unificada. 


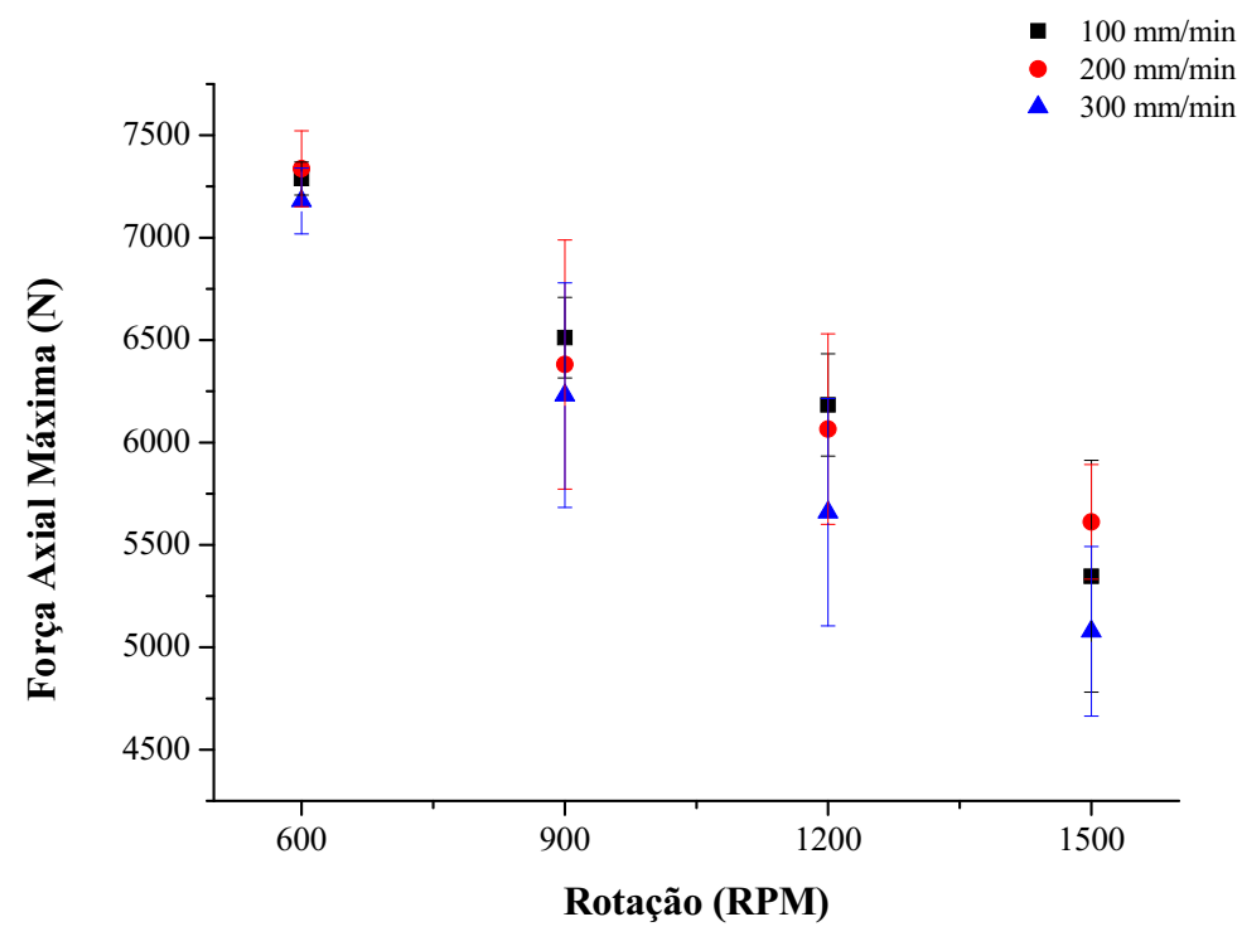

Figura 70 - Força Axial Máxima durante a fase de descida da ferramenta.

$$
y=8562,352-2,182 x ; R^{2}=0,988
$$

A redução da força axial máxima com o aumento da rotação da ferramenta também foi observada por outros autores [14][26][27][28][47].

$S U$, et al [14] utilizou a mesma velocidade de descida da ferramenta, porém encontrou valores muito superiores aos encontrados neste estudo mesmo utilizando ferramenta cônica e com rosca. Este fato ocorreu, entretanto, por que a liga de alumínio utilizada possuía propriedades mecânicas diferentes. 


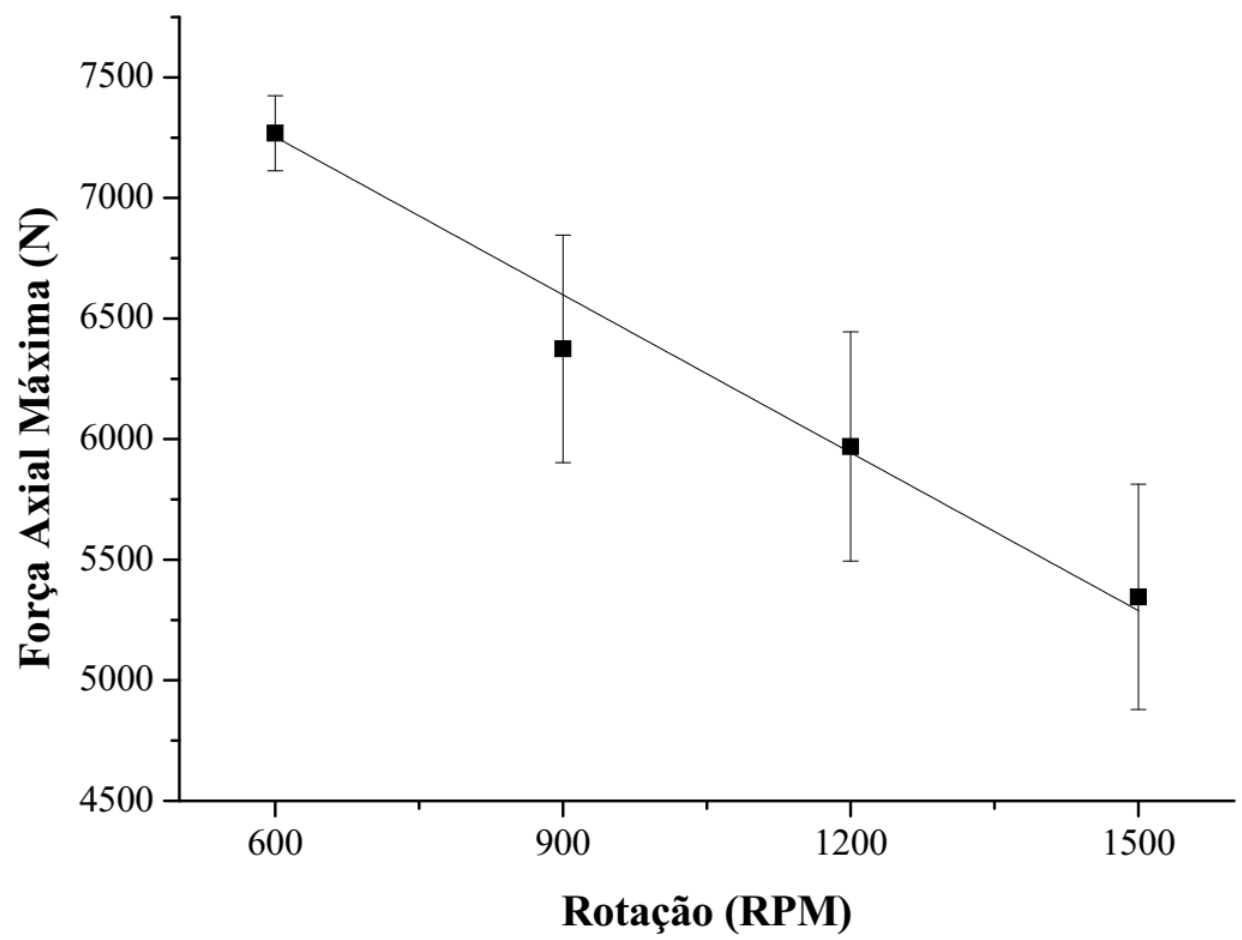

Figura 71 - Força Axial Máxima Unificada: valores médios e desvio padrão.

QUINTANA [26][27][28] utilizando ferramenta sem rosca e com pino cilíndrico encontrou valores de força axial máxima superiores aos valores apresentados neste estudo.

Assim, é observado que a geometria e velocidade de descida da ferramenta influenciam nos valores de força axial máxima [26][27][28].

\subsubsection{Força Axial no Percurso}

Neste ponto, no final da soldagem, a força axial sofre influência das velocidades de soldagem e da rotação. Pela Figura 72 pode-se observar que as forças diminuem conforme o aumento da rotação e que os grupos de velocidade de soldagem estão bem definidos. 


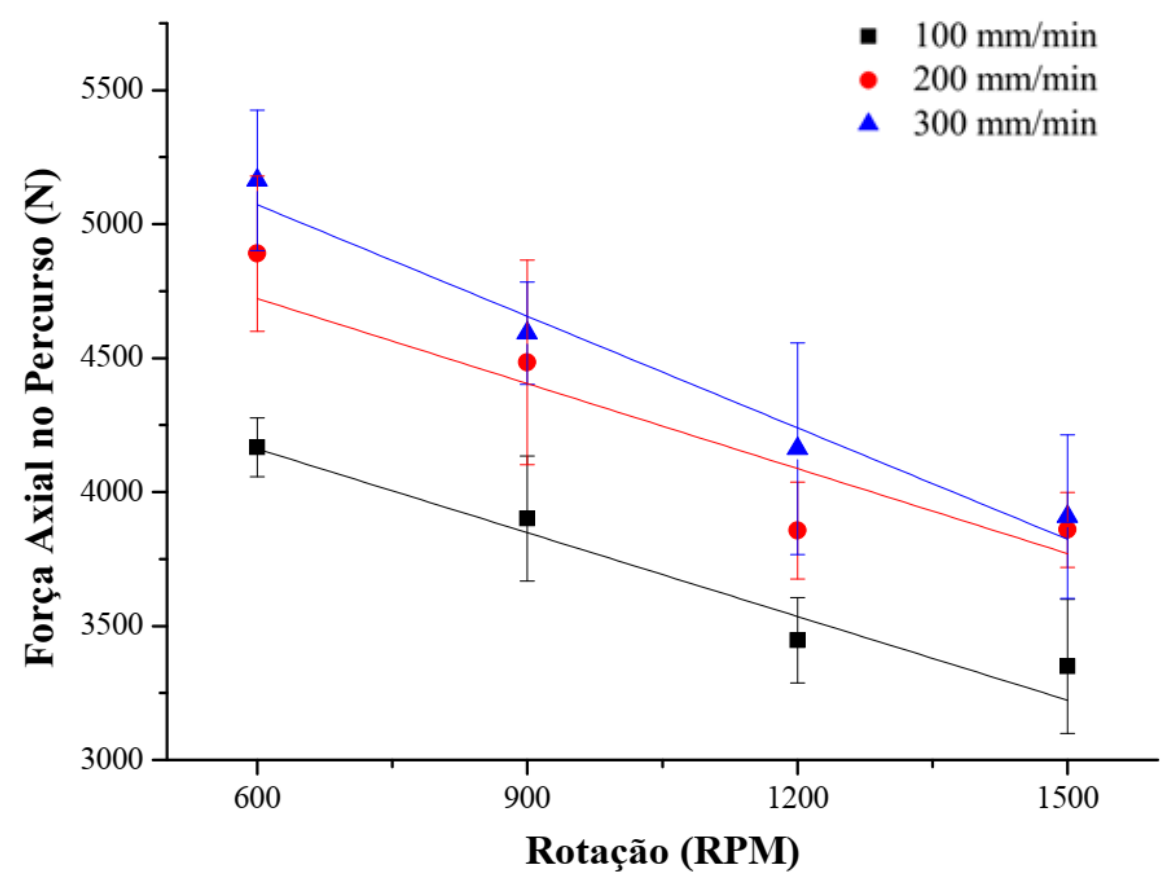

Figura 72 - Força Axial no Percurso em função da rotação separada pelas velocidades de rotação.

As eq. (44), eq. (45) e eq. (46) trazem a função linear para cada velocidade de soldagem.

Eq. (44)

$$
y(100)=4786,793 x-1,043 ; R^{2}=0,96695
$$

Eq. (45)

$$
y(200)=5357,313 x-5357,313 x-1,058 ; R^{2}=0,80838
$$

Eq. (46)

$$
y(300)=5905,73454 x-1,388 ; R^{2}=0,96815
$$

$S U, H$., et al [14] as forças axiais possuem valores maiores que as forças de soldagem. Isto é confirmado neste estudo, onde a força axial é aproximadamente dez vezes maior que as forças de soldagem. 


\subsection{Força de Soldagem no Início da Soldagem}

A força de soldagem é responsável pelo esforço necessário para que a soldagem seja realizada, ou seja, é a força que move a ferramenta para frente. A Figura 73 traz o gráfico descrevendo o comportamento da força de soldagem durante os experimentos. $\mathrm{O}$ ponto 1 mostra a entrada da ferramenta e o ponto $2 \mathrm{o}$ final da soldagem, ou seja, a saída da ferramenta.

As forças de soldagem na entrada não sofrem influência da velocidade de soldagem. Assim, são apenas valores dentro de uma dispersão que podem ser unificados. A Figura 74 traz o gráfico representativo para as forças de soldagem na entrada.

Os pontos foram ajustados por uma função linear, resultando na eq. (47):

$$
y=57,268+0,506 x ; R^{2}=0,995
$$

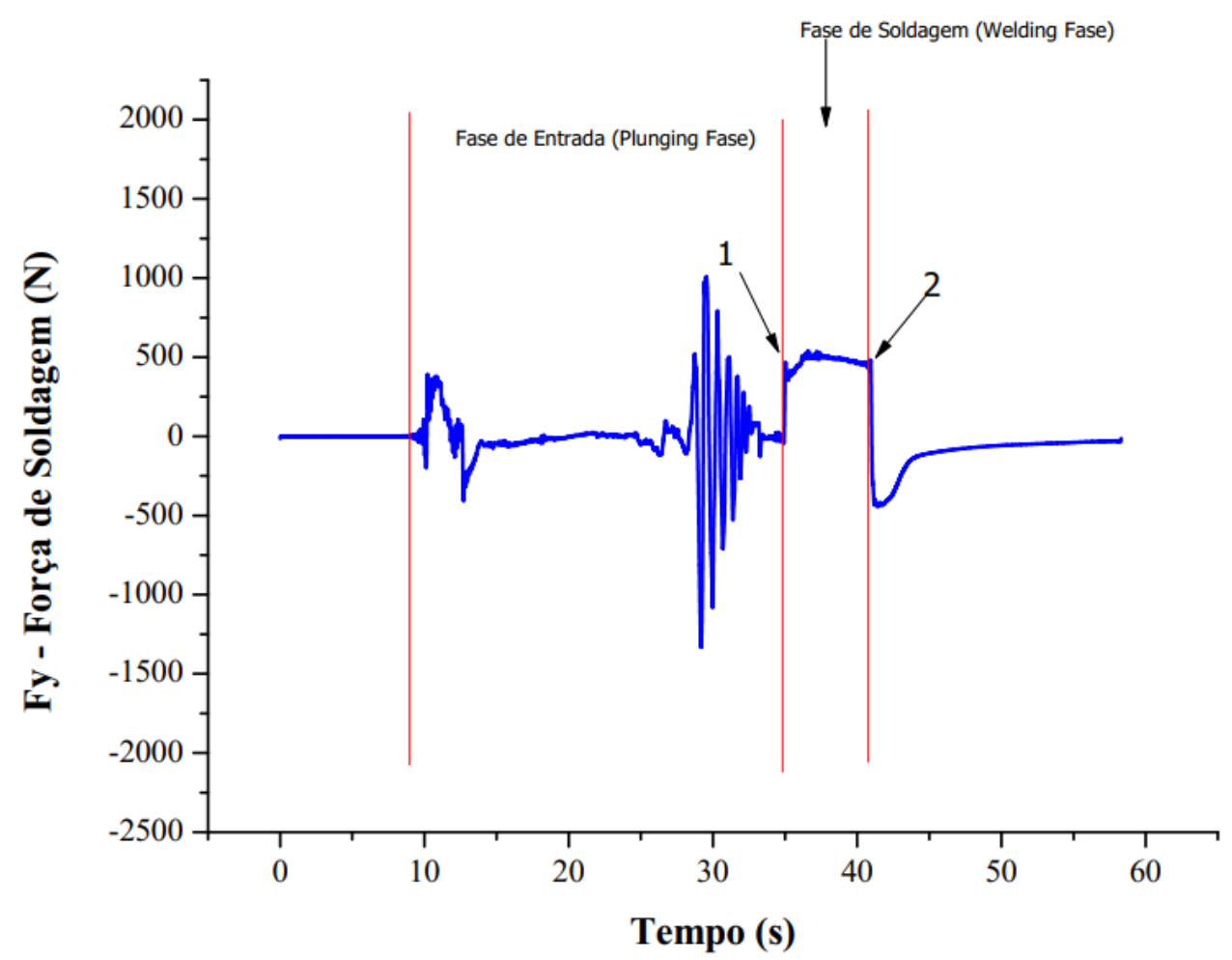

Figura 73 - Gráfico Força de Soldagem CP-5 600RPM e 300 mm/min. 


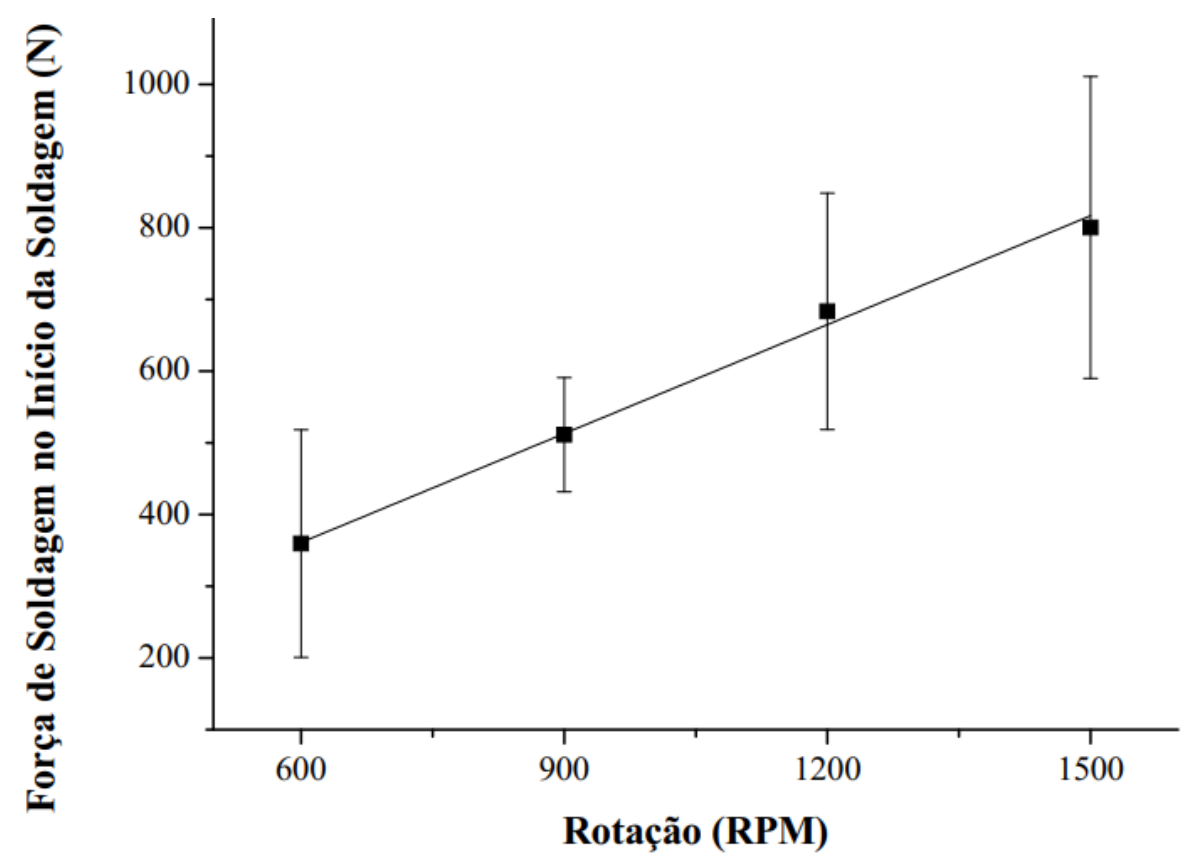

Figura 74 - Regressão linear para os valores de Força de Soldagem na Entrada.

\subsection{Forças de Soldagem no Percurso}

A Força de soldagem no percurso não sofre variação com a variação da rotação para as velocidades de 100 e $200 \mathrm{~mm} / \mathrm{min}$. Pode se observar que para estas velocidades há um valor médio, quase invariável. A Figura 75 traz o gráfico de forças de soldagem por rotação separada por grupo de velocidades de soldagem.

Foi observado que para a velocidade de soldagem de $300 \mathrm{~mm} / \mathrm{min}$ a força de soldagem sofreu maior influência da velocidade de rotação. Assim foi feito um gráfico com as forças em função da velocidade de soldagem. A Figura 76 traz as forças de soldagem no percurso em função da velocidade de soldagem.

Assim, por fim, foi observado que as forças de soldagem no percurso, apresentam um valor médio e uma dispersão em relação à velocidade de 300 $\mathrm{mm} / \mathrm{min}$. Foi feito um novo gráfico com as forças de soldagem em função da velocidade de soldagem, mas apenas com valores médios. A Figura 77 traz o gráfico final para velocidade de soldagem. 


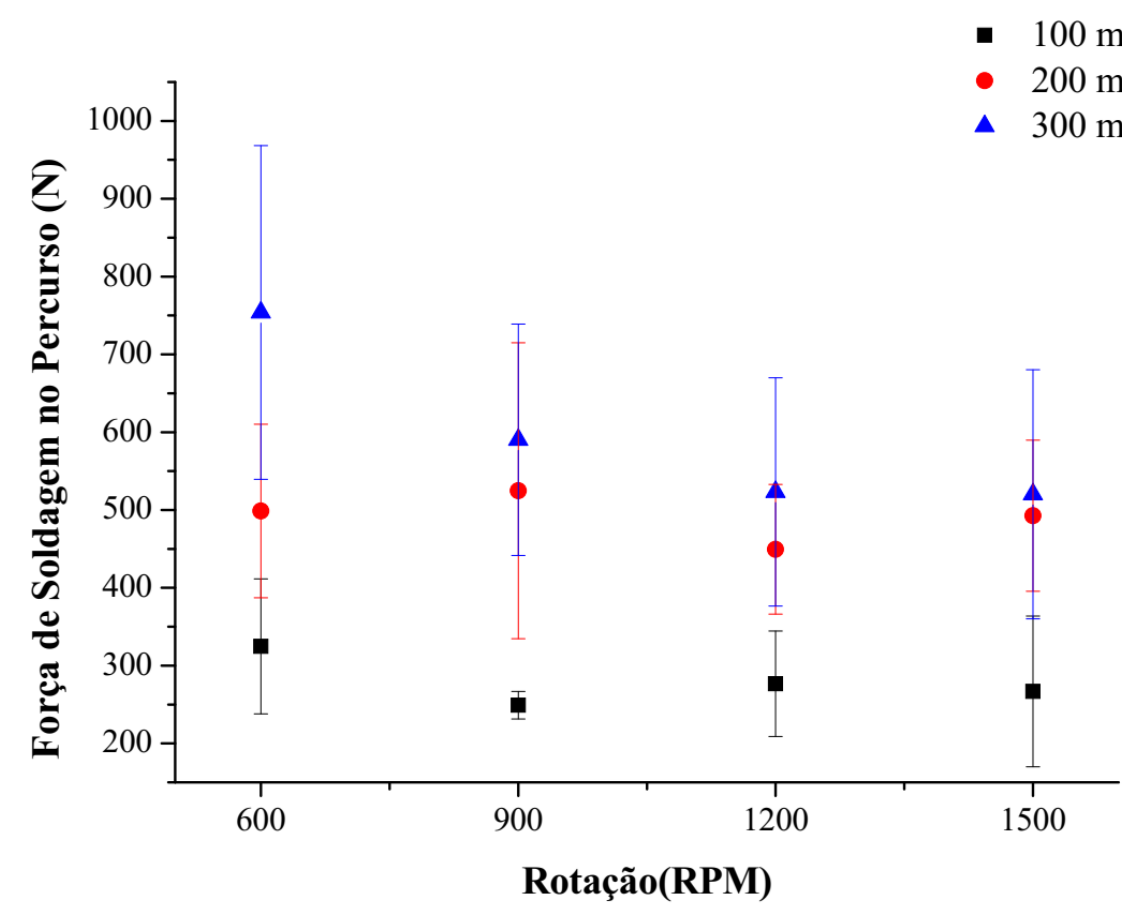

Figura 75 - Gráfico de Forças de Soldagem no Percurso.

Os pontos foram ajustados por uma função linear resultando na eq. (48):

Eq. (48)

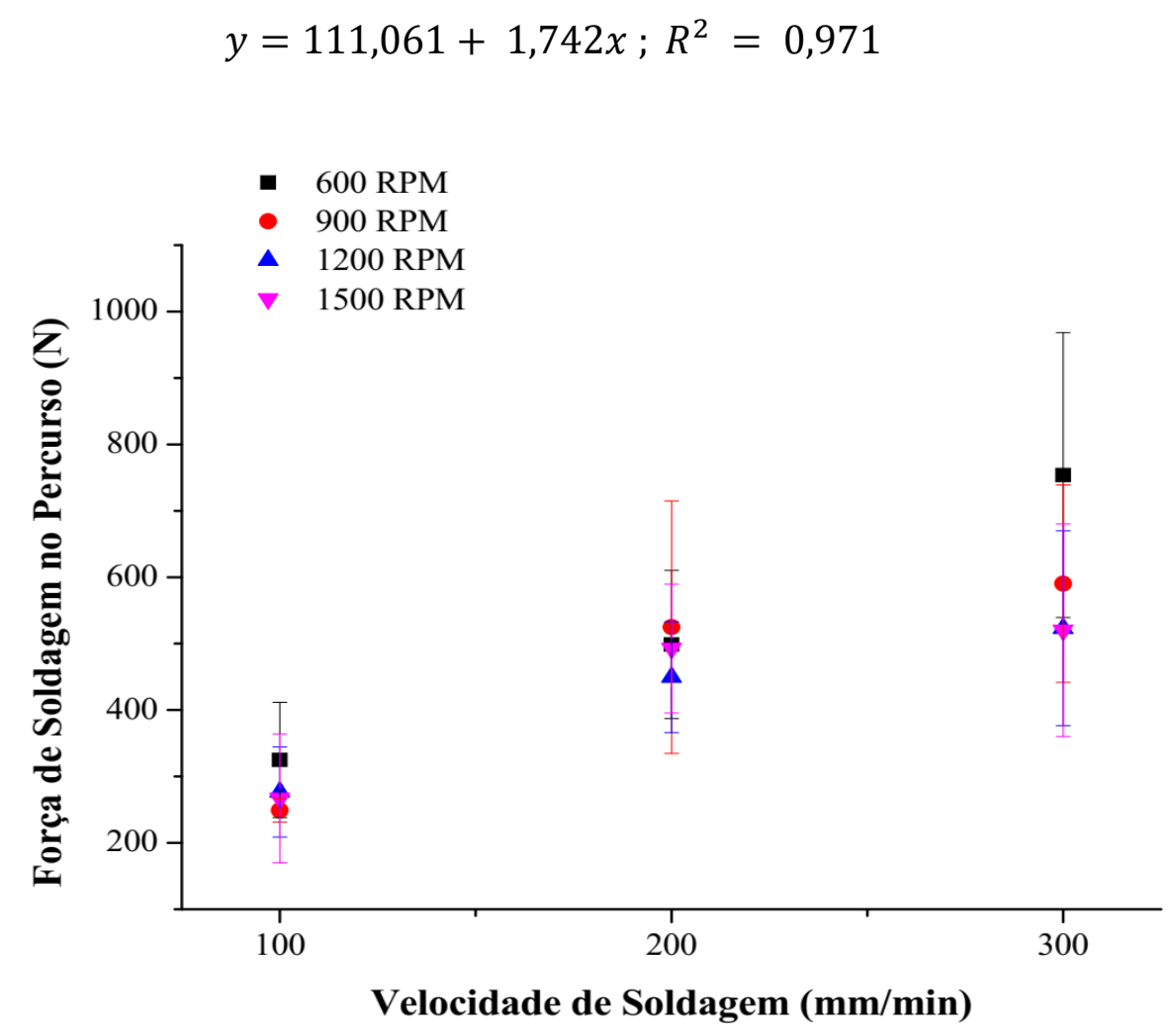

Figura 76 - Forças de Soldagem no Percurso em função da velocidade de soldagem. 




Figura 77 - Gráfico de Força de Soldagem no Percurso com valores unificados médios.

Assim como apresentando em outros estudos, a força de soldagem é proporcional a velocidade de soldagem [14][26][27][28].

\subsection{Força Transversal no Início da Soldagem.}

A força transversal é responsável pelo cisalhamento do pino da ferramenta. A Figura 78 apresenta o gráfico da força transversal para um experimento. O ponto 1 mostra a entrada da ferramenta e o ponto 2 o final da soldagem, ou seja, a saída da ferramenta. Na entrada não houve influência da velocidade de soldagem. A Figura 79 traz o gráfico representativo para as forças de soldagem na entrada.

Os pontos foram ajustados por uma função linear resultando na eq. (49):

$$
y=196,806+0,391 x ; R^{2}=0,877
$$




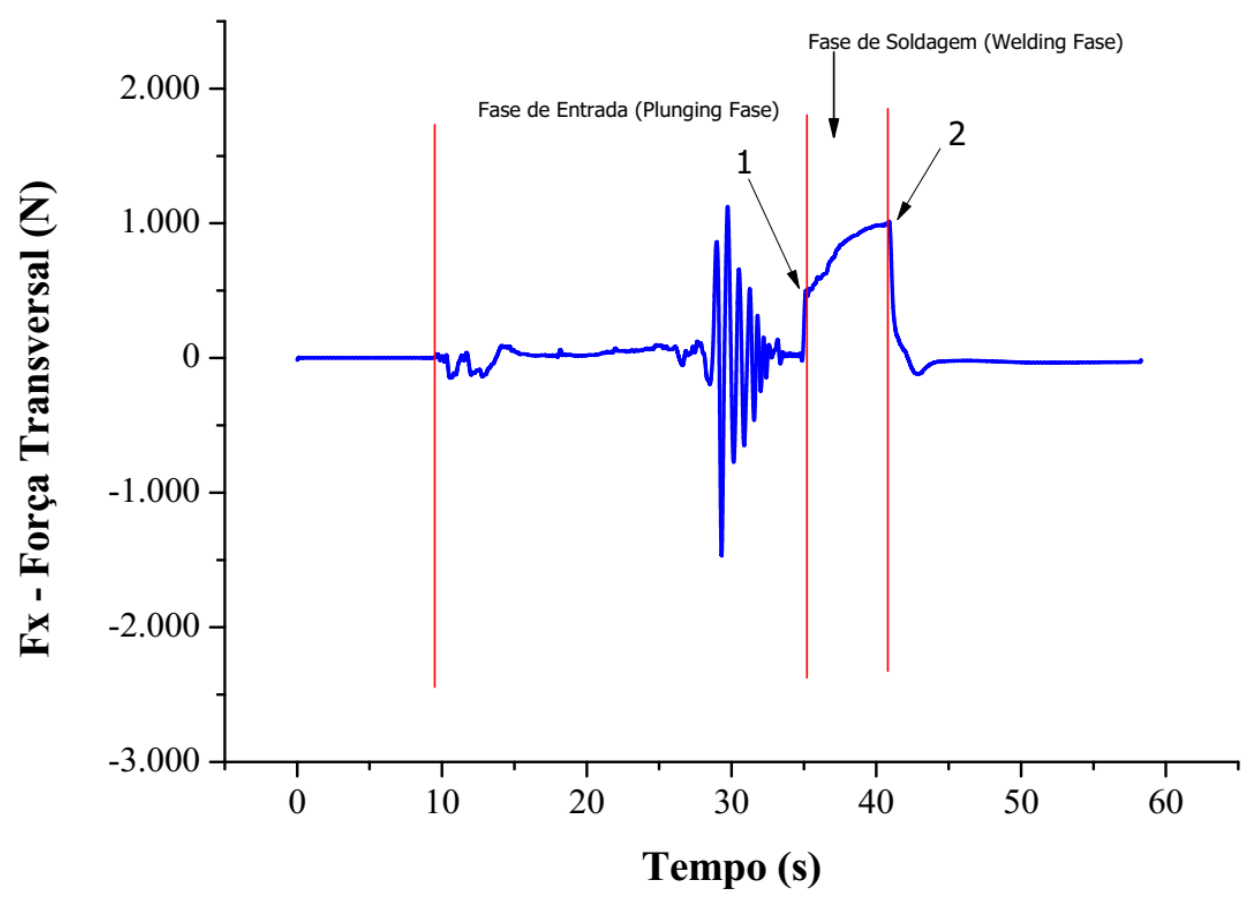

Figura 78 - Gráfico de Fora transversal. CP - 5600 RPM; 300 mm/min.

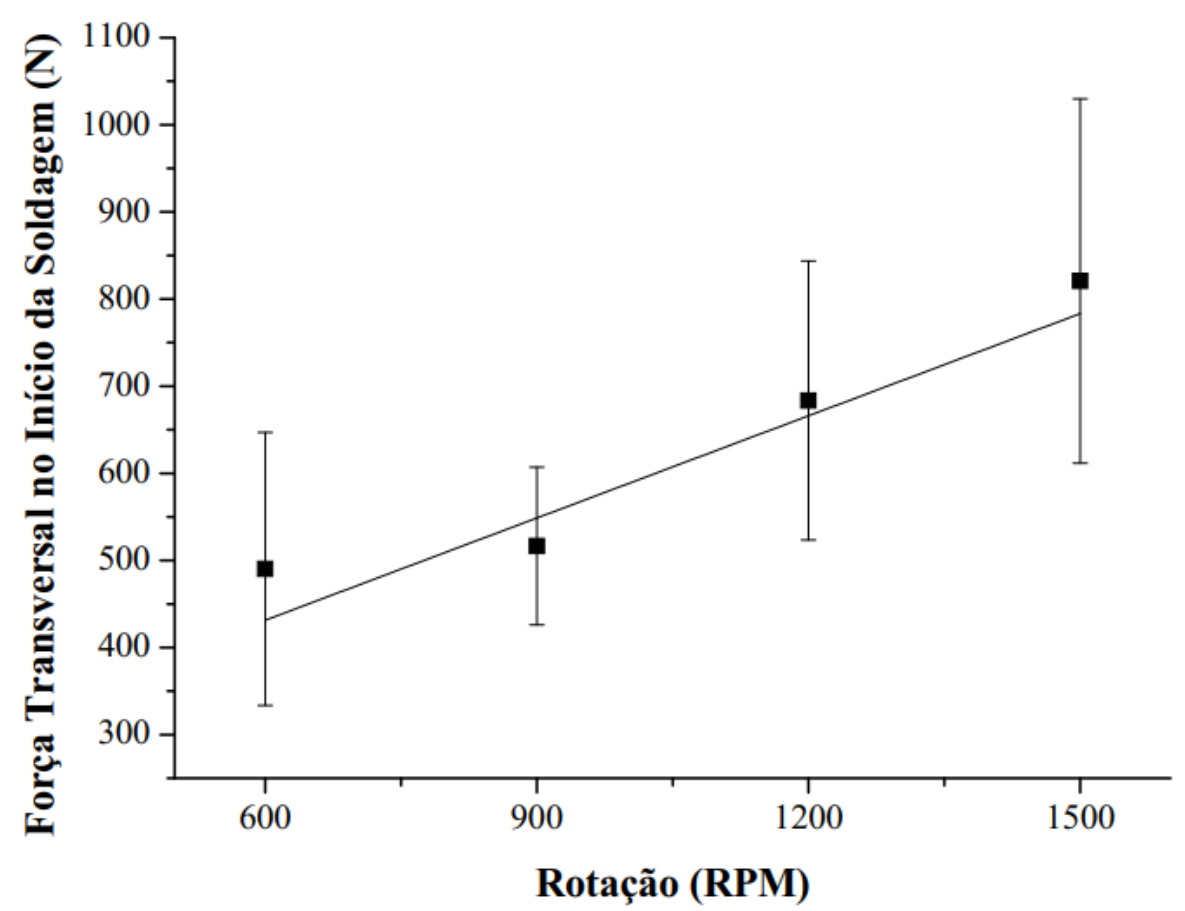

Figura 79 - Regressão linear para os valores de Força Transversal na Entrada.

\subsection{Força Transversal no Percurso}

A Figura 80 traz as forças transversais no percurso em função da velocidade de soldagem. 
Foi observado que os valores das forças de soldagem no percurso podem ser considerados como pontos médios com uma dispersão. Assim foi feito um gráfico com os pontos unificados, fazendo-se uma média com desvio padrão para cada velocidade de soldagem. A Figura 81 traz o gráfico final para força transversal em função da velocidade de soldagem.

As forças transversais de soldagem no percurso são descritas pela eq. (50):

$$
y=948,881+0,553 x ; R^{2}=0,969
$$

As forças transversais possuem valores menores que os apresentados por [7], o que pode estar associado à presença de rosca na ferramenta.

Foi realizada a comparação entres os valores encontrados nos experimentos deste estudo com os valores encontrados nos experimentos de QUINTANA [7] a partir da variação percentual descrita pela eq. (51):

Eq. (51)

$$
\% C=\frac{V E-V Q}{V Q} \times 100
$$

Onde:

- $\% C$ : Valor Percentual de Variação do Parâmetro.

- $V E$ : Valor do parâmetro neste estudo.

- $\quad V Q$ : Valor do parâmetro no estudo de QUINTANA [7]

A Tabela 18, Tabela 19 e Tabela 20 trazem a comparação de variação entre os valores encontrados nos experimentos deste estudo e os experimentos de QUINTANA [7]. 


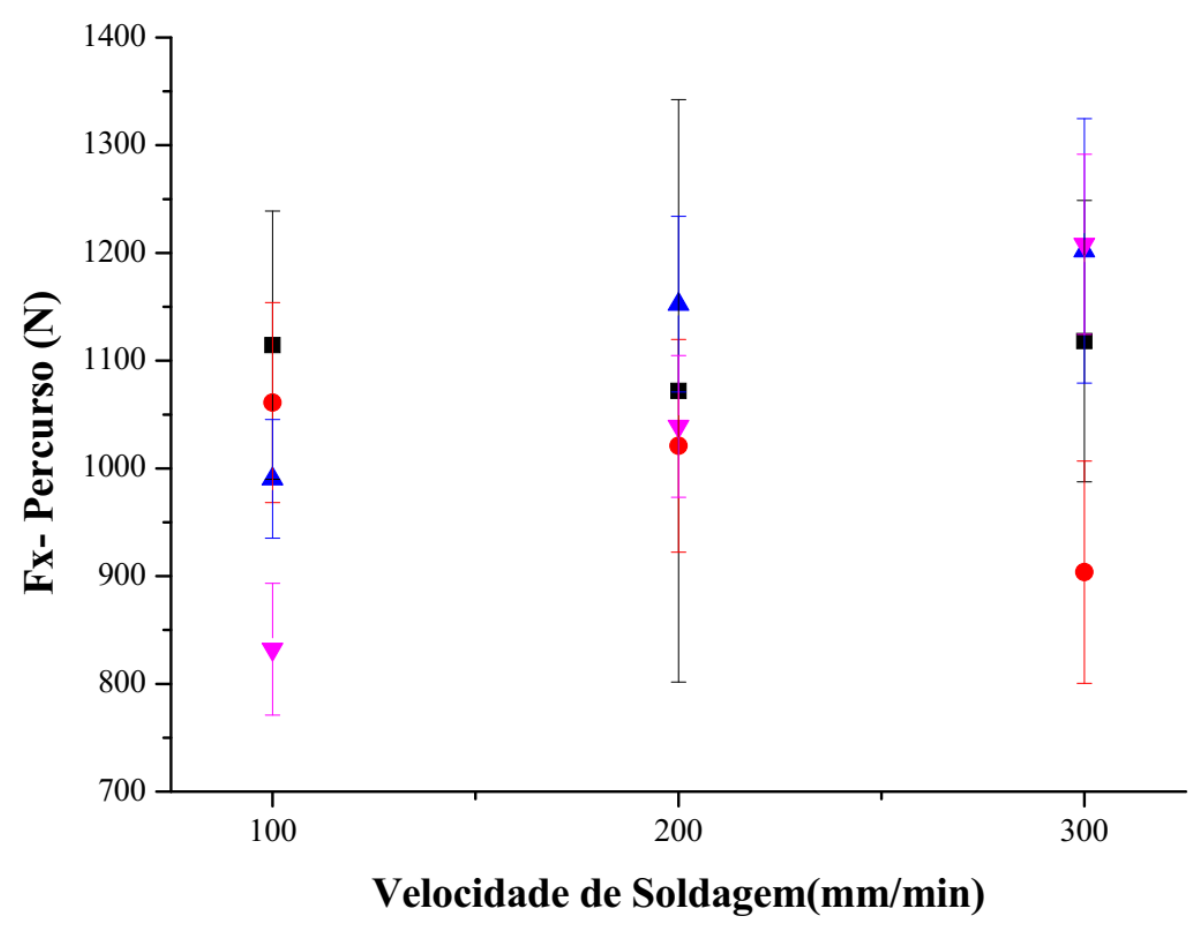

Figura 80 - Forças Transversais no Percurso em função da velocidade de soldagem.

Assim, observa-se que os esforços de Torque na entrada, Torque no Percurso, Força Axial Máxima e Força Axial no Percurso neste estudo são maiores do que os observados por QUINTANA [7], pois a ferramenta com rosca tem uma maior área de contato (pino/material), o que geraria maior atrito e em consequência disto maiores esforços para a realização do processo.

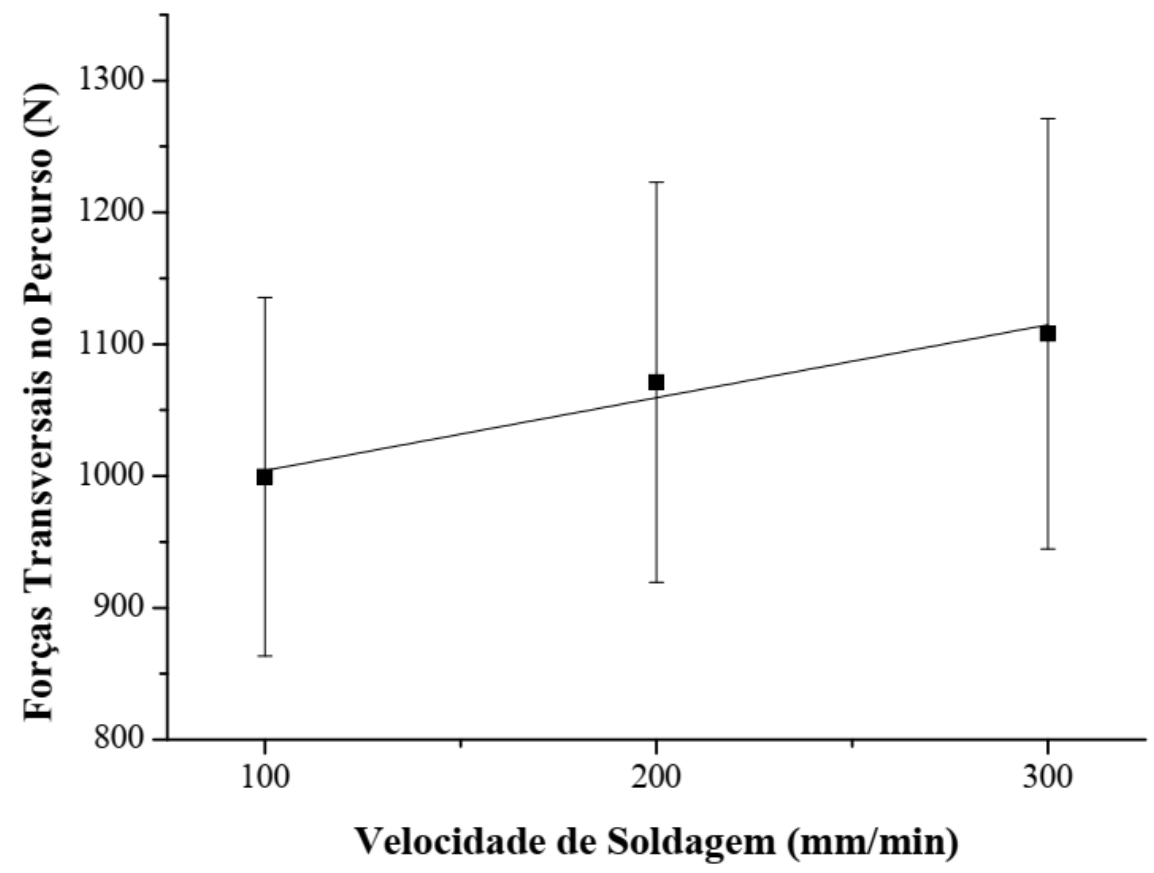

Figura 81 - Gráfico de Forças Transversais no Percurso por velocidade de soldagem com valores unificados. 
Tabela 18 - Tabela com a comparação entre os valores das forças com velocidade de soldagem de $100 \mathrm{~mm} / \mathrm{min}$.

\begin{tabular}{|c|c|c|c|c|c|c|}
\hline \multicolumn{2}{|c|}{$\mathbf{1 0 0 ~ \mathbf { ~ m m } / \mathbf { m i n }}$} \\
\hline $\begin{array}{c}\text { Rotação } \\
(\mathbf{R P M})\end{array}$ & $\begin{array}{c}\text { Torque } \\
\text { Entrada } \\
(\mathbf{N m})\end{array}$ & $\begin{array}{c}\text { Torque no } \\
\text { Percurso } \\
(\mathbf{N m})\end{array}$ & $\begin{array}{c}\text { Força } \\
\text { Axial } \\
\text { Máxima } \\
\text { (N) }\end{array}$ & $\begin{array}{c}\text { Força Axial } \\
\text { no } \\
\text { Percurso } \\
\text { (N) }\end{array}$ & $\begin{array}{c}\text { Força } \\
\text { Transversal no } \\
\text { Percurso (N) }\end{array}$ & $\begin{array}{c}\text { Força de } \\
\text { Soldagem } \\
\text { no } \\
\text { Percurso } \\
\text { (N) }\end{array}$ \\
\hline $\mathbf{6 0 0}$ & $44,15 \%$ & $15,42 \%$ & $10,67 \%$ & $9,24 \%$ & $3,51 \%$ & $77,42 \%$ \\
\hline $\mathbf{9 0 0}$ & $37,70 \%$ & $18,94 \%$ & $19,09 \%$ & $13,52 \%$ & $13,09 \%$ & $42,60 \%$ \\
\hline $\mathbf{1 2 0 0}$ & $39,23 \%$ & $15,79 \%$ & $26,79 \%$ & $9,88 \%$ & $0,27 \%$ & $60,85 \%$ \\
\hline $\mathbf{1 5 0 0}$ & $38,63 \%$ & $27,11 \%$ & $17,06 \%$ & $12,91 \%$ & $-10,36 \%$ & $29,16 \%$ \\
\hline
\end{tabular}

Tabela 19 - Tabela com a comparação entre os valores das forças com velocidade de soldagem de $200 \mathrm{~mm} / \mathrm{min}$.

\begin{tabular}{|c|c|c|c|c|c|c|}
\hline \multicolumn{2}{|c|}{ Rotação } \\
$\left(\begin{array}{c}\text { RPM) } \\
\text { Torque }\end{array}\right.$ & $\begin{array}{c}\text { Entrada } \\
(\mathbf{N m})\end{array}$ & $\begin{array}{c}\text { Torque no } \\
\text { Percurso } \\
(\mathbf{N m})\end{array}$ & $\begin{array}{c}\text { Força } \\
\text { Axial } \\
\text { Máxima } \\
(\mathbf{N})\end{array}$ & $\begin{array}{c}\text { Força } \\
\text { Axial no } \\
\text { Percurso } \\
(\mathbf{N})\end{array}$ & $\begin{array}{c}\text { Força } \\
\text { Transversal } \\
\text { no Percurso } \\
(\mathbf{N})\end{array}$ & $\begin{array}{c}\text { Força de } \\
\text { Soldagem } \\
\text { no } \\
\text { Percurso } \\
(\mathbf{N})\end{array}$ \\
\hline $\mathbf{6 0 0}$ & $37,01 \%$ & $37,95 \%$ & $9,40 \%$ & $6,27 \%$ & $-16,94 \%$ & $10,35 \%$ \\
\hline $\mathbf{9 0 0}$ & $38,98 \%$ & $57,88 \%$ & $18,48 \%$ & $14,90 \%$ & $-17,47 \%$ & $53,52 \%$ \\
\hline $\mathbf{1 2 0 0}$ & $37,75 \%$ & $44,61 \%$ & $25,12 \%$ & $6,49 \%$ & $-9,67 \%$ & $40,30 \%$ \\
\hline $\mathbf{1 5 0 0}$ & $42,92 \%$ & $50,99 \%$ & $20,41 \%$ & $10,77 \%$ & $-25,30 \%$ & $41,96 \%$ \\
\hline
\end{tabular}

Tabela 20 - Tabela com a comparação entre os valores das forças com velocidade de soldagem de $300 \mathrm{~mm} / \mathrm{min}$.

\begin{tabular}{|c|c|c|c|c|c|c|}
\hline \multicolumn{7}{|c|}{$\mathbf{3 0 0} \mathbf{~ m m} / \mathbf{m i n}$} \\
$\begin{array}{c}\text { Rotação } \\
\text { (RPM) }\end{array}$ & $\begin{array}{c}\text { Torque } \\
\text { Entrada } \\
(\mathbf{N m})\end{array}$ & $\begin{array}{c}\text { Torque no } \\
\text { Percurso } \\
(\mathbf{N m})\end{array}$ & $\begin{array}{c}\text { Força } \\
\text { Axial } \\
\text { Máxima } \\
\mathbf{( N )}\end{array}$ & $\begin{array}{c}\text { Força Axial } \\
\text { no Percurso } \\
\text { (N) }\end{array}$ & $\begin{array}{c}\text { Força } \\
\text { Transversal no } \\
\text { Percurso (N) }\end{array}$ & $\begin{array}{c}\text { Força de } \\
\text { Soldagem } \\
\text { no } \\
\text { Percurso } \\
\text { (N) }\end{array}$ \\
\hline $\mathbf{6 0 0}$ & $39,98 \%$ & $51,54 \%$ & $7,67 \%$ & $3,28 \%$ & $-23,80 \%$ & $-32,14 \%$ \\
\hline $\mathbf{9 0 0}$ & $41,94 \%$ & $47,13 \%$ & $15,20 \%$ & $6,10 \%$ & $-31,09 \%$ & $4,55 \%$ \\
\hline $\mathbf{1 2 0 0}$ & $36,85 \%$ & $40,61 \%$ & $16,75 \%$ & $7,18 \%$ & $-17,81 \%$ & $22,39 \%$ \\
\hline $\mathbf{1 5 0 0}$ & $31,19 \%$ & $59,70 \%$ & $15,76 \%$ & $18,70 \%$ & $-22,68 \%$ & $47,10 \%$ \\
\hline
\end{tabular}

Para as Forças de soldagem no Percurso observa-se que os valores encontrados também são maiores, com exceção do ponto a 600 RPM e 300 $\mathrm{mm} / \mathrm{min}$. Este pode ser um ponto que deve ser refinado. 
As Forças Transversais no Percurso apresentam valores menores para as velocidades de soldagem de $200 \mathrm{~mm} / \mathrm{min}$ e $300 \mathrm{~mm} / \mathrm{min}$. Para a velocidade de $100 \mathrm{~mm} / \mathrm{min}$ existe apenas um ponto com valor menor.

Na Tabela 21 estão mostrados os valores de potência de soldagem para cada parâmetro de soldagem, calculados pela eq. (1) (página 21). Observa-se que os valores de potência de soldagem aumentam com o aumento da velocidade de rotação e com a velocidade de soldagem.

Tabela 21 - Potência de soldagem para os experimentos realizados.

\begin{tabular}{|c|c|c|c|}
\hline $\begin{array}{c}\text { Rotação } \\
\text { (RPM) }\end{array}$ & $100 \mathrm{~mm} / \mathrm{min}$ & $200 \mathrm{~mm} / \mathrm{min}$ & $300 \mathrm{~mm} / \mathrm{min}$ \\
\hline 600 & 9817,30 & 13788,50 & 16525,00 \\
\hline 900 & 11440,08 & 13711,20 & 17540,25 \\
\hline 1200 & 11237,07 & 13141,89 & 16644,00 \\
\hline 1500 & 12384,77 & 14045,40 & 18350,95 \\
\hline
\end{tabular}

\subsection{Análise metalográfica}

A partir das análises realizadas foi observado que onze amostras apresentaram macroscopicamente defeito aparente; somente uma amostra teve defeito menor.

$\mathrm{O}$ ataque químico foi eficiente e revelou a área de mistura da solda. A Figura 82 traz um corpo de prova soldado com 600 RPM e $300 \mathrm{~mm} / \mathrm{min}$, como exemplo, e o metal de base não atacado.

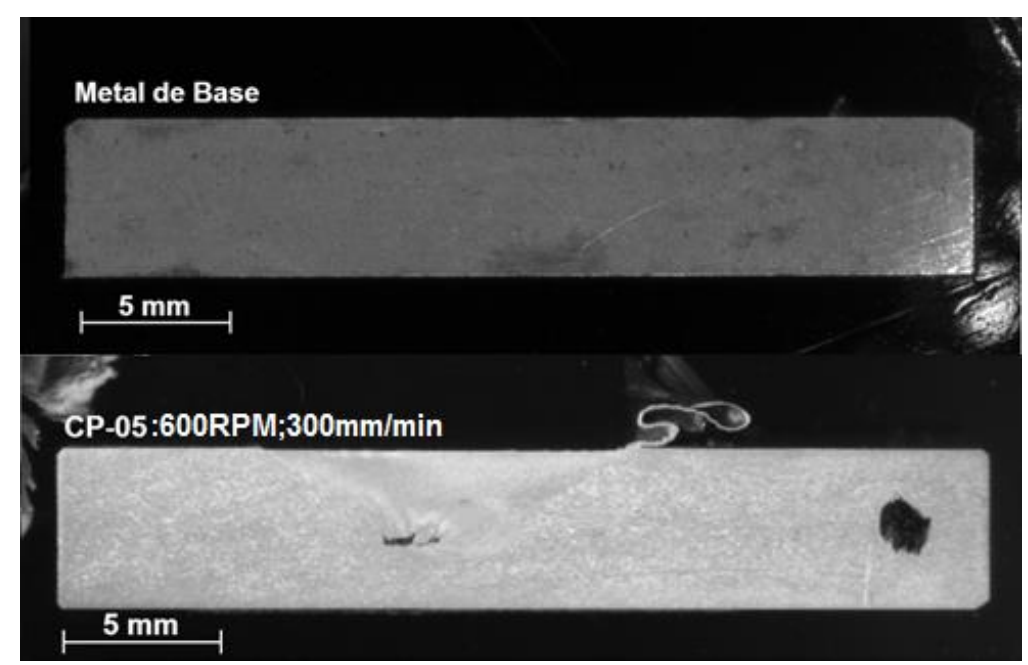

Figura 82 - Imagem do Corpo de prova CP 5 - 600 RPM; $300 \mathrm{~mm} / \mathrm{min}$ atacado quimicamente e o metal de base não atacado. 
A Figura 83 traz a imagem de todas das amostras analisadas nesse trabalho. A amostra que apresentou o menor defeito foi a soldagem realizada com 600 RPM com 100 mm/min de velocidade de soldagem como mostrado na Figura 84. 


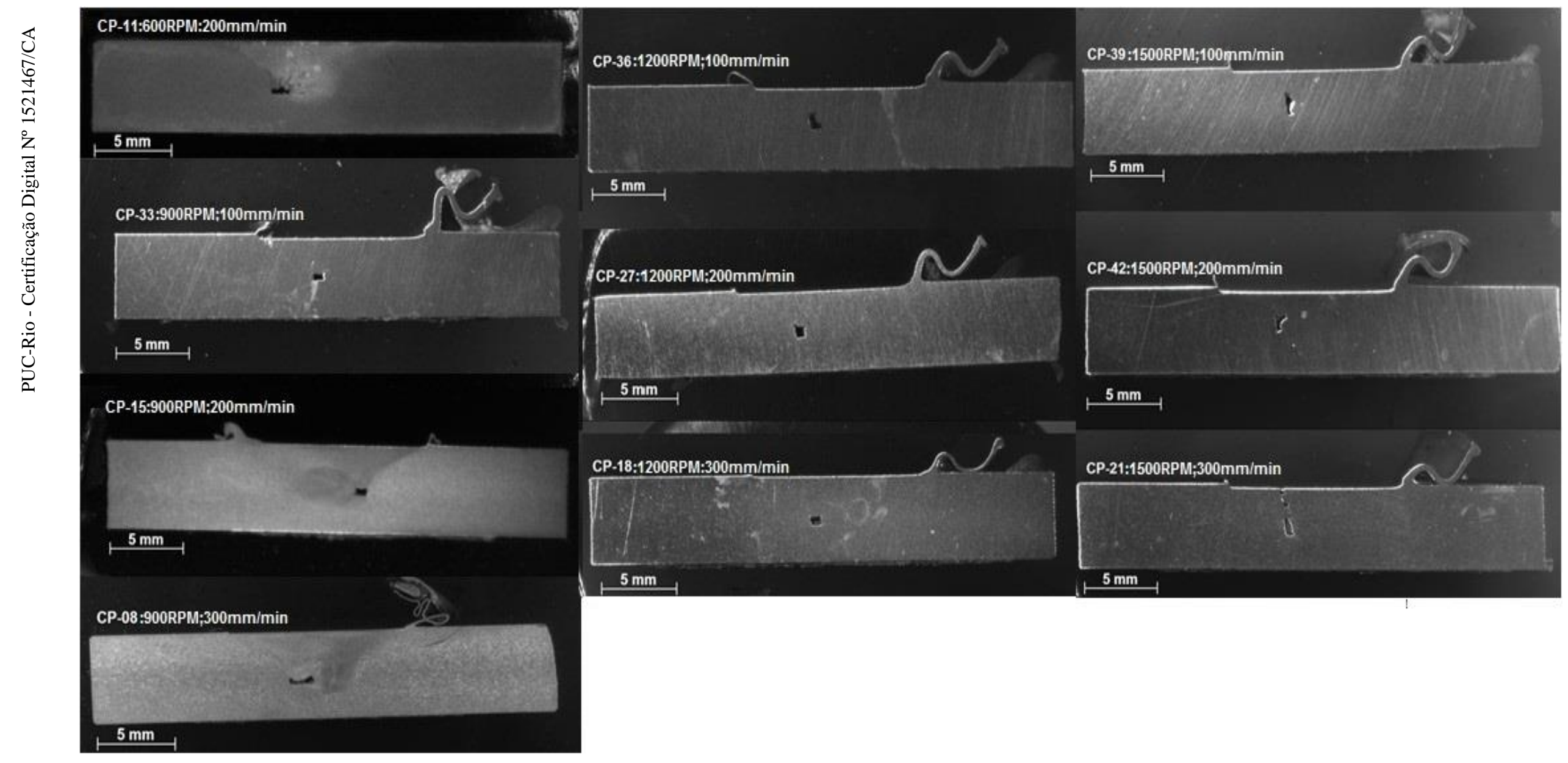

Figura 83 - Imagem de todas as amostras e seus respectivos defeitos. 


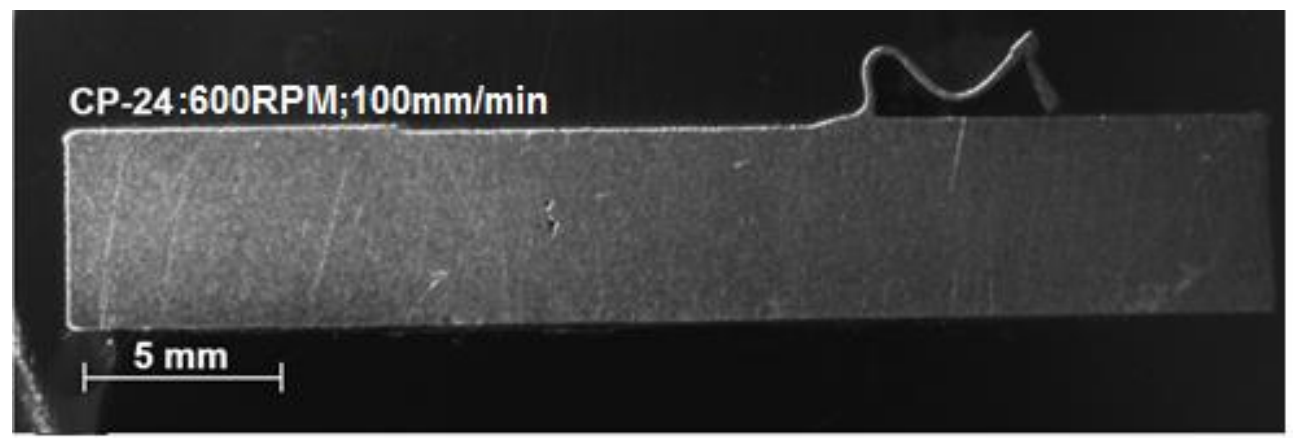

Figura 84 - Corpo de prova com menor defeito.

Os defeitos gerados pela soldagem foram medidos em sua dimensão horizontal e vertical, ou seja, a maior dimensão paralela ao eixo horizontal e a maior dimensão paralela ao eixo vertical como mostrado pela Figura 85 .

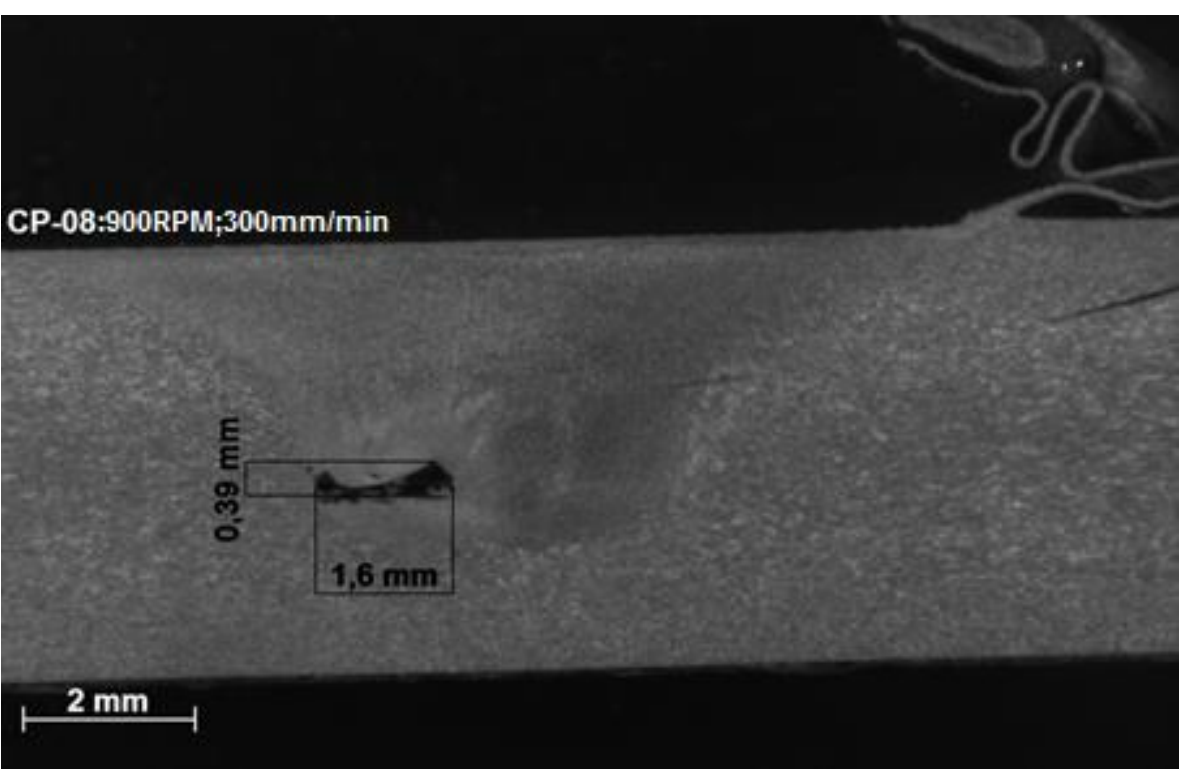

Figura 85 - Exemplo de como foram medidos os defeitos gerados pela soldagem.

A Tabela 22 traz as medidas dos defeitos em sua dimensão horizontal e vertical para todos os corpos de prova analisados. Foi observada a possibilidade de separar os corpos de prova por tipo de defeito, ou seja, o defeito com dimensões verticais maiores que as horizontais $(\mathrm{v}>\mathrm{h})$ e defeitos com dimensões horizontais maiores que a dimensão vertical (h>v) A Tabela 23 traz os corpos de prova separados por tipo de defeito seguindo esta lógica.

Os corpos de prova soldados com velocidade de rotação de 600RPM (exceto CP-24) e 900RPM possuem defeitos com dimensões horizontais superiores as dimensões verticais. Já os corpos de prova soldados com velocidade de rotação de 
1200 RPM (exceto CP-18) e 1500 RPM possuem defeitos com dimensões verticais superiores as dimensões horizontais.

Tabela 22 - Dimensões dos defeitos dos corpos de prova analisados.

\begin{tabular}{|c|c|c|c|}
\hline Corpo de Prova & Parâmetros & $\begin{array}{c}\text { Horizontal } \\
(\mathbf{m m})\end{array}$ & $\begin{array}{c}\text { Vertical } \\
(\mathbf{m m})\end{array}$ \\
\hline $\mathbf{5}$ & 600RPM; 300mm/min & 1,06 & 0,24 \\
\hline $\mathbf{8}$ & 900RPM; 300mm/min & 1,60 & 0,39 \\
\hline $\mathbf{1 1}$ & 600RPM $200 \mathrm{~mm} / \mathrm{min}$ & 1,13 & 0,30 \\
\hline $\mathbf{1 5}$ & 900RPM; 200mm/min & 0,74 & 0,42 \\
\hline $\mathbf{1 8}$ & 1200RPM; 300mm/min & 0,88 & 0,54 \\
\hline $\mathbf{2 1}$ & 1500RPM; 300mm/min & 0,56 & 1,13 \\
\hline $\mathbf{2 4}$ & 600RPM; 100mm/min & 0,29 & 1,03 \\
\hline $\mathbf{2 7}$ & 600RPM; 300mm/min & 0,99 & 0,96 \\
\hline $\mathbf{3 3}$ & 900RPM; 100mm/min & 0,76 & 0,27 \\
\hline $\mathbf{3 6}$ & 1200RPM; 100mm/min & 0,83 & 0,97 \\
\hline $\mathbf{3 9}$ & 1500RPM; 100mm/min & 0,73 & 1,12 \\
\hline $\mathbf{4 2}$ & 1500RPM; 200mm/min & 0,83 & 1,04 \\
\hline
\end{tabular}

Tabela 23 - Distribuição de corpos de prova segundo as características dos defeitos.

\begin{tabular}{|l|l|}
\hline \multicolumn{1}{|c|}{$\mathbf{v}>\mathbf{h}$} & \multicolumn{1}{c|}{$\mathbf{h}>\mathbf{v}$} \\
\hline CP-21(1500RPM; 300mm/min); & CP-5 (600RPM; 300mm/min); \\
CP-24 (600RPM; 100mm/min); & CP-8 (900RPM; 300mm/min); \\
CP-27 (1200RPM; 200mm/min); & CP-11(600RPM; 200mm/min); \\
CP-36 (1200RPM; 100mm/min); & CP-15 (900RPM; 200mm/min); \\
CP-39 (1500RPM; 100mm/min); & CP-18 (1200RPM; 300mm/min); \\
CP-42 (1500RPM; 200mm/min). & CP-33 (900RPM; 100mm/min). \\
& \\
\hline
\end{tabular}

Com o auxílio das Tabelas 22 e 23, foi gerada a Tabela 24 que traz os valores de torque no percurso em ordem crescente para cada corpo de prova ensaiado. 
Tabela 24 - Torque no Percurso em ordem crescente para cada corpo de prova.

\begin{tabular}{|c|c|c|c|c|}
\hline Corpo de & Parâmetros & \multicolumn{2}{|c|}{ Torque no Percurso } & $\begin{array}{c}\text { Característica do } \\
\text { Defeito }\end{array}$ \\
\hline 39 & 1500RPM; $100 \mathrm{~mm} / \mathrm{min}$ & 7,96 & $\pm 0,76$ & \multirow{6}{*}{$\mathrm{h}>\mathrm{V}$} \\
\hline 36 & 1200RPM; $100 \mathrm{~mm} / \mathrm{min}$ & 9,28 & $\pm 0,59$ & \\
\hline 42 & 1500RPM; 200mm $/ \mathrm{min}$ & 9,35 & $\pm 0,19$ & \\
\hline 21 & 1500RPM; 300mm $/ \mathrm{min}$ & 10,5 & $\pm 0,43$ & \\
\hline 27 & 600RPM; 300mm/min & 10,93 & $\pm 0,53$ & \\
\hline 18 & 1200RPM; $300 \mathrm{~mm} / \mathrm{min}$ & 11,69 & $\pm 0,98$ & \\
\hline 33 & 900RPM; 100mm/min & 12,25 & $\pm 0,53$ & \multirow{6}{*}{$\mathrm{v}>\mathrm{h}$} \\
\hline 15 & 900RPM; 200mm/min & 15,19 & $\pm 0,65$ & \\
\hline 24 & 600RPM; 100mm/min & 15,46 & $\pm 0,20$ & \\
\hline 8 & 900RPM; 300mm/min & 16,21 & $\pm 0,49$ & \\
\hline 11 & 600RPM 200mm/min & 20,21 & $\pm 0,30$ & \\
\hline 5 & 600RPM; 300mm/min & 21,26 & $\pm 0,65$ & \\
\hline
\end{tabular}

Foi observado que os corpos de prova que apresentaram valores de torque no percurso maiores ou iguais ao valor $11,69 \mathrm{Nm} \pm 0,98$, sendo este valor de torque no percurso para o CP-18 (1200RPM; 300mm/min), possuem defeitos com dimensões horizontais maiores que as verticais, à exceção do CP-24 (600RPM; $100 \mathrm{~mm} / \mathrm{min})$.

Foi observado também que os corpos de prova que apresentaram valores de torque no percurso menores ou iguais a $11,69 \mathrm{Nm} \pm 0,98$, sendo este valor de torque no percurso para o CP-18 (1200RPM; 300mm/min), possuem defeitos com dimensões verticais maiores que as horizontais.

Em relação ao tamanho do defeito, foi observado que não há defeito com dimensão, seja ela vertical ou horizontal, maior que $2 \mathrm{~mm}$. Para as amostras CP-5, CP-8 e CP-11 a dimensão horizontal é aproximadamente quatro vezes maior que a dimensão vertical. Já as amostras CP-21, CP-39 e CP-42 apresentam dimensão vertical maior que a dimensão horizontal e todas foram soldadas com velocidade de rotação 1500 RPM.

A amostra CP-21 foi a que apresentou o pior defeito, pois o túnel chegou a ser formado na parte superior da peça. As condições de soldagem para esta amostra foram as mais extremas, ou seja, maior velocidade de rotação e de 
soldagem e esta amostra gerou os maiores torque e força axial para sua soldagem. A Figura 86 traz a imagem com 2,5X de aumento mostrando o defeito.

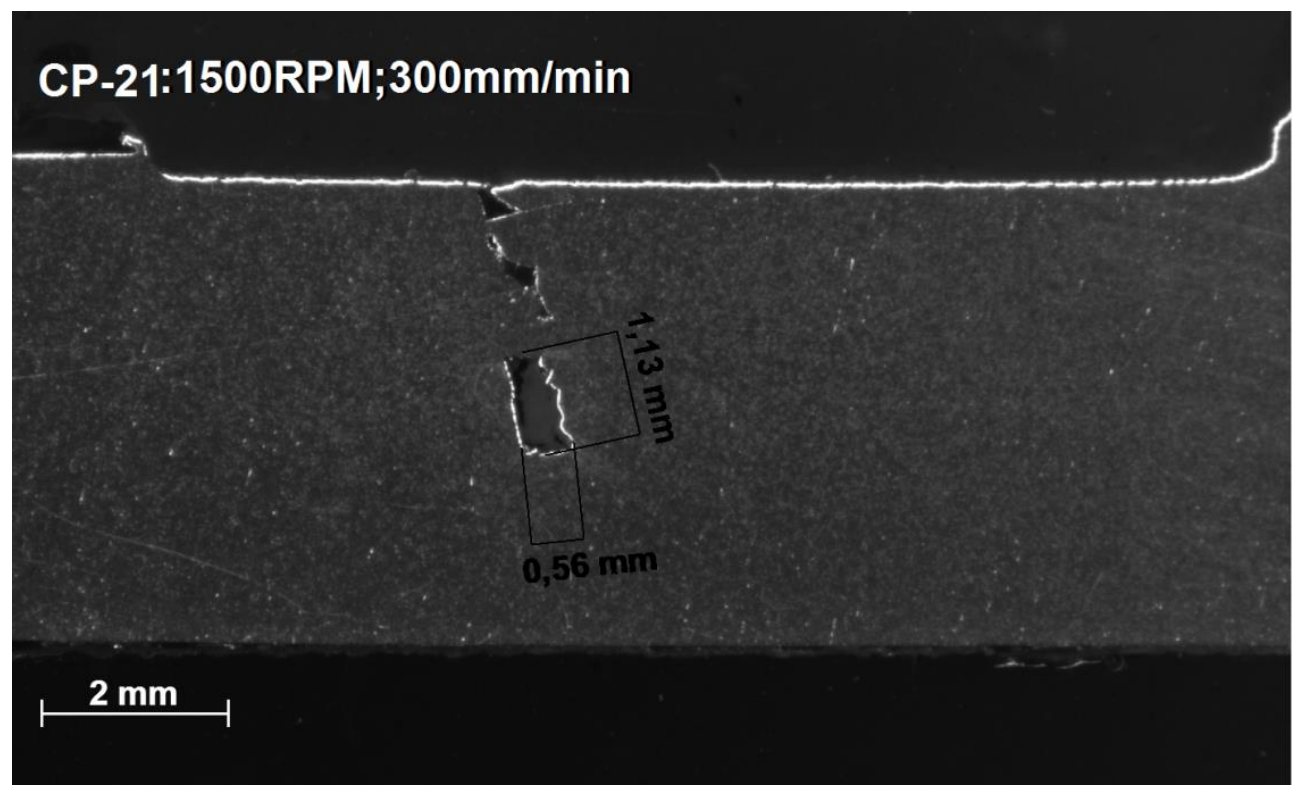

Figura 86 - Defeito gerado pela soldagem com 1500RPM e $300 \mathrm{~mm} / \mathrm{min}$.

Nas amostras CP-27 e CP-36 a dimensão horizontal tem um valor próximo ao da dimensão vertical. Esses dois corpos de prova foram soldados com 1200RPM com velocidades de $200 \mathrm{~mm} / \mathrm{min}$ e $100 \mathrm{~mm} / \mathrm{min}$ respectivamente.

Y.G. Kim et al. [49], utilizou ferramentas de rosca com corpo cilíndrico e como parâmetros de processo a força axial constante com valores entre $6,9 \mathrm{kN}$ e $14,2 \mathrm{kN}$, velocidade de soldagem entre $250 \mathrm{~mm} / \mathrm{min} 1000 \mathrm{~mm} / \mathrm{min}$ e rotação entre 500 e 1500RPM.

Em seu estudo apresentou três tipos distintos de defeito que podem ocorrer durante o processo de soldagem por atrito, sendo estes: excesso de calor aportado, mistura insuficiente e calor insuficiente.

A amostra que foi soldada com 1500RPM e $300 \mathrm{~mm} / \mathrm{mim}$, o processo que tinha as condições mais extremas de soldagem, apresentou insuficiente mistura do material. As demais amostras apresentaram o defeito de excesso de calor aportado ou calor insuficiente onde os parâmetros utilizados possuem correlação com estes defeitos, ou seja, o primeiro ocorre por altas rotações e altas velocidades de soldagem, já o segundo ocorre por baixas rotações e velocidade de soldagem alta.

Isso mostra que a ferramenta com rosca juntamente com os parâmetros utilizados gerou defeitos no processo de soldagem [38][49]. 
De acordo com o trabalho de Quintana et al. [38], a ferramenta cilíndrica tenderia a gerar defeitos. No presente trabalho foi utilizada uma ferramenta que possui corpo cilíndrico com rosca. Desta forma, seria avaliado se a presença da rosca tenderia a não gerar defeitos. Pelos resultados obtidos verificou-se que os defeitos surgiram da mesma forma e a presença da rosca não fez com que o defeito de túnel não ocorresse.

\subsection{Microdureza}

\subsubsection{Metal de base}

Foram realizadas dez indentações no corpo de prova de Metal de Base para que se pudesse ter o valor de dureza Vickers e Módulo de Young sob compressão do material deste estudo. A Tabela 25 traz os valores encontrados em cada indentação e a Tabela 26 traz os valores de médios e o desvio padrão para a dureza e módulo de elasticidade instrumentado.

A Figura 87 traz a curva característica do ensaio de indentação instrumentada. do primeiro ponto realizado no corpo de prova de metal de base.

A Figura 88 traz a curva de carregamento e descarregamento utilizada no primeiro ponto do corpo de prova, no metal de base. Essa curva é representativa de todos os ensaios subsequentes de microindentação instrumentada.

Tabela 25 - Valores de Dureza (HV) e Módulo de Elasticidade Instrumentado para o metal de base.

\begin{tabular}{|c|c|c|}
\hline Indentação & HV & EIT $(\mathbf{G P a})$ \\
\hline $\mathbf{1}$ & 94,55 & 84,82 \\
\hline $\mathbf{2}$ & 99,99 & 98,08 \\
\hline $\mathbf{3}$ & 102,49 & 101,44 \\
\hline $\mathbf{4}$ & 99,40 & 102,44 \\
\hline $\mathbf{5}$ & 94,40 & 90,97 \\
\hline $\mathbf{6}$ & 104,18 & 97,66 \\
\hline $\mathbf{7}$ & 81,30 & 86,90 \\
\hline $\mathbf{8}$ & 104,00 & 109,10 \\
\hline $\mathbf{9}$ & 107,24 & 96,65 \\
\hline $\mathbf{1 0}$ & 102,23 & 100,50 \\
\hline
\end{tabular}


Tabela 26 - Média e Desvio Padrão para a Dureza e o Módulo de Elasticidade Instrumentado do Metal de Base.

\begin{tabular}{|c|c|c|}
\hline & HV & EIT $(\mathbf{G P a})$ \\
\hline Média & 98,98 & 96,86 \\
\hline Desvio Padrão & 7,44 & 7,43 \\
\hline
\end{tabular}

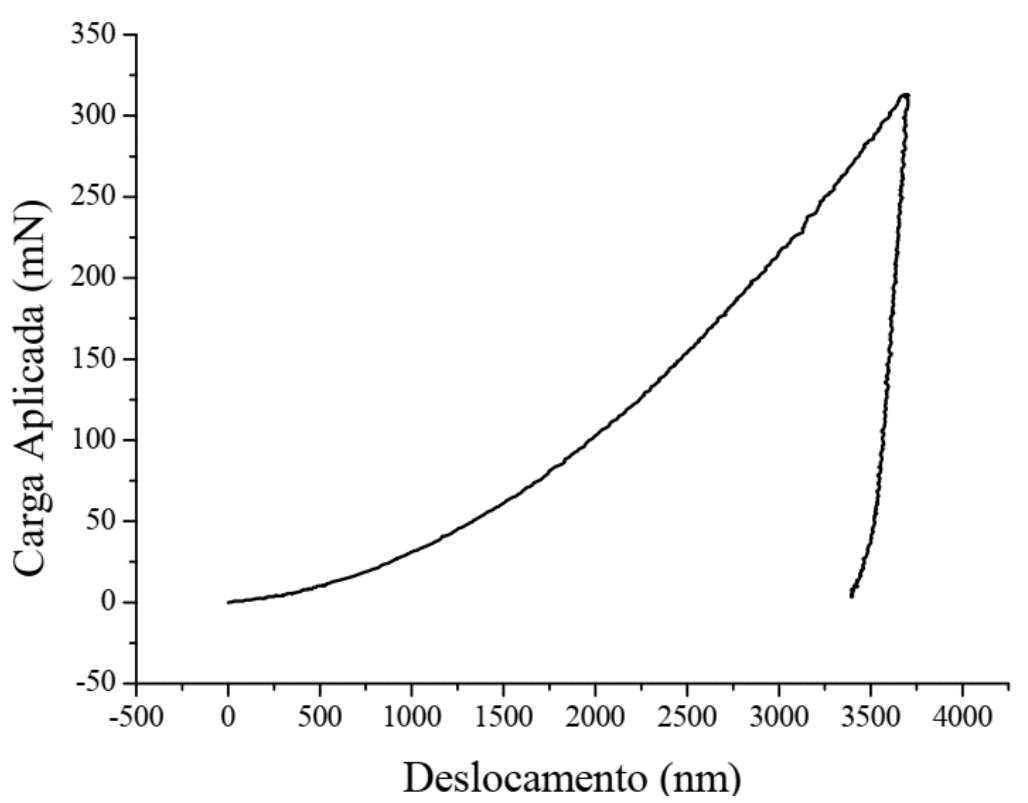

Figura 87 - Curva de Deslocamento característica do ensaio de Micro indentação instrumentada para os ensaios realizados no metal de base.



Figura 88 - Curva de Carga para os ensaios de microindentação instrumentada utilizada neste estudo. 


\subsubsection{Região da solda}

Os valores obtidos do teste de microindentação instrumentada confirmam uma variação característica de dureza na região que passou pelo processo de soldagem.

A primeira indentação foi realizada no ponto (0) localizado a $500 \mu \mathrm{m}$ do defeito gerado pela soldagem. É importante observar que este ponto não é sempre exatamente o ponto central da solda, pois as amostras têm variação no tamanho de seus defeitos. Assim, estar a $500 \mu \mathrm{m}$ de distância deste defeito não garante estar exatamente no centro da zona de mistura. O ponto (1) seria o ponto central da zona de soldagem, ou seja, o ponto que possui o menor valor de dureza. O ponto (2) representa o final da zona de mistura, ou seja, a fronteira entra zona soldada e zona termicamente afetada. O ponto (3) representa o final da zona termicamente afetada; este ponto é chamando de soft point [23][29][32]. A Figura 89 traz o perfil completo de microdureza do corpo de prova com 1500RPM e $300 \mathrm{~mm} / \mathrm{min}$ (CP-21). As Figuras 90 até 97 trazem os gráficos com os perfis de dureza para cada amostra.

Os valores encontrados em cada indentação serão mostrados em tabelas no anexo III.

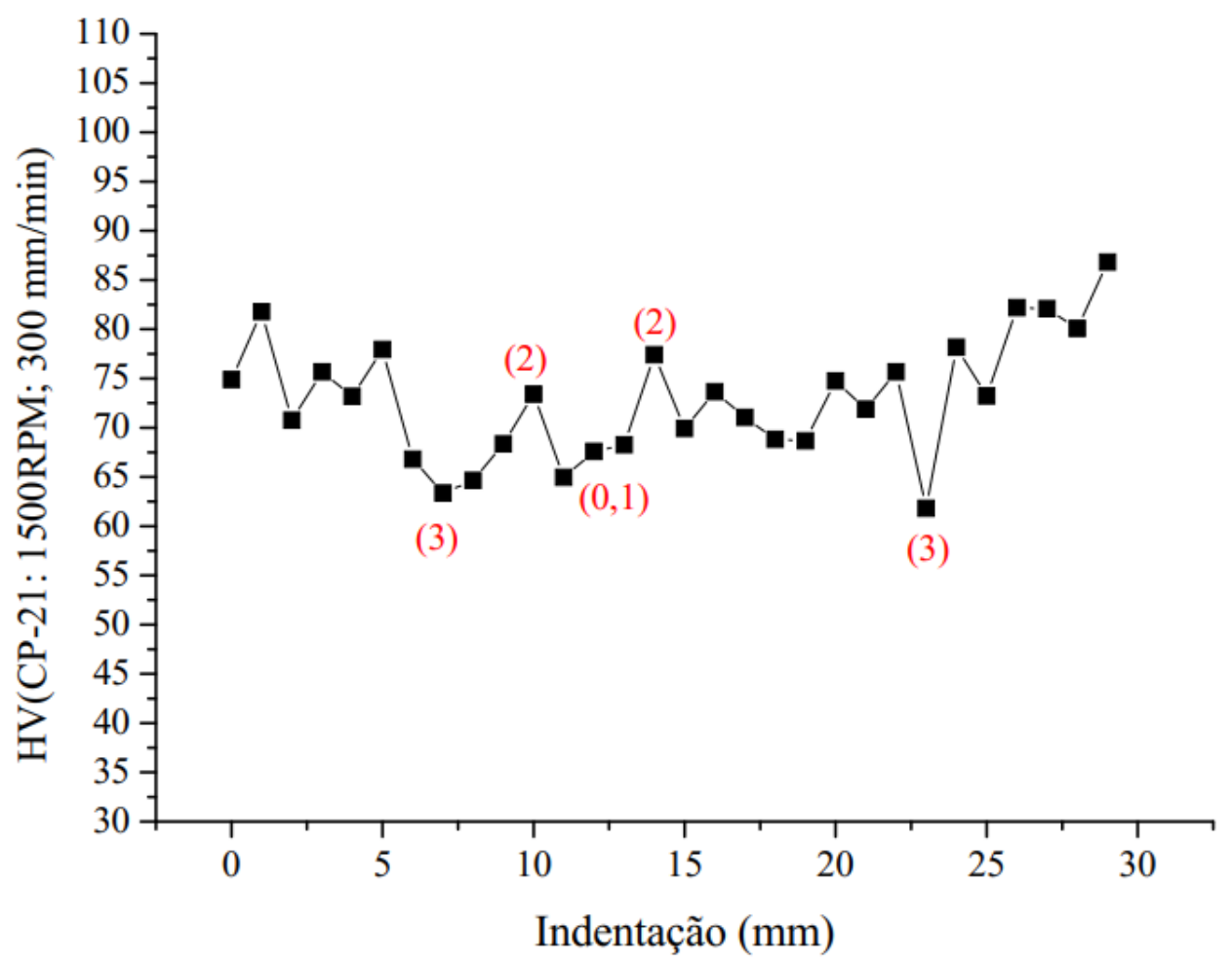


Figura 89 - Perfil completo de distribuição de dureza CP-21: 1500 RPM; 300 mm/min.

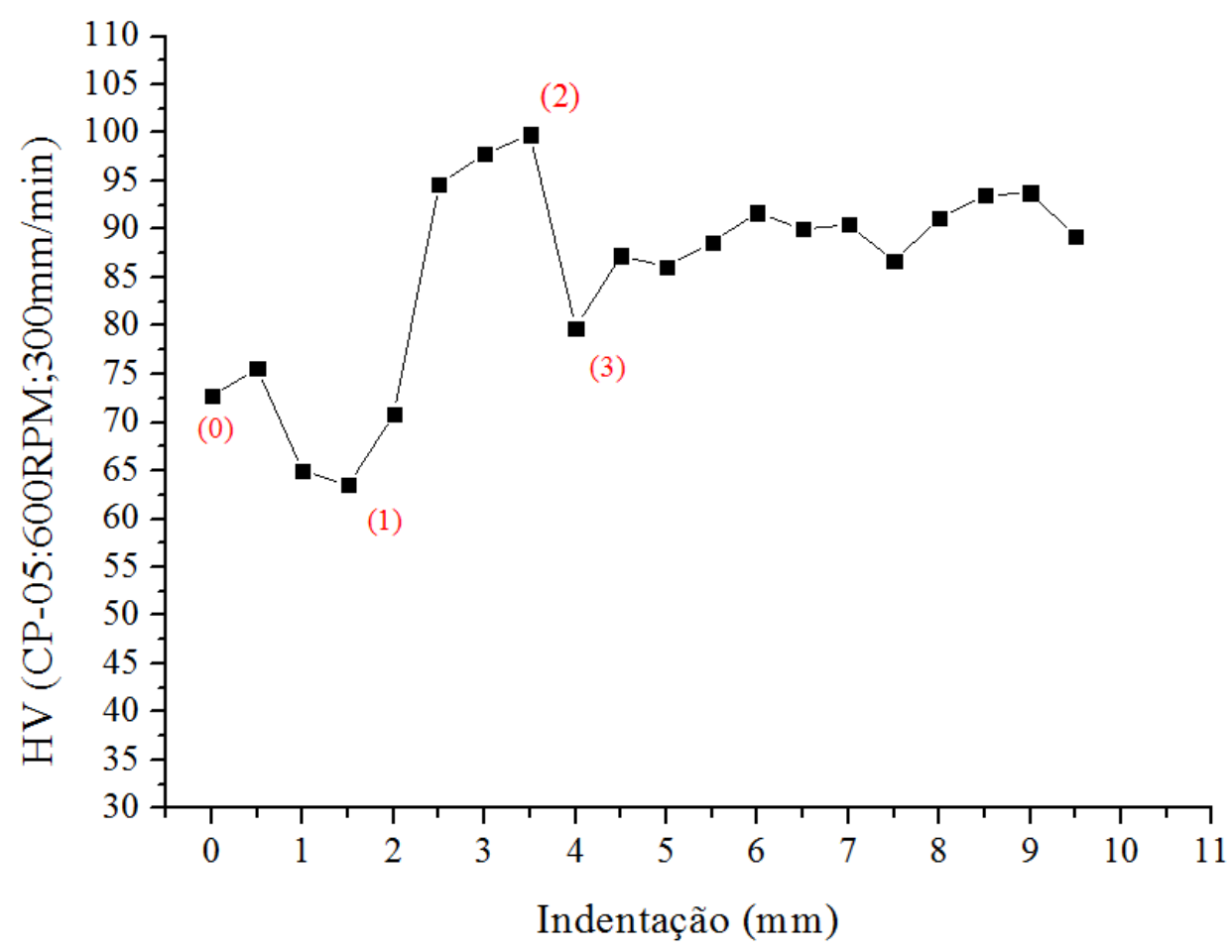

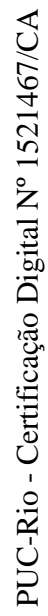

Figura 90 - Gráfico de distribuição de dureza CP-05: 600 RPM; 300 mm/min.

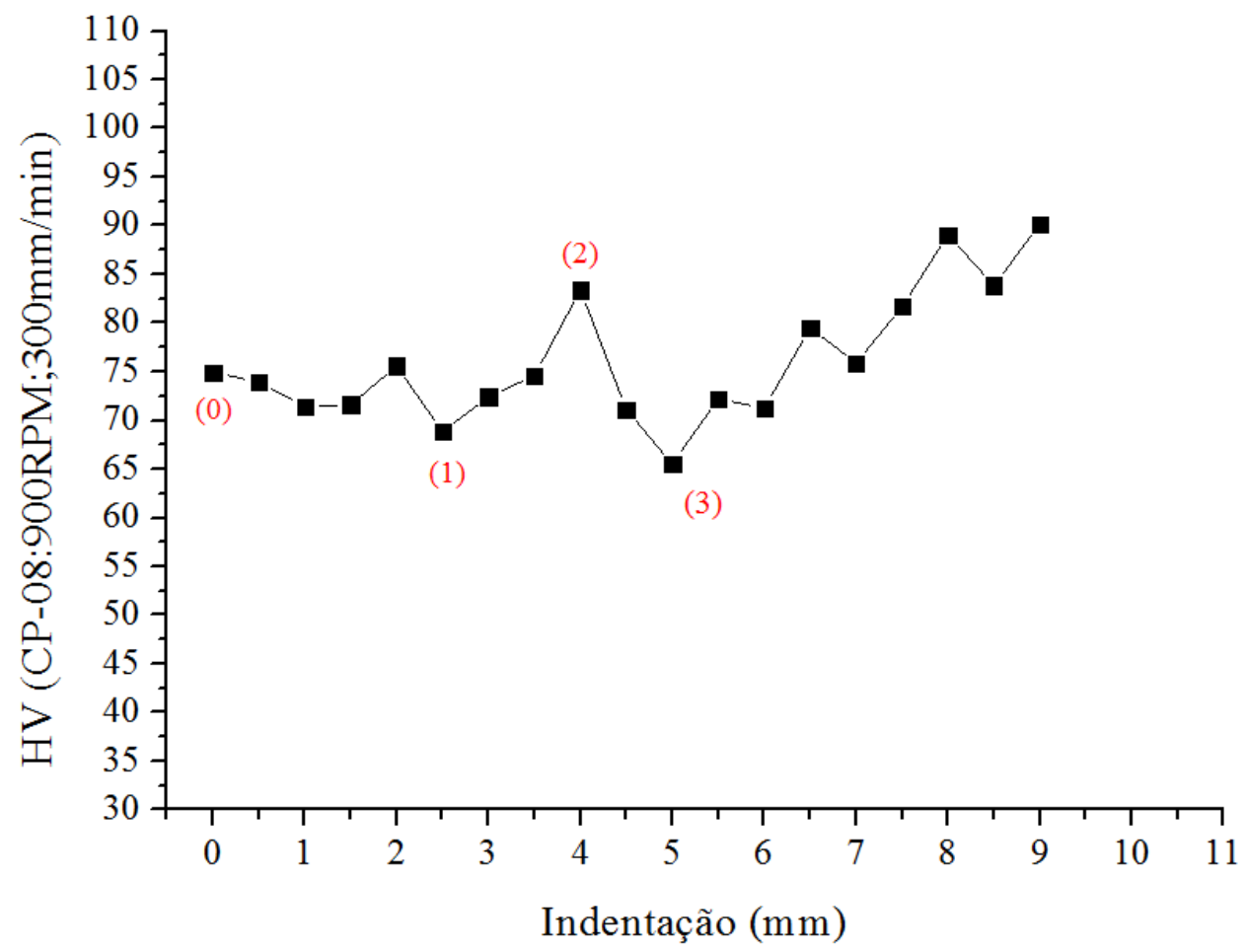

Figura 91 - Gráfico de distribuição de dureza CP-08: 900 RPM; 300 mm/min. 


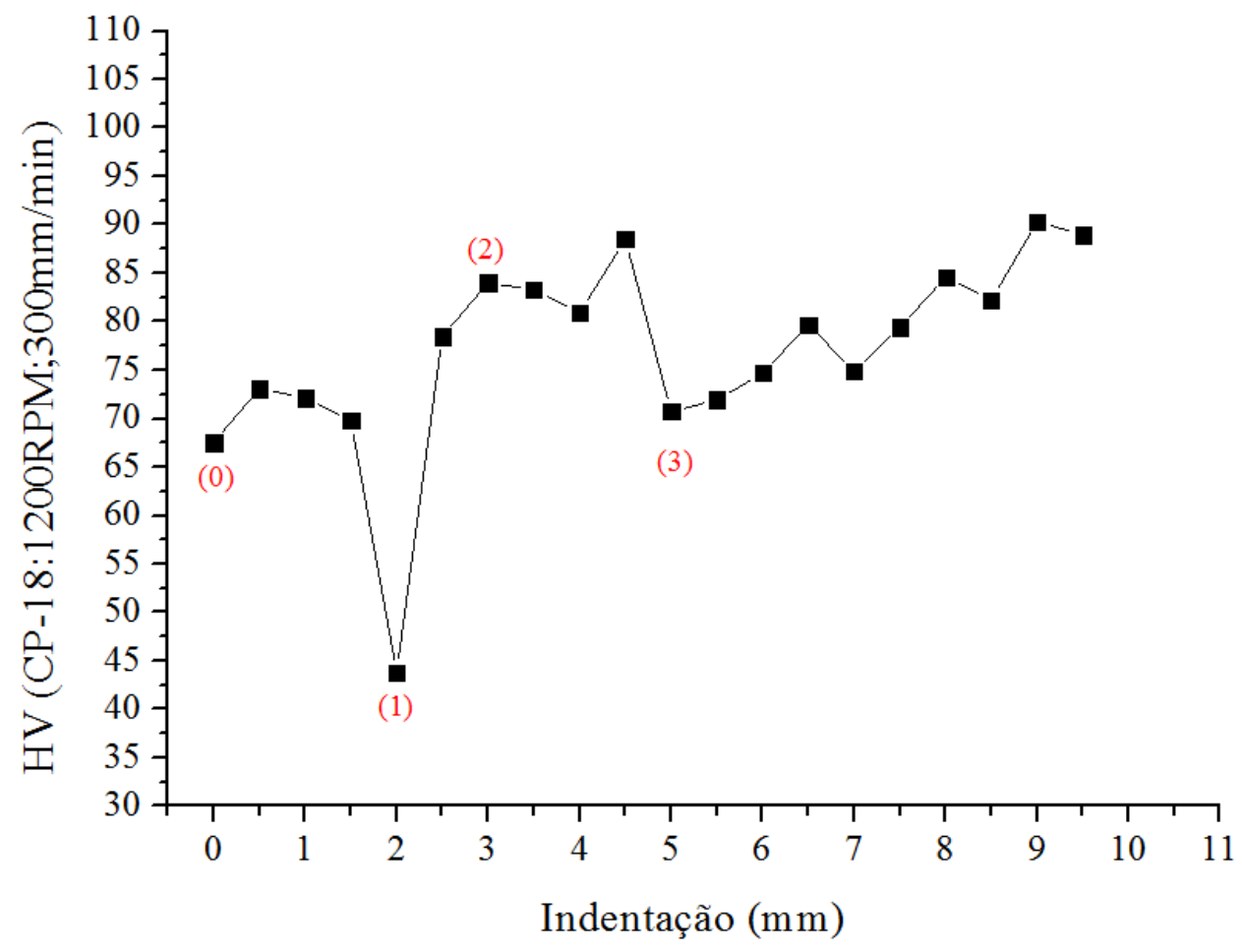

Figura 92 - Gráfico de distribuição de dureza CP-18: 1200 RPM; 300 mm/min.

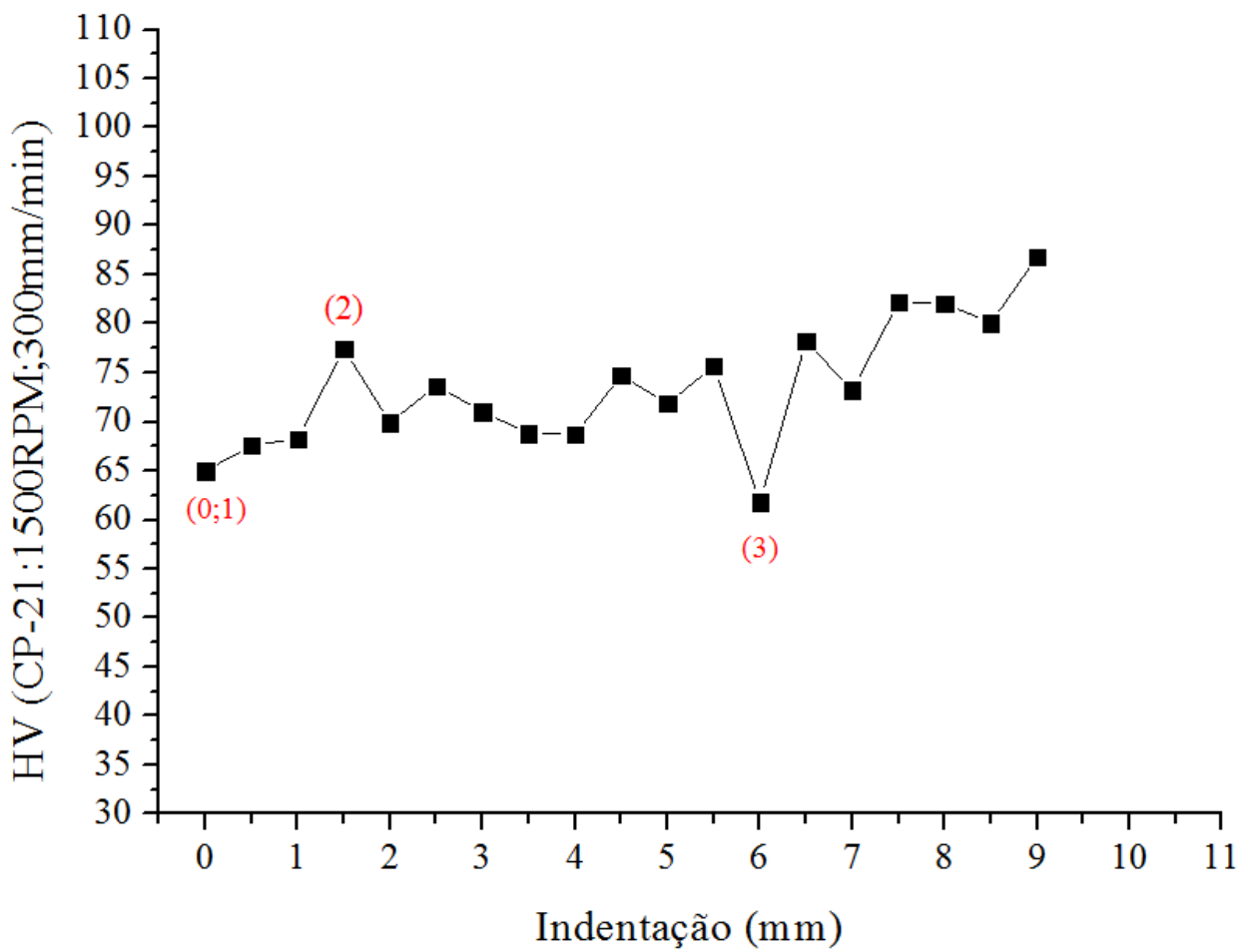

Figura 93 - Gráfico de distribuição de dureza CP-21: 1500 RPM; 300 mm/min. 


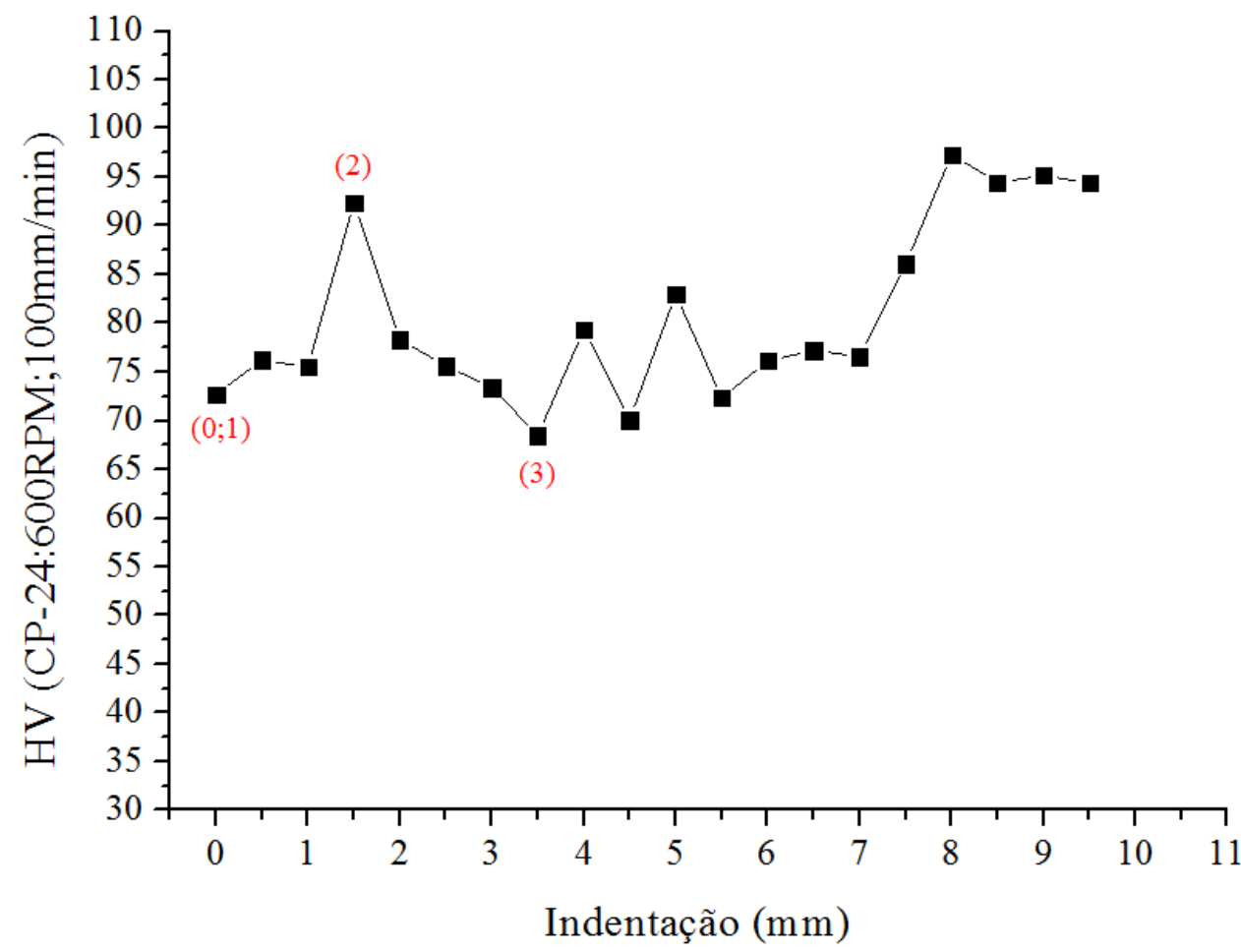

Figura 94 - Gráfico de distribuição de dureza CP-24: 600 RPM; 100 mm/min.

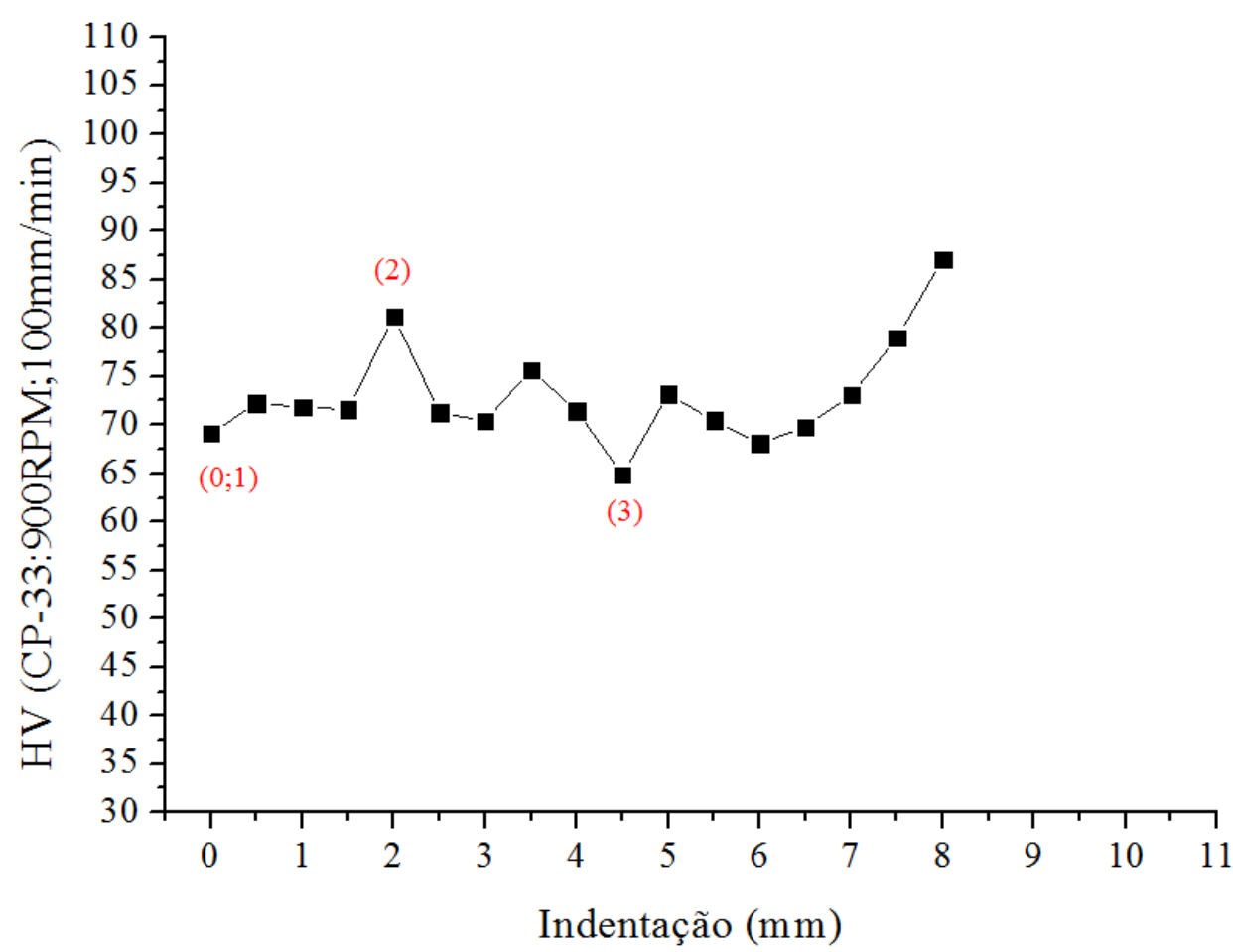

Figura 95 - Gráfico de distribuição de dureza CP-33: 900 RPM; 100 mm/min. 


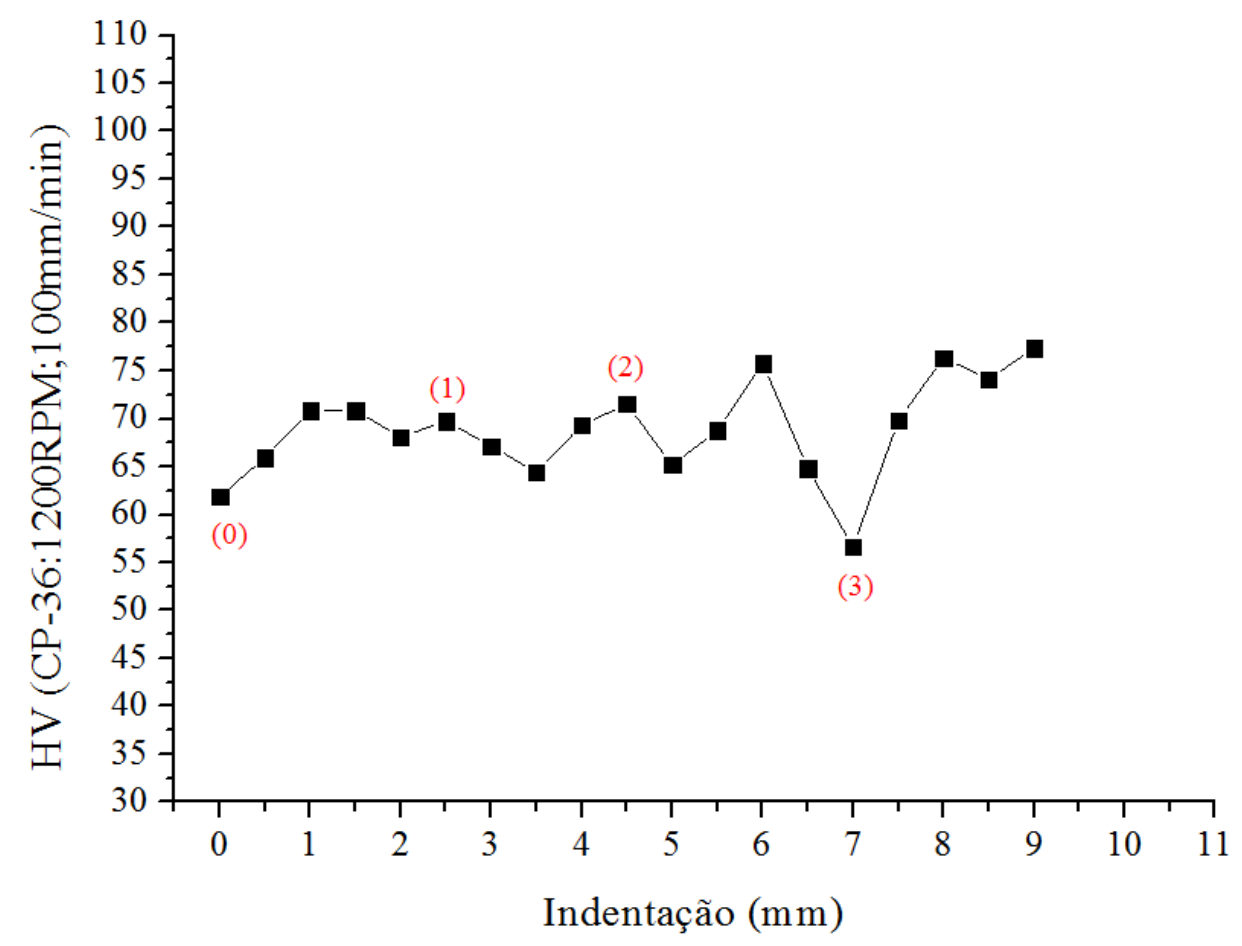

Figura 96 - Gráfico de distribuição de dureza CP-36: 1200 RPM; 100 mm/min.



Figura 97 - Gráfico de distribuição de dureza CP-39: 1500 RPM; 100 mm/min.

Foi observado que em alguns testes o ponto (0) e o ponto (1) coincidiram. Isto ocorre pelo fato de que um defeito pode ser muito grande e a primeira indentação coincide de estar no centro da zona de mistura. 
Todas as amostras apresentaram variação em sua medida de dureza ao longo da linha de eixo neutro [16][23][29][32][39][40]. Os corpos de prova CP-05 (600RPM), CP-08 (900RPM) e CP-18 (1200RPM) e CP-21(1500RPM), todos os soldados com velocidade de soldagem $300 \mathrm{~mm} / \mathrm{min}$ possuem os pontos do gráfico bem definidos, ou seja, apresentam uma clara mudança de dureza entre a zona de mistura, a zona termicamente afetada e o metal de base [16][23][29][32[39][40].

Os corpos de prova CP-24 (600RPM), CP-33 (900RPM) CP-36(1200RPM), e CP-39 (1500RPM), soldados com velocidade de soldagem $100 \mathrm{~mm} / \mathrm{min}$, foram o que apresentaram uma maior clareza na mudança de zona de mistura, zona termicamente afetada e metal de base [16][23][29][32][39][40].

Os corpos de prova CP-05 (600RPM) e CP-21(1500RPM), ambos soldados com velocidade de soldagem de $300 \mathrm{~mm} / \mathrm{min}$, apresentam a menor e a maior zona termicamente afetada, respectivamente. $\mathrm{O}$ primeiro por possuir uma baixa rotação (600RPM) teria menos potência em relação ao segundo cuja velocidade é muito maior (1500RPM), assim gerando menos calor na amostra e, por conseguinte terá uma menor zona termicamente afetada.

O corpo de prova CP-18 (1200RPM, $300 \mathrm{~mm} / \mathrm{min})$ apresenta a menor medida de dureza no ponto central da zona de mistura.

O perfil de dureza possui o comportamento esperado, conforme foi observado em outros estudos [16][23][29][32][39][40], onde há uma variação dos valores de dureza ao longo da linha de eixo neutro e as zonas de mistura e termicamente afetada estão bem definidas.

A Tabela 27 traz os valores de tensão de escoamento $\left(\sigma_{0}\right)$ dos parâmetros deste trabalho, obtidos a partir da eq. (15) e eq.(16) (páginas 53 e 54) [45].

Foi observado que os corpos de prova CP-05 (600RPM, $300 \mathrm{~mm} / \mathrm{min})$, CP08 (900RPM, 300 mm/min), CP-18 (1200RPM, 300 mm/min), CP-24 (600RPM, $100 \mathrm{~mm} / \mathrm{min}$ ) e CP-33 (90RPM, $100 \mathrm{~mm} / \mathrm{min}$ ) possuem grande variação nos pontos de dureza e todos possuem tensão de escoamento acima de 28,09 $\mathrm{MPa}$.

Desse modo, a combinação dos parâmetros de processo tenderia à variação abrupta de dureza entre o centro da solda, sua zona de mistura e zona termicamente afetada.

O cálculo da potência de soldagem pela eq. (1) (página 23) está apresentado na Tabela 28. Foi observado que para a velocidade de soldagem de $100 \mathrm{~mm} / \mathrm{min}$ 
há um aumento gradativo da potência requerida para soldagem com o aumento da velocidade de rotação.

Comparando-se os pontos 900RPM e 1200 RPM, ambos soldados com velocidade de soldagem de $200 \mathrm{~mm} / \mathrm{min}$, percebe-se que o primeiro possui valor de força de soldagem maior que o segundo e por isso sua potência de soldagem é maior.

Os experimentos realizados com velocidade de soldagem de $300 \mathrm{~mm} / \mathrm{min}$, a 600RPM e 1500 RPM, apresentam a menor e a maior potência de soldagem deste grupo. Para as rotações de 900RPM e 1200 RPM, apesar dos valores de potência serem relativamente próximos, não estão em ordem crescente. Este fato pode ocorrer devido a dispersão dos valores obtidos. A Tabela 29 traz os valores de potência de soldagem em ordem crescente.

Tabela 27 - Tensão de escoamento calculada para cada conjunto de parâmetros.

\begin{tabular}{|c|c|c|c|}
\hline \multicolumn{4}{|c|}{ Tensão de escoamento (MPa) } \\
\hline RPM & $\mathbf{1 0 0} \mathbf{~} \mathbf{m} / \mathbf{m i n}$ & $\mathbf{2 0 0} \mathbf{~} \mathbf{m} / \mathbf{m i n}$ & $\mathbf{3 0 0} \mathbf{~} \mathbf{m} / \mathbf{m i n}$ \\
\hline $\mathbf{6 0 0}$ & 37,14 & 48,56 & 51,08 \\
\hline $\mathbf{9 0 0}$ & 29,43 & 36,50 & 38,95 \\
\hline $\mathbf{1 2 0 0}$ & 21,58 & 26,26 & 28,09 \\
\hline $\mathbf{1 5 0 0}$ & 19,12 & 22,46 & 25,23 \\
\hline
\end{tabular}

Tabela 28 - Potência de Soldagem caldulada para o conjunto de parâmetros.

\begin{tabular}{|c|c|c|c|}
\hline \multicolumn{4}{|c|}{ Potência $\mathbf{( k W})$} \\
\hline $\mathbf{R P M}$ & $\mathbf{1 0 0} \mathbf{~ m m} / \mathbf{m i n}$ & $\mathbf{2 0 0} \mathbf{~ m m} / \mathbf{m i n}$ & $\mathbf{3 0 0} \mathbf{~} \mathbf{m} / \mathbf{m i n}$ \\
\hline $\mathbf{6 0 0}$ & 0,97 & 1,27 & 1,34 \\
\hline $\mathbf{9 0 0}$ & 1,15 & 1,43 & 1,53 \\
\hline $\mathbf{1 2 0 0}$ & 1,13 & 1,38 & 1,47 \\
\hline $\mathbf{1 5 0 0}$ & 1,25 & 1,47 & 1,65 \\
\hline
\end{tabular}


Tabela 29 - Paramentros organizados em ordem crescente de potência de soldagem.

\begin{tabular}{|c|c|c|}
\hline RPM & Velocidade de Soldagem & Potência $(\mathbf{k W})$ \\
\hline $\mathbf{6 0 0}$ & $\mathbf{1 0 0} \mathbf{~} \mathbf{m} / \mathbf{m i n}$ & 0,97 \\
\hline $\mathbf{9 0 0}$ & $\mathbf{1 0 0} \mathbf{~} \mathbf{m} / \mathbf{m i n}$ & 1,15 \\
\hline $\mathbf{1 2 0 0}$ & $\mathbf{1 0 0} \mathbf{~} \mathbf{m} / \mathbf{m i n}$ & 1,17 \\
\hline $\mathbf{1 5 0 0}$ & $\mathbf{1 0 0} \mathbf{~} \mathbf{m} / \mathbf{m i n}$ & 1,25 \\
\hline $\mathbf{6 0 0}$ & $\mathbf{2 0 0} \mathbf{~ m m} / \mathbf{m i n}$ & 1,27 \\
\hline $\mathbf{6 0 0}$ & $\mathbf{3 0 0} \mathbf{~} \mathbf{m} / \mathbf{m i n}$ & 1,34 \\
\hline $\mathbf{1 2 0 0}$ & $\mathbf{2 0 0} \mathbf{~} \mathbf{m} / \mathbf{m i n}$ & 1,38 \\
\hline $\mathbf{9 0 0}$ & $\mathbf{2 0 0} \mathbf{~} \mathbf{m} / \mathbf{m i n}$ & 1,43 \\
\hline $\mathbf{1 5 0 0}$ & $\mathbf{2 0 0} \mathbf{~} \mathbf{m} / \mathbf{m i n}$ & 1,47 \\
\hline $\mathbf{1 2 0 0}$ & $\mathbf{3 0 0} \mathbf{~} \mathbf{m} / \mathbf{m i n}$ & 1,47 \\
\hline $\mathbf{9 0 0}$ & $\mathbf{3 0 0} \mathbf{~} \mathbf{m} / \mathbf{m i n}$ & 1,53 \\
\hline $\mathbf{1 5 0 0}$ & $\mathbf{3 0 0} \mathbf{~} \mathbf{m} / \mathbf{m i n}$ & 1,65 \\
\hline
\end{tabular}

\subsection{Tomografia}

Nessa análise foi utilizada apenas a porção da amostra que contém a saída da ferramenta, pois seria exatamente o ponto final da soldagem, onde foram retirados os valores de força axial no percurso e torque no percurso.

O teste de tomografia é o mais adequado para analisar este tipo de soldagem, pois pode mostrar todo o defeito interno da solda e pode quantificar as dimensões dos defeitos, como mostrado nas Figuras 98 até 101 A Tabela 30 traz os valores dos defeitos medidos horizontalmente e verticalmente nos corpos de prova ensaiados por tomografia.

Tabela 30 - Medidas dos defeitos dos corpos de prova ensaiados por tomografia.

\begin{tabular}{|c|c|c|}
\hline Corpo de Prova & Horizontal $(\mathbf{m m})$ & Vertical (mm) \\
\hline CP-25 (600 RPM; $\mathbf{1 0 0} \mathbf{~ m m} / \mathbf{m i n})$ & 1,56 & 0,75 \\
\hline CP-34 (900 RPM; $\mathbf{1 0 0} \mathbf{~ m m} / \mathbf{m i n})$ & 1,65 & 0,32 \\
\hline CP-13P $(\mathbf{1 2 0 0} \mathbf{~ R P M ; ~ 3 0 0 ~} \mathbf{~ m m} / \mathbf{m i n})$ & 1,00 & 0,60 \\
\hline CP-22 $(\mathbf{1 5 0 0} \mathbf{R P M ;} \mathbf{3 0 0} \mathbf{~ m m} / \mathbf{m i n})$ & 2,58 & 1,54 \\
\hline
\end{tabular}

Foi percebido que os parâmetros de 1500 RPM e $300 \mathrm{~mm} / \mathrm{min}$ geram o maior defeito em ambas as medidas. Os valores apresentados são muito superiores comparados aos defeitos gerados quando outros conjuntos de parâmetros foram usados. Este fato ocorre pois, este conjunto de parâmetros (1500 RPM e 300 
$\mathrm{mm} / \mathrm{min}$ ) seria o mais extremo. Ou seja, traria um maior aporte térmico, exigiria maior potência do equipamento e teria um menor tempo de soldagem, porém, traria consigo a possibilidade de gerar um defeito grande. Para os demais corpos de prova analisados por tomografia, os valores estão bem próximos.

Foi realizada também a análise completa por tomografia no corpo de prova soldado com 600RPM e $100 \mathrm{~mm} / \mathrm{min}$ para mostrar todo o defeito de túnel [38] presente dentro do cordão de solda, como apresentado na Figura 102.

Para QUINTANA, K.J., et.al. [38], soldas livres defeitos necessitariam de mudança na geometria da ferramenta. Mantendo-se a geometria da ferramenta o defeito poderia ser minimizado mas não eliminado.

Segundo KIM, Y.G et.al. [49], o defeito de túnel é causado pela escolha de parâmetros de soldagem, ou seja, a geometria da ferramenta, velocidade de soldagem e rotação-

Conforme a análise por tomografia mostrou, todas as soldagens geraram defeitos indicando que o perfil escolhido para a ferramenta, combinado com os parâmetros utilizados, não seriam os mais adequados para gerar soldagem livre de defeitos. O estudo mostrou também como a mudança de parâmetros afeta o tamanho do defeito gerado, a dureza do material e o quanto de potência é demandada do equipamento para a realização do procedimento de soldagem. 




Figura 98 - Tomografia do Corpo de prova réplica para 600RPM e 100 mm/min. 


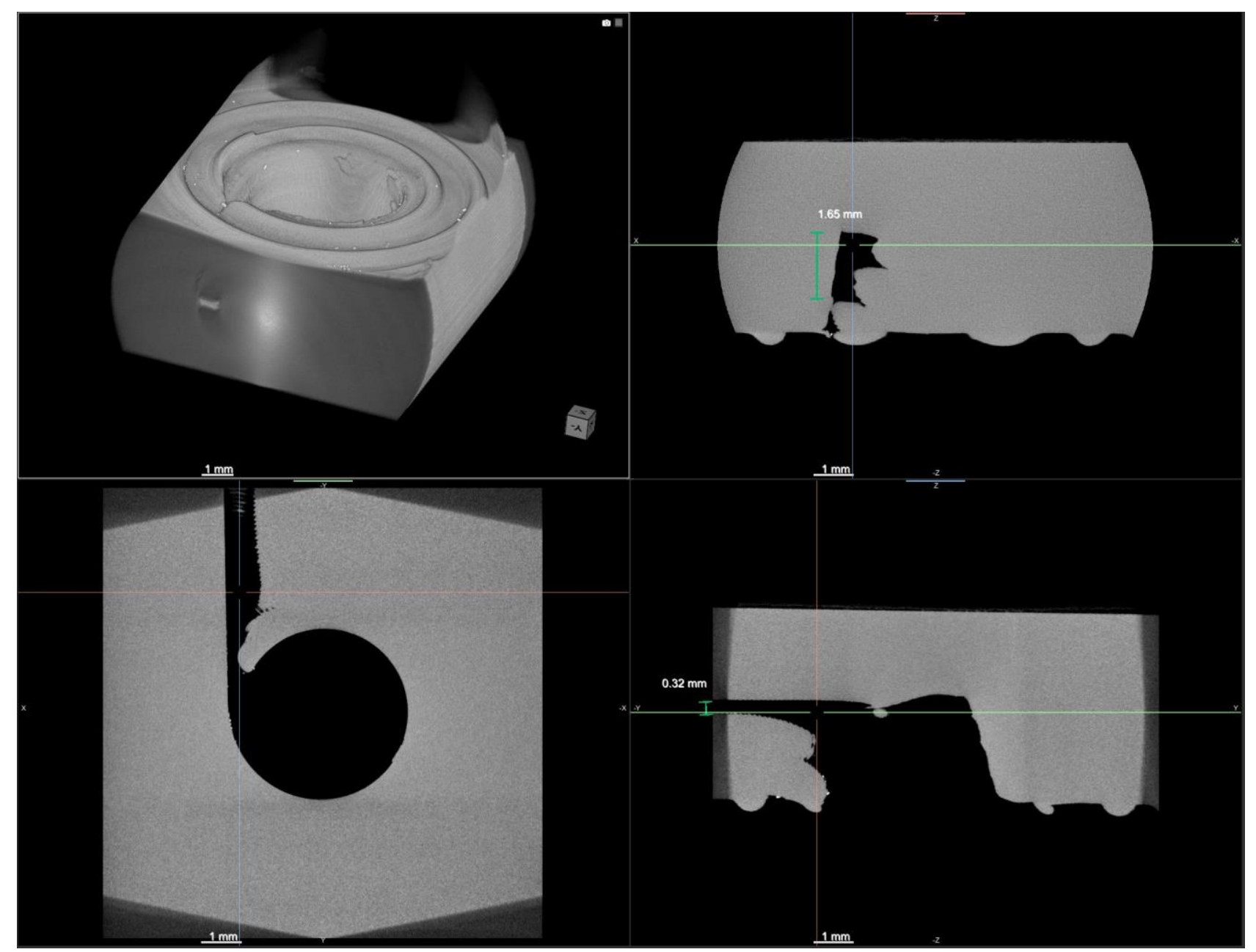

Figura

99

Tomografia

do

Corpo

de

prova

réplica

para

900RPM

e 


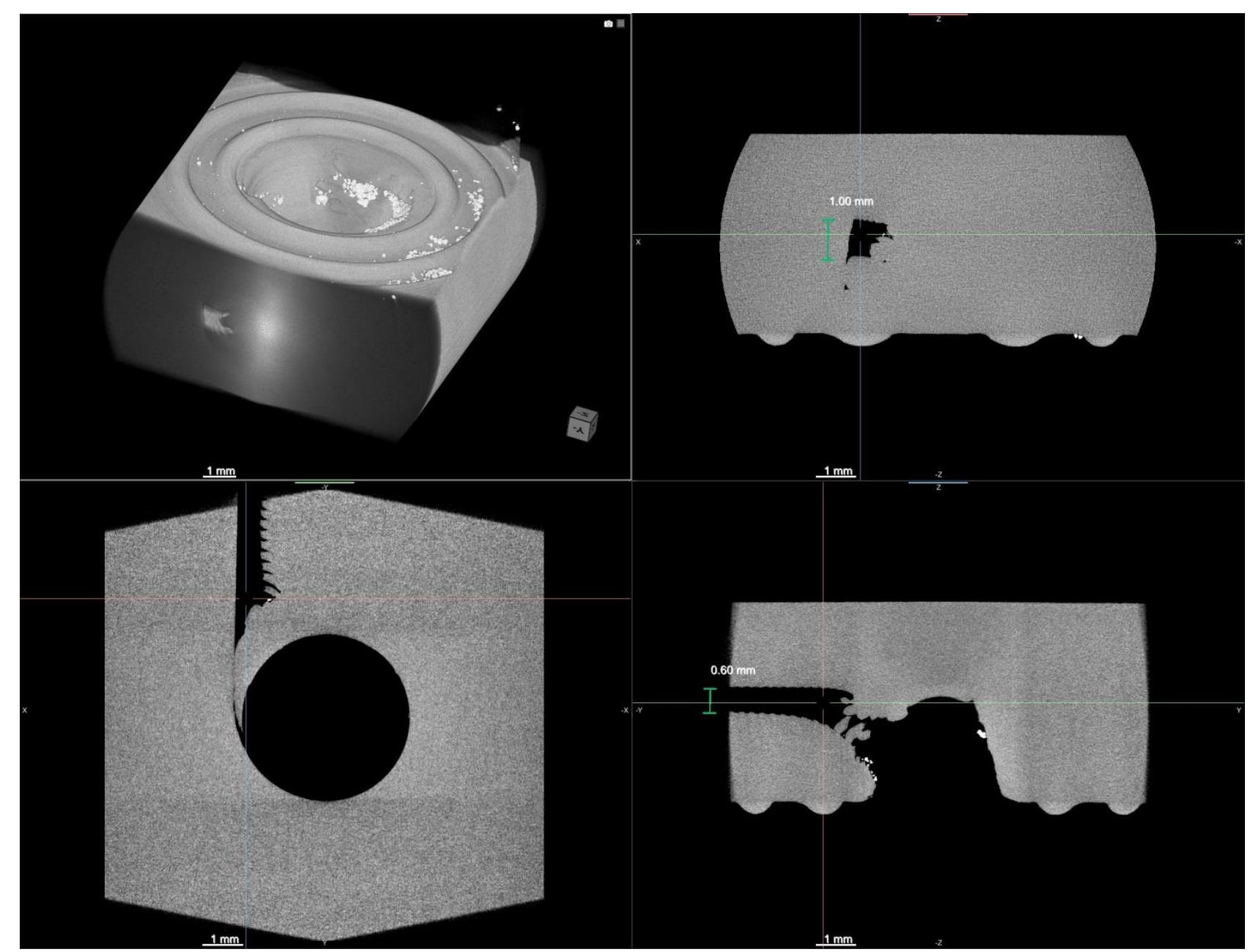

Figura 100 - Tomografia do Corpo de prova réplica para 1200RPM e 300 mm/min. 


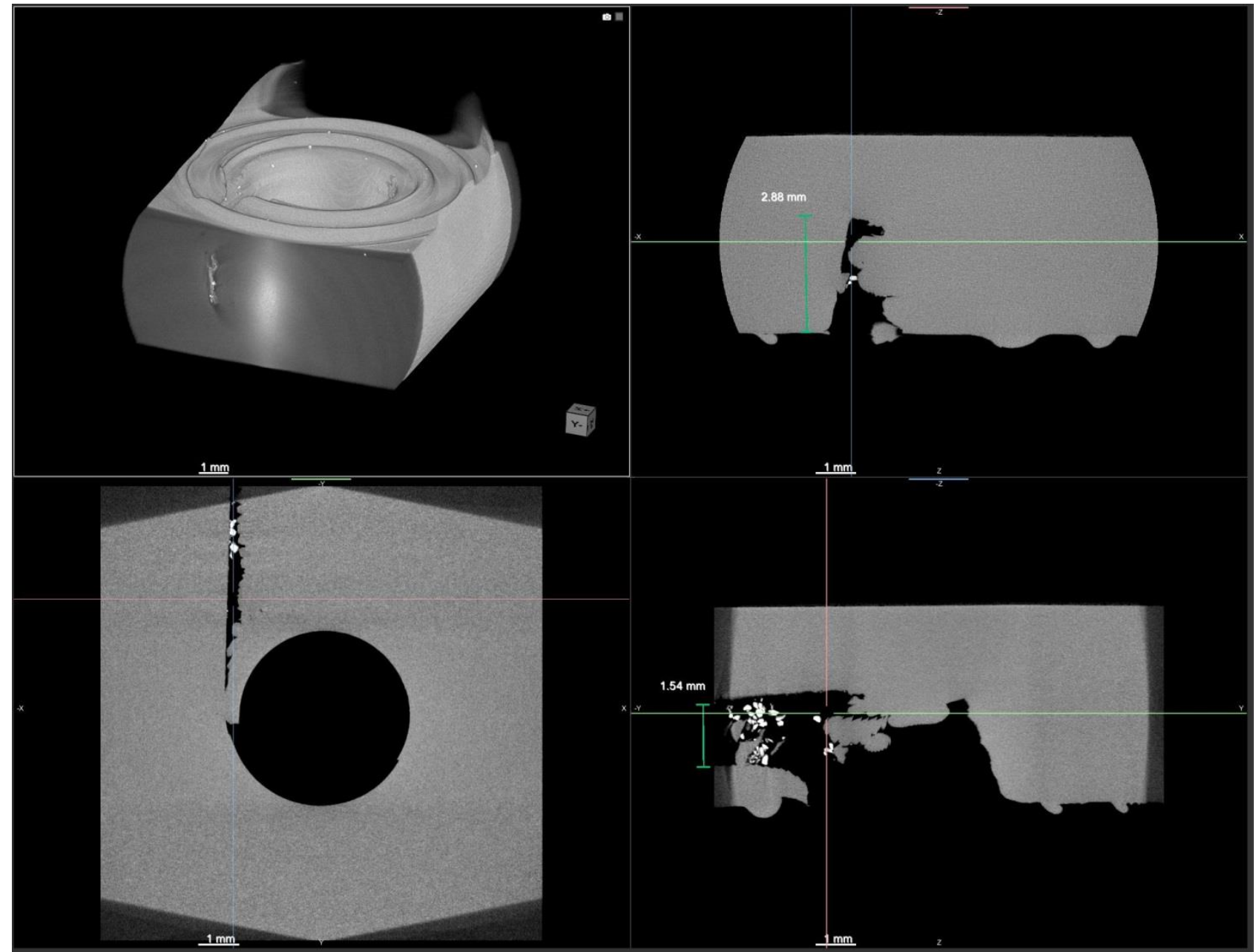

Figura 101 - Tomografia do Corpo de prova réplica para 1500RPM e 300 mm/min. 




Figura 102 - Tomografia do Corpo de prova inteiro réplica para 600RPM e $100 \mathrm{~mm} / \mathrm{min}$. 


\section{Conclusões}

No presente trabalho foram analisados os resultados experimentais para o processo de soldagem por fricção utilizando ferramenta com rosca. Ao todo, foram realizados 72 experimentos com variações da rotação e da velocidade de soldagem.

Comparando os resultados encontrados neste trabalho com os resultados encontrados por Quintana [7], o torque no percurso e força axial no percurso, e a força de soldagem, sofreram um aumento em seus valores.

Este resultado deve-se ao fato da força de atrito da ferramenta com rosca ser maior, resultando em maiores esforços. Além disso, com a maior área de contato da rosca da ferramenta com a peça, há mais material sendo deformado plasticamente, gerando maiores esforços.

Já as forças transversais sofrem uma diminuição em seus valores, pois representam as forças de cisalhamento do pino. Como o pino da ferramenta usada neste estudo é de menor diâmetro e tem formato cônico, este provocaria um menor esforço cisalhante da ferramenta.

O torque e a força axial apresentaram valor máximo na fase de entrada da ferramenta na peça e as forças de soldagem e transversal durante a fase do percurso. No entanto, de uma forma geral, a força axial é a que apresenta maiores valores e, assim, esta é a força crítica a ser considerada para seleção da ferramenta e equipamento de soldagem.

Foi concluído que o torque e a força axial diminuem com o aumento da rotação e aumentam com o aumento da velocidade de soldagem. Entretanto, a velocidade de soldagem tem maior influência sobre a força transversal e sobre a força de soldagem, as quais aumentam com o aumento da velocidade de soldagem.

A ferramenta cilíndrica com rosca apresentou defeito de túnel. A mudança de parâmetros de soldagem tão somente gerara a minimização dos defeitos.

Os defeitos gerados apresentaram dois grupos com características distintas e foi possível definir, a partir dos valores de torque no percurso e as dimensões dos defeitos como separá-los. O corpo de prova CP-24 (600RPM; 100mm/min) é uma exceção a esta conclusão podendo ser um ponto a ser mais estudado. 
A microdureza instrumentada apresentou a mudança de dureza sobre a linha de eixo neutro. As amostras CP-08 (900RPM; 300 mm/min),CP-21 (1500RPM; $300 \mathrm{~mm} / \mathrm{min})$, CP-36(1200RPM; $100 \mathrm{~mm} / \mathrm{min})$, CP-39(1500RPM; $100 \mathrm{~mm} / \mathrm{min})$ apresentaram a menor variação nas medidas de dureza realizadas o que resultaria numa soldagem com menores tensões internas e menor fragilidade da zona soldada.

O corpo de prova CP-21(1500RPM; $300 \mathrm{~mm} / \mathrm{min})$ possui a maior zona termicamente afetada, pois é a amostra que possui os parâmetros de soldagem que demandam maior potência para soldagem. Logo, tem um gasto energético maior e gera um maior aporte térmico.

Com o teste de tomografia foi possível revelar o defeito de túnel e quantificar as dimensões dos defeitos gerados pela soldagem em todos os eixos. 


\section{Sugestões para trabalhos futuros}

1. Reproduzir os testes de dureza, imagens por lupa e tomografia para as réplicas para obter uma medida estatística dos resultados.

2. Modificar a geometria da ferramenta, ou seja, mudar de cônica para cilíndrica ou o passo da rosca por exemplo.

3. Inserir mais parâmetros de soldagem como, por exemplo: um valor fixo das forças envolvidas no processo.

4. Realizar soldagens com menor velocidade de soldagem diferentes.

5. Realizar medições de temperatura e correlacioná-las com as variáveis do processo e com as medições e os modelos do torque e das forças.

6. Realizar experimentos com temperatura controlada.

7. Realizar experimentos com fluidos refrigerantes com capacidade calorífica diferente entre si.

8. Modelar numericamente o comportamento das forças e do torque.

9. Procurar através da modificação dos parâmetros, forças e temperatura envolvida na soldagem para minimizar ou eliminar o defeito que aparece.

10. Reproduzir amostras de $600 \mathrm{RPM}$ e $100 \mathrm{~mm} / \mathrm{min}$ e quantificar estatisticamente o tamanho do defeito. 


\section{Referências Bibliográficas}

[1] THOMAS, W.M., NICHOLAS, E.D., NEEDHAM, J.C., MURCH, M.G., TEMPLESMITH, P., DAWES, C.J., (1991) International Patent Application No. PCT/GB92/02203 and GB Patent Application No. 9125978.8.

[2] THORNTON, P., KRAUSE, A., DAVIES, R., The aluminum spot weld. Welding Journal, v. 75, n. 3, pp. 101-108, 1996

[3] DEHGHANI, M., AMADEH, A., MOUSAVI, ASGHAR S.A., Investigations on the effects of friction stir welding parameters on intermetallic an defect formation in joining aluminum alloy to mild steel. Materials \& Design, v. 49, pp. 433-441, 2013

[4] MISHRA, R., MA, Z.Y., Friction stir welding and processing. Materials Science \& Engineering r-reports, v. 50, n. 1-2, pp. 1-78, 2005

[5] PADMANABAN, G., BALASUBRAMANIAN, V.,Metallurgical haracterization of pulsed current gas tungsten arc, friction stir and laser beam welded \{AZ31B\} magnesium alloy joints. Materials Chemistry and Physics, v. 125 , n. 3 , pp. $686-697,2011$

[6] ROSE, A. R., MANISEKAR, K., BALASUBRAMANIAN, V., Effect of axial force on microstructure and tensile properties of friction stir welded 105 AZ61A magnesium alloy. Transactions of Nonferrous Metals Society of China, v. 21, n. 5, pp. 974-984, 2011

[7] QUINTANA, K.J., Modelos para forças e torque na soldagem por atritomistura. 2016, 132p. Tese Doutorado - Faculdade de Engenharia Mecânica, Universidade Federal do Rio de Janeiro.

[8] UPADHYAY, P., REYNOLDS, A. P., Effects of thermal boundary conditions in friction stir welded AA7050-T7 sheets. Materials Science, v.527, n. 6, pp. $1537-1543,2010$

[9] QUINTANA, K.J., et al, A study on internal defects in Friction Stir Welding of Aluminium Alloys. 31 ${ }^{\text {st }}$ International Manufacturing Conference (IMC31), Cork (Ireland), pp.69-74, 2014

[10] PIETA, G., et al., Optimization of Friction Spot Welding Process Parameters for AA2198-T8. Sheets. Materials and Manufacturing Processes, v.29, pp.934-940, 2014

[11] KHANDKAR, M., KHAN, J., REYNOLDS, A., Prediction of temperature distribution and thermal history during friction stir welding: input torque based model. Science and Technology of Welding and Joining, v. 8, n. 3, pp. 165-174, 2003

[12] ARORA, A., NANDAN, R., REYNOLDS, A. P., et al., Torque, power requirement and stir zone geometry in friction stir welding through modeling and experiments. Scripta Materialia, v. 60, n. 1, pp. 13-16, 2009 
[13] ARORA, A., MEHTA, M., DE, A., DEBROY, T., Load bearing capacity of tool pin during friction stir welding. International Journal of Advanced Manufacturing Technology, v. 61, n. 9-12, pp. 911-920, 2012

[14] SU, H., WU, C., PITTNER, A., et al., Simultaneous measurement of tool torque, traverse force and axial force in friction stir welding. Journal of Manufacturing Processes, v. 15, n. 4, pp. 495- 500, 2013

[15] MEHTA, M., CHATTERJEE, K., DE, A., Monitoring torque and traverse force in friction stir welding from input electrical signatures of driving motors. Science and Technology of Welding and Joining, v. 18, n.3, SI, pp. 191-197, 2013

[16] PEW, J. W., NELSON, T. W., SORENSEN, C. D., Torque based weld power model for friction stir welding. Science and Technology of Welding and Joining, v. 12, n. 4, pp. 341-347, 2007

[17] LONGHURST, W. R., STRAUSS, A. M., COOK, G. E., et al., Torque control of friction stir welding for manufacturing and automation. International Journal of Advanced Manufacturing Technology, v. 51, n. 9-12, pp. 905-913, 2010

[18] SCHMIDT, H., HATTEL, J., WERT, J., An analytical model for the heat generation in friction stir welding. Modelling and Simulation in Materials Science and Engineering, v. 12, n. 1, pp. 143-157, 2004

[19] ZHANG, X. X., XIAO, B. L., MA, Z. Y., A Transient Thermal Model for Friction Stir Weld. Part II: Effects of Weld Conditions. Metallurgical and Materials Transactions A-Physical Metallurgy and Materials Science, v. 42-A, n. 10, pp. 3229-3239, 2011

[20] HAMILTON, C., DYMEK, S., KALEMBA, I., et al., Friction stir welding of aluminium 7136-T76511 extrusions. Science and Technology of Welding and Joining, v. 13, n. 8, pp. 714-720, 2008

[21] SEIDEL, T., REYNOLDS, A.P., Two-dimensional friction stir welding process model based on fluid mechanics. Science and Technology of Welding and Joining, v. 8, n. 3, pp. 175-183, 2003.

[22] PARK, J.P., Mechanical properties of friction stir welded aluminum alloys 5083 and 5383. International Journal of Naval Architecture and Ocean Engineering, v.1, n.1, pp.39-49, 2009

[23] AMBRIZ, R.R., et al., Local mechanical properties of the 6061-T6 aluminium weld using micro-traction and instrumented indentation. European Journal of Mechanics A/Solids, v.30, n.3, pp.307- 315, 2011

[24] QUINTANA, K.J., SILVEIRA, J.L., Analysis of torque in friction stir welding of aluminum alloy 5052 by inverse problem method. Journal of Manufacturing Science and Engineering, v.139, n.4., pp.410-417, 2017 
[25] CUI, S., CHEN, Z.W., ROBSON, J.D., A model relating tool torque and its associated power and specific energy to rotation and forward speeds during friction stir welding/processing. International Journal of Machine Tools and Manufacture, v.50, n.12, pp.1038-1047, 2010

[26] QUINTANA, K.J., SILVEIRA, J.L., Mechanistic models and experimental analysis for the torque in FSW considering tool geometry and process velocities. Journal of Manufacturing Process, v.30, pp.406-417, 2017

[27] QUINTANA, K.J., SILVEIRA, J.L., (2018). Analysis for the forces in FSW for aluminum alloy considering toll geometry and process velocities. Journal of the Brazilian Society of Mechanical Sciences and Engineering, v.40, pp.229-240, 2018

[28] QUINTANA K.J., SILVEIRA J.L., Mechanistic models for the forces in FSW of aluminum alloy 5052-H34. The International Journal of Manufacturing Process, v. 96, n. 9-12, pp. 3993-4008, 2018

[29] UPADHYAY P., REYNOLDS A.P., Effects of thermal boundary conditions in friction stir welded AA7050-T7 sheets. Materials Science and Engineering A, v.527, n.6 pp.1537-1543, 2010

[30] ROSENTHAL, D., Mathematical Theory of Heat Distribution during Welding and Cutting. Welding Journal, v.20, pp. 220-234, 1941

[31] YAN, J., SUTTON, M., REYNOLDS, P.A.,Process-structure-property relationships for nugget and heat affected zone regions of AA2524-T351 friction stir welds. Science and Technology of Welding and Joining, $v$. 10, n. 6, pp. 725-736, 2005

[32] PIETA, G., SANTOS, J., STROHAECKER,R.T., CLARKE,T., Optimization of Friction Spot Welding Process Parameters for AA2198-T8 Sheets. Materials and Manufacturing Processes, v.29, n.8, pp..934-940, 2014

[33] LONG, T., TANG, W. and REYNOLDS, A.P., Process Response Parameter Relationships in Aluminium Alloy Friction Stir Welds. Science and Technology of Welding and Joining, v.12, n.4, pp.311-317, 2007

[34] SATO, Y. S., URATA, M. AND KOKAWA, H., Parameters controlling microstructure and hardness during friction-stir welding of precipitationhardenable aluminum alloy 6063. Metallurgical and Materials Transactions A, v.33, n.3, pp.625-635, 2002

[35] KHANDKAR, M.Z.H. KHAN, J.A., REYNOLDS, A.P., Predicition of temperature distribution and thermal history during friction stir welding, torque based model. Science and Technology of Welding and Joining, v.8, n.3, pp.165-174, 2003

[36] KRAMER, R. In-service performance of aluminum structural details. Ship Structure Committee Report, SSC-447, Washington DC, 2007

[37] PAIK, J.K. Buckling collapse testing of friction stir welded aluminum stiffened plate structures. Ship Structure Committee Report, SR-1454, Washington DC, 2009 
[38] QUINTANA, K.J., et al., A study on internal defects in friction stir welding of aluminium alloys. $31^{\text {st }}$ International Manufacturing Conference (IMC31), Cork (Ireland), pp.69-74, 2014

[39] AMBRIZ, R.R., et al., Local mechanical properties of the 6061-T6 aluminium weld using micro-traction and instrumented indentation, European Journal of Mechanics A/Solids, v.30, pp.307-315, 2011

[40] NOHAVA J., et al., Mechanical Properties of Aluminum Alloys by Instrumented Indentation Case Study on Almigo Hard. Key Engineering Materials, v.586, pp. 59-62, 2014

[41] ASM Handbook Volume 2: Properties and Selection: Nonferrous Alloys and Special-Purpose Materials, 1328p, 1990

[42] Site do fabricante www.kistler.com visitado em 21/05/2018

[43] OLIVER, W.C., PHARR, G.M, An improved technique for determining hardness and elastic-modulus using load and displacement sensing indentation experiments. Journal Materials Research, v.7, pp.1564-1583, 1992

[44] OLIVER, W.C., PHARR, G.M, Measurement of hardness and elastic modulus by instrumented indentation- Advances in understanding and refinements to methodology. Journal Materials Research, v.19, n.1, pp.320, 2004

[45] MALHEIRO, L.M., Avaliação de propriedades mecânicas por meio da técnica de indentação instrumentada de revestimentos de carbono amorfo sobre aço. 2012. 41p Projeto de Graduação - Faculdade de Engenharia de Materiais, Universidade Federal do Rio de Janeiro.

[46] ASM Handbook Volume 9: Metallography and Microstructures, 1184p 2004

[47] KUMAR, R., SINGH, K., PANDEY, S., Process forces and heat input as function of process parameters in AA5083 friction stir welds. Transactions of Nonferrous Metals Society of China, v.22, pp.288-298, 2012

[48] LEITÃO, C., LOURO, R., RODRIGUES, D.M., Using torque sensitivity analysis in accessing Friction Stir Welding/Processing conditions. Journal of Materials Processing Technology, v.212,n.10, pp.2051-2057, 2012

[49] KIM, Y.G., FUJII, H., TSUMURA, T., KOMAZAKI, T., NAKATA, K., Three defect types in friction stir welding of aluminum die casting alloy. Materials Science and Engineering A, v.415, n.1-2, pp.250-254, 2006 
Anexo I

\section{Base do Suporte}


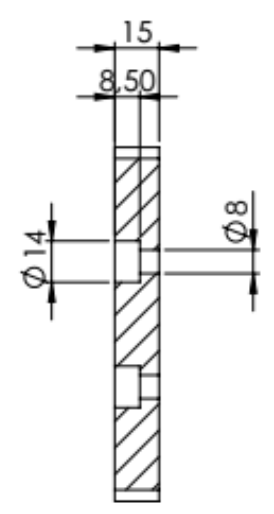

SEÇĀO A-A

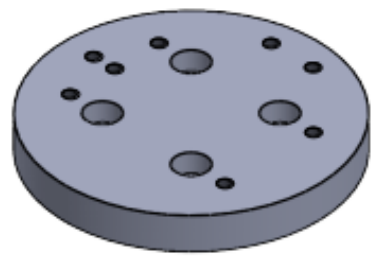

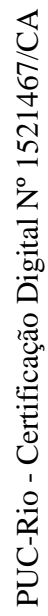




\section{Batente}
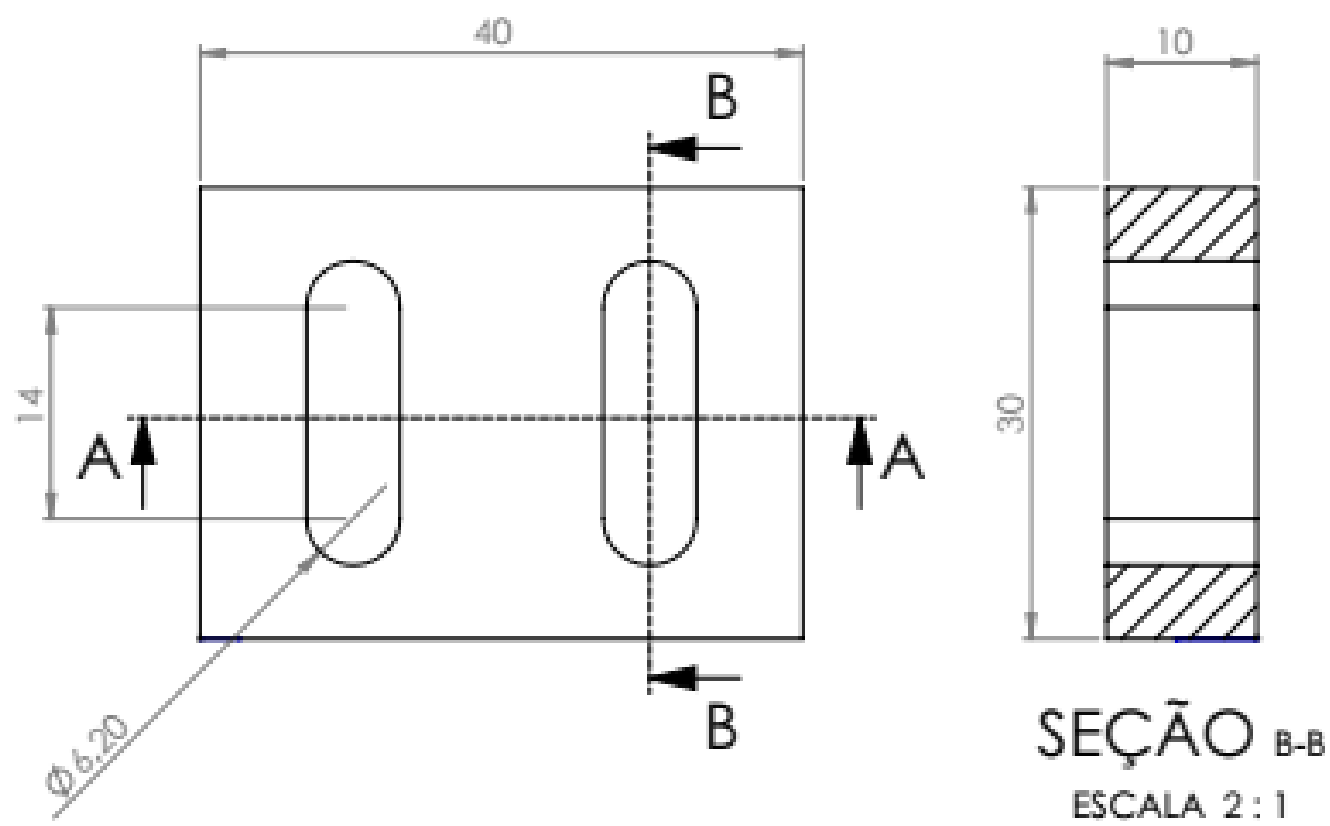



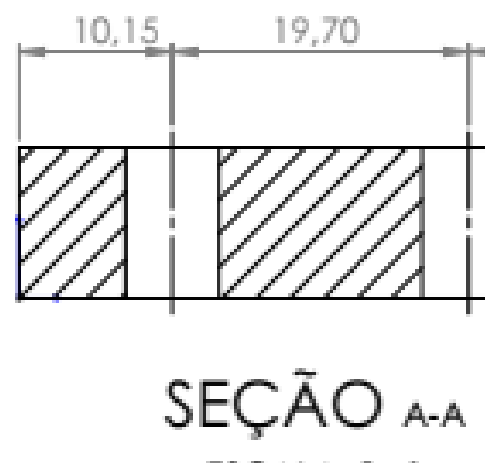

10,15 ESCALA 2:1




Presilha
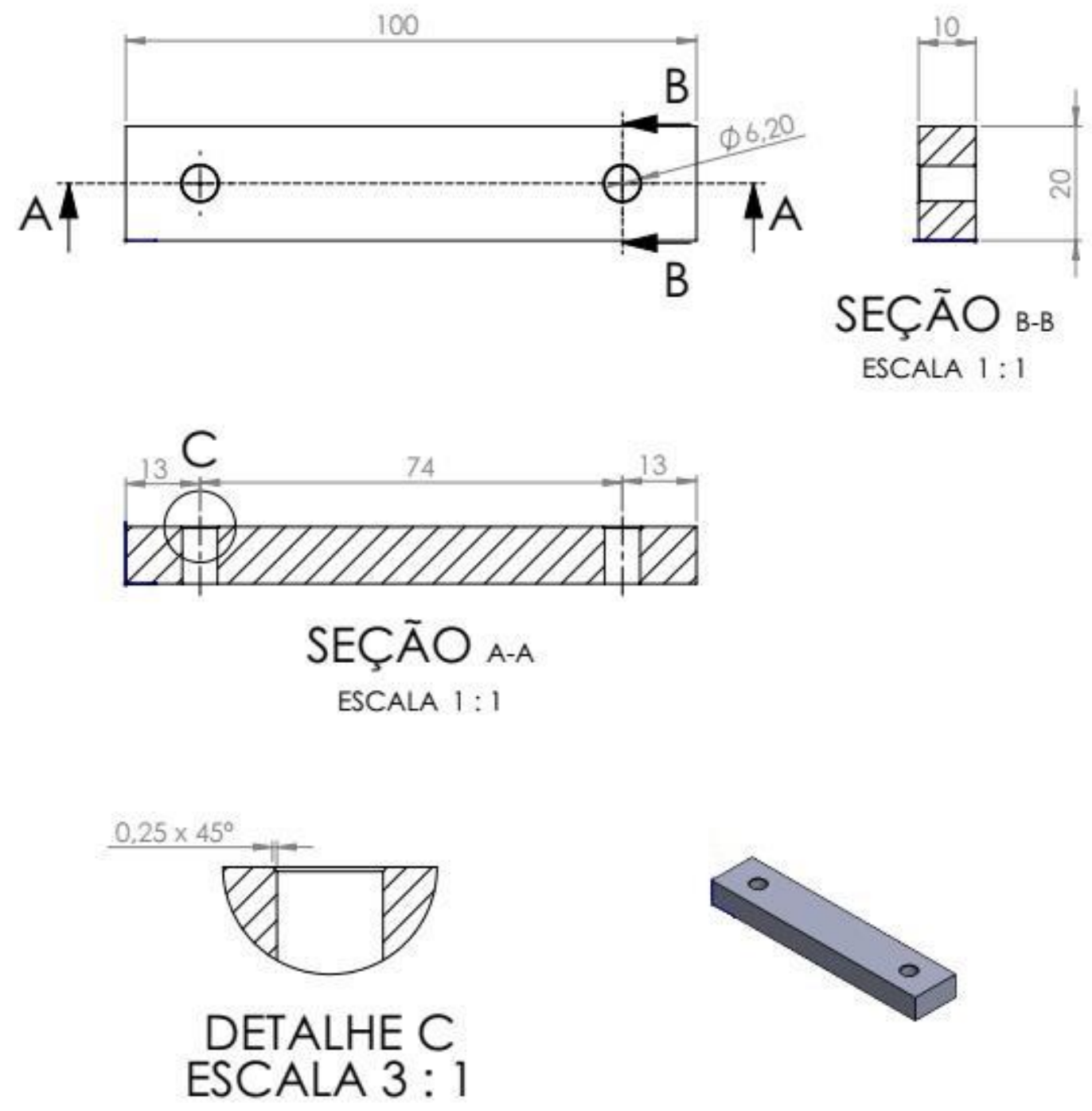
ESCALA 3:1 


\section{Bucha de Adaptação}

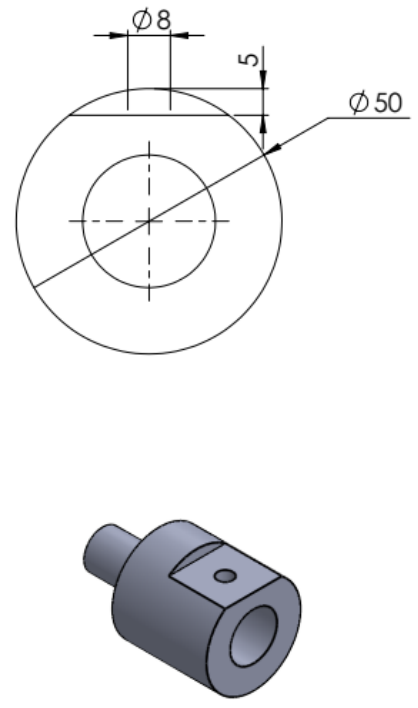

SEÇÃO A-A 
Ferramenta


SEÇĀO A-A



ESCALA $1: 1$

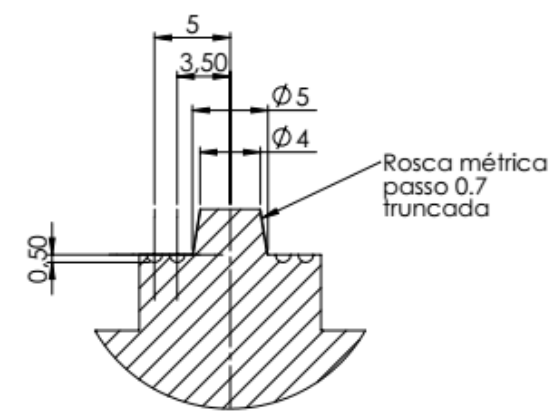

DETALHE B ESCALA $3: 1$

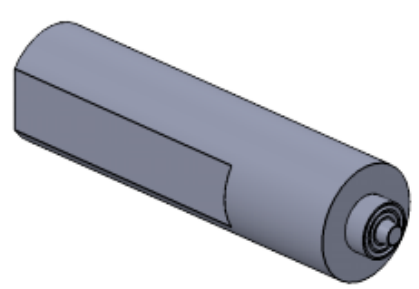




\section{Anexo II}

\section{Tabela de Resultados de Torque}

\begin{tabular}{|c|c|c|c|c|c|c|c|}
\hline \multirow[b]{2}{*}{$\begin{array}{c}\text { Rotação } \\
\text { (RPM) }\end{array}$} & \multirow[b]{2}{*}{ Valores } & \multicolumn{2}{|c|}{$100 \mathrm{~mm} / \mathrm{min}$} & \multicolumn{2}{|c|}{$200 \mathrm{~mm} / \mathrm{min}$} & \multicolumn{2}{|c|}{$300 \mathrm{~mm} / \mathrm{min}$} \\
\hline & & $\begin{array}{l}\text { Torque Entrada } \\
\text { (Nm) }\end{array}$ & $\begin{array}{l}\text { Torque no Percurso } \\
(\mathbf{N m})\end{array}$ & $\begin{array}{c}\text { Torque Entrada } \\
\text { (Nm) }\end{array}$ & $\begin{array}{c}\text { Torque no Percurso } \\
(\mathbf{N m})\end{array}$ & $\begin{array}{l}\text { Torque Entrada } \\
\text { (Nm) }\end{array}$ & $\begin{array}{c}\text { Torque no Percurso } \\
\text { (Nm) }\end{array}$ \\
\hline \multirow{2}{*}{600} & Média & 24,42 & 15,46 & 23,82 & 20,21 & 23,57 & 21,26 \\
\hline & $\begin{array}{l}\text { Desvio } \\
\text { Padrão }\end{array}$ & 0,49 & 0,20 & 0,09 & 0,30 & 0,80 & 0,65 \\
\hline \multirow{2}{*}{900} & Média & 16,12 & 12,25 & 16,39 & 15,19 & 17,13 & 16,21 \\
\hline & $\begin{array}{l}\text { Desvio } \\
\text { Padrão }\end{array}$ & 0,30 & 0,53 & 0,16 & 0,49 & 0,65 & 0,49 \\
\hline \multirow{2}{*}{1200} & Média & 12,22 & 9,28 & 12,22 & 10,93 & 11,99 & 11,69 \\
\hline & $\begin{array}{l}\text { Desvio } \\
\text { Padrão }\end{array}$ & 0,17 & 0,59 & 0,95 & 0,53 & 0,58 & 0,98 \\
\hline \multirow[b]{2}{*}{1500} & Média & 9,60 & 7,96 & 9,73 & 9,35 & 9,06 & 10,50 \\
\hline & $\begin{array}{l}\text { Desvio } \\
\text { Padrão }\end{array}$ & 0,22 & 0,76 & 0,58 & 0,19 & 0,14 & 0,43 \\
\hline
\end{tabular}




\section{Tabela de Resultados de Forças}

\begin{tabular}{|c|c|c|c|c|c|c|c|c|c|c|c|c|c|}
\hline & & \multicolumn{4}{|c|}{$100 \mathrm{~mm} / \mathrm{min}$} & \multicolumn{4}{|c|}{$200 \mathrm{~mm} / \mathrm{min}$} & \multicolumn{4}{|c|}{$300 \mathrm{~mm} / \mathrm{min}$} \\
\hline $\begin{array}{c}\text { Rotação } \\
\text { (RPM) }\end{array}$ & Valores & $\begin{array}{c}\text { Força } \\
\text { Axial } \\
\text { Máxima } \\
\text { (N) }\end{array}$ & $\begin{array}{c}\text { Força } \\
\text { Axial no } \\
\text { Percurso } \\
\text { (N) }\end{array}$ & $\begin{array}{c}\text { Força } \\
\text { Transversal } \\
\text { no Percurso } \\
\text { (N) }\end{array}$ & $\begin{array}{c}\text { Força de } \\
\text { Soldagem } \\
\text { no } \\
\text { Percurso } \\
\text { (N) }\end{array}$ & $\begin{array}{c}\text { Força } \\
\text { Axial } \\
\text { Máxima } \\
\text { (N) }\end{array}$ & $\begin{array}{c}\text { Força } \\
\text { Axial no } \\
\text { Percurso } \\
\text { (N) }\end{array}$ & $\begin{array}{c}\text { Força } \\
\text { Transversal } \\
\text { no Percurso } \\
\text { (N) }\end{array}$ & $\begin{array}{c}\text { Força de } \\
\text { Soldagem } \\
\text { no } \\
\text { Percurso } \\
\text { (N) }\end{array}$ & $\begin{array}{c}\text { Força } \\
\text { Axial } \\
\text { Máxima } \\
\text { (N) }\end{array}$ & $\begin{array}{c}\text { Força } \\
\text { Axial no } \\
\text { Percurso } \\
\text { (N) }\end{array}$ & $\begin{array}{c}\text { Força } \\
\text { Transversal } \\
\text { no Percurso } \\
\text { (N) }\end{array}$ & $\begin{array}{c}\text { Força de } \\
\text { Soldagem } \\
\text { no } \\
\text { Percurso } \\
\text { (N) }\end{array}$ \\
\hline \multirow[b]{2}{*}{600} & Média & 7289,22 & 4167,46 & 1114,43 & 324,78 & 7336,59 & 4890,36 & 1071,97 & 498,75 & 7179,43 & 5163,58 & 1118,12 & 753,80 \\
\hline & $\begin{array}{l}\text { Desvio } \\
\text { Padrão }\end{array}$ & 80,60 & 109,39 & 124,54 & 86,74 & 185,52 & 289,70 & 270,37 & 111,47 & 160,67 & 261,46 & 130,62 & 214,45 \\
\hline \multirow[b]{2}{*}{900} & Média & 6511,98 & 3901,14 & 1061,10 & 249,05 & 6380,90 & 4483,40 & 1021,00 & 524,75 & 6230,93 & 4593,02 & 903,75 & 590,25 \\
\hline & $\begin{array}{l}\text { Desvio } \\
\text { Padrão }\end{array}$ & 196,36 & 233,23 & 92,87 & 17,72 & 608,13 & 381,90 & 98,68 & 190,08 & 548,11 & 190,39 & 103,17 & 148,62 \\
\hline \multirow[b]{2}{*}{1200} & Média & 6183,36 & 3446,58 & 990,24 & 276,64 & 6065,27 & 3855,74 & 1152,45 & 449,50 & 5659,72 & 4161,72 & 1201,96 & 523,20 \\
\hline & $\begin{array}{l}\text { Desvio } \\
\text { Padrão }\end{array}$ & 249,71 & 159,30 & 55,06 & 67,77 & 465,22 & 180,95 & 81,51 & 83,41 & 555,44 & 394,31 & 122,75 & 146,72 \\
\hline \multirow[b]{2}{*}{1500} & Média & 5346,96 & 3349,18 & 832,14 & 266,86 & 5612,47 & 3859,03 & 1039,01 & 492,73 & 5078,08 & 3908,54 & 1208,05 & 520,19 \\
\hline & $\begin{array}{l}\text { Desvio } \\
\text { Padrão }\end{array}$ & 565,75 & 250,37 & 61,13 & 96,94 & 279,79 & 139,98 & 65,74 & 97,12 & 414,35 & 305,36 & 83,55 & 160,10 \\
\hline
\end{tabular}


Tabela de Resultados de Torque Karen Johanna Quintana [7]

\begin{tabular}{|c|c|c|c|c|c|c|c|}
\hline \multirow[b]{2}{*}{$\begin{array}{c}\text { Rotação } \\
\text { (RPM) }\end{array}$} & \multirow[b]{2}{*}{ Valores } & \multicolumn{2}{|c|}{$100 \mathrm{~mm} / \mathrm{min}$} & \multicolumn{2}{|c|}{$200 \mathrm{~mm} / \mathrm{min}$} & \multicolumn{2}{|c|}{$300 \mathrm{~mm} / \mathrm{min}$} \\
\hline & & $\begin{array}{l}\text { Torque Entrada } \\
\text { (Nm) }\end{array}$ & $\begin{array}{c}\text { Torque no Percurso } \\
\text { (Nm) }\end{array}$ & $\begin{array}{l}\text { Torque Entrada } \\
\text { (Nm) }\end{array}$ & $\begin{array}{c}\text { Torque no Percurso } \\
\text { (Nm) }\end{array}$ & $\begin{array}{l}\text { Torque Entrada } \\
\text { (Nm) }\end{array}$ & $\begin{array}{c}\text { Torque no Percurso } \\
\text { (Nm) }\end{array}$ \\
\hline \multirow[b]{2}{*}{600} & Média & 16,94 & 13,40 & 17,39 & 14,65 & 16,84 & 14,03 \\
\hline & $\begin{array}{l}\text { Desvio } \\
\text { Padrão }\end{array}$ & 0,76 & 0,68 & 0,28 & 0,19 & 0,56 & 0,92 \\
\hline \multirow[b]{2}{*}{900} & Média & 11,71 & 10,30 & 11,80 & 9,62 & 12,07 & 11,01 \\
\hline & $\begin{array}{l}\text { Desvio } \\
\text { Padrão }\end{array}$ & 0,11 & 0,69 & 0,17 & 0,40 & 0,07 & 0,11 \\
\hline \multirow[b]{2}{*}{1200} & Média & 8,77 & 7,76 & 8,87 & 7,56 & 8,76 & 8,32 \\
\hline & $\begin{array}{l}\text { Desvio } \\
\text { Padrão }\end{array}$ & 0,13 & 0,20 & 0,30 & 0,34 & 0,12 & 0,03 \\
\hline \multirow[b]{2}{*}{1500} & Média & 6,93 & 6,26 & 6,81 & 6,19 & 6,90 & 6,58 \\
\hline & $\begin{array}{l}\text { Desvio } \\
\text { Padrão }\end{array}$ & 0,14 & 0,08 & 0,11 & 0,12 & 0,08 & 0,09 \\
\hline
\end{tabular}


Tabela de Resultados de Forças Karen Johanna Quintana [7]

\begin{tabular}{|c|c|c|c|c|c|c|c|c|c|c|c|c|c|}
\hline & & \multicolumn{4}{|c|}{$100 \mathrm{~mm} / \mathrm{min}$} & \multicolumn{4}{|c|}{$200 \mathrm{~mm} / \mathrm{min}$} & \multicolumn{4}{|c|}{$300 \mathrm{~mm} / \mathrm{min}$} \\
\hline $\begin{array}{c}\text { Rotação } \\
\text { (RPM) }\end{array}$ & Valores & $\begin{array}{c}\text { Força } \\
\text { Axial } \\
\text { Máxima } \\
(\mathbf{N})\end{array}$ & $\begin{array}{c}\text { Força } \\
\text { Axial no } \\
\text { Percurso } \\
\text { (N) }\end{array}$ & $\begin{array}{c}\text { Força } \\
\text { Transversal } \\
\text { no Percurso } \\
\text { (N) }\end{array}$ & $\begin{array}{c}\text { Força de } \\
\text { Soldagem } \\
\text { no } \\
\text { Percurso } \\
\text { (N) }\end{array}$ & $\begin{array}{c}\text { Força } \\
\text { Axial } \\
\text { Máxima } \\
\text { (N) }\end{array}$ & $\begin{array}{c}\text { Força } \\
\text { Axial no } \\
\text { Percurso } \\
\text { (N) }\end{array}$ & $\begin{array}{c}\text { Força } \\
\text { Transversal } \\
\text { no Percurso } \\
\text { (N) }\end{array}$ & $\begin{array}{c}\text { Força de } \\
\text { Soldagem } \\
\text { no } \\
\text { Percurso } \\
\text { (N) }\end{array}$ & $\begin{array}{c}\text { Força } \\
\text { Axial } \\
\text { Máxima } \\
\text { (N) }\end{array}$ & $\begin{array}{c}\text { Força } \\
\text { Axial no } \\
\text { Percurso } \\
\text { (N) }\end{array}$ & $\begin{array}{c}\text { Força } \\
\text { Transversal } \\
\text { no Percurso } \\
\text { (N) }\end{array}$ & $\begin{array}{c}\text { Força de } \\
\text { Soldagem } \\
\text { no } \\
\text { Percurso } \\
\text { (N) }\end{array}$ \\
\hline \multirow[b]{2}{*}{600} & Média & 6586,53 & 3814,86 & 1076,61 & 183,05 & 6705,99 & 4601,66 & 1290,63 & 451,98 & 6667,92 & 4999,66 & 1467,43 & 1110,78 \\
\hline & $\begin{array}{l}\text { Desvio } \\
\text { Padrão }\end{array}$ & 113,79 & 188,40 & 68,15 & 1,61 & 181,23 & 75,31 & 26,48 & 18,22 & 21,54 & 86,91 & 29,18 & 17,92 \\
\hline \multirow[b]{2}{*}{900} & Média & 5468,27 & 3436,59 & 938,31 & 174,65 & 5385,71 & 3901,87 & 1237,17 & 341,81 & 5408,98 & 4328,79 & 1311,49 & 564,59 \\
\hline & $\begin{array}{l}\text { Desvio } \\
\text { Padrão }\end{array}$ & 26,95 & 43,91 & 4,64 & 19,25 & 16,47 & 114,32 & 58,80 & 12,94 & 57,92 & 60,03 & 29,45 & 28,45 \\
\hline \multirow[b]{2}{*}{1200} & Média & 4876,67 & 3136,68 & 987,58 & 171,99 & 4847,65 & 3620,72 & 1275,80 & 320,39 & 4847,65 & 3883,05 & 1462,37 & 427,48 \\
\hline & $\begin{array}{l}\text { Desvio } \\
\text { Padrão }\end{array}$ & 81,87 & 81,20 & 20,14 & 15,08 & 60,81 & 112,30 & 74,21 & 28,06 & 30,40 & 10,67 & 36,58 & 22,41 \\
\hline \multirow[b]{2}{*}{1500} & Média & 4567,52 & 2966,19 & 928,31 & 206,61 & 4661,01 & 3483,85 & 1390,85 & 347,09 & 4386,58 & 3292,76 & 1562,34 & 353,64 \\
\hline & $\begin{array}{l}\text { Desvio } \\
\text { Padrão }\end{array}$ & 50,85 & 65,28 & 6,86 & 12,04 & 69,07 & 29,51 & 10,19 & 19,42 & 143,24 & 167,47 & 39,72 & 46,93 \\
\hline
\end{tabular}




\section{Anexo III}

Tabela de Indentações para os corpos de prova com velocidade de soldagem $300 \mathrm{~mm} / \mathrm{min}$.

\begin{tabular}{|c|c|c|c|c|c|c|c|c|c|}
\hline \multicolumn{2}{|l|}{ CP-05 } & \multicolumn{2}{|l|}{ CP-08 } & \multicolumn{2}{|l|}{ CP-18 } & \multicolumn{4}{|c|}{ CP-21 } \\
\hline Indentação (mm) & HV & Indentação (mm) & HV & Indentação (mm) & HV & Indentação (mm) & HV & Indentação (mm) & HV \\
\hline 0,0 & 72,71 & 0,0 & 74,94 & 0,0 & 67,53 & 0,0 & 74,896 & 9,5 & 68,662 \\
\hline 0,5 & 75,57 & 0,5 & 73,97 & 0,5 & 73,08 & 0,5 & 81,776 & 10 & 74,742 \\
\hline 1,0 & 65,00 & 1,0 & 71,43 & 1,0 & 72,15 & 1,0 & 70,757 & 10,5 & 71,866 \\
\hline 1,5 & 63,49 & 1,5 & 71,63 & 1,5 & 69,81 & 1,5 & 75,668 & 11 & 75,662 \\
\hline 2,0 & 70,80 & 2,0 & 75,58 & 2,0 & 43,79 & 2,0 & 73,182 & 11,5 & 61,813 \\
\hline 2,5 & 94,64 & 2,5 & 68,86 & 2,5 & 78,49 & 2,5 & 77,939 & 12 & 78,17 \\
\hline 3,0 & 97,81 & 3,0 & 72,42 & 3,0 & 84,02 & 3,0 & 66,802 & 12,5 & 73,234 \\
\hline 3,5 & 99,82 & 3,5 & 74,61 & 3,5 & 83,27 & 3,5 & 63,366 & 13 & 82,181 \\
\hline 4,0 & 79,81 & 4,0 & 83,42 & 4,0 & 80,90 & 4,0 & 64,636 & 13,5 & 82,077 \\
\hline 4,5 & 87,26 & 4,5 & 71,11 & 4,5 & 88,50 & 4,5 & 68,339 & 14 & 80,08 \\
\hline 5,0 & 86,13 & 5,0 & 65,55 & 5,0 & 70,74 & 5,0 & 73,414 & 14,5 & 86,805 \\
\hline 5,5 & 88,69 & 5,5 & 72,21 & 5,5 & 71,93 & 5,5 & 64,957 & & \\
\hline 6,0 & 91,73 & 6,0 & 71,25 & 6,0 & 74,68 & 6,0 & 67,589 & & \\
\hline 6,5 & 90,01 & 6,5 & 79,51 & 6,5 & 79,69 & 6,5 & 68,253 & & \\
\hline 7,0 & 90,50 & 7,0 & 75,88 & 7,0 & 74,92 & 7,0 & 77,407 & & \\
\hline 7,5 & 86,73 & 7,5 & 81,71 & 7,5 & 79,42 & 7,5 & 69,916 & & \\
\hline 8,0 & 91,13 & 8,0 & 89,06 & 8,0 & 84,60 & 8,0 & 73,659 & & \\
\hline 8,5 & 93,52 & 8,5 & 83,86 & 8,5 & 82,22 & 8,5 & 71,037 & & \\
\hline 9,0 & 93,78 & 9,0 & 90,16 & 9,0 & 90,32 & 9,0 & 68,814 & & \\
\hline
\end{tabular}


Tabela de Indentações para os corpos de prova com velocidade de soldagem $100 \mathrm{~mm} / \mathrm{min}$.

\begin{tabular}{|c|c|c|c|c|c|c|c|}
\hline \multicolumn{2}{|c|}{ CP-24 } & \multicolumn{2}{|c|}{ CP-33 } & \multicolumn{2}{c|}{ CP-36 } & \multicolumn{2}{c|}{ CP-39 } \\
\hline Indentação (mm) & $\mathbf{H V}$ & Indentação (mm) & HV & Indentação (mm) & HV & Indentação (mm) & HV \\
\hline 0,0 & 72,68 & 0,0 & 69,10 & 0,0 & 61,87 & 0,0 & 79,42 \\
\hline 0,5 & 76,24 & 0,5 & 72,25 & 0,5 & 65,94 & 0,5 & 75,80 \\
\hline 1,0 & 75,49 & 1,0 & 71,84 & 1,0 & 70,82 & 1,0 & 75,74 \\
\hline 1,5 & 92,38 & 1,5 & 71,61 & 1,5 & 70,88 & 1,5 & 74,33 \\
\hline 2,0 & 78,33 & 2,0 & 81,22 & 2,0 & 68,08 & 2,0 & 71,09 \\
\hline 2,5 & 75,63 & 2,5 & 71,28 & 2,5 & 69,77 & 2,5 & 75,95 \\
\hline 3,0 & 73,41 & 3,0 & 70,44 & 3,0 & 67,18 & 3,0 & 70,92 \\
\hline 3,5 & 68,49 & 3,5 & 75,67 & 3,5 & 64,39 & 3,5 & 75,06 \\
\hline 4,0 & 79,35 & 4,0 & 71,47 & 4,0 & 69,34 & 4,0 & 73,54 \\
\hline 4,5 & 70,07 & 4,5 & 64,82 & 4,5 & 71,52 & 4,5 & 80,49 \\
\hline 5,0 & 82,97 & 5,0 & 73,18 & 5,0 & 65,20 & 5,0 & 70,80 \\
\hline 5,5 & 72,33 & 5,5 & 70,46 & 5,5 & 68,76 & 5,5 & 72,57 \\
\hline 6,0 & 76,14 & 6,0 & 68,09 & 6,0 & 75,79 & 6,0 & 69,22 \\
\hline 6,5 & 77,22 & 6,5 & 69,84 & 6,5 & 64,81 & 6,5 & 73,07 \\
\hline 7,0 & 76,60 & 7,0 & 73,11 & 7,0 & 56,61 & 7,0 & 74,54 \\
\hline 7,5 & 86,10 & 7,5 & 78,97 & 7,5 & 69,85 & 7,5 & 72,08 \\
\hline 8,0 & 97,31 & 8,0 & 87,11 & 8,0 & 76,36 & 8,0 & 75,76 \\
\hline 8,5 & 94,47 & 8,5 & - & 8,5 & 74,10 & 8,5 & 75,34 \\
\hline 9,0 & 95,17 & 9,0 & - & 9,0 & 77,37 & 9,0 & 79,10 \\
\hline 9,5 & 94,39 & 9,5 & - & 9,5 & - & 9,5 & 83,62 \\
\hline & & & & & & & \\
\hline
\end{tabular}

